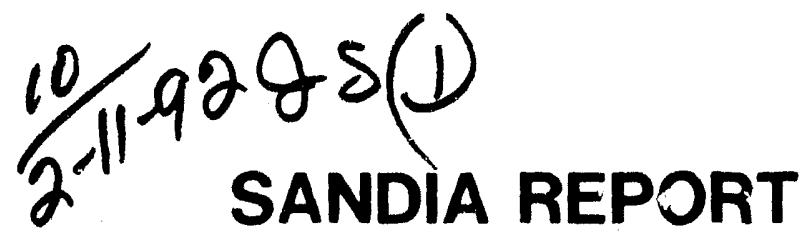

SAND88-3032 - UC -814

Unlimited Release

Printed December 1991

Yucca Mountain Site Characterization Project

Prediction of Pseudo Relative Velocity Response Spectra at Yucca Mountain for Underground Nuclear Explosions Conducted in the Pahute Mesa Testing Area at the Nevada Test Site

James S. Phillips

Prepared by

Sandia National Laboratories

Albuquerque. New Mexico 87185 and Livermore, California 94550

for the United States Department of Energy

under Contract DE-AC04-76DP00789 
"Prepared by Yucea Mountain Site Characterization Project (YMS(CP) participants as part of the Civilian Radioactive Waste Management Program (C'RWM). The YMSC $P$ is managed by the Yucca Mountain Project Office of the (ISt. Department of Energy, DOE Field Office, Nevada (I)OF/NV). YMS('P' work is sponsored by the Office of Geologic Repositories (O(iR) of the I)(OF Office of ('ivilian Radioactive Waste Management (OC'RWM)."

Issued by Sandia National Laboratories, operated for the United States Department of Energy by Sandia Corporation.

NOTICE: 'This report was prepared as an account of work sponsored by an agenc $;$ of the United States (invernment. Neither the United States Ginvernment nor any agency thereof, nor any of their emplovees, nor any of their contracturs. subcont ractors, or their employees, makes any warranty, express or implied. or assumes any legal liability or responsibility for the accuracy. completeness, or usefulness of any information, apparatus, product, or process disclosed, or represents that its use would not infringe privately cwned rights. Reference herein to any specific commercial product, process, or service by trade name, trademark, manufacturer, or otherwise, does not necessarily constitute or imply its endorsement, recommendation, or favoring bi the United States Government, any agency thereof or any of their contractors or subountractors. The views and opinions expressed herein do mot necessadrily state or reflect those of the Unit:d States Government, any anency theresif or any of their contractors.

Primted in the United States of America. This report has been reproduced directly from the best available copy.

Available 10 I)OE and DOE contractors from

Office of sicientific and Technical Information

P() Bon 6.2

()ak Ridge. TN :37x:31

Prices available from (615) $576-8401$, Fres 626-840)

Available to the public from

National Technical Information Service

Is loepartment of commerce

izhi Port Roval Rd

springtield, VA 22161

NTIS price codes

Printed copy: A11

Microfiche cops: A01 
SAND88-3032

DE92 006613

Unlimited Release

Printed December 1991

\title{
PREDICTION OF PSEUDO RELATIVE VELOCITY RESPONSE SPECTRA AT YUCCA MOUNTAIN FOR UNDERGROUND NUCLEAR EXPLOSIONS CONDUCTED IN THE PAHUTE MESA TESTING AREA AT THE NEVADA TEST SITE
}

\author{
James S. Phillips \\ Currently with \\ Special Projects Division, 9514 \\ formerly of \\ Ground Motion and Seismic Division, 9311 \\ Sandia National Laboratories \\ Albuquerque, NM 87185
}

\begin{abstract}
Pseudo relative velocity response spectra (PSRV) have been calculated for a large body of surface ground motions generated by underground nuclear explosions. These spectra have been analyzed and fit using multiple linear regression techniques to develop a credible prediction technique for surface PSRVs. In addition, a technique for estimating downhole PSRVs at specific stations is included. A data summary, data analysis, prediction development, prediction evaluation, software summary and FORTRAN listing of the prediction technique are included in this report.
\end{abstract}


This work was performed under WBS $1 \cdot 2 \cdot 3 \cdot 2 \cdot 8 \cdot 3 \cdot 3$.

\section{Acknow ledgements}

$J$. G. Lee was responsible for data acquisition and J. D. Pearcey was responsible for data processing. J. W. Long reviewed the original manuscript and assisted in retrieval of older UNE test data, programming and data processing. K. A. Sabisch assisted in retrieval of the older UNE test data. M. C. Walck provided valuable advice on several technical areas of this work. 


\section{Foreword}

The Yucca Mountain Site Characterization Project (YMP), managed by the Office of Geologic Disposal of the Office of Civilian Radioactive Waste Management of the U. S. Department of Energy, is examining the feasibility of siting a repository for commercial, high-level nuclear wastes at Yucca Mountain on and adjacent to the Nevada Test Site (NTS). This work, intended to extend our understanding of the ground motion at Yucca Mountain resulting from testing of nuclear weapons on the NTS, was funded by the Yucca Mountain project and the Military Applications Weapons Test Program. This report summarizes one aspect of the weapons test seismic investigations conducted in FY88. 


\section{Preface}

The Weapons Test Seismic Investigations (WTSI) project has been working in support of the Yucca Mountain Site Characterization Project (YMP). If a waste storage facility is located near the Nevada Test Site (NTS) it will be subjected to ground shaking generated by underground nuclear weapons tests. A knowledge of expected ground motion levels from these tests will enable the designers to provide for the necessary structural support in the designs of the various components of the repository. The primary mission of the WTSI project involves recording and analyzing ground motion data from these underground nuclear explosions (UNEs) and developing a method to predict the amplitude of ground motions generated at the repository site from future weapons tests.

The WTSI project has deployed a total of 29 seismic stations specifically for the YMP. These seismic stations consist of triaxial accelerometers (i.e., accelerometers are mounted such that accelerations are measured in three mutually perpendicular directions), amplifiers, voltage controlled oscillators (VCO), multiplexers, and transmitters. All stations consist of surface accelerometers. Some of the stations also have companion instrumentation installed below the ground surface (generally at depths greater than $100 \mathrm{~m}$ ). Initially, these stations were located at several points around the NTS. After the Yucca Mountain area became the focus of characterization activities in 1980 , the first WTSI seismic station at Yucca Mountain was installed. Since that time, the WTSI project has had a total of 11 stations in the Yucca Mountain area. At the present time, five stations are active and four of these stations consist of surface and downhole instrumentation.

The data acquisition process consists of selecting UNEs of interest to the Project, turning the seismic stations on by radio and recording the ground motion on analog tape. The analog tape is sent to Sandia National Laboratories in Albuquerque, NM where it is digitized, processed, analyzed, and stored for future reference.

UNEs are selected primarily on the basis of explosive yields. Yields of interest to the Project are between 80 and $150 \mathrm{kt}$. The lower yield limit was selected because ground motions generated by these lower yields are of a very low amplitude and are of very little interest. The upper yield limit is mandated by the Threshold Test Ban Treaty of March 1976. The distance between the underground explosions of interest and Yucca Mountain varies from about 35 $\mathrm{km}$ to $50 \mathrm{~km}$. Approximately five UNEs conducted annually that are of interest, to the Project.

As stated above, the primary objective of this effort is to provide a method to predict ground motions at the repository site from future underground weapons tests. This requires not only the development, of a prediction model, but a selection of the appropriate future UNE for use in design. A requirement of the design basis UNE is that it, provide the largest. 
ground motions at Yucca Mountain of any future UNE. The selection of the future UNE has been made on the basis of real estate availability studies and off-site damage criteria. This design basis event is defined as a $700 \mathrm{kt}$ explosion in the Buckboard Area of NTS. The distance between this future UNE and Yucca Mountain is about $22.8 \mathrm{~km}$ (this is the distance from the closest point in the Buckboard Area suitable for testing to Yucca Mountain). The prediction model could be developed by either theoretical studies or empirical studies. Both approaches have limitations. Because of the complex nature of the geology, the three-dimensional nature of the problem, and limitations of current finite element or finite difference computer codes, quantitative results from theoretical studies would be subject, to large uncertainties. The empirical approach uses past observations to predict future occurrences. The major limitation in this approach stems from the fact that the future event of interest to the Project falls outside of the realm of the existing data base. Even with this limitation, the empirical approach will have smaller uncertainties associated with the quantitative results than those from a theoretical study.

Because the UNE-generated ground motion data recorded at Yucca Mountain are from explosions of limited yield and distance variations, which do not encompass the design basis UNE, it is important to include ground motion data of larger yields and smaller distances in the analysis effort. Ground motion generated by UNEs has been of interest since the beginning of underground weapons testing. Ground motion data from UNEs, with yields up to $1400 \mathrm{kt}$, at both close-in locations (at distances within a few burial depths of the explosion) and at seismic distances (measured in terms of tens of burial depths from the explosion) have been recorded and studied. Many of these data were used to develop prediction models for the amplitude of ground motion and to study the transmission characteristics of the NTS area. These studies were conducted prior to the YMP and are not directly applicable to the project. However, the data from some of these older UNEs exist on tape and have been analyzed in the context of the YMP.

The resulting UNE ground motion data base assembled by the WTSI project for the YMP consists of ground motion data from a total of 61 UNEs. Of this number, 38 have been recorded at Yucca Mountain seismic stations. These 38 UNEs have explosive yields between 80 and $150 \mathrm{kt}$ (the current treaty upper limit) and are located in the Yucca Flat and Pahute Mesa testing areas of the NTS. These areas are roughly 35 to $50 \mathrm{~km}$ away from Yucca Mountain. The remainder of the UNEs that make up the data base consists of earlier events with yields ranging up to $1.400 \mathrm{kt}$ and recording stations located at various points on the NTS at distances of $1 \mathrm{~km}$ and greater.

In addition to the primary objective discussed above, the WTST project is analyzing the UNE ground motion data to understand another important issue. This is the relationship of the transmission of seismic waves and the geologic structure between the testing areas of NTS and Yucca Mountain. 
Table P-1 lists the analysis reports that the WTSI project has prepared for the YMP. At this point in time, these reports may be categorized in three basic groups: (as shown in the table). 1) quality assurance related 2) motions. (The subject of the transmission of seismic waves is discussed in both group 2 and 3 reports.) The work discussed in this report is covered by Problem Definition Memo 75-8 of the SNL-NWRT department. This report fits in categories 2 and 3 . It addresses the subject of the prediction of surface ground motions as represented by the pseudo relative velocity (PSRV) response spectra. In addition it incorporates the work from SAND87-2381 to provide a prediction of downhole PSRV spectra. This report deals with component ground motions recorded at various stations on the NTS and in the Yucca Mountain area from UNEs in the Pahute Mesa Testing area of NTS. The prediction techniques developed in this effort provide acceptable results for UNE ground motions in the Yucca Mountain area as well as NTS in general. 
Table P-1. Reports Generated by WTSI for the Yucca Hountain Site Characterization Project

SAND79-1002

SAND80-1.020/1

SAND81-0784

SAND81-2214

SAND82-0174

SAND8 2-1647

SAND $82-2478$

SAND83-1553

SAND $03-2625$

SANI)BS-1605

SAN1)SB-0439
Prediction of Ground Motion from Nuclear Weapons Tests at NTS, Vortman, L. J. (Group 2).

Prediction of Ground Motion from Underground Nuclear Weapons Tests as it Relates to Siting of a Nuclear Waste Storage Facility at NTS and Compatibility with the Weapons Test Program, Vortman, L. J.(Group 2).

A Field Comparison of the Kistler 303 and QFLEX 1100 and 1200 Accelerometers, Vortman, L. J.(Group 1).

Ground Motion from Earthquakes and Underground Nuclear Weapons Tests: A Comparison as it Relates to Siting a Nuclear Waste Storage Facility at NTS, Vortman, L. J.(Group 2).

Effects of Repository Depth on Ground Motion The Pahute Mesa Data, Vortman, L. J. and Long, J. W. (Group 3).

Effect of Repository Depth on Ground Motion The Yucca Flats Data, Vortman, L. J. and Long, J. W. (Group 3).

Prediction of Downhole Waveforms, Long, J. W., Sabisch, K. A., Stearns, S. D., and Vortman, L. J. (Group 3).

Stresses and Strains at Yucca Mountain from Underground Nuclear Explosions, Vortman, L. J.(Group 2).

Proceedings of the Conference on DDE Ground Motion and Seismic Programs On, Around and Beyond NTS, Vortman, L. J., Ed. (Groups 2 \&).

Ground Motion at Yucca Mounta in from Pahute Mesa Underground Nuclear Explosions, Vortman, L. J.(Group 2).

Component, Ground Motion at the Nevada Test Site from Pahute Mesa Underground Nuclear Explosions, Long, J. W. (Group 2). 
Table P-1. Reports Generated by WTSI for the Yucca Mountain Site Characterization Project (concluded)

SAND 86-2201

SAND $87-1811$

SAND $87-2381$
Verification of Ground Motion Data Processing Codes, Phillips, J. S.(Group 1).

Evaluation of Equations for the Prediction of Peak

Ground Motions at Yucca Mountain from Underground Nuclear Explosions in Paiute Mesa, Phillips, J. S. (Group 2).

Analysis of Component Surface/Downhole Ground Motions at Yucca Mount in from Underground Nuclear Explosions in Paiute Mesa, Phillips, J. S.(Group 3).

$-v i i i-$ 


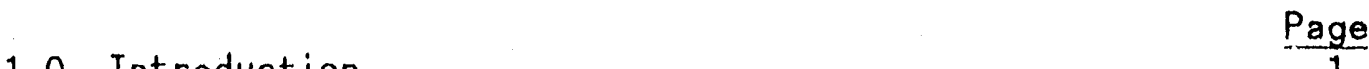

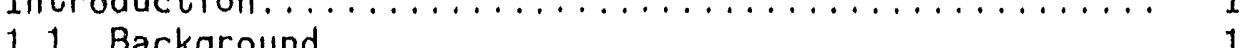

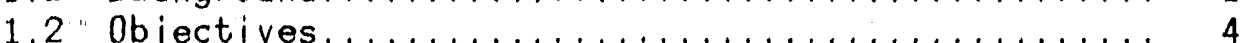

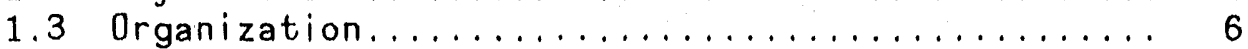

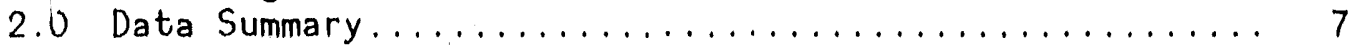

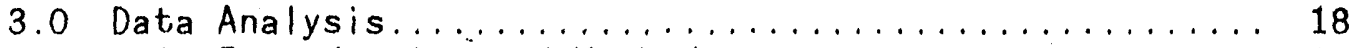

3.1 Introduction and Method.................. 18

3.2 Single Event Analysis...................... 22

3.2 .1 Anomalous Stations................. 23

3.2 .2 Yucca Mountain Stations............... 33

3.3 Multiple Event Analysis................... 40

3.4 Downhole Mot,ions........................ 47

3.5 Summary......................... 48

4.0 Predictions............................ 49

4.1 Equation Coefficients.................... 49

4.2 Evaluation of Predictions................ 56

4.3 Comparison of the Prediction of the

Design Ground Motions.................. 83

4.4 Comparison of UNE and Earthquake PSRVs........ 85

5.0 Conclusions and Recommendations................ 89

6.0 References............................. 90

Appendix A: Computer Codes Used to Develop

Prediction Procedure................ 92

PSRV Code............................. 104

Program FIT Multiple Event Version...... 138

Program FIT Single Event Version....... 148

Program SORT.................... 159

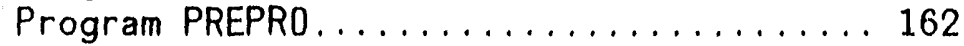

Program COMPARE................ 165

Appendix B: Prediction Procedure for PSRVs........... 179

Appendix C: SEPDB and RIB Information........... 208 
Figure $1-1$

Figure 1-2

Figure 2-1

Figure 2-2

Figure $3-1$

Figure $3-3$

Figure 3-4

Figure 3-5

Figure 3-6

Figure 3-7

Figure $3-8$

Figure 3-9

Figure $3-10$

Figure $3-11$

Figure $3-12$

Figure $3-13$

Figure $3-14$

ligure $3-15$

Figure 3-16
Single-degree-of-freedomi-system subjected to base motion........................

Example of a PSRV plotted on tripartite paper, Event Hardin, Station W26.......... Location of current testing areas, past and present WTSI seismic stations, the design bas is UNE, and Yucca Mountain on NTS....... Location of the Yucca Mountain stations.... Psuedo Velocity versus Scaled Range for a Frequency of $0.35 \mathrm{~Hz}$ Vertical Acceleration Data............................... Comparison of the average PSRV and actual PSRV for Station W-3, Event 38.......... Comparison of the average PSRV and actual PSRV for Station $W-6$, Event $38 \ldots \ldots \ldots \ldots$ Comparison of the average PSRV and actual PSRV for Station $W-9$, Event $38, \ldots \ldots \ldots \ldots$ Comparison of the average PSRV and actual PSRV for Station $W-15$, Event $38 \ldots \ldots \ldots \ldots$ Comparison of the average PSRV and actual PSRV for Station A, Event $38 \ldots \ldots \ldots \ldots \ldots$ Comparison of the average PSRV and actual PSRV for Station B, Event $38 \ldots \ldots \ldots \ldots \ldots$ Comparison of the average PSRV and actual PSRV for Station C, Event 38............. Comparison of the average PSRV and actual PSRV for Station D, Event $38 \ldots \ldots \ldots \ldots \ldots$ Ratios of measured/average pseudo velocities for events recorded at Station $W-14 \ldots \ldots$. . Ratios of measured/average pseudo velocities for events recorded at Station $W-23 . . . . .$. Ratios of measured/average pseudo velocities for events recorded at Station $W-22 \ldots \ldots \ldots$. Ratios of measured/average pseudo velocities for events recorded at Station $W-21 \ldots \ldots \ldots$. Topographic map showing the location of Stations $W-14, W-21, W-22$, and $W-23 \ldots$ Comparison of Groups I, II, and III Rock Geology for the design basis UNE...... Comparison of Groups I, II, and III Rock and alluvium geologies for the design basis UNE 
Figure $3-17$

Figure $3-18$

Figure $3-19$

Figure 4-1

Figure 4-2

Figure 4-3

Figure 4-4

Figure $4-5$

Figure 4-6

Figure $4-7$

Figure $4-8$

Figure 4-9

Figure $4-10$
Comparison of Groups I, II, and III -

Rock Geology for a typical UNE...........

Comparison of Groups I, II, and III -

Rock and alluvium geologie for the

design basis IJNE.....................

Comparison of the recommended prediction

procedure and an earlier procedure for

the design basis UNE.

Comparison of the predicted and measured

PSRVs for a recent UNE recorded at rucca

Mountain station W-25 surface.

(station geology classified as rock)- UNE1..

Comparison of the predicted and measured

PSRVs for a recent. UNE recorded at

Yucca Mountair. station W-25 downhole.

(station geology classified as rock)- UNE1..

Comparison of the predicted and measured

PSRV for a recent UNE recorded at

Yucca Mountain station W-26.

(station geology classified as alluvium)-UNE1. .

Comparison of the predicted and measured

PSRVs for a recent UNE recorded at

Yucca Mountain station W-28 surface.

(station geology classified as rock)- UNE1....

60

Comparison of the predicted and neasured

PSRVs for a recent UNE recorded at

Yucca Mountain station W-28 downhole.

(station geology classified as rock)-UNE1....

Comparison of the predicted and measured

PSRVs for a recent UNE recorded at

Yucca Mountain station W-29 surface.

(station geology classified as alluvium)- UNE1..

Comparison of the predicted and measured

PSRV for a recent INNE recorded at

Yucca Mountain station W-29 downhole.

(station geology classified as alluvium)- UNE1...

Comparison of the predicted and measured

PSRV for a recent UNE recorded at

Yucca Mountain station W-30 surface.

(station geology classified as rock)- UNE1....

Comparison of the predicted and measured

PSRV s for a recent UNE recorded at

Yucca Mountain station W-? surface.

(station geology classified as rock)-UNE2 .....

Comparison of the predicted and measured

PSRV for a recent UNE recorded at

Yucca Mountain station W-25 downhole.

(station geology classified as rock)- UNE2 ..... 
Figure $4-11$

Figure $4-12$

Figure $4-13$

Figure 4-14

Figure $4-15$

Figure $4-16$

Figure 4-17

Figure $4-18$

Figure $4-19$

Figure $4-20$

Figure $4-21$
Comparison of the predicted and measured PSRVs for a recent UNE recorded at

Yucca Mourtain station W-26.

(station geology classified as alluvium)-UNE2..

Comparison of the predicted and measured

PSRVs for a recent UNE recorded at

Yucca Mountain station W-28 surface.

(station geology classified as rock)-UNE2....

Comparison of the predicted and measured

PSRVs for a recent UNE recorded at

Yucca Mountain station W-28 downhole.

(station geology classified as rock)-UNE2.....

Comparison of the predicted and measured

PSRVs for a recent UNE recorded at

Yucca Mountain station W-29 surface.

(station geology classified as alluvium)-UNE2...

70

Comparison of the predicted and measured

PSRV for a recent UNE recorded at

Yucca Mountain station W-29 downhole.

(station geology classified as alluvium)-UNE2....

Comparison of the predicted and measured

PSRV s for a recent UNE recorded at

Yucca Mountain station W-30 surface.

(station geology classified as rock)-UNE2 ........

Comparison of the predicted and measured

PSRVs for a recent UNE recorded at

Yucca Mountain station W-25 surface.

(station geology classified as rock)-UNE3........

Comparison of the predicted and measured

PSRV $\mathrm{fC}$ - a recent UNE recorded at

Yucca Mountain station W-25 downhole.

(station geology classified as rock)-UNE3........

Comparison of the predicted and measured

PSRVs for a recent UNE recorded at

Yucca Mountain station W-26.

(station geology classified as alluvium)-UNE3....

Comparison of the predicted and measured

PSRV for a recent, UNE recorded at,

Yucca Mountain station W-28 surface.

(station geology classified as rock)-UNE3........

Comparison of the predicted and measured

PSRV for a recent UNE recorded at,

Yucca Mountain station W-28 downhole

(station geology classified as rock)-UNE? 
Figure $4-22$

Figure $4-23$

Figure $4-24$

Figure $4-25$

Figure $4-26$

Figure $4-27$

Figure $4-28$

Figure $A-1$

Figure $A-2$

Figure $A-3$

Figure $A-4$

Figure $A-5$

Figure A-6

Figure $A-7$

Figure $B-1$

Figure $B-2$
Comparison of the predicted and measured

PSRVs for a recent UNE recorded at

Yucca Mountain station W-29 surface.

(station geology classified as alluvium)-UNE3.....

-omparison of the predicted and measured

PSRVs for a recent UNE recorded at

Yucca Mountain station W-29 downhole.

(station geoloy; =! assified as alluvium)-UNE3.... 80

Comparison of the predicted and measured

PSRVs for a recent UNE recorded at

Yucca Mountain station W-30.

(station geology classified as rock)-UNE3.........

Comparison of the predicted and measured

PSRVs for a large yield event (>500 kt)

(station geology classified as rock)-UNE4 ....... 82

Comparison of the prediction of the

design basis UNE and design earthquakes

1 and 2 (URS/Blume, 1986) for a rock site........

Comparison of the prediction of PSRVs

from an "equivalent" UNE, earthquake pair

for a rock geology, radial motion............ 86

Comparison of the prediction of PSRVs

from an "equivalent" UNE, earthquake pair

for a rock geology, transverse motion......... 87

Processing scheme used for handling

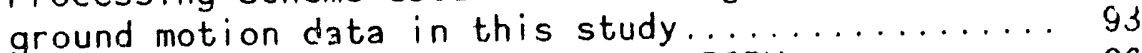

Difference between NOS and VAX - PSRVs......... 96

Difference between NOS and VAX - PSRVs.......... 97

Logic flow and subroutine description of FIT..... 99

Test data used for FIT .................. 100

Output from Problem FIT................. 101

Plot of results from test run on FIT code........ 101

Block diagram showing overall structure of

PREDICT code........................ 181

Input sequence for PSRV prediction code......... 183 


\section{TABLES}

Table 2-1

Table 2-2

Tabie 2-3

Table 4-1

Table 4-2

Table 4-3

Table 4-4

Table $4-5$

Table 4-6

Table $B-1$
Weapons Test Seismic Investigation Station

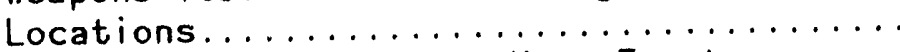

Summary of OIder Pahute Mesa Events

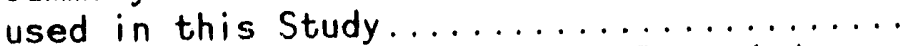

14

Summary of Pahute Mesa Events Recorded

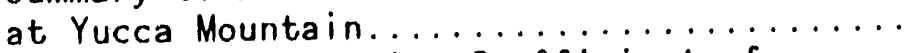

15

Summary of Prediction Coefficients for

Vertical PSRV for Stations on Alluvium....

50

Summary of Prediction Coefficients for

Vertical PSRVs for Stations on Rock........

Summary of Prediction Coefficients for

Radial PSRVs for Stations on Alluvium......

Summary of Prediction Coefficients for

Radial PSRVs for Stations on Rock.........

Summary of Prediction Coefficients for

Transverse PSRVs for Stations on

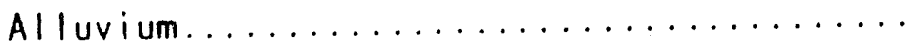

54

Summary of Prediction Coefficients for

Tranisverse PSRVs for Stations on Rock......

55

Description of the Major Components

of the PSRV Prediction Code..............

182 


\subsection{INTRODUCTION}

\subsection{Background}

One of the primary goals of the Yucca Mountain Site Characterization Project is the understanding and quantification of the seismic risk at the Yucca Mountain site. This seismic risk consists of both natural and man-made events. The major man-made events of interest to the Project are the underground nuclear explosions (INES) conductud at the Nevada Test Site (NTS). The quantification of seismic risk involves development of a credible prediction procedure for UNE-generated ground motions. Several ground motion quantities can be predicted (i.e. peak amplitudes, time histories or response spectra of either vector or component ground motions). Maximum amplitudes of ground motion are useful for some applications, such as gage ranging for upcoming UNEs, but are of limited value for structural analysis because they only provide one asr ct of the ground motion environment. Time histories provide a complete picture of the ground motion environment, but they contain so much information it is difficult to determine which aspect of the environment is of most interest in the structural anaiysis. Response spectra condense the time history information into a form that is more useful than maximum amplitudes and less confusing than the full time histories. The subject of this report is the development of a prediction procedure for pseudo relative velocity (PSRV) response spectra. Only surface ground motions are analyzed in this report. A short discussion of the prediction of downhole motions based on earlier analyse's is included in Chapter 3.0.

The PSRV spectrum is the response of a single degree-of-freedom (SDOF) system to a transient input, as a function of the system natural frequency. Many engineering systems may be represented as an SOOF system or a combination of SDOF systems such as that shown in Figure 1-1. This figure shows a schematic representation of an SDOF system subjected to a base motion. The paraneters of this system are mass $(n)$, spring stiffness (k), damping (c), base displacement $(y)$, mass displacement $(x)$, relative displacement $(u)$, and time $(t)$. A corivenient representation of the response of such a system to tho amplitude and frequency content of input ground motion is the response spectrum. The response spectrum may be expressed in terms of the relative displacement between the mass and the base, the relative velocity between the mass and the base, or the absolute acceleration of the mass. The following discussion will provide some background on the concept of the PSRV response spectrum. " Much of this information was condensed from Higgins et al., (1978), Newmark and Rosenbluth (1971), and Crawford et al., (1974).

1. Note that the PSRV response spectrum will be referrad to as the "PSRV" throughout this report. 


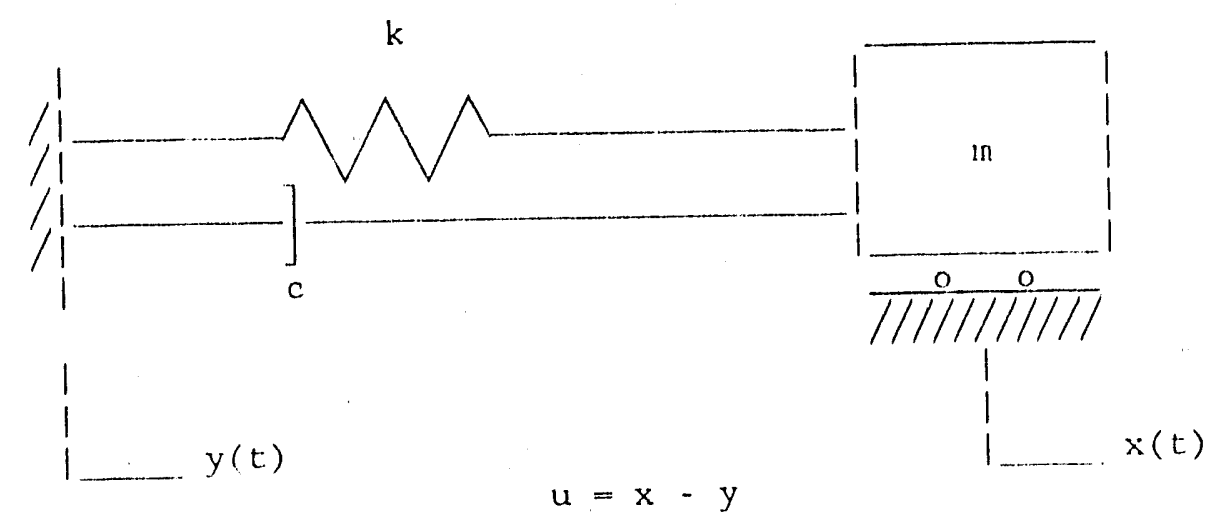

Figure 1-1. Single-Degree-of-Freedom-System Subjected to Base Motion.

The equation of motion for the mass in Figure $1-1$ is

$$
\ddot{u}(t)+2 \beta \omega_{n} \dot{u}(t)+\omega_{n}^{2} u(t)=-\ddot{y}(t),
$$

where

$\mathrm{x}, \mathrm{y}$ and $\mathrm{u}$ are as described above

the dot indicates differentiation with respect to time;

$\beta$ is the damping ratio $(\mathrm{c} / 2 \sqrt{\mathrm{km}})$

$\omega$ is the undamped natural frequency $(\sqrt{\mathrm{k} / \mathrm{m}})$.

Assuming zero initial conditions, this equation can be solved to yield an expression for relative displacement (Higgins et al., 1978). This expression is

$$
u=\frac{-1}{\omega_{n} \sqrt{1-\beta^{2}}} \int_{0}^{t} \ddot{y}(r) e^{-\beta \omega_{n}(t-\tau)} \sin \left(\omega_{n} \sqrt{1-\beta^{2}}(t-\tau)\right) d \tau
$$

Eepressions for relative velocity and absolute acceleration may be derived through manipulation (differentiation with respect to time, the use of the relationship between relative displacement and acceleration, and simplification. The maximun values from equation $1-2$, and the derived expressions for absolute acceleration and relative velocity can be computed as a function of natural frerquency and damping of the system for any base motion and ploted as a function of frequency. The resulting curves are the responso spectra for the system. Fach of these parameters is important in describing, the respense of the system. The maximum relative velocity spectrun is a 
direct measure of the maximum energy per unit mass in the system; the relative displacement spectrum is related to system strain; and absolute acceleration spectrum is related to the lateral force coefficient frequently used in building codes.

These spectra are usually simplified by making the assumption of small damping (i.e., $\beta<0.2$, such that $\sqrt{1-\beta^{2}}-1$ ). This simplifies Equation $1-2$ to

$$
u=\frac{-1}{\omega_{n}} \int_{0}^{t} \ddot{y}(\tau) e^{-\beta \omega_{n}(t-\tau)} \sin \omega_{n}(t-\tau) d \tau .
$$

Performing the same manipulations discussed above and dropping the separate terms with $\beta$ and $\beta^{2}$ yields expressicns for absolute acceleration and relative velocity. The maximum values of pseudo absolute acceleration (or simply pseudc acceleration) and relative displacement are related in the following manner

where

$$
A=\omega_{n}^{2}[
$$

$A$ is the pseudo acceleration

$D$ is the relative displacement.

Pseudo acceleration amplitudes are generally close to the absolute acceleration (Newmark and Rosenbluth, 1971). The derived expression for the pseudo relative velocity differs from the other two parameters by a factor of the natural frequency and the fact that it contains a cosine function rather than a sine function. If the cosine is replaced by the sine in the expression for the relative velocity, the three parameters are related in the following manner

$$
\frac{1}{\omega_{n}} A=V=\omega_{n} D
$$

where

$y$ is the pseudo relative velocity.

Relative velocity and pseudo velocity will be significantly different when the system period 19 much longer than the duration of the input ground motion (Higgins et al., 1978). For many instances, however, the pseudo velocity and relative velocity will be roughily equal. 
The $A, V$ and $D$ parameters are generally plotted in $\log$ space on tripartite graph paper. An example is shown in Figure 1-2. The horizontal axis is frequency and the vertical axis is pseudo relative velocity. Any point on this plot for a given frequency describes the system strain, energy absorbed by the system, and the maximum force in the system.

The ground motion quantities that are actually measured are ground velocity and ground acceleration versus time. These time histories are recorded in and $\mathrm{Og}$, digitized, processed, and filtered. In general, the frequencies most. ofton filtered from the "raw" data are those less than $0.3 \mathrm{~Hz}$ and greater than $311 \mathrm{H}:$. These filtered waveforms are used as input to the computer code used to calculate PSRV (see Appendix A). The PSRV are run at a damping factor of (1) Although the PSRV is not technically observed ground motion, it will he i.. lererd to as "observed data" in the text of this report. In some instances, plote of PSRVs will be presented in this report that show data extending from (i.) $10100 \mathrm{~Hz}$. This is done merely as a plotting convenience. The analyses anci discussions that follow apply only to 58 damped PSRVs at frequencies hetwen 0.3 and $30 \mathrm{~Hz}$.

The quantities discussed in this report are measured in the following init.s:

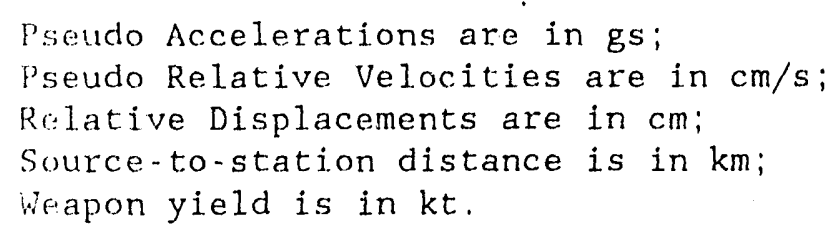

These are the units used in the regression analyses and are the units used in. input into the prediction procedure. Source-to-station distance, as def ined in this report, is the slant range from the shot point to the incasurement location.

\section{1.? objectives}

The primary objective of this report is to document the development of a credihle prediction technique for PSRVs of UNE-generated ground motions at. Mun Mountain. This effort will focus on the prediction of surface ground In: innc but incorporate past work on downhole motions as well (Phillips, 1:1). In addition, some effort is made to identify and quantify station Hfres at the Yucca Mountain stations. 


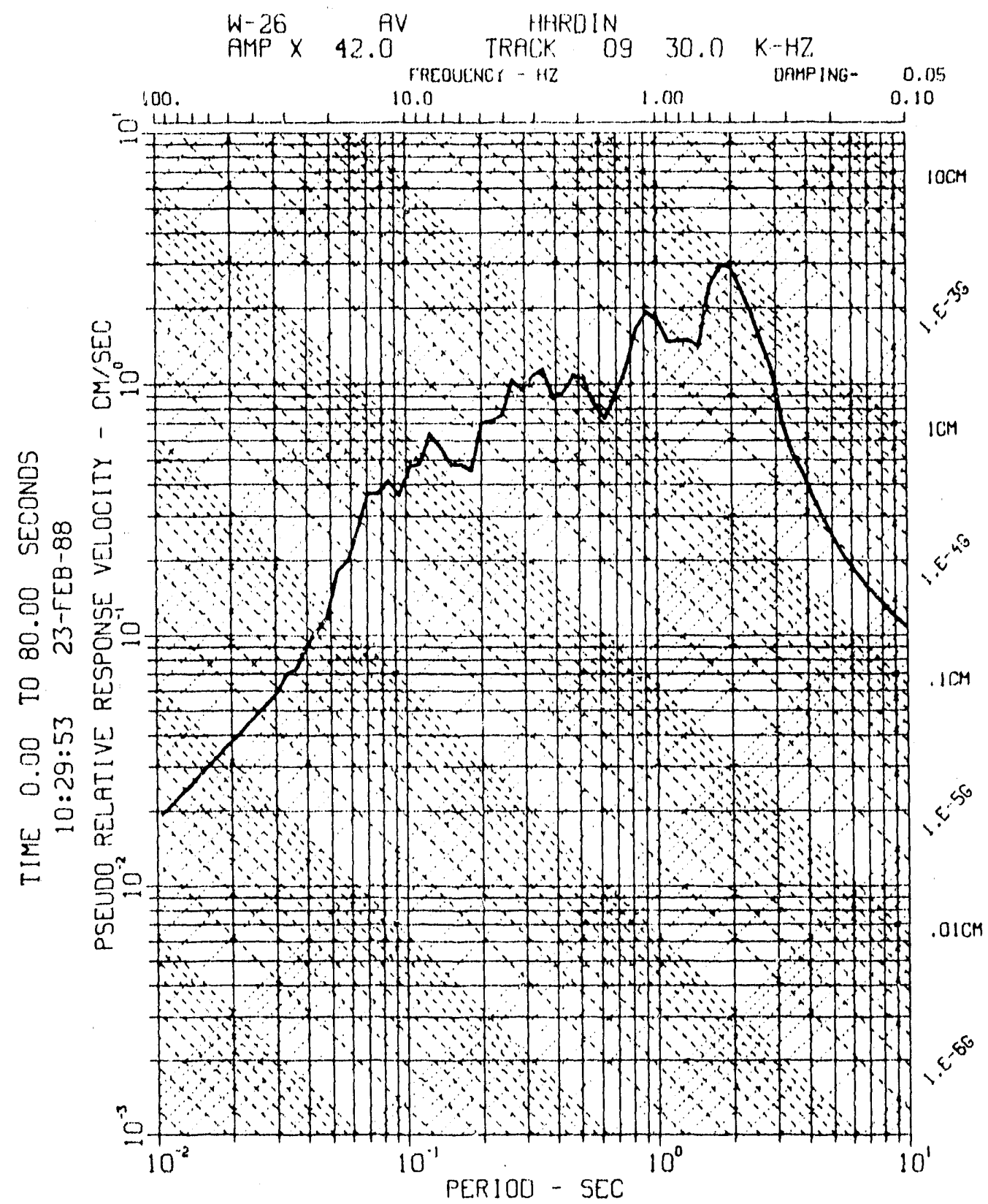

Figure 1-2. Example of a PSRV plotted on Tripartite Paper (Event Hardin, Station W26) 


\subsection{Organization}

This report contains a large amount of information. In addition, some aspects of this effort are classified. In an effort to present the information in a logical manner and protect the classified material, this report is organized as follows. Chapter 2 contains an unclassified summary of the data base used in the analyses presented in this report. A summary of the data analyses is contained in Chapter 3 . The recommended prediction equations and an evaluation of these equations are presented in Chapter 4. Conciusions are given in Chapter 5. A total of three appendices are included in this report.

Appendix A contains the verification and description of the computer codes used in the analyses. Appendix B contains a FORTRAN listing of the prediction procedure developed in this study. A classified summary of the data base used for this effort will be published as a separate report. 


\subsection{DATA SUMMARY}

A map of NTS is shown in Figure 2-1. This map shows the relative locations of the majui weapons testing areas (of interest to the project) and Yucca Mountain. The UNEs discussed in this report have been conducted in Areas 19 and 20 of NTS (Pahute Mesa). Included on this figure are the approximate locations of the design basis UNE and the various stations that have been fielded in support of the Yucca Mountain Site Characterization Project. Table 2-1 lists the locations and dates of operation of the WTSI stations that have been used in the support of the Yucca Mountain Site Characterization Project. Figure 2-2 shows an enlargement of the Yucca Mountain area. A total of eleven stations ( $f i v e$ of which had downhole instrumentation) have been fielded in the Yucca mountain area. Currently, there are five active stations four of which have companion downhole instrumentation.

The core of the ground motion data used in this effort was originally selected for the analyses presented in Vortman (1986).

(This study was similar in objectives to the current effort, however, only peak amplitudes were analyzed.) This initial seiection, described by Vortman, was made on the basis of judgement and experience. The study reported herein expanded and edited the original data base.

Table 2-2 summarizes the event names, dates, general locations and a description of the type of ground-motion monitoring for older UNEs used in this study. Ground motions were generally monitored for two reasons in this group of events. The first reason was to understand close-in ground motion. These stations were at distances generally less than $10 \mathrm{~km}$ from the UNE. These are noted as "scientific" stations in Table 2-2. The second reason for monitoring ground motions was to assess off-site safety. These stations were both onsite and off-site. These stations are listed as nUSGS" in Table 2-2. In addition, a number of UNEs included in this set were monitored after the initiation of the Nevada Nuclear Waste Site Investigations (predecessor to the Yucca Mountain Site Characterization Project), but prior to the narrowing of those investigations to the Yucca Mountain area. These events have stations categorized as "NNWSI" in Table 2-2. In this effort, the ground motion data from these UNEs were examined for suitability and quality. The last column in Table 2-2 indicates the number of ground motion records used in this study. The off-site stations were not used because the facilities of concern to this project are primarily on-site. Ground motions from close-in stations which exhibited the characteristics of spall were also eliminated from the data set. ${ }^{2}$ Pahute Mesa UNEs that have been monitored through FY 88

\footnotetext{
2.Spall results when a compressive wave impinges on a free surface. The compressive wave is reflected back into the material as a tonsilo wavo. Geologic materials are very woak in tension and the material fractures. When falluro occurs "layers" of materiai are thrown into the oir. At some point the upward velocity of the layers is
} 
at the Yucca Mountain stations are shown in Table 2-3. In general, the data from this group of events are internally consistent and of good quality. Very few data records were eliminated from this set because of problems. Ground motion at Yucca Mountain was first recorded in 1980. The reader should be aware that between 1980 and 1986 this effort was designated at the lowest quality assurance (Q/A) level. During FY86 the Q/A level was upgraded to the highest level. Events in Table 2-3 designated as QI were recorded in compliance with the requirements of this higher $Q / A$ level.

The final data base used for this siudy consists of recorded ground moliuns from 49 UNEs. Ground motions were recorded at Yucca Mountain for 28 of these events. The remaining 21 UNEs predate the installation of recording instruments at Yucca Mountain. The sol-ceto -.station distance variation in this data base is from approximately 1 to $60 \mathrm{~km}$. The yield variation is from 80 to $1400 \mathrm{kt}$. The distiribution of yields in the data base is as follows: 9 events had yields greater than $500 \mathrm{kt} ; 7$ events had yields between 150 and 500 $\mathrm{kt}_{\mathrm{t}}$; and the remainder of the events had yields between 80 and $150 \mathrm{kt}$ (all (INEs recorded at Yucca Mountain are included in this last group). The final data set included a total of 585 vertical, 585 radial and 587 transverse component records. This data base was selected to provide as broad a spectrum in source-to-station distances and yie!ds as possible. This is necessary to minimize the bias to a specific range of yields and source-to-station distances in the data base and to encompass the distance and yield parameters of the design basis UNE.

In addition to the 49 UNEs used to derive the prediction equations, 1 UNEs which were not included in the data set were used to evaluate the prediction equations. These events consist of one large yield event (>500) and three recent UNEs recorded at Yucca Mountain (yield between 80 and $150 \mathrm{kt}$ ). These events were selected to try to gage the accuracy of the procedure in a "true" predictive situation.

The analysis of this data set is discussed in the subsequent chapters of this report.

rancelled by the gravitational forces and the layers fall back to the surface. This whenomenon is observed at close-in stations but is not representative of the ground molions that will be observed in the Yucca Mountair area from current or future UNEs. 


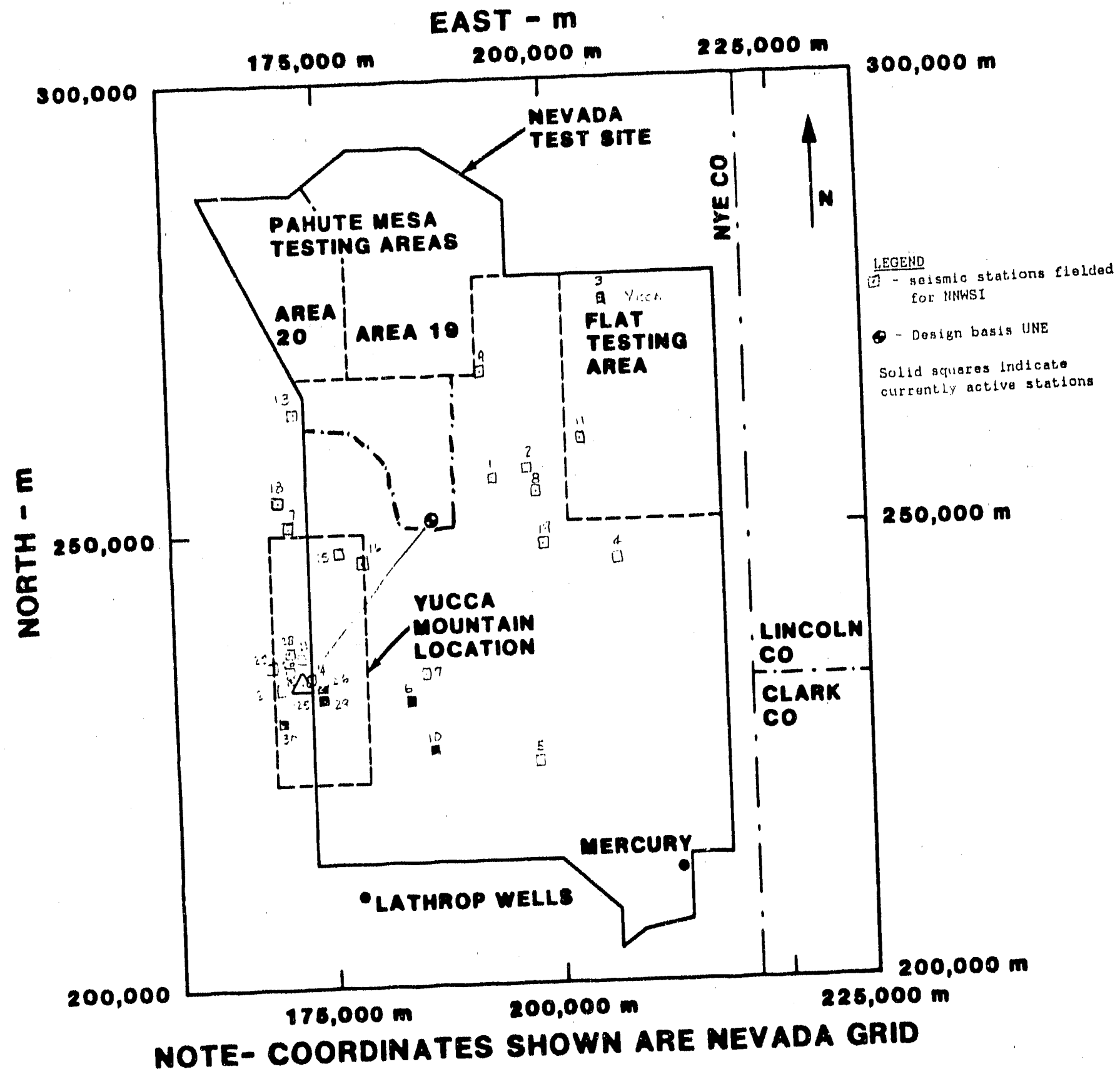

Figure 2-1. Location of Current Testing Areas, Past and Present WTSI Seismic Stations, the Design Basis UNE, and Yucca Mountain on NTS 


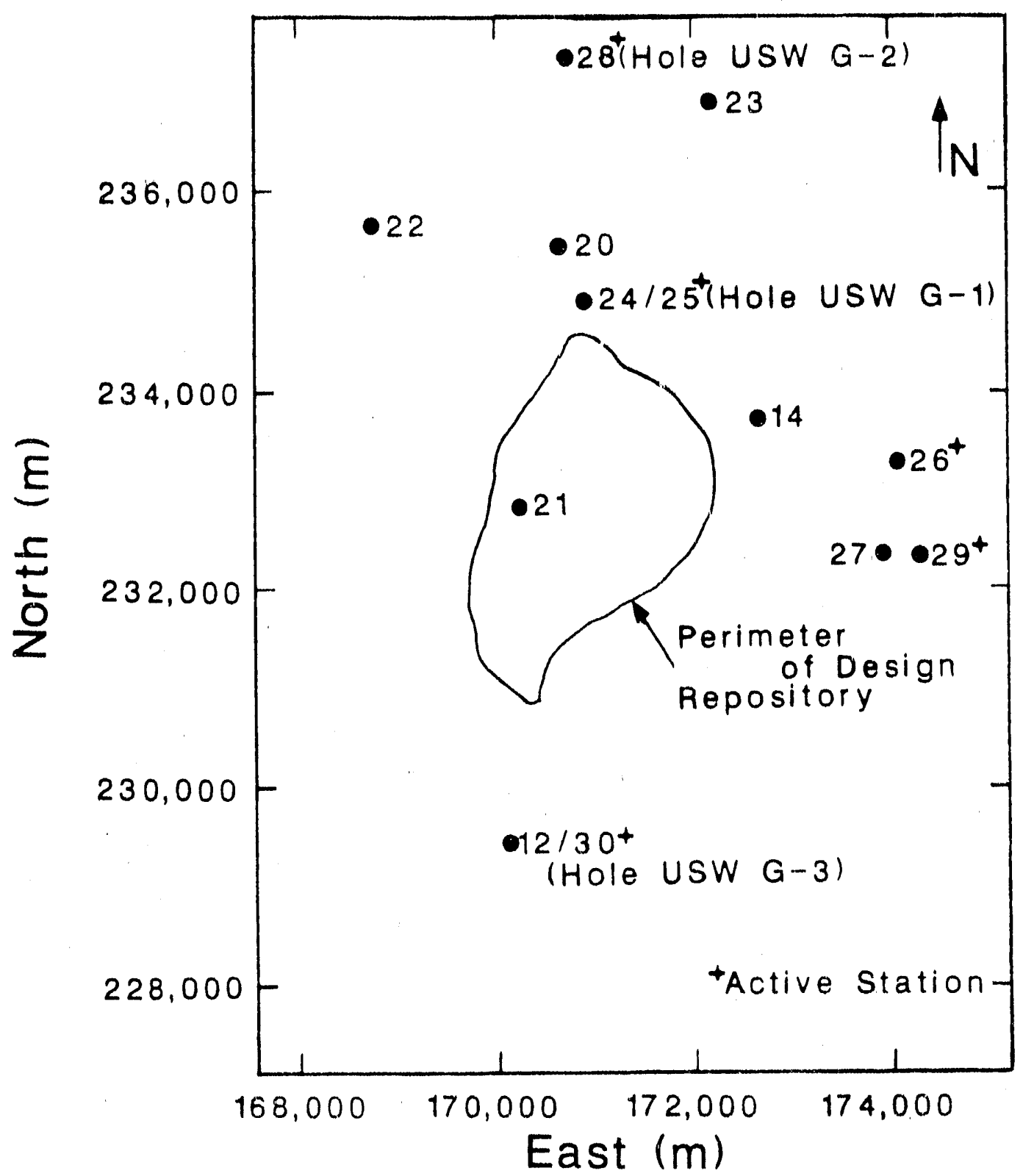

Figure 2-2. Location of the Yucca Mountain Stations 
TABLE $2-I$ WEAPONS TEST SEISMIC INVESTIGATION STATION LOCATIONS.

\begin{tabular}{|c|c|c|c|c|c|}
\hline Station & Location & Hole No. & $\begin{array}{l}\text { Depth } \\
(\mathrm{mi})\end{array}$ & Medium & Date Installed \\
\hline$n-1$ & Area 16 & None & $\begin{array}{l}\text { Surface } \\
\text { Only }\end{array}$ & Eleana Shale & $\begin{array}{c}8 / 77 \\
\text { (Removed 11/77) }\end{array}$ \\
\hline W- 2 & Syncline Ridge & None & $\begin{array}{l}\text { Surface } \\
\text { Only }\end{array}$ & $\begin{array}{l}\text { Limestone over } \\
\text { Eleana Shale }\end{array}$ & $\begin{array}{l}8 / 77 \\
\text { (Removed 6/78) }\end{array}$ \\
\hline W- 3 & Piledriver & Ue-15.01 & $\begin{array}{l}\text { Surface } \\
\quad 417\end{array}$ & Granite & $\begin{array}{l}\quad 9 / 77 \\
(\text { Removed 5/83) }\end{array}$ \\
\hline W -4 & Area 6 & $\mathrm{Ue}-6 \mathrm{~b}$ & $\begin{array}{c}\text { Surface } \\
130\end{array}$ & Alluvi.um & $\begin{array}{l}\quad 4 / 77 \\
(\text { Removed 5/78) }\end{array}$ \\
\hline W- 5 & Skull Mountain & None & $\begin{array}{c}\text { Surface } \\
\text { Only }\end{array}$ & Tuff & $\begin{array}{c}10 / 77 \\
\text { (Moved } 5 / 81 \text { ) } \\
\text { (Removed } 10 / 83 \text { ) }\end{array}$ \\
\hline$W-6$ & ETS - 2 & None & $\begin{array}{l}\text { Surface } \\
\text { Only }\end{array}$ & Alluvium & $10 / 77$ \\
\hline W-7 & Calico Hills & None & $\begin{array}{l}\text { Surface } \\
\text { Only }\end{array}$ & Eleana Shale & $10 / 77$ \\
\hline$W-8$ & Yacht Hole & Ue-1L & $\begin{array}{c}\text { Surface } \\
679\end{array}$ & $\begin{array}{l}\text { Alluvium over } \\
\text { Eleana Shalle }\end{array}$ & $\begin{array}{c}3 / 78 \\
(\text { Removed } 8 / 78) \\
570 a\end{array}$ \\
\hline$W-9$ & Rainier Mesa & $\begin{array}{l}\mathrm{U}-12 \mathrm{~g} .08 \\
\mathrm{CH} \mathrm{No.} 1\end{array}$ & $\begin{array}{c}\text { Surface } \\
432\end{array}$ & Tuff & $\begin{array}{c}12 / 77 \\
\text { (Removed } 4 / 84 \text { ) }\end{array}$ \\
\hline$w-10$ & Well J-II & $J-11$ & $\begin{array}{l}\text { Surface } \\
356 b \\
343\end{array}$ & $\begin{array}{l}\text { Alluvium over } \\
\text { TuEf }\end{array}$ & $3 / 78 \quad 4 / 78$ \\
\hline$w-10^{\prime}$ & 200 & $J-11^{\prime}$ & $\begin{array}{l}\text { Surface } \\
61\end{array}$ & Al1uvium & $\begin{array}{l}3 / 78 \\
\text { (Removed } 7 / 81)\end{array}$ \\
\hline$w-11$ & Area 4 & Le-4aa & $\begin{array}{l}\text { Surtace } \\
346\end{array}$ & $\begin{array}{l}\text { Alluvium over } \\
\text { Limestonf: }\end{array}$ & $\begin{array}{l}3 / 78 \\
\text { (R.emoved } 4 / 84)\end{array}$ \\
\hline $\begin{array}{l}w-12 \\
(w-30)\end{array}$ & Fucca Mountain & USW-GU3 & $\begin{array}{l}\text { Surface } \\
352\end{array}$ & Tuff & $\begin{array}{c}3 / 83 \\
(w-30 \text { on } 1 / 85)\end{array}$ \\
\hline
\end{tabular}




\begin{tabular}{|c|c|c|c|c|c|}
\hline Station & Location & Hole No. & $\begin{array}{l}\text { Depth } \\
(\mathrm{m})\end{array}$ & Medium & Date Installed \\
\hline$w-13$ & Area 18 & $\mathrm{Ue}-18 \mathrm{r}$ & $\begin{array}{c}\text { Surface } \\
762\end{array}$ & $\begin{array}{l}\text { Tuff over } \\
\text { Welded Tuff }\end{array}$ & $\begin{array}{l}6 / 788 / 78 \\
\text { (Removed 4/84) }\end{array}$ \\
\hline$w-14$ & Yucca Mountain & None & $\begin{array}{l}\text { Surface } \\
\text { Only }\end{array}$ & Tuff & $\begin{array}{c}6 / 80 \\
\text { (Removed 7/85) }\end{array}$ \\
\hline$w-15$ & Dome Mountain & None & $\begin{array}{l}\text { Surface } \\
\text { Only }\end{array}$ & Lava & $\begin{array}{l}10 / 78 \\
\text { (Removed 6/82) }\end{array}$ \\
\hline Station & Location & Hole No. & $\begin{array}{l}\text { Depth } \\
(m)\end{array}$ & Medium & Date Installed \\
\hline$w-16$ & 40 Mile Canyon & None & $\begin{array}{l}\text { Surface } \\
\text { Only }\end{array}$ & Rhyolite & $\begin{array}{l}10 / 78 \\
\text { (Removed 8/82) }\end{array}$ \\
\hline$\ddot{i}-17$ & N. Timber Mtil & None & $\begin{array}{l}\text { Surface } \\
\text { Only }\end{array}$ & Tuff & $\begin{array}{l}\quad 7 / 78 \\
\text { (Removed 8/82) }\end{array}$ \\
\hline$n-18$ & S. Timber Mtn & None & $\begin{array}{l}\text { Surface } \\
\text { Only }\end{array}$ & Tuff & $\begin{array}{l}7 / 78 \\
\text { (Removed 8/82) }\end{array}$ \\
\hline$\ddot{w}-19$ & Mine Mountain & None & $\begin{array}{l}\text { Surface } \\
\text { Only }\end{array}$ & Limestone & $\begin{array}{l}2 / 79 \\
\text { (Removed 9/80) }\end{array}$ \\
\hline w. 20 & Yucca Mountain & None & $\begin{array}{l}\text { Surface } \\
\text { Only }\end{array}$ & Tuff & $\begin{array}{l}\quad 7 / 80 \\
\text { (Moved to } \\
\text { USW-G1 } 4 / 82 \text { ) }\end{array}$ \\
\hline$W-21$ & Yucca Mtn, SW & None & $\begin{array}{l}\text { Surface } \\
\text { Only }\end{array}$ & Tuff & $\begin{array}{l}7 / 80 \\
\text { (Removed 8/85) }\end{array}$ \\
\hline$\therefore-22$ & iucca Mtn, NW & None & $\begin{array}{l}\text { Surface } \\
\text { Only }\end{array}$ & Tuff & $\begin{array}{l}7 / 80 \\
\text { (Removed 8/85) }\end{array}$ \\
\hline$x-23$ & Yucca Mtn, IE & None & $\begin{array}{l}\text { Surface } \\
\text { Only }\end{array}$ & Tuff & $\begin{array}{l}\quad 7 / 80 \\
\text { (Removed 8/85) }\end{array}$ \\
\hline$\therefore \therefore$ & Tucca Mountain & USW-GI & $\begin{array}{c}\text { Surface } \\
564\end{array}$ & Tuff & $\begin{array}{c}3 / 82 \\
\text { (Removed 7/83) }\end{array}$ \\
\hline
\end{tabular}


TABLE $2-1$ WEAPONS TEST SEISMIC INVESTIGATTON STATION LOCATTONS. (conC Hule (1)

\begin{tabular}{|c|c|c|c|c|c|}
\hline station & Location & Hole No. & Depth & Medium & Date Insta1.1ed \\
\hline$\overline{W-25}$ & Yucca Mountain & USW-GI & $\begin{array}{c}\text { Surface } \\
358 \\
305 c\end{array}$ & Tuff: & $8 / 83$ \\
\hline$W-26$ & Yucca Mountain & None & $\begin{array}{l}\text { Surface } \\
\text { Only }\end{array}$ & Alluvium & $4 / 84$ \\
\hline$W-27$ & Yurca Mountain & None & $\begin{array}{l}\text { Surface } \\
35\end{array}$ & Alluvium & $\begin{array}{l}\quad 6 / 84 \\
\text { (Removed 8/84) }\end{array}$ \\
\hline$W-28$ & Yucca Mountain & USW-G2 & $\begin{array}{c}\text { Surface } \\
375 \\
358 c\end{array}$ & Tuff & $6 / 84$ \\
\hline$W-29$ & Yucca Mountain & UE25 RF-4 & $\begin{array}{l}\text { Surface } \\
\quad 82\end{array}$ & Alluvium & $2 / 85$ \\
\hline A & Jackass Flats & None & $\begin{array}{l}\text { Surface } \\
\text { Only }\end{array}$ & Alluvium & $8 / 78$ \\
\hline B & Jackass Flats & None & $\begin{array}{l}\text { Surface } \\
\text { Only }\end{array}$ & Alluvium & $\begin{array}{c}8 / 78 \\
\text { (Removed } 8 / 84 \text { ) }\end{array}$ \\
\hline $\mathrm{C}$ & Jackass Flats & None & $\begin{array}{l}\text { Surface } \\
\text { Only }\end{array}$ & Alluvium & $\begin{array}{l}\quad 8 / 78 \\
\text { (Removed 8/84) }\end{array}$ \\
\hline D & Jackass Flats & None & $\begin{array}{c}\text { Surface } \\
\text { Only }\end{array}$ & Alluvium & $\begin{array}{l}8 / 78 \\
\text { (Removed } 8 / 84)\end{array}$ \\
\hline
\end{tabular}
a. after $4 / 78$
b. before $12 / 78$
c. after $4 / 87$ 
TABLE 2-2 SUMMARY OF OLDER PAHUTE MESA EVENTS USED IN THIS STUDY

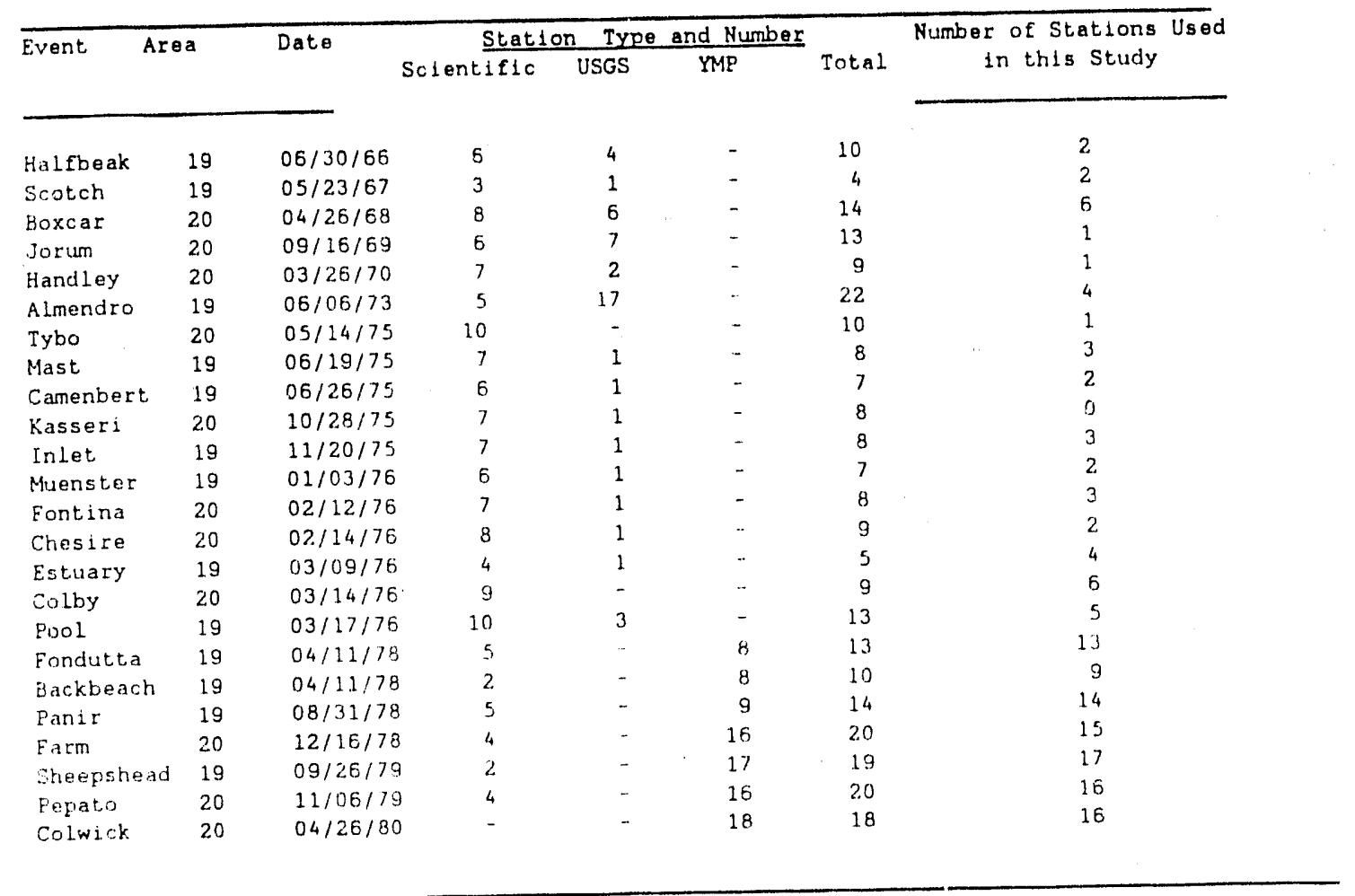




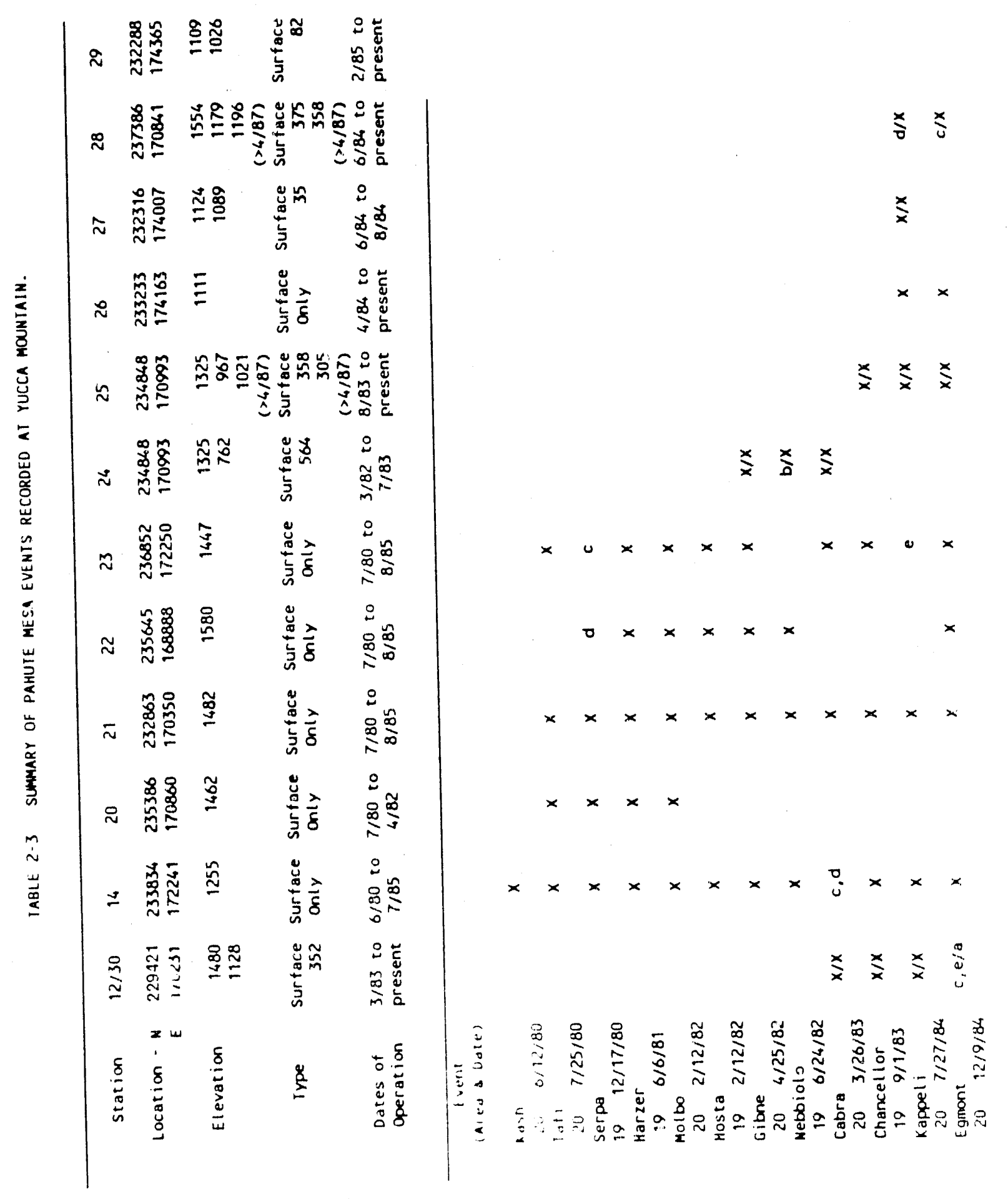




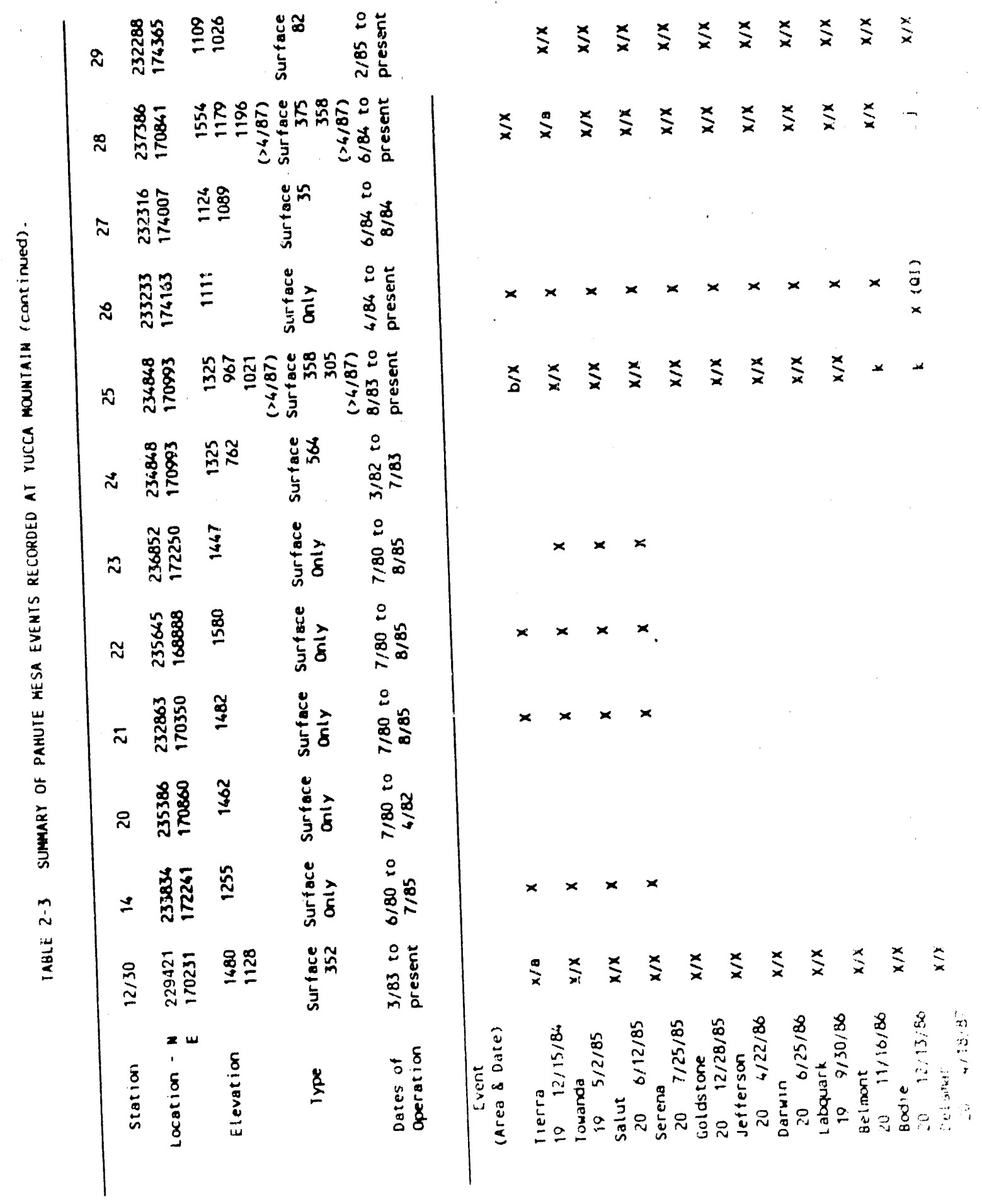




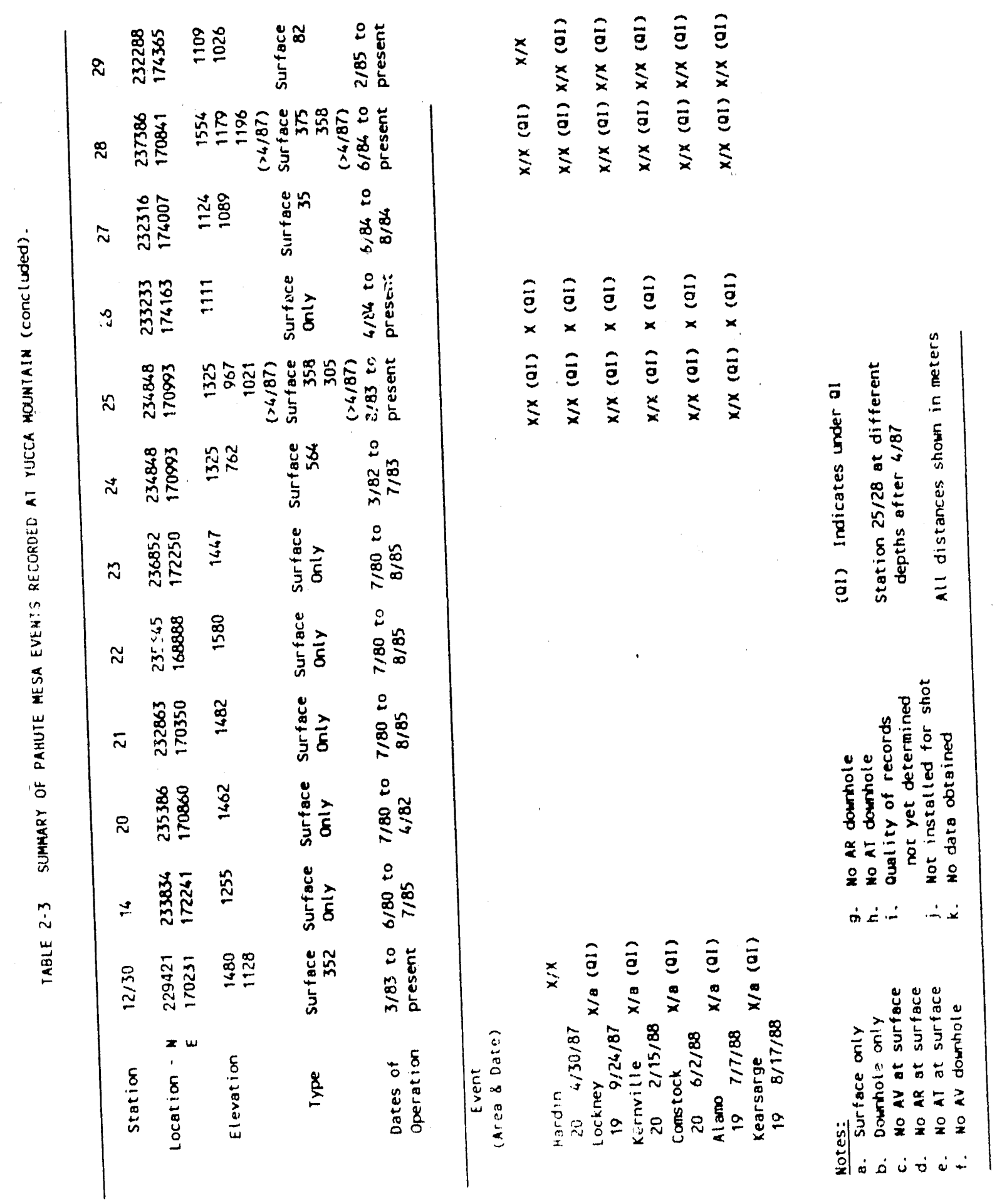




\subsection{DATA ANALYSIS}

\subsection{Introduction and Method}

Observed ground motion is a function of the source (encrgy and coupling), source-to-station distance and the geology. This geology is made up of the source geology, receiver (or station) geology and the travel path geology. A prediction procedure for any aspect of ground motion should take these parameters into consideration. In this study, as in others done for this project, all sources are assumed to be the same (i.e., a radially expanding, compressional shock front at the shot point). Source encrgy is described in terms of the explosive yield of the UNE. Differences in source geology are assumed to be small because all. UNEs in this study were conducted in pahute Mesa. In addition, differences in coupling are considered to be of only minor importance (as shown in the analyses of Vortman, 1986) in this data set largely because of the similarity in source geologies. Differences in travel path geology are largely ignored in this approach. (Travel path is implicitly considered in the Yucca Mountain data set because the source and receiver: areas are the same; i.e., essentially only one path. This approach is not: without precedent or success; e.g., Environmental Research Corporation, 1984. Station geology is broadly classified as either alluvium or rock to account: for differences in receiver structure.

Using the principles discussed above, empirical prediction models for UNE ground motions (and PSRVs) generally assume that observed ground motions are primarily a function of yield and distance. In addition, the assumption i.s made that the data are lognormally distributed and distance attenuation behavior is adequately described as linear in $\log -\log$ space (a power curve). The equation of the power curve has the form:

$$
P=K W^{a} R^{b}
$$

where $\quad P$ is the parameter of interest;

$W$ is the yield;

$R$ is the source-to-station distance;

$K$ is a fitting coefficient (intercept at $x=1$ );

$a$ is the fitting coefficient on $W$;

b is the fitting coefficient on $R$. For the data in this study, $b$ is: a) ways negative.

Fundamental least square linear regressjon techniques are used to determine the $k$, $a$, and b coefficients for this equation. These best fit equations are an average of all data inoluded in the regressions and can be used to prodict best estimate UNE pround motions. The associated statistics generated in the repression can be used to provide uncertainiy intormation on this best r.stinate for this work, the complete prediction of the PSRV will consist of the best estimate and the uncertainty bounds. The uncertainty bounds discussed in this study are the 95 go confidence intervals (i.e., 95 o ot lhe 
data will be included in the upper and lower bounds). This corresponds to the 97.58 nonexceedance probability level.

The linear regression routines provide the upper and lower bounds on all three coefficients of Equation 3-1. Initially, the upper and lower bounds were determined from the variation of all three coefficients. Determining the upper and lower bounds in this manner produced an uncertainty spread of almost: two orders of magnitude (top to bottom). After review, it was apparent that: the data, the best estimate, and the bounds should be compared on the same basis. This is not the case when all three coefficients vary independently. Using the fact that $b$ is negative, equation 3-1 can be expressed as follows:

$$
P=k\left(\frac{R}{w^{a / b}}\right)^{-b}
$$

where

$$
\frac{\mathrm{R}}{\mathrm{W}^{\mathrm{a} / \mathrm{b}}} \text { is the scaled range. }
$$

The equations for the bounds were "converted" such that the yield coefficient (a/b in Equation 3-2) was the same as the best estimate. An example of the data and the bounds scaled to the same basis as the best estimate is shown in Figure 3-1. (This figure shows the vertical acceleration data-a total of 537 points.) Note, the spread of the upper and lower bounds vary from about 3 to about 8 (top to bottom.) Using the regression coefficients in this way allows the intercept and the attenuation (range) coefficient to vary but holds the yield coefficient constant for a data group (i.e., one frequency). The data fit in this manner provide a reasonable description of the best estimate and the uncertainty associated the prediction using these correlations.

As discussed earlier, the PSRV consists of response parameters calculated at discrete frequencies. In this study the response parameter analyzed is the pseudo velocity. The computer code used in this effort calculates pseudo velocity from the ground motion time history at 48 different frequencies between 0.3 and $30 \mathrm{~Hz}$. The empirical prediction of the PSRV will involve the use of 48 individual equations of the form of Equation 3-1. 
Basically two analyses were performed on these data. These analyses ar. 1 isted below and will be discussed in detail in the remaining sections of this chapter.

Single Event Analysis - A total of 15 of the events inclucled in this study had a sufficient number of stations and a large enough variation in source-to-station distance that a single event analysis could be performed. This "single event arialysis" involved a linear regression analysis of the calculated PSRVs. The linear regression was determined with all available data for: an event, then some data were eliminated and the regression repeated. Comparison of the various regressions with the "observed" PSRVs allowed an assessment of receiver effects both al Yucca Mountain stations and other NTS stations identified as anomalous.

Multiple Event Analysis - Data from all events were grouped in the same fashion as discussed in Vortman (1986). A multiple linear regression was computed for each group and subgroup for each component (vertical, radial or transverse) and the results compared. The rationale behind this approach is to determine which group provides the most accurate prediction for the problem of interest. 


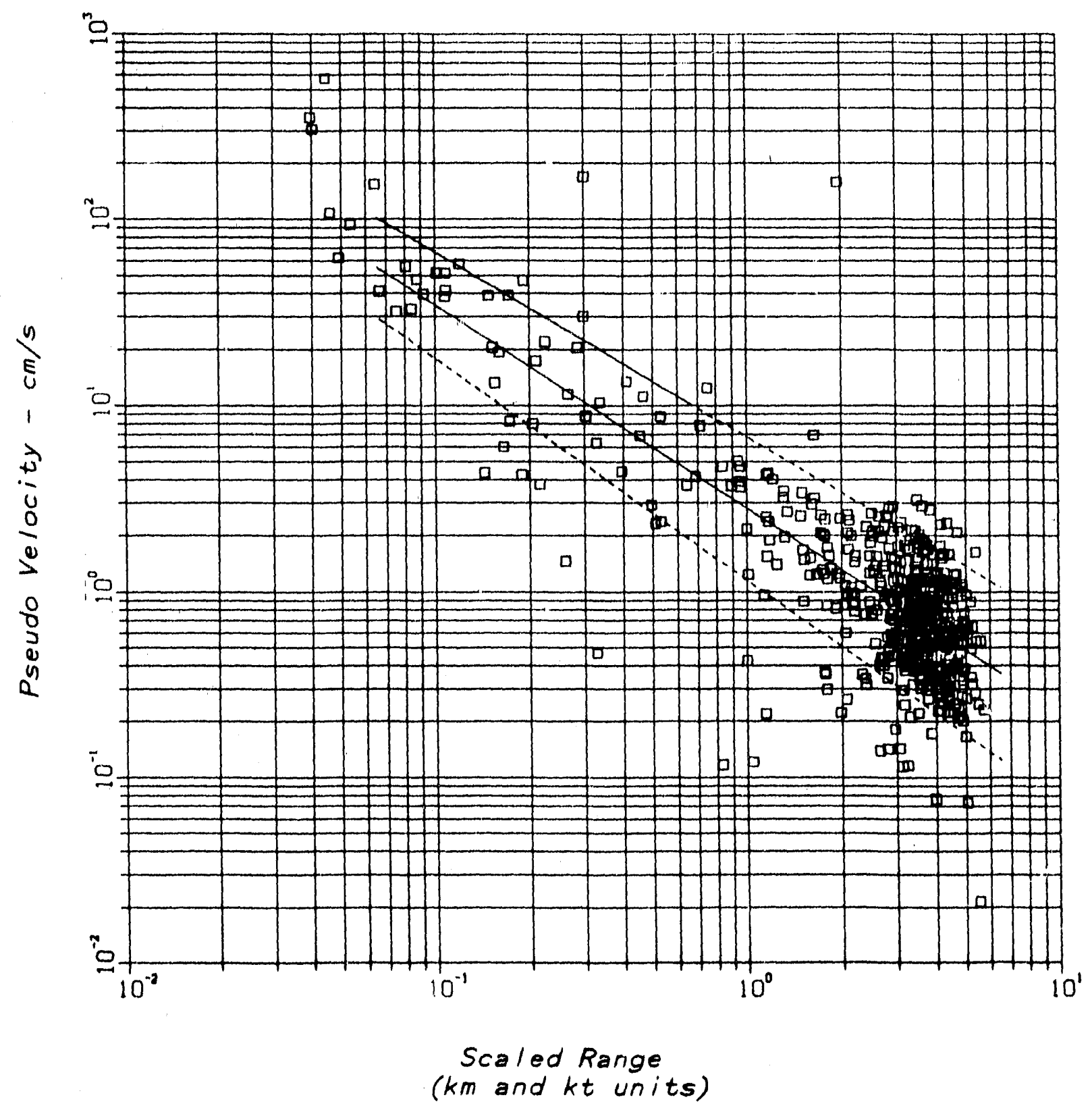

Figure 3-1 Pseudo Velocity versus Scaled Range for a Frequency of $0.35 \mathrm{~Hz}$ Vertical Acceleration Data 


\subsection{Single Event Analys is}

As mentioned above, 15 events were instrumented well enough to do an individual analysis. The purpose of these analyses was to 1dentify anomalous behavior at particular stations. Anomalous behavior in this instance is defined as a substantial deviation from the overall event average. The objective of the total effort is to develop a prediction procedure that is generally applicable to NTS and Yucca Mountain. The empirical approach used here determines the average value (via linear regression) of pseudo velocity from a number of observations. In general, observations that deviate substantially and consistently from the average should not be included in the average, if a plausible explanation of the deviation can be determined and it is shown not to be a contributing factor to observed ground motions at Yucca Mountain. By analyzing a relatively complete ground motion data set from a single event, source characteristics, source coupling, and source geology are eliminated as possible variables in the problem. Because many of the same stations are used on these events, the assimilation of the results of these analyses will provide an indication of the nature and amplitude of the anomalous behavior as well as station effects observed at Yucca Mountain.

In general, the procedure used in these analyses was to perform the regression on all data avaliable for the event. Because source characteristics (yield) are eliminated from the analysis the linear regression equation is of the form:

$$
P=K R^{b}
$$

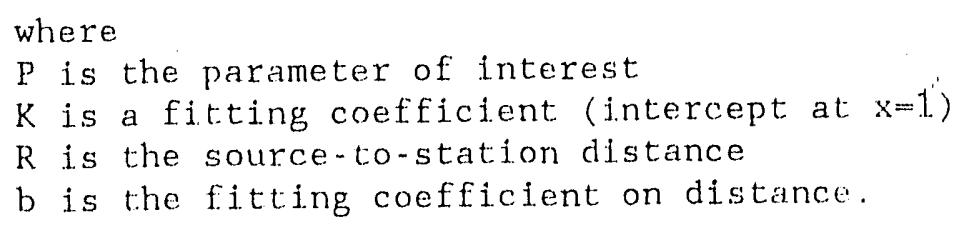

These regression equations were then used to "predict: the PSRV for each station which was compared to the observed PSRVs. Yucca Mountain stations were eliminated from the event clata set (if available) and an additional set. of regression equations were determined. These regression equations were also used to "predict" PSRVs. These "predictions" were compared to the observed PSRVs at Yucca Mountain. 


\subsubsection{Anomalous Stations}

In earlier work (Vortinan, 1.986), stations $W-3, W-6, W-9, W-15, A, B, C$, and $D$ were determined to be anomalous. The nature of the anomalous betavior was determined from observations of maximum vector amplitude. These anomalies were attributed to station geology. Station $W-3$ was installed on Climax granite and produced maximum velocity and displacements that were low relative to the overall average. Stations $W-6$ and $A$ through $D$ were installed on alluvium and are located in the NRDS area of the NTS. Observed ground accelerations from these stations are high relative to the overall average (by as much as a factor of 10 at $W-6$, with smaller differences at $A-D$ ). Stations W-9 (installed on tuff at Rajnier Mesa) and W-15 (installed on lava at Done Mountain) had larger observed displacements than the overall average. These differences were identified as topographic effects.

In this current effort, the PSRV for these elght stations were compared to the individual event average. Examples of these comparisons for the vertical, radial, and transverse components from a typical UNE are shown in: Figures 3-2 through 3-9. The observed PSRVs (indicated as dashed lines on Figure 3-2 at station $W-3$ are well below the event average at all frequencies for all three components. This comparison is typical of station.w-3 for all events studied. Comparisons of observed and average PSRVs for station $W-6$ are shown in Figure 3-3. At frequencies above $2 \mathrm{~Hz}$, observed PSRVs are well above the event average for this station. At frequencies less than $2 \mathrm{~Hz}$, the average and observed PSRVs are about the same. This is typical of most UNEs recorded at this station. The observed PSRVs at station W-9 (Figure 3-4) are average at frequencies above $1 \mathrm{~Hz}$ but become greater than the average at lower: frequencies. The comparisons for the various events recorded at station $W-9$ do not indicate a strong trend to be elther above or below the event average. Figure 3-5 shows the comparison of observed PSRVs and the event average for station $W-15$. The event average compares favorably on the radial and transverse components in frequency content as well as amplitude with the observed value. The vertical component is generally less than the event average for this station. For most of the 15 events, all components compare favorably with event averages at this station. Stations A through D (Figures 3-6 and 3-7) exhibit much the same behavior as observed for station $W-15$ (i.e., neither consistently high nor low).

In summary, only stations $W-3$ and $W-6$ appeared to be anomalous (on a consistent basis) with respect to the event average. The other stations appear to have equal likelihood of being either high or low.

The contributing factor to the anomalous behavior at station $w-3$ is the station geology. This is the only station in the group founded on granite. The propertics of this material are substantially different from the other "rock" included in the data set and not typical. of the material present at Yucca Mountain. 

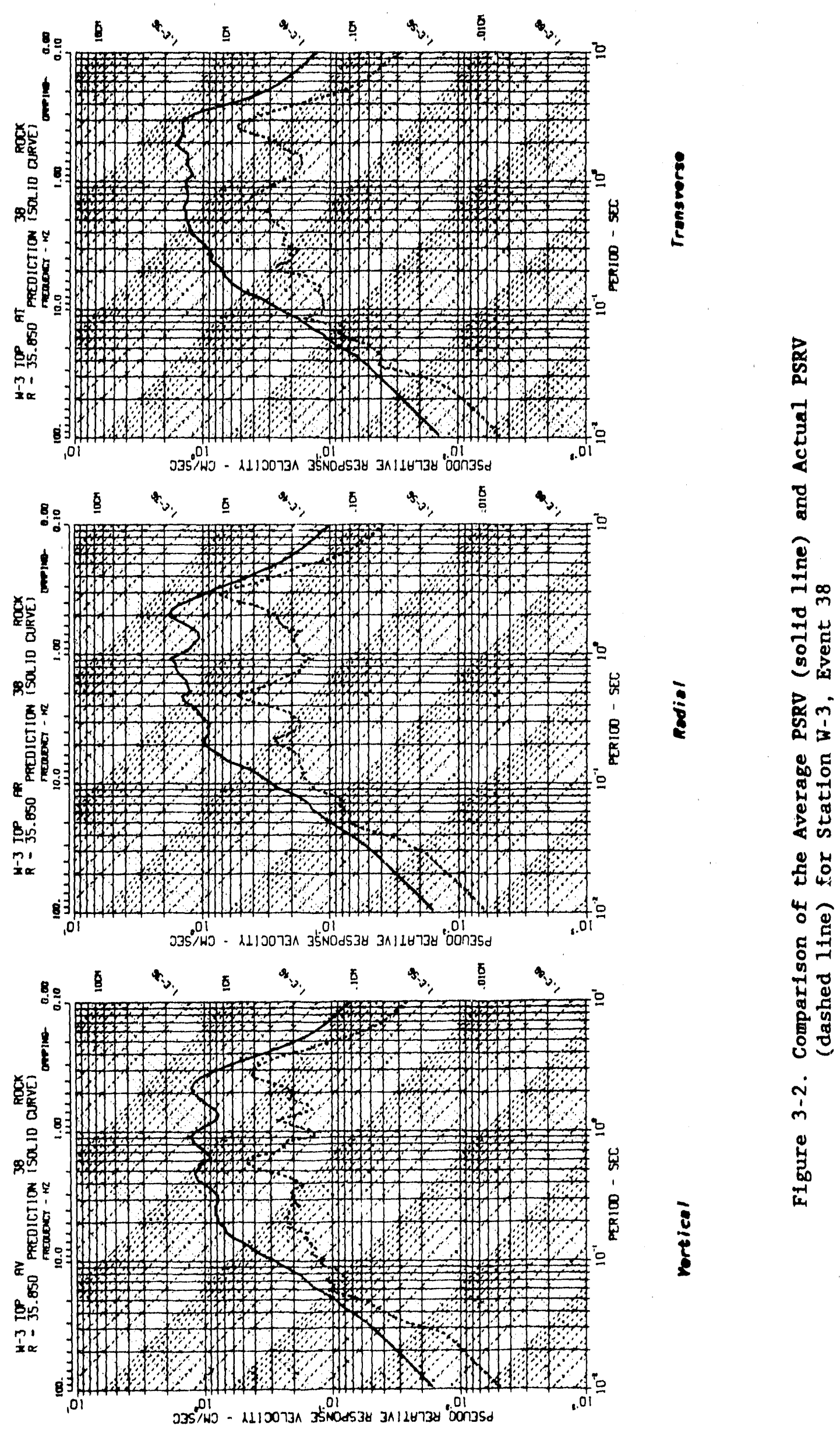


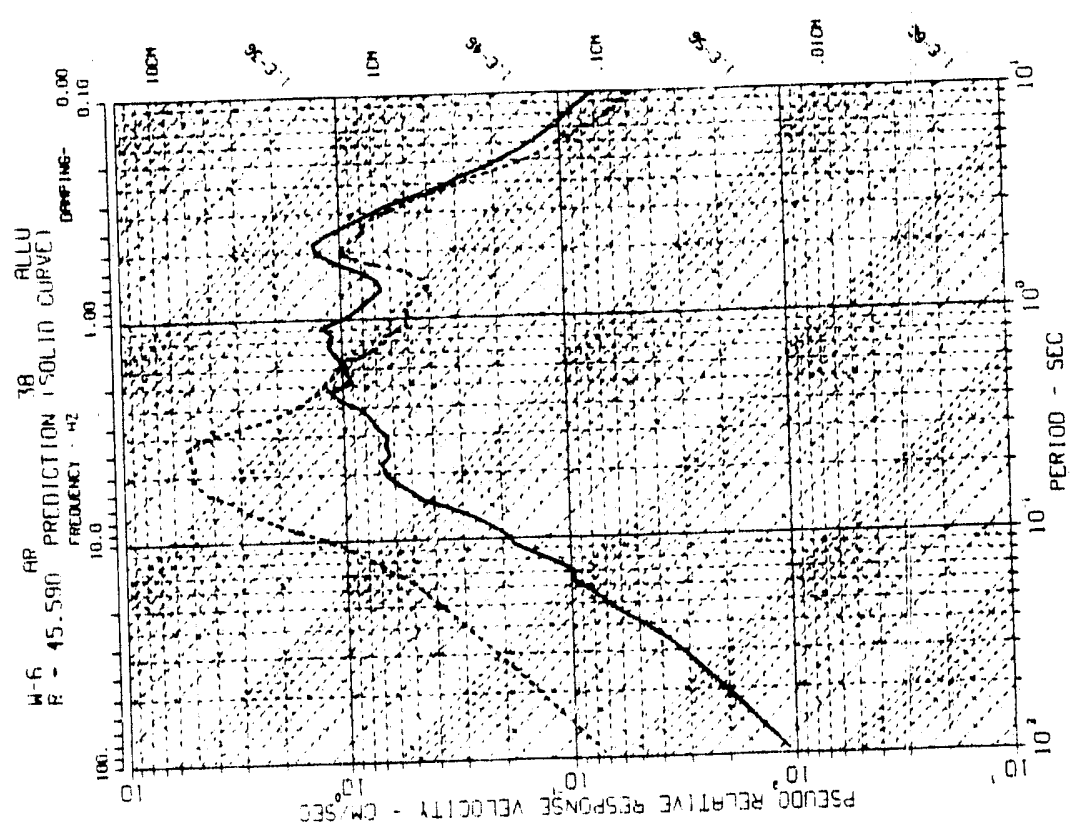

है

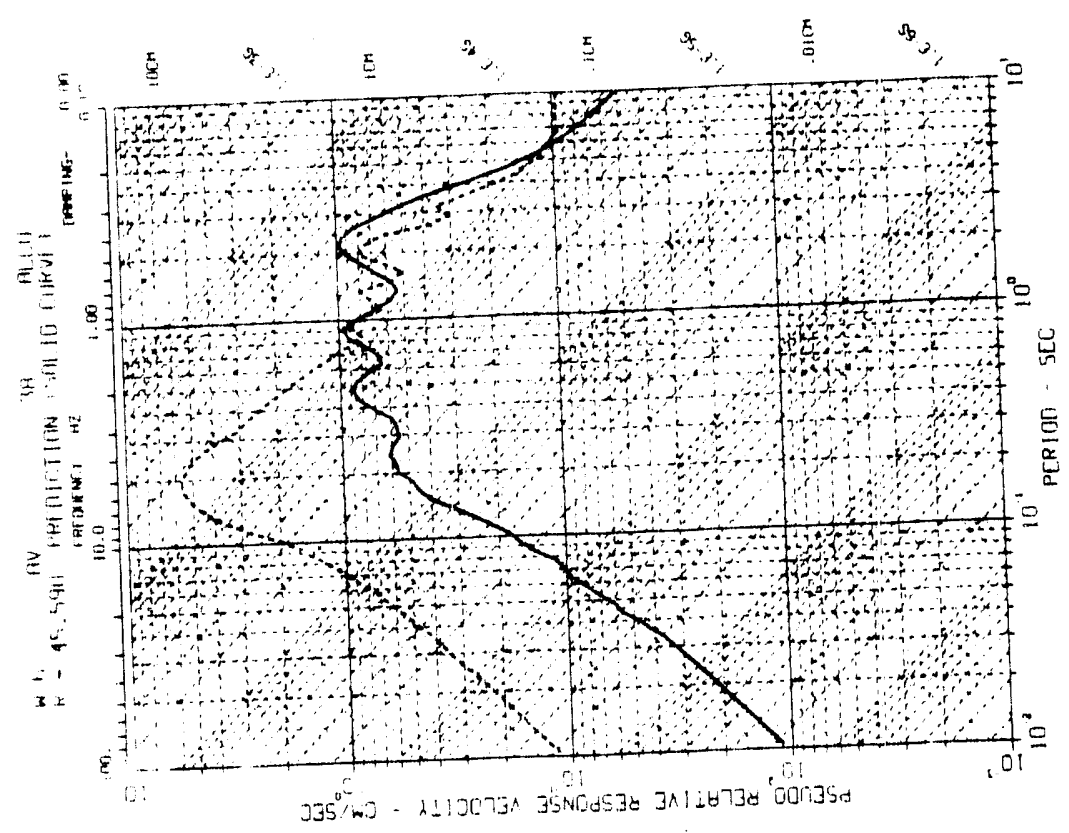

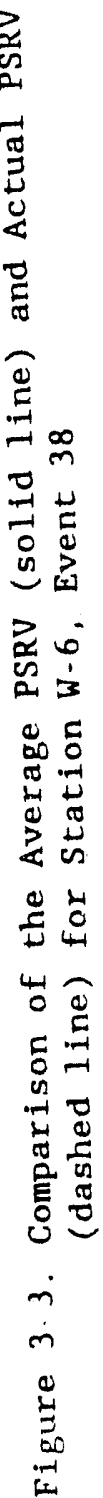




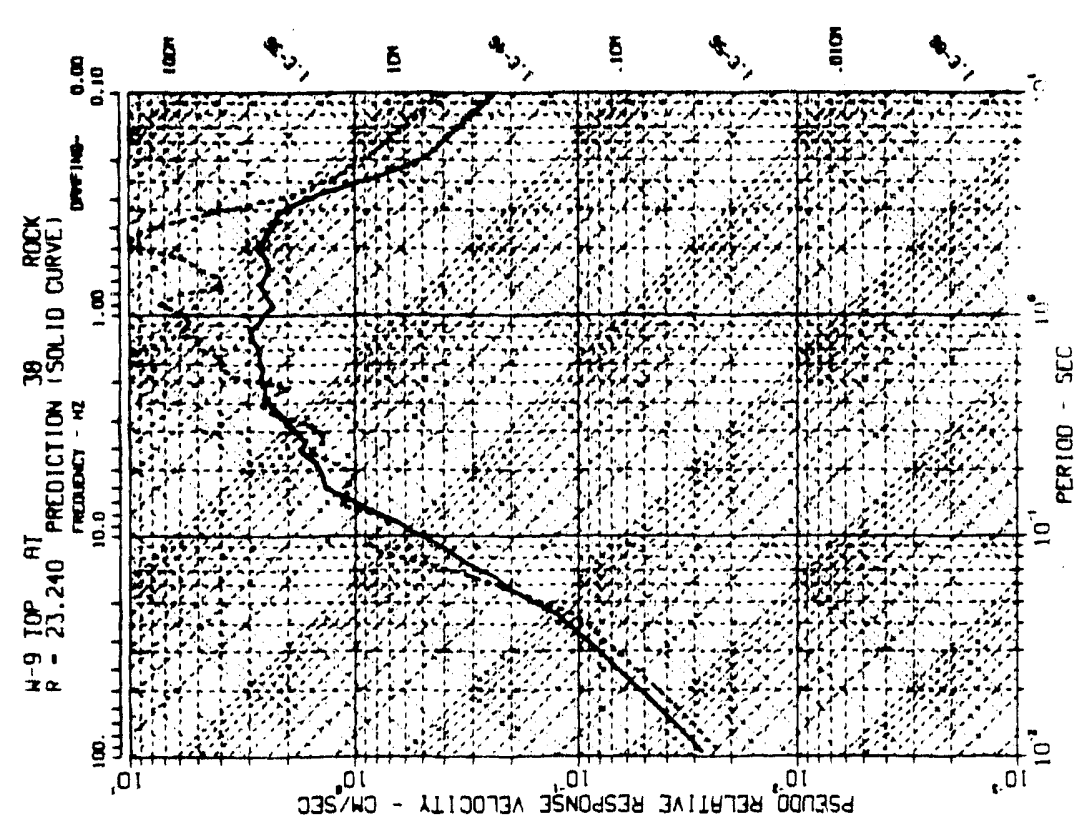

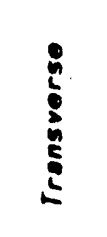
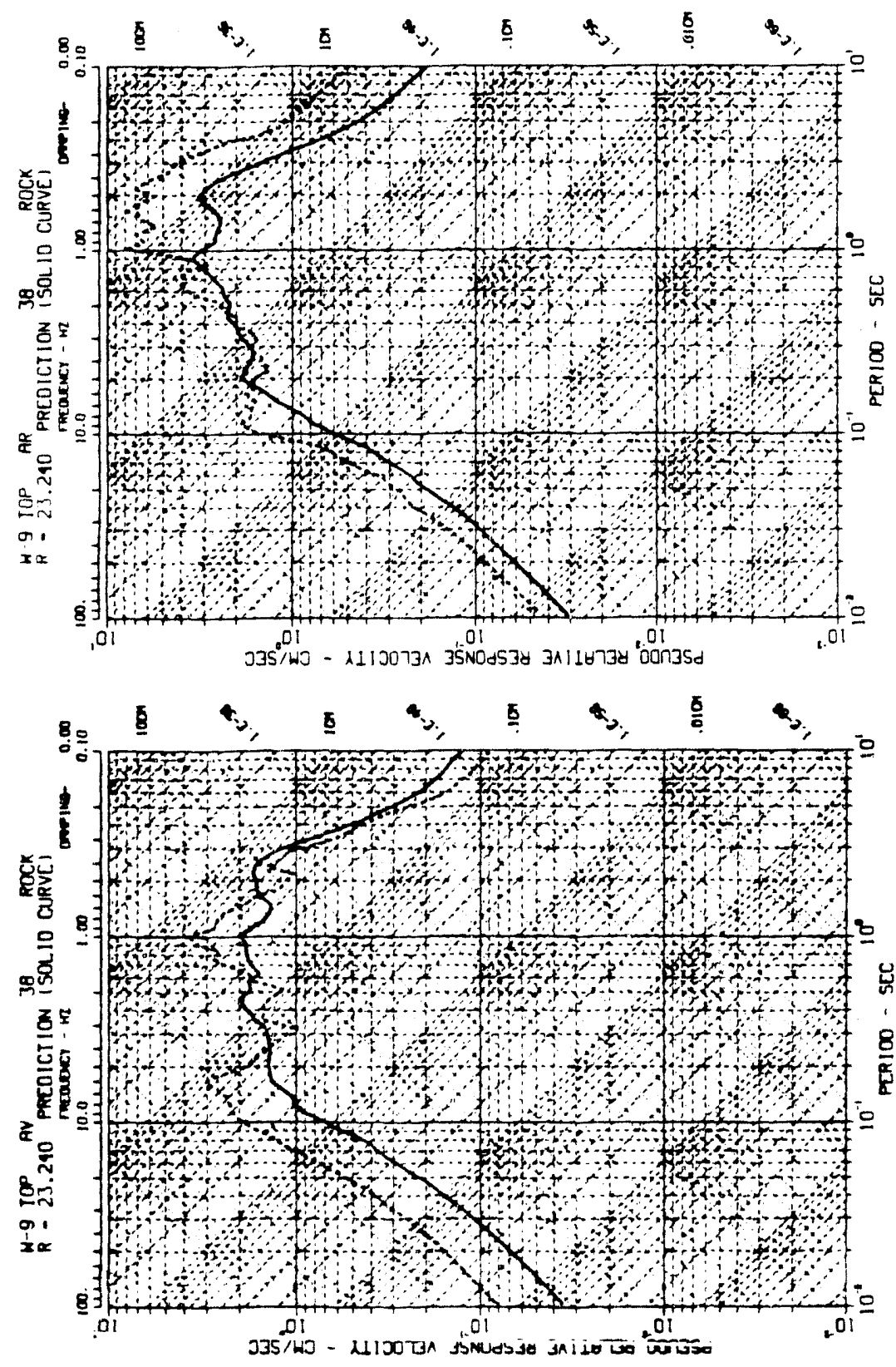

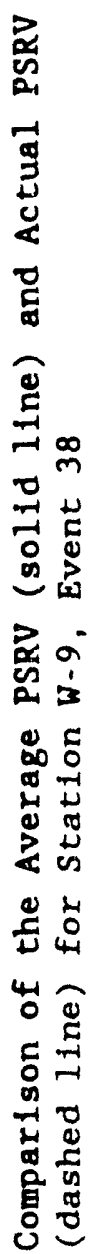

蒋 

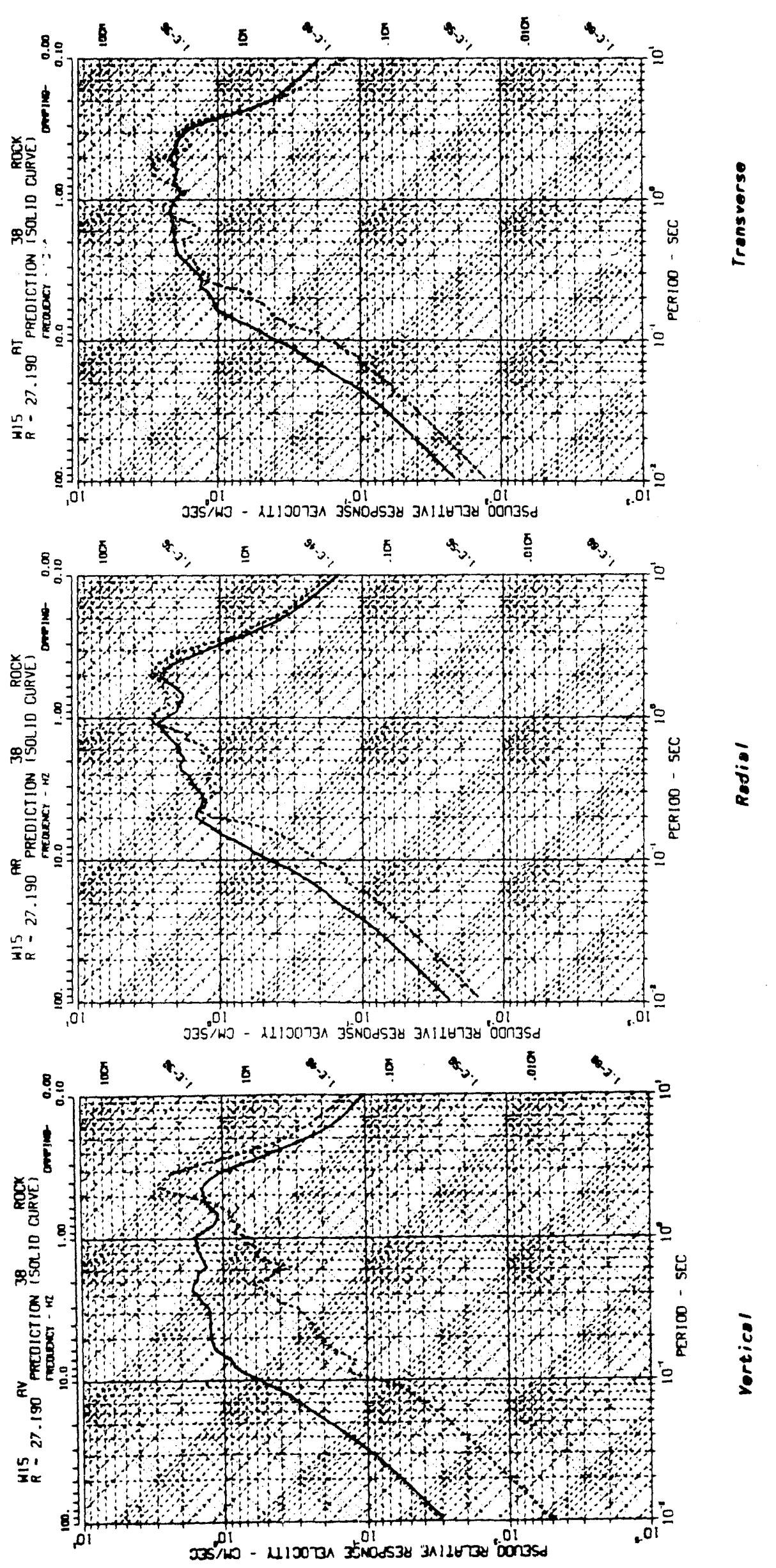

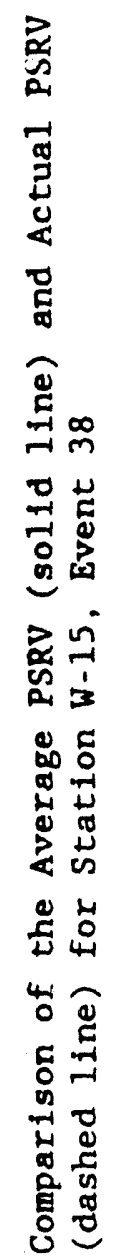

in 

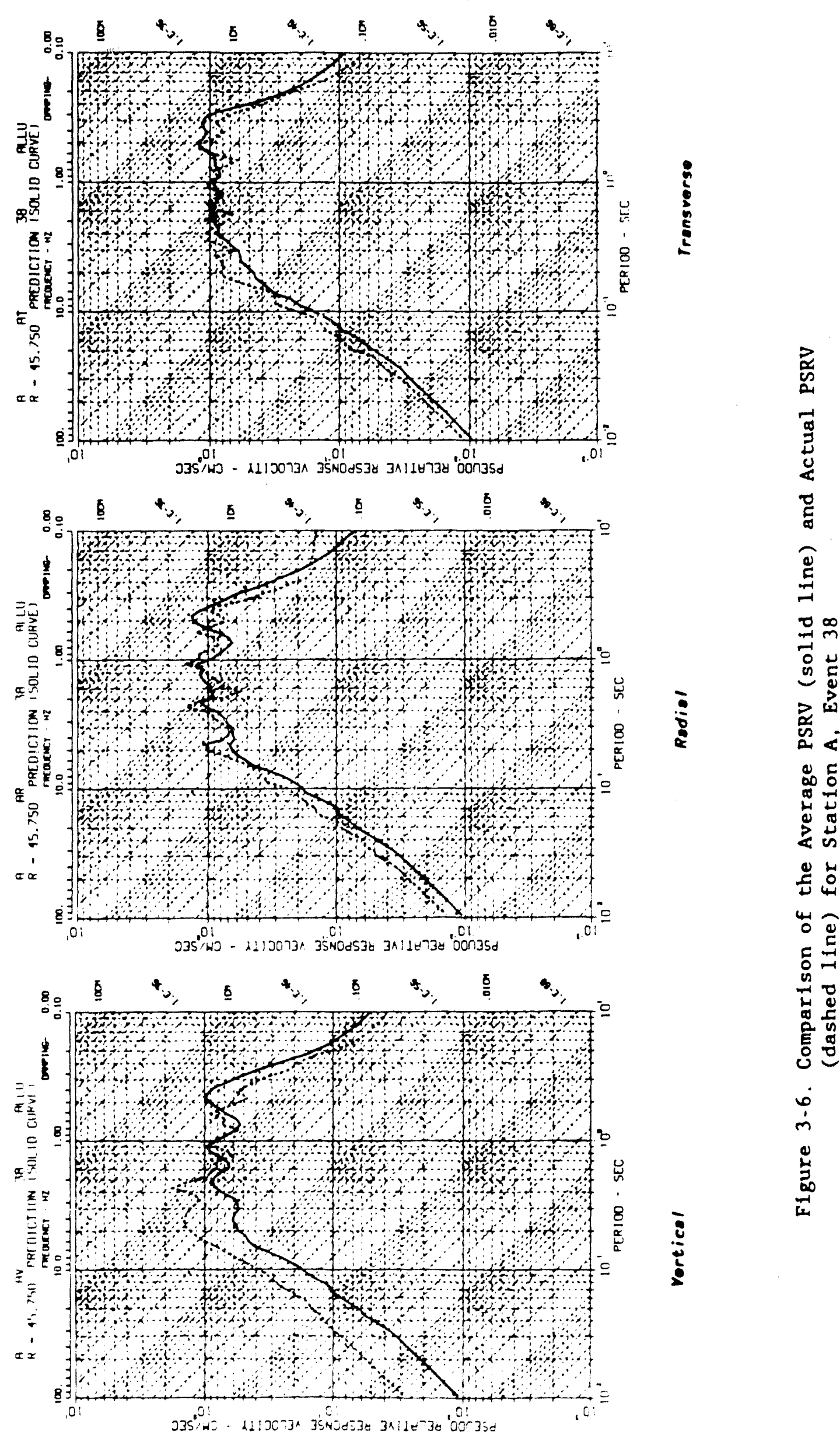

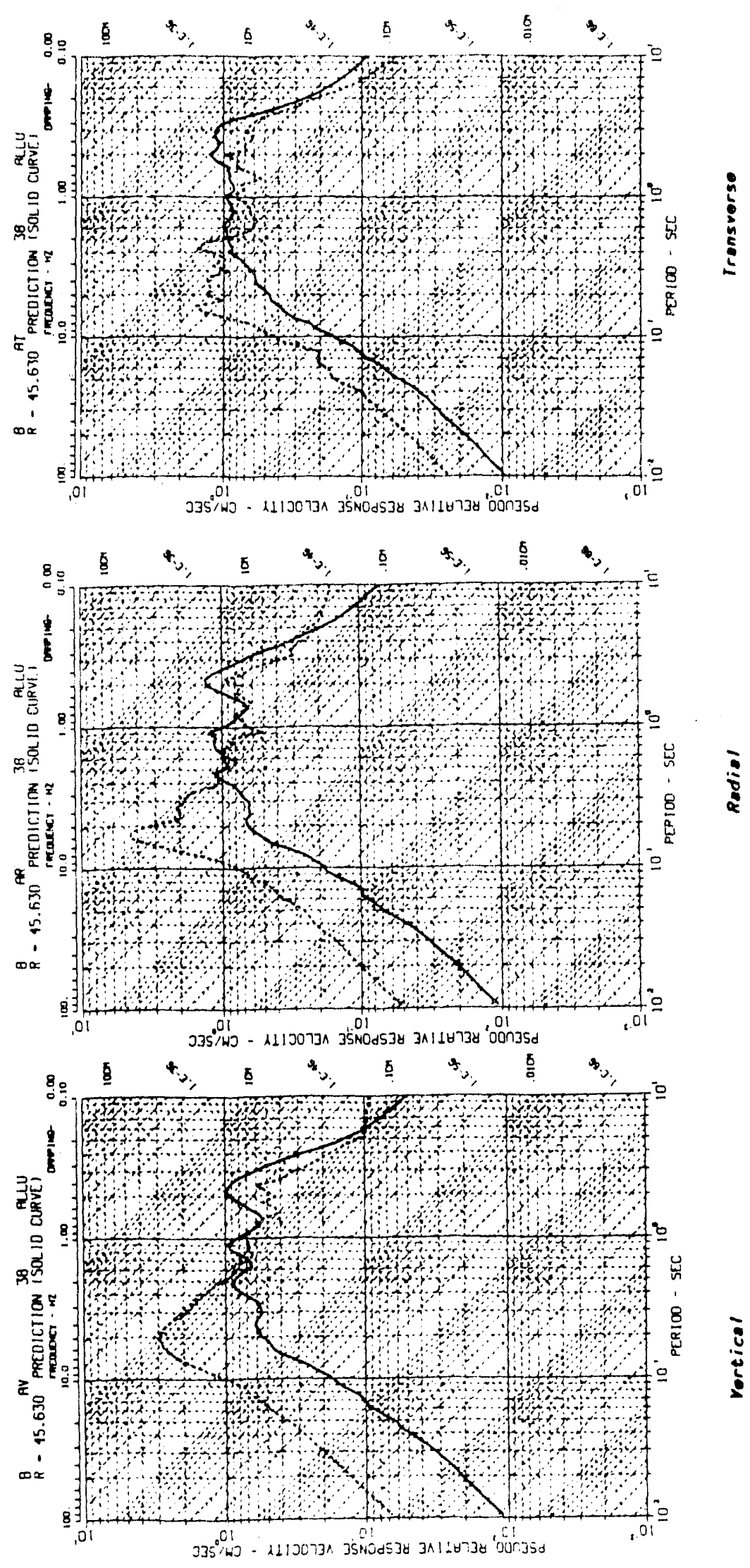

年 

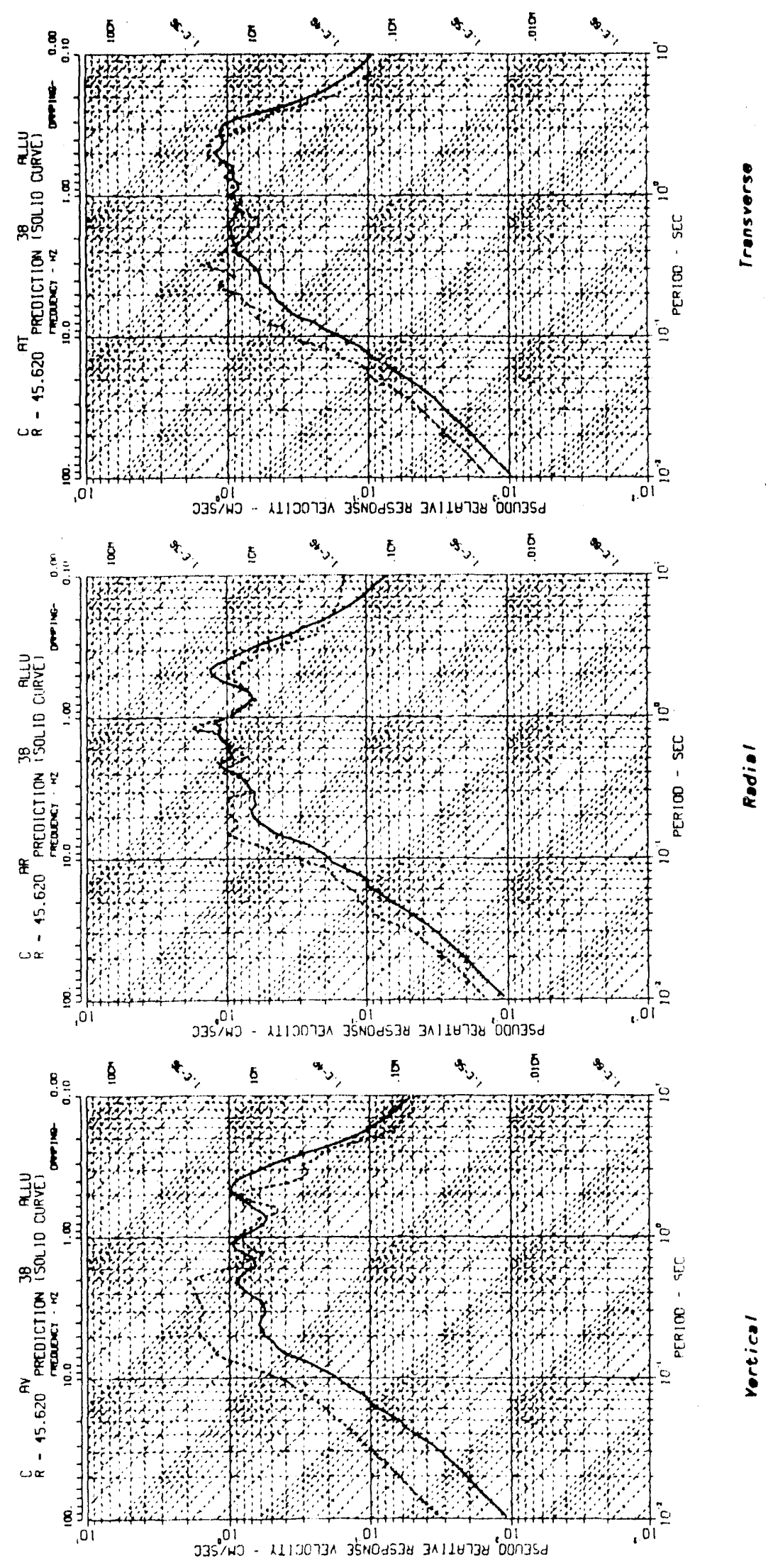

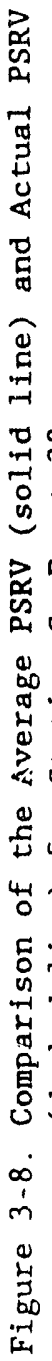



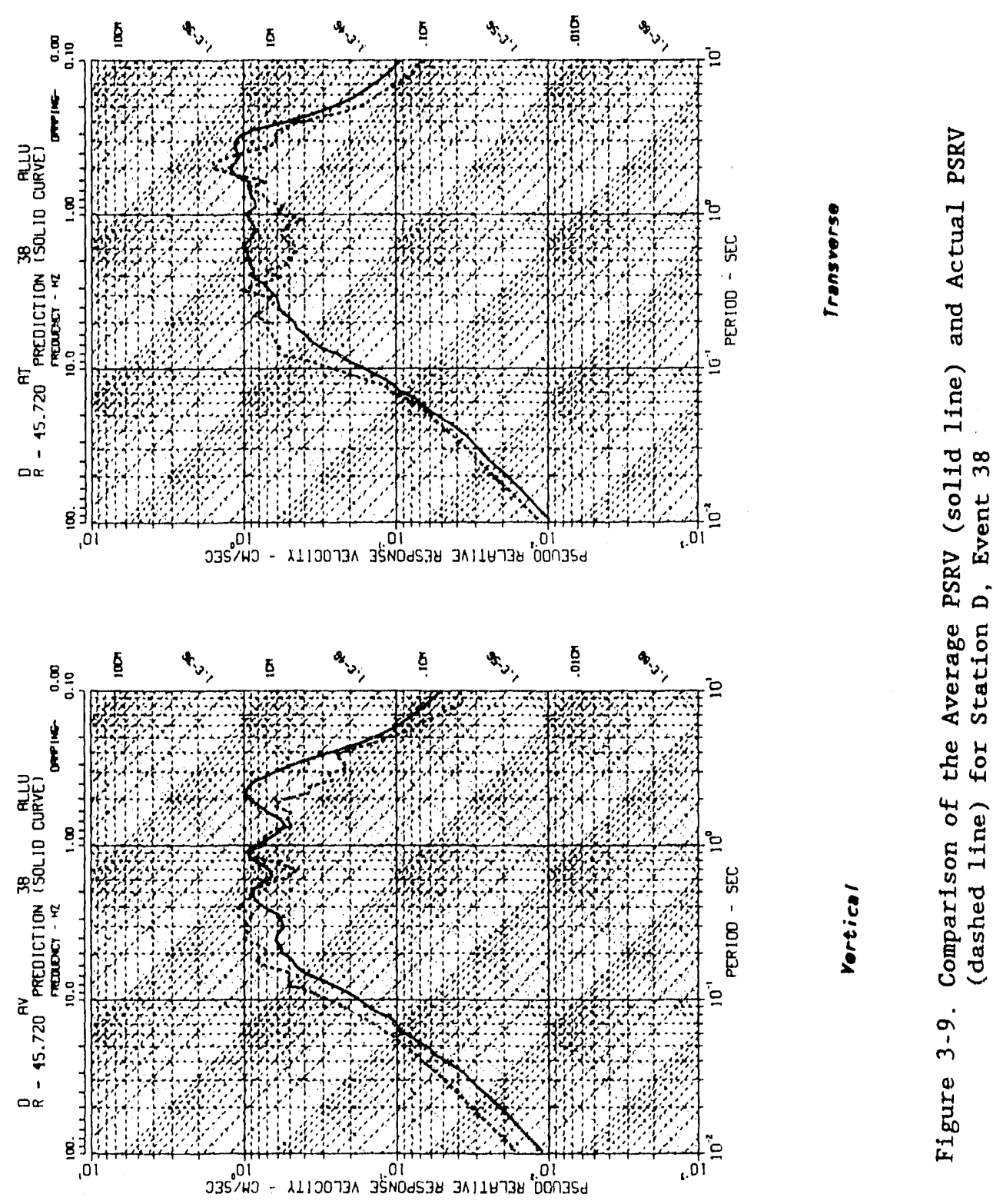

娄 
The anomalous ground motions observed at station $W-6$ are attributed to the travel path geology between Pahute Mesa and Jackass Flats on the NTS.

Whok (1988) presents evidence that this anomaly is a function of the

stucture under the Timber Mountain Caldera. This structure has the effect of focusing seismic energy at this station over a narrow band of azimuths. Fven though the travel path between Yucca Mountain and Pahute Mesa runs through the Jimbor Mountain Caldera, the study in (in preparation, b) found very little, if ary, effect of this geologic structure on observed motions at Yucci Momian. The studies support the elimination of data recorded at this $\therefore$ ation as anomalous and not a part of the expected ground motion environment it Yucca Mountain. 


\subsubsection{Yucca Mountain Stations}

of the 15 events andyzed on an individualized hasts, bs wore recorded at rucca Mountain. The Yucea Mountain stat ions that were most active iu this time frame, (i. e., recorded a majortty of these UNfis) were $W-14 . W . ? 1$, W.2.2 and $W-23$. Ratios of observed pseudo velocitjes lo avorage (delfromined from 1 inear regression) pseudo velocitios wero calcinated for each of those four rucca Mountain stations. These ratios vere pletted versus frequency and all. events recorded at a station were overlaid. Thuse plots are shown in Figures 3-10 through 3-13. A value of 1 on these figures indicates that observed and average values are equal. Values greater than 1 indicate that the observol values are grater than the average.

Most of the pseudo velocities observed at the Yucca Mountain stations wore greatex tun the event average and the amplitude of the ratio varies as a function of Erequency. In addition, the amplitude of the ratio varies substantially from one event to another at the same station. In most instances, howevor, there appears to be a characteristic shape of the ratio versus frequency curve for a component at a station. The ratio versus frequency curve for stations $W-14$ (Figure 3-10) and $W-2.3$ (Figure 3-11) are generally similar in shape. The largest differences between the observed and arerage pseudo velocities for these stations are generally in the low frequencifs ( $<4 \mathrm{ll}$ ). The amplitudes of the difference ratios generally vary between 2 and $/ 4$ for station $W-1 / 4$ and 2 and 8 for station W-2.3. The largert differences in the amplitude ratios occurred at frequencies greater than $3 \mathrm{~Hz}$ fol station $W-22$ (Figure 3-1.2). The amplitude of the difference ratio observed at this station varies between? and 7 . The differences hetwen the ohserved and average pseudo velocities at station W-21 (Figure 3-13) occur. over most frequencies. The amplitude of the difference ratio varies hetwren 1. and $l_{4}$.

Figure 3-14 shows the topography in the vicinity of these stations. A11. four of these stations were installed on ridges. In general, the other stations used in the linear regression were located in relatively flat terrain. It is likely that the increase in PSRV amplitude at these stations is due to topographic effects. Topographic effects have boen olserved on earchquakes ard UNEs. A review of theoretical and experimental studics (celi ot al. 1988) indicated that on the mountain tops, there is generally a broadband amplification for wavelengths comparable to the mountain width. This is coupled with an alternation of amplification and deamplification as the bose of the mountain, beginning with a deamplification at low frequencios (wavelengths greater than mountain width). For the stations of interest her the "mountain widths" vary from approsimate?y 750 m near station w-?2 to ?/lo in near station $w \cdot 21$. The determination of these widths is some what ambigunte given the topography and the travel path direction (e.g., at station W-22, the 

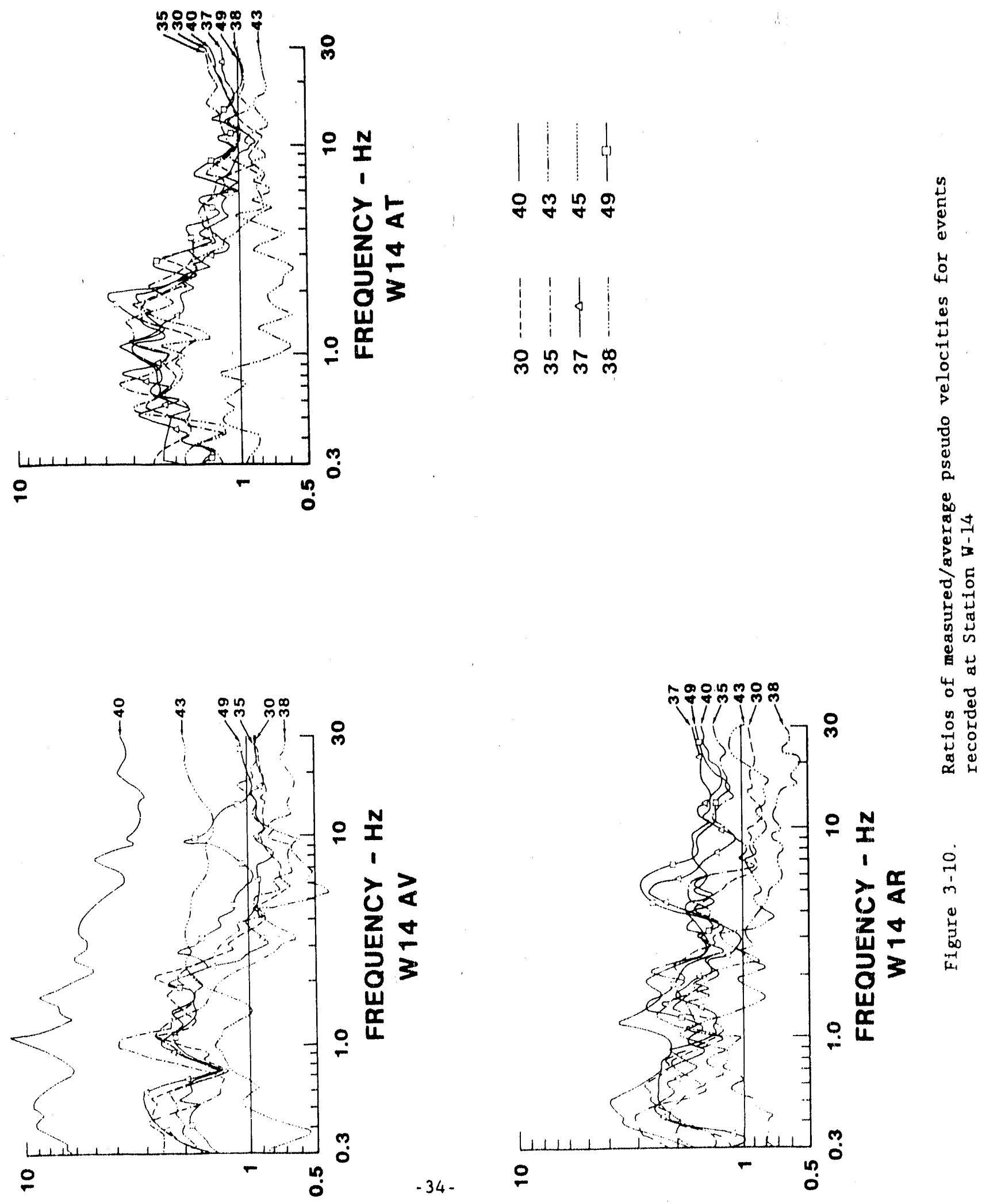


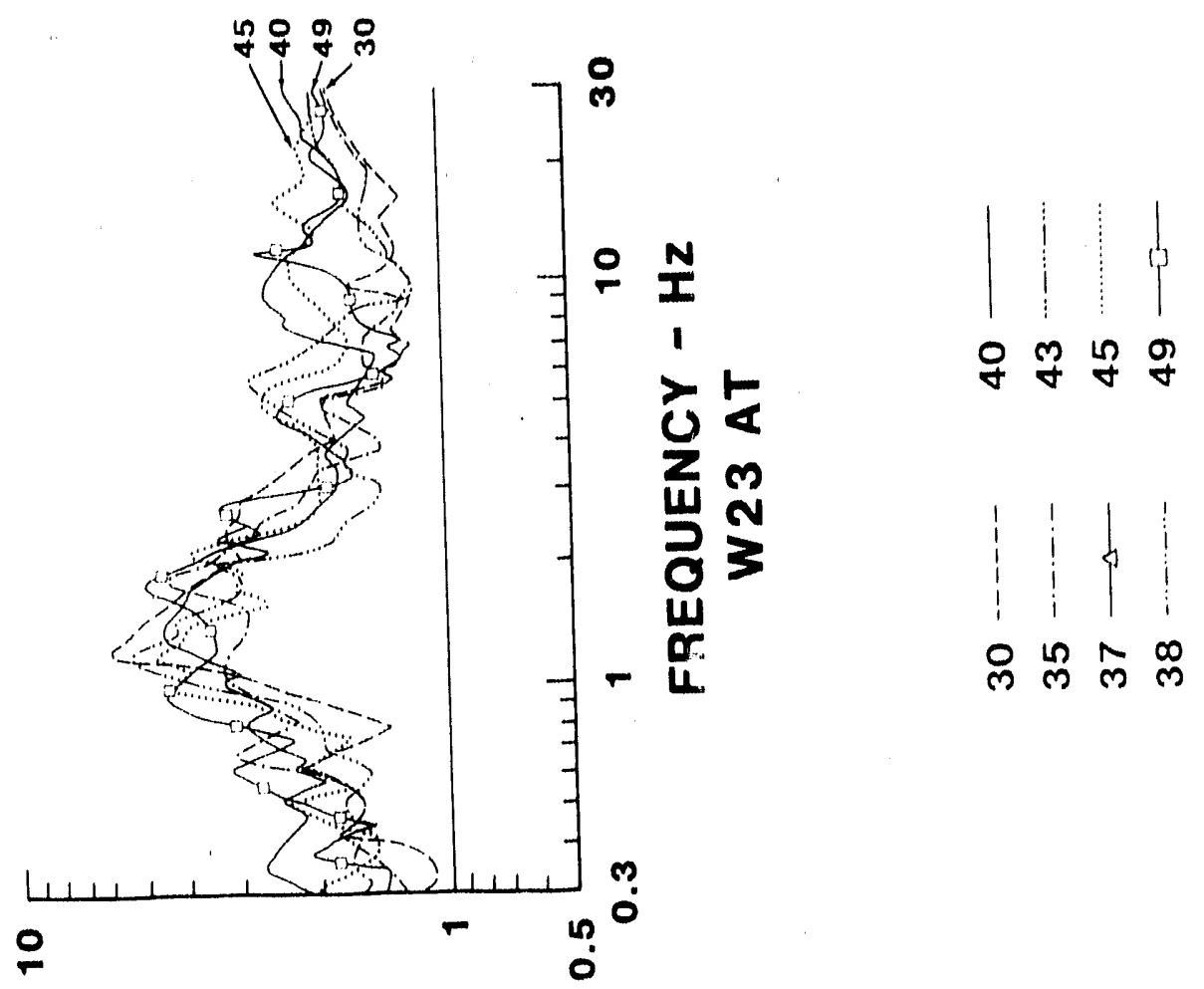

0
4
0
0
0
0
0
4
0
$4-1$
0
0
$0-1$
13
$0-1$
0
0
-1
0
5
0
0
7
0
0
0
0
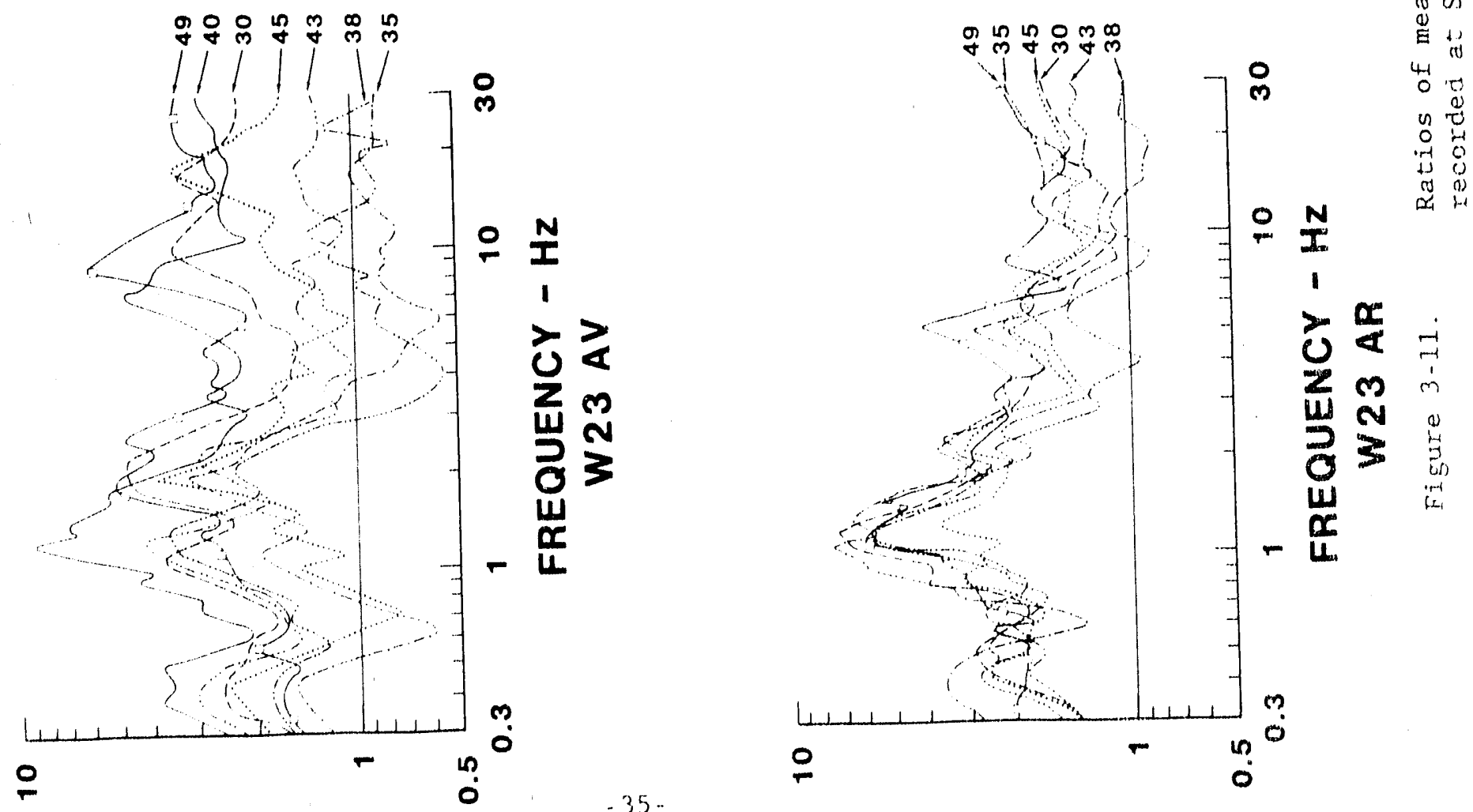

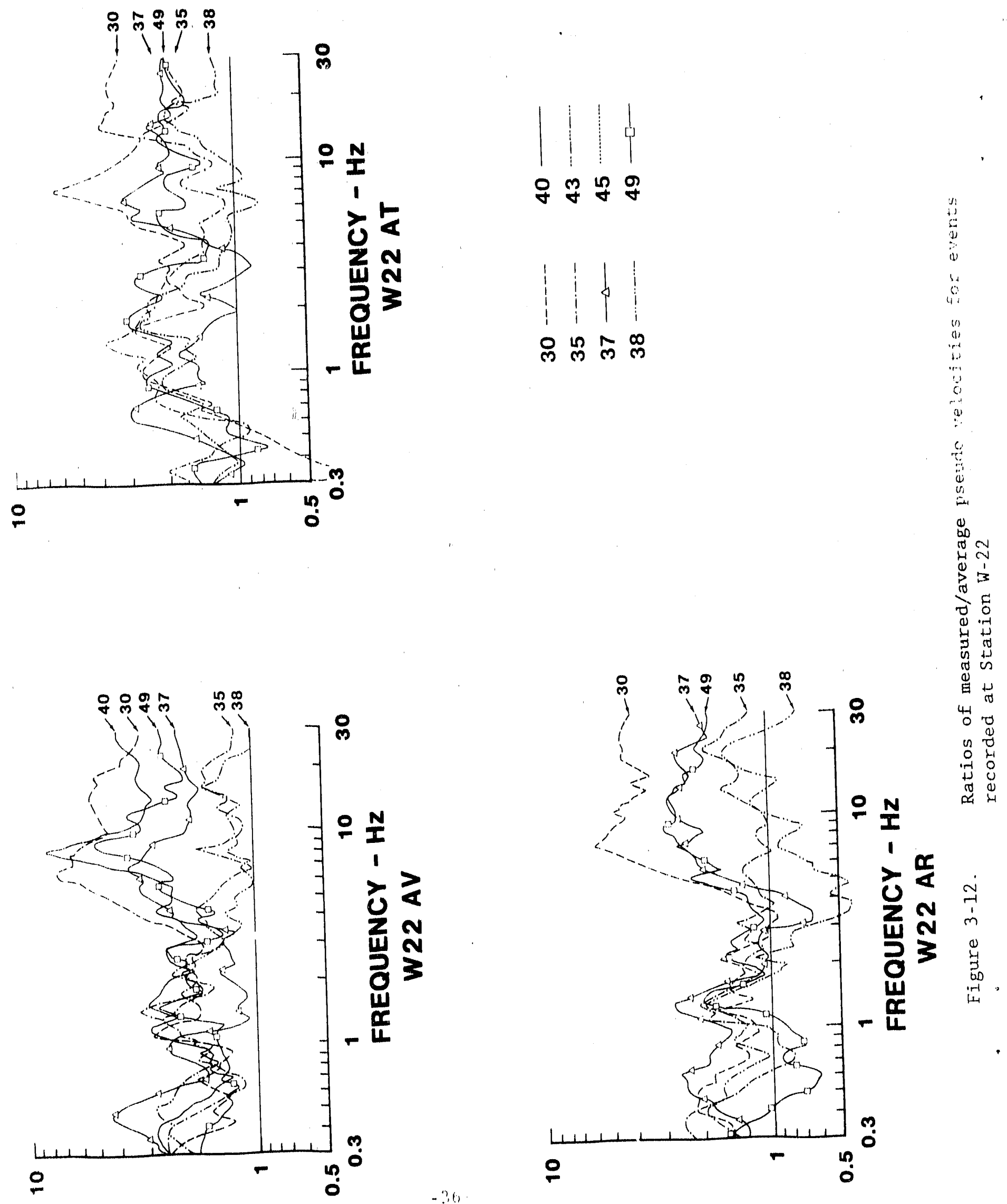

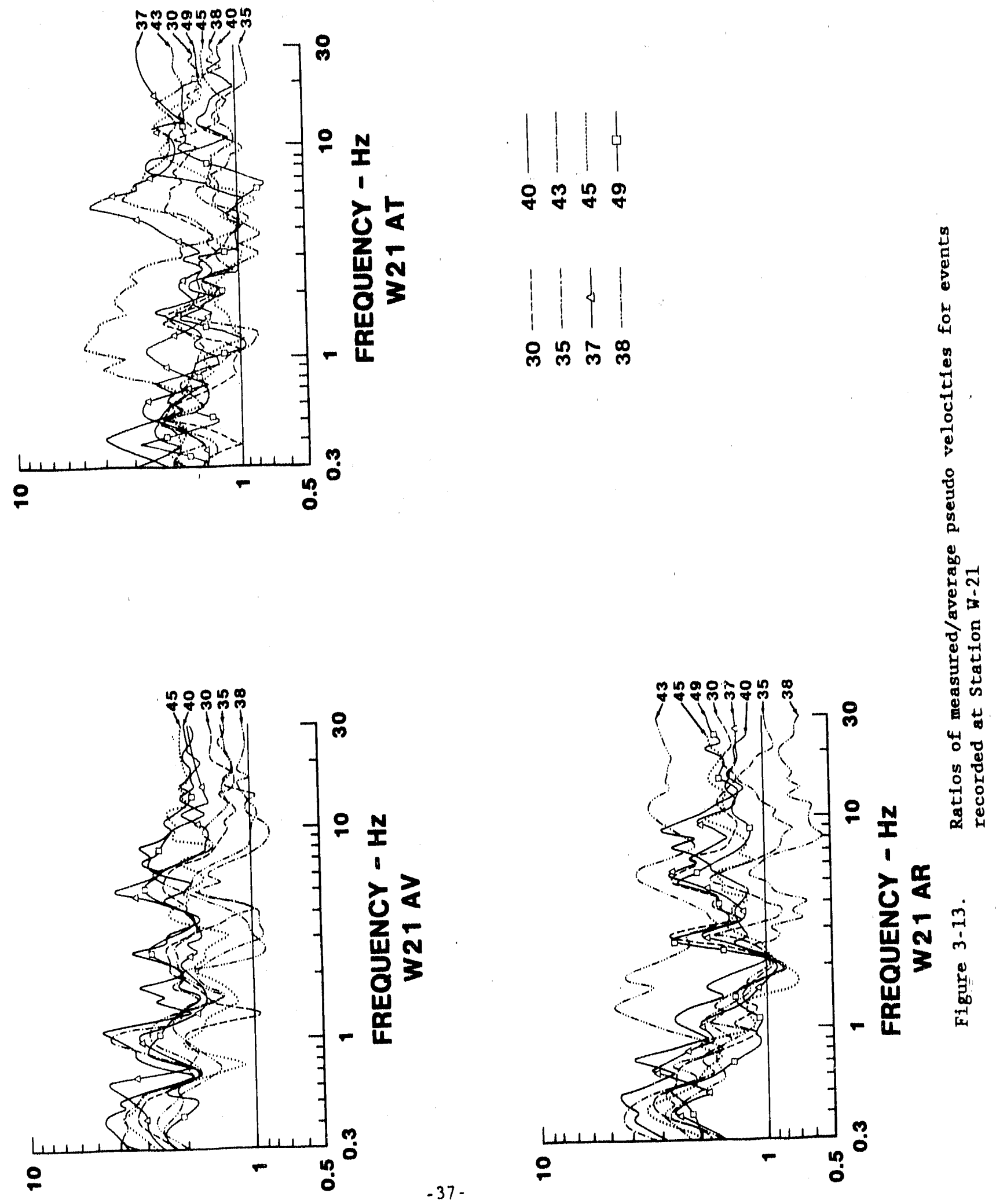


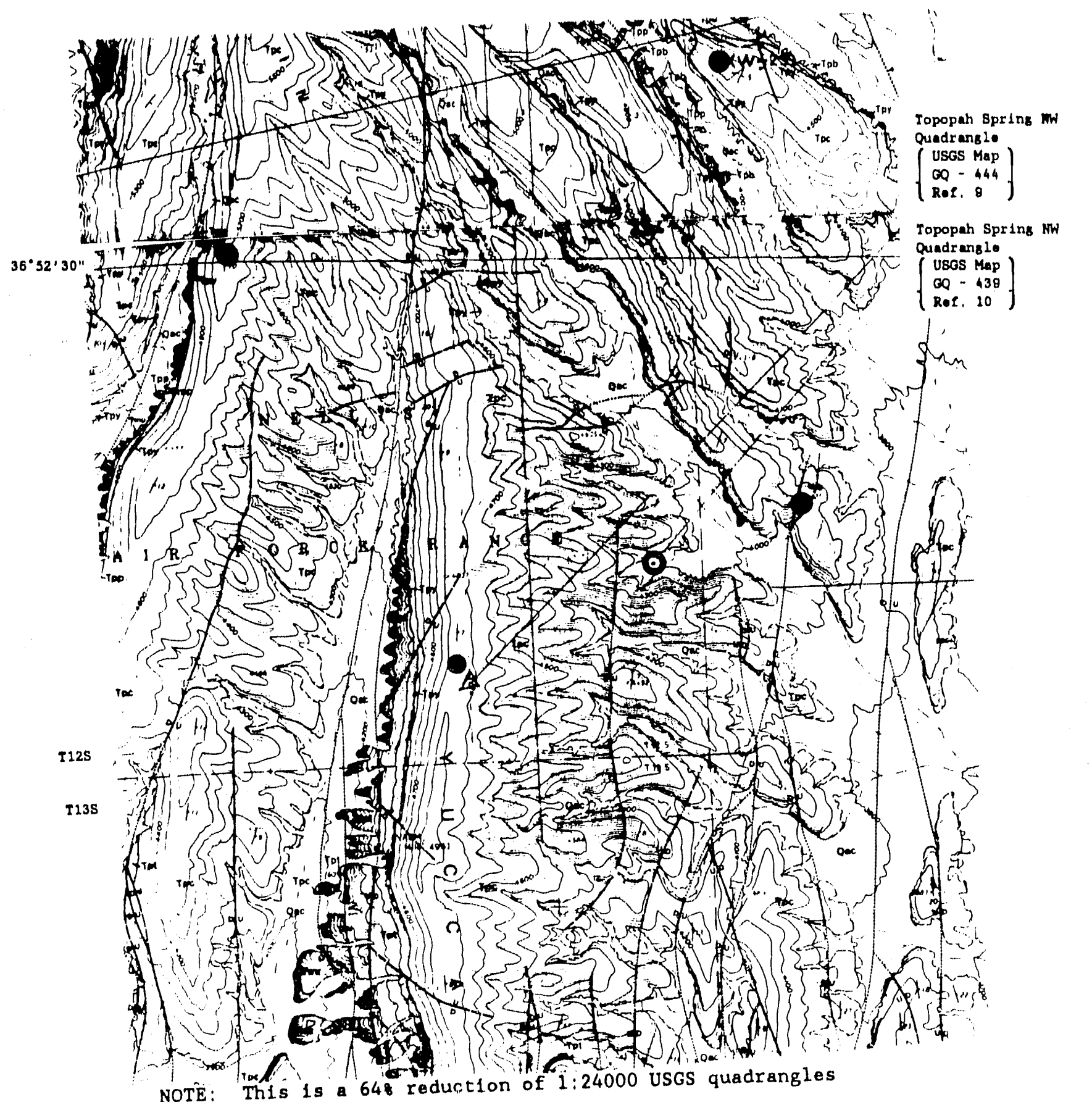

Figure 3-14. Topographic map showing the location of Stations W-14, W-21, พ-22, and $\mathrm{w}-23$. 
width could be taken as $750 \mathrm{~m}$ or $3000 \mathrm{~m}$ ). If a wave speed of $5100 \mathrm{~m} / \mathrm{s}$ is assul ed (this is the apparent wave speed determined from arrival time and sourc-to-station distance), the approximare frequency of amplification shoul.t range between 6.8 and $2.4 \mathrm{~Hz}$. These values of frequenc " are not inconsistent with the observations noted eatlier on Flgures 3.2.2-1 through 3.2.2-4. Theoretical and experimental studies do mot agree on the amount of amplification that will occur at a particular station. As reported by Geli et al., (1988), observations of ground motion amplification have ranged Erom factors of 30 (seismic motions generated by cavity collapse observed at Butler. Mountain, NV) to 1.25 (UNE generated motions observed at NASA Mountain, NV). The degree of amplification observed at the Yucca Mountain stations discussed here falls within these bounds. 


\subsection{Multiple Event Analys is}

The data from all events were grouped in several ways. Group I included all data. Group II consisted of Group I data minus data from the anomalous stations ( $w-3$ and $W-6$ as identified earlier). Group III consisted of Group II data minus all Yucca Mountain stations. In addition, each major group described above was further subdjvided into groups based on receiver geology. These subgroups were only stations on rock only stations on alluvium and all stations regardless of geology. A total of 27 regressions is dictated by this grouping scheme. In the course of the analysis it was determined that the alluvium-only data set did not have enough variation in source-to-station distance to do satisfactory regressions. Therefore, the total number of regressions performed was reduced to 18 .

To evaluate the adequacy of the regressions of the various groups two hasic comparisons were made. These consisted of comparing "predictions," using the derived equations, of two primary events. The first was a $700-\mathrm{kt}$ UNE at $22.8 \mathrm{~km}$ away (the design basis UNE). This would help determine the differences in the various groups at the predictive end of the spectrum. The second was a $150 \mathrm{kt}$ UNE at $45 \mathrm{~km}$ away. This second event is "typical" of the majority of the data in the data base and would help gage the bias factor associated with each group.

Comparison plots of the predicted PSRVs for the design basis UNE are shown in Figures $3-15$ and 3-16. It is clear from these figures that the differences between the various data groups are small. It was noted earlier that the Yucca Mountain stations are to the high side of the average. The sffect of the elimination of these stations (Group III) can be seen in these figures. As might be expected, the Group III (dotted) curve is slightly less than the other two groups. The Group II curve is indistinguishable on these plots because relatively few data points were removed (Group I vs. Group II) For the case where the rock and alluvium data were grouped together, the inomalous stations tend to cancel each other out (i.e., one high and one low).

Similar conclusions may be drawn from the comparisons made for the typical UNE (Figures $3-17$ and 3-18). For the data recorded at stations on a rock geology (Figure 3-17), the three groups show more separation than the comparisons made for the design basis UNE. This stems from the fact that inere are more data at these typical ranges and yields and, therefore, more -atter. In addition, the Yucca Mountain stations are more significant at ihis range. The Group II fit is higher because the anomalous station in this group was low relative to the average. The Group III fit is lower because the ucca Mountain stations tend to be higher than the average station. 

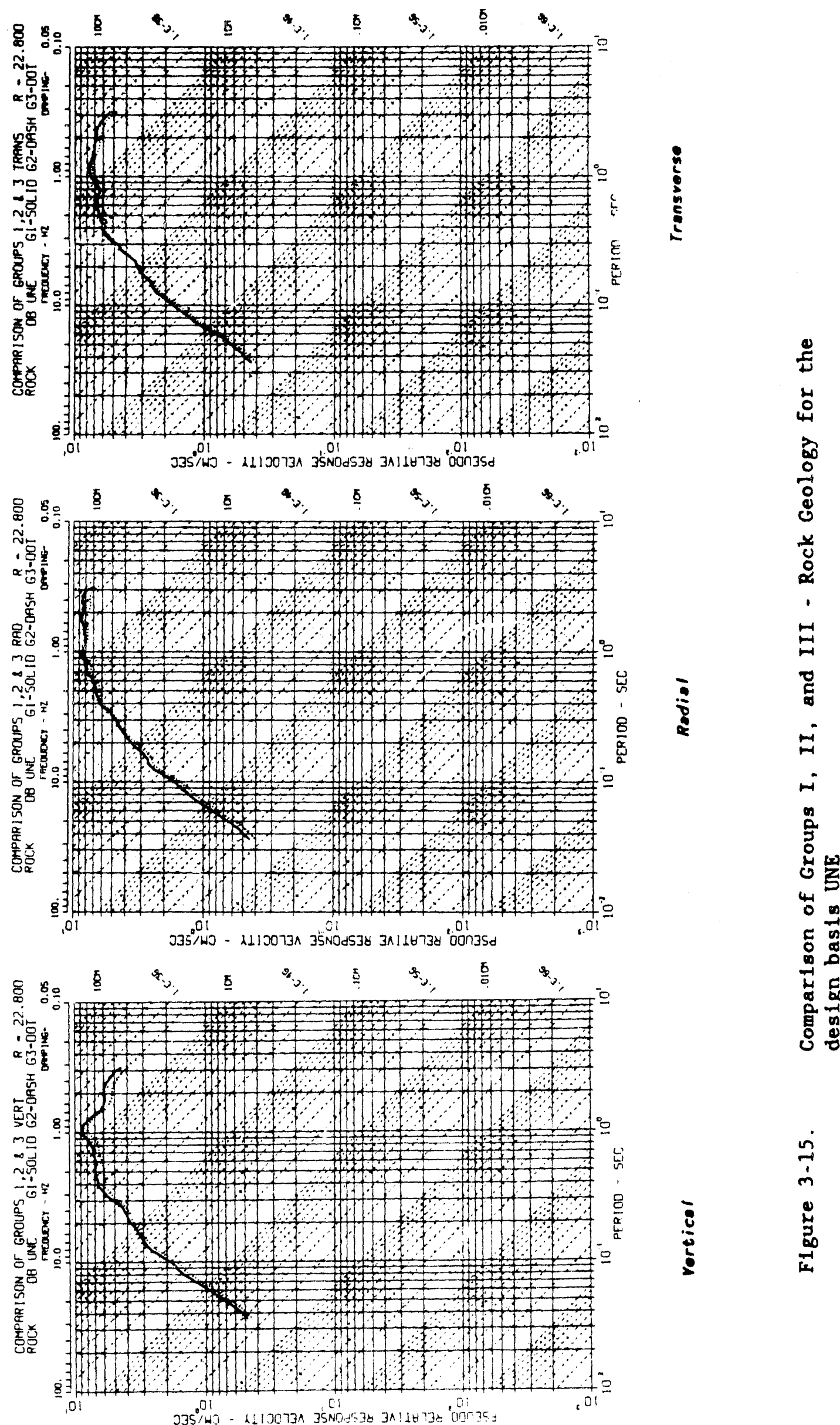

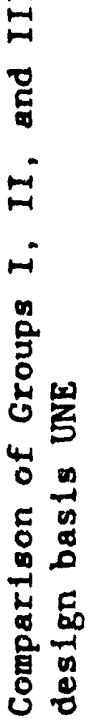



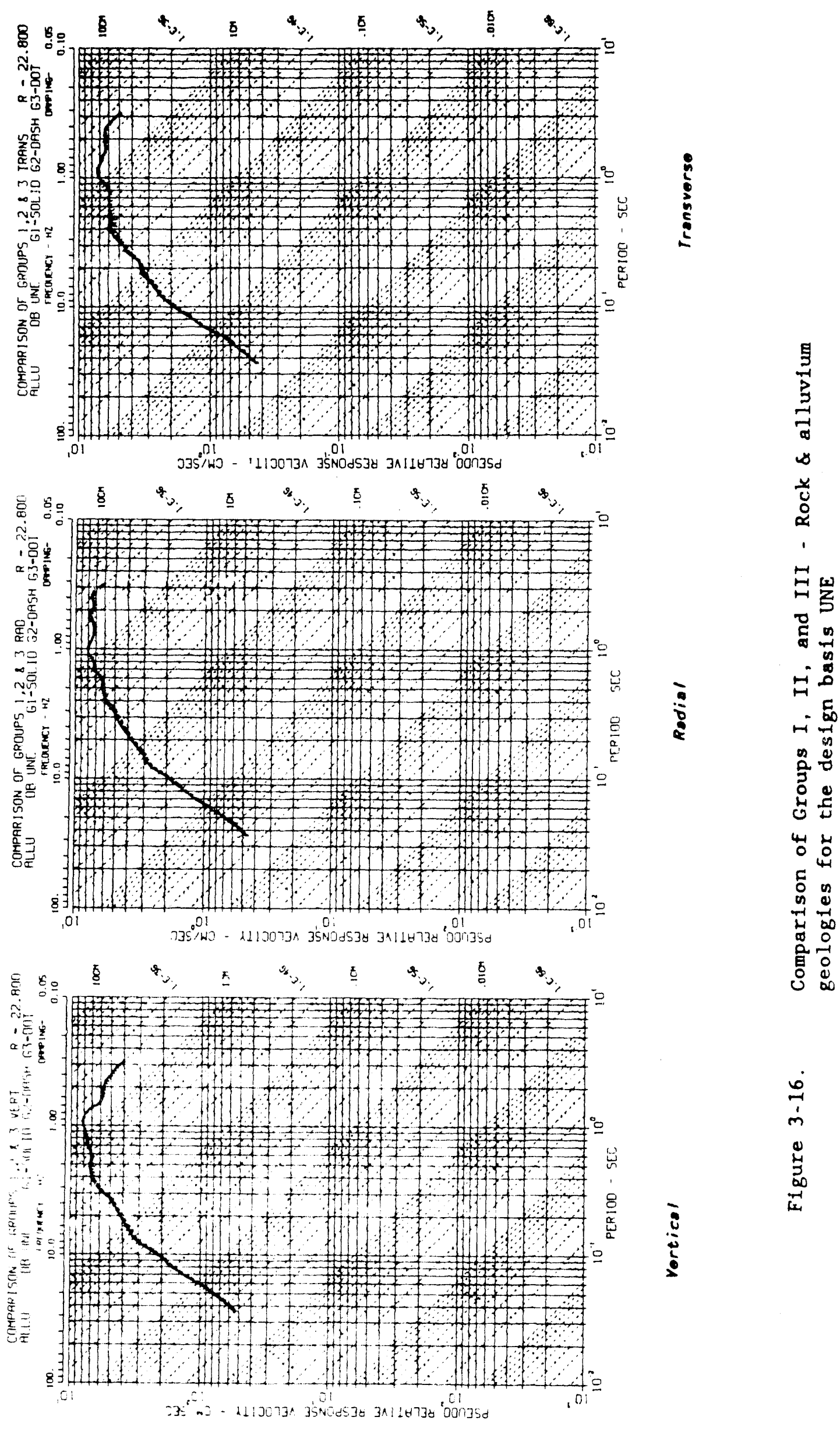

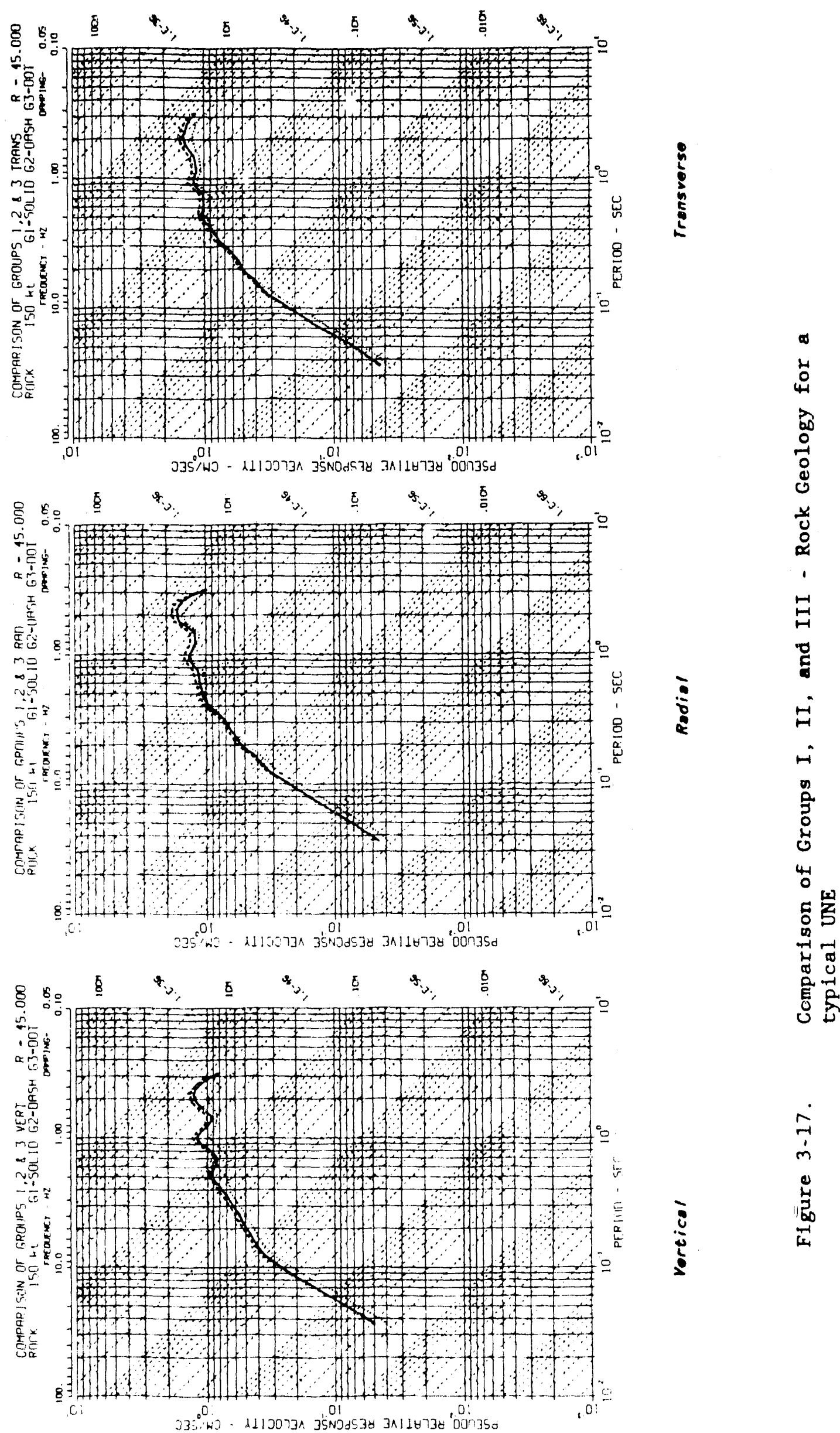

官 

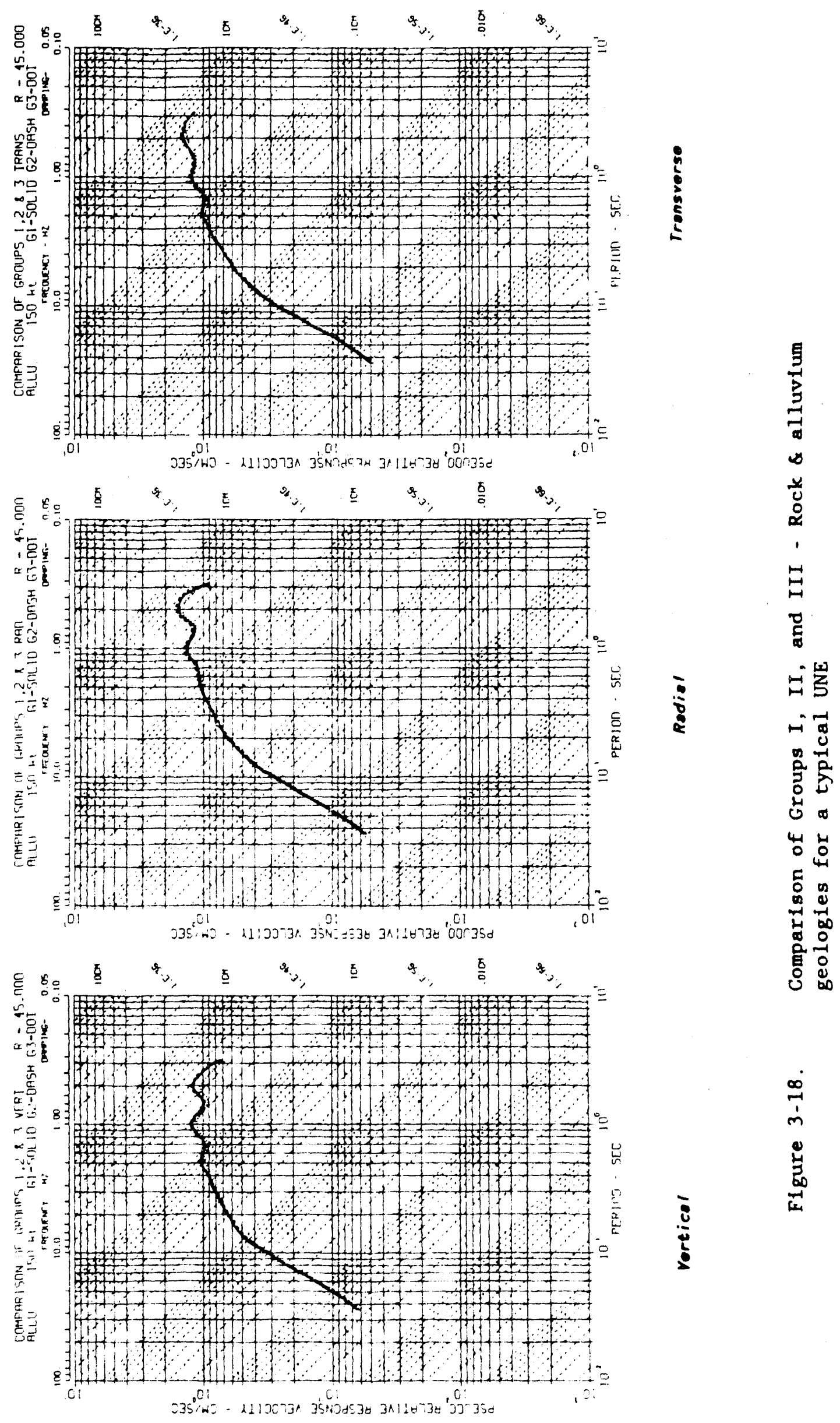

$-44$. 
Based on these comparisons, it is difficult to strongly argue that ariy one of these groups is better than another for predictive purposes. The differences observed are not statistically significant. Based solely on judgement, exclusion of data from the Yucca Mountain stations (Group III data set) does not seem appropriate. After all, the objective of the prediction procedure is to predict ground motions at Yucca Mountain. It also appears that inclusion of the anomalous stations (Group I data set) is inappropriate. The factors that contribute to the anomalous observations at station $W-3$ do not affect Yucca Mountain at all. The factors that contribute to the anomalous observations at station W-6 do not appear to significantly influence the ground motions observed in the Yucca Mountain area. Therefore, Group II regressions are selected as the recommended equations. For stations founded on rock, the "rock only" subgroup equations should be used. Predictions of stations installed in an alluvium geology should be performed with the "rock and alluvium" subgroup equations.

As a consistency check, the recommended regression equations were compared to an earlier prediction model. This earlier model was developed for horizontal ground motions from UNEs conducted in Pahute Mesa (Lynch, 1969). Lynch incorporated data from 11 UNEs that were recorded at a total of 64 stations. The yield maximum of the data set was $1200 \mathrm{kt}$ and the variation in source-to-station distances was from 4.4 to $551 \mathrm{~km}$. The comparison of the two procedures for the design basis UNE (for a station on a rock geology) is shown in Figure 3-19. The best estimate and the $95 \%$ confidence intervals for the prediction equations developed in this effort are represented by the solid and dashed lines, respectively. The Lynch prediction procedure is represented by the chain dashed line. The two procedures compare favorably both in shape and amplitude.

The regression coefficients and an evaluation of the predictions are given in Chapter 4 . 


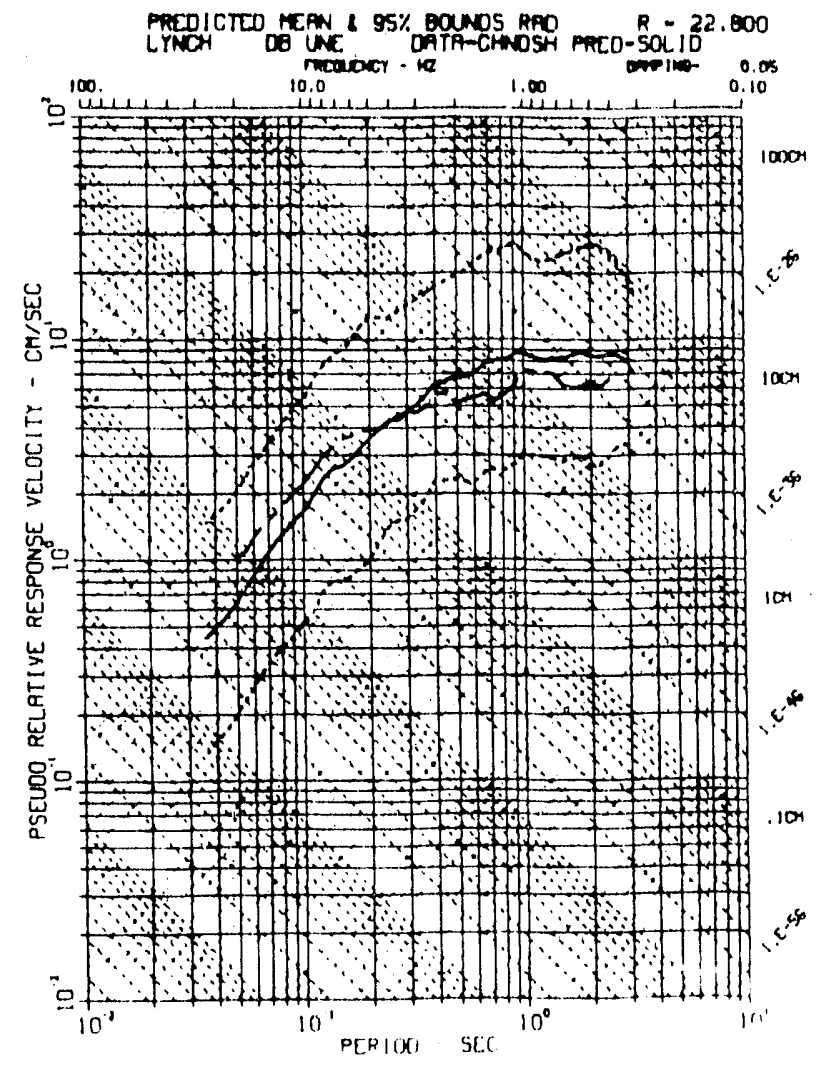

Rodial

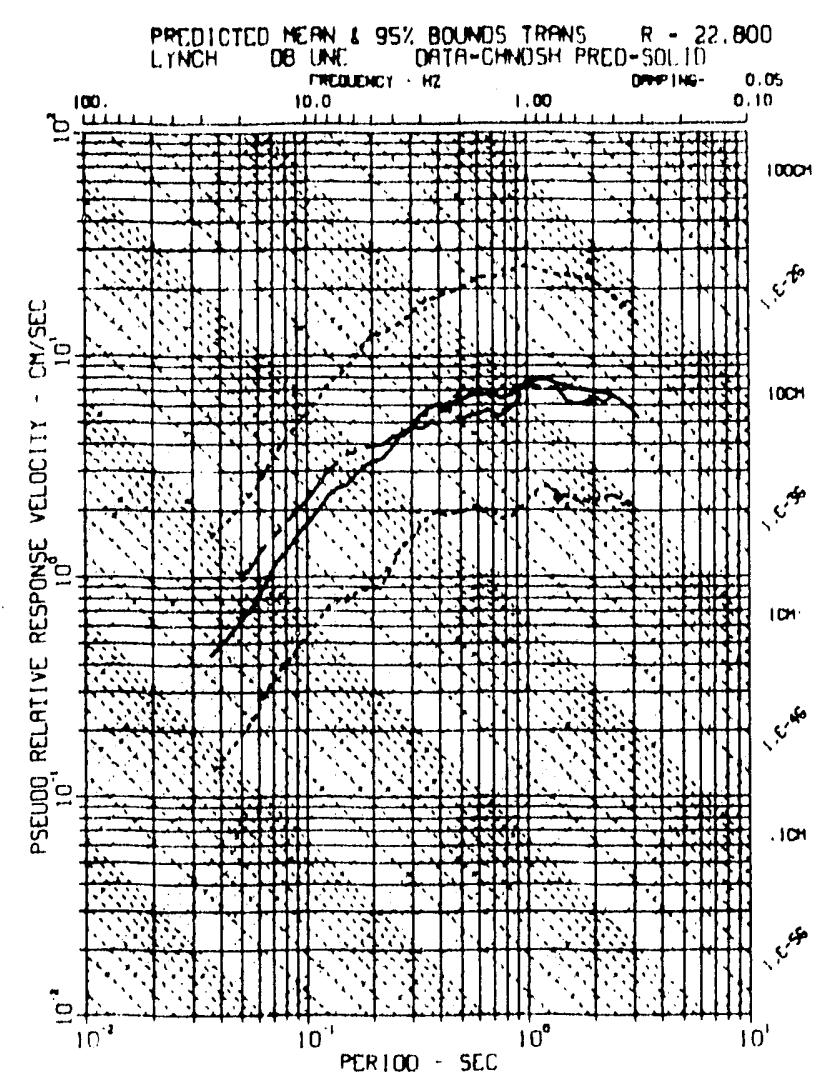

Trensverse

Figure 3-19. Comparison of recommended prediction procedure and an earlier procedure for the design basis UNE 


\subsection{Downhole Motions}

Analysis of component surface and downhole PSRVs was reported by phi11.ips (1987). Ratios of surface to downhole pseudo velocity were calculated as a function of frequency. Each station, with companion surface and downhole instrumentation, was studied on an individual basts. The stations analyzed were $W-12 / 30, W-25, W-28$ and $W-29$ (see Figure 2-2 for station locations). Ground motion from all. UNEs available at the time of the analysis were included in the analysis. The conclusions from that study that are of interest here are as follows:

- For each station and each component there was a characteristic shape to the ratio versus frequency curve. Therefore, an average ratio was calculated for every component at every station.

- There is insufficient data to develop an empirically based general dopth. attenuation model. for the Yucca Mountain area. The best that can be done is to predict downhole motions at existing station locations using the ratios determined in the study.

The average ratios reported by Phillips (1987) were incorporated into the prediction procedure. These average ratios were applied to the best estimate and the 958 confidence intervals, developed for surface ground motions, to produce the downhole PSRV prediction. The use of the average ratio and the surface 95 o confidence intervals is not a "true" estimate of the $95 \%$ confidence intervals of the downhole motions. In reality, the uncertainty in the prediction of downhole PSRVs is both a function of the uncertainty. in the surface PSRVs and the standard deviation of the average ratio. Inclusion of: the standard deviation of the average ratio will increase the spread of the uncertainty bounds on the prediction of downhole PSRVs. This additional accuracy was not considered necessary at this point in time. The predicted PSRVs generated by this approach will be evaluated in Chapter 4. 


\subsection{Summary}

The results of the data analyses presented in this chapter are summarized below.

1. Two anomalous stations were identified. Station $\mathrm{W}-3$ produced PSRVs that were always below average for all frequencies and station W- 6 produced ground motions at frequencies greater than 2. $\mathrm{Hz}$ that were always greater than average. The causes of these anomalies were judged not to be a factor in the observed ground motions at Yucca Mountain. Therefore, ground motions that were observed at these stations were excluded in the development of the recommended prediction equations.

2. Yucca Mountain stations W-14, W-21, W-22, and W-23 produced PSRV that were generally greater than the average. This amplification appears to be related to the surface topography at the stations.

3. There was very little difference in the results of regressions performed on the various data groups. Based primarily on judgement, the regression equations developed for Group II were selected as the recommended prediction equations. Predictions for stations founded on "rock" should be made with the regressions from the "rock only" subgroup of Group I.I. For stations placed on alluvium, the appropriate prediction equations are from the "rock and alluvium" subgroup of Group II.

4. Downhole PSRV s may be predicted at stations $W-12 / 30, W-25, W-28$, and $W$ 29 using the results of an earlier analysis. A general method for the prediction of downhole motions in the Yucca Mountain area does not exist at this time. 


\subsection{PREDICTIONS}

\subsection{Equation Coefficients}

The prediction procedure developed from the analyses discussed in chapter: 3 is summarized and evaluated here. The prediction of a PSRV constists of the best estimate and a measure of the uncertainty on that best estimate. In this effort the 958 confidence intervals ( 2 standard deviations) were selected for: the uncertainty bounds. Note, this corresponds to the $9 \% .5 \%$ nonexceedance probability level. Because of the relatively large number of equations (144) necessary to generate a prediction and the usefulness of the computergenerated tripartite plot, this procedure was automated. The source listing of this code and general. instructions for its use are given in Appendix $B$.

The coefficients for the best estimate and 958 confidence bounds for stations on rock and alluvium are presented in Tables 4-1 through 4-6. Recal1, the regression equation of the form:

$P=K W^{a} R^{b}$

where

$W$ is the yield of the UNE - $k t$

$R$ is the source-to-station slant distance - $\mathrm{km}$

$\mathrm{P}$ is pseudo velocity - $\mathrm{cm} / \mathrm{s}$

$\mathrm{K}, \mathrm{a}, \mathrm{b}$ are the parameters listed in the tables. 
TABLE 4-1 SUMMARY OF EREOICT'TON COEFFICLENTS FOR VERTTICAL PSRVB FOR ST'A'TIONS ON ALLUVIUM.

\begin{tabular}{|c|c|c|c|c|c|c|c|c|c|}
\hline \multirow{2}{*}{$\begin{array}{l}\text { Frefuatioy } \\
(1 \mathrm{z})\end{array}$} & \multicolumn{3}{|c|}{ Bost Eslalonte Eiguations } & \multicolumn{3}{|c|}{ Lower Bonnd Ergations } & \multicolumn{3}{|c|}{ Uyour Bround Erount lones } \\
\hline & $\underline{a}$ & $\underline{1}$ & $\mathrm{k}$ & g & $\underline{b}$ & $\underline{k}$ & $\underline{a}$ & $\underline{b}$ & $\underline{s}$ \\
\hline 0.314 & 0.609 & -1.116 & 2.410 & 0,663 & -1.214 & 1.007 & 0.556 & -1.018 & 5.763 \\
\hline 0.345 & 0.564 & -1.105 & 3.532 & 0.616 & -1.206 & 1.439 & 0.513 & $-1.00 \mathrm{~s}$ & $8.6 \%$ \\
\hline 0.380 & 0.526 & -1.112 & 4.968 & 0.575 & $-1.21 \%$ & $1.9 !, \beta$ & 0.476 & $-1,008$ & 12.608 \\
\hline 0.418 & 0.507 & -1.116 & 6.083 & 0.5 .55 & -1.221 & 2.384 & 0.459 & $\cdot 1,011$ & 15.521 \\
\hline 0.4 .59 & 0.499 & -1.121 & 6.955 & 0.544 & -1.223 & 2.794 & 0.453 & -1.119 & 17.314 \\
\hline 0.505 & 0.490 & $-1.12 \%$ & 7.710 & 0.534 & -1.228 & 3.116 & 0.445 & -1.025 & 10.078 \\
\hline 0.556 & 0.505 & $\because 1.161$ & 7.62 .5 & 0.549 & -1.262 & 3.156 & $0,4 f i 1$ & -1.050 & 19.1101 \\
\hline 0.612 & 0.562 & -1.214 & 6.475 & 0.608 & $-1.31 i$ & 2.676 & 0.516 & $-1,115$ & 15.668 \\
\hline 0.673 & 0.634 & $\cdots 1.253$ & 4.835 & 0.682 & -1.349 & $2.0 \% 7$ & 0.586 & -1.158 & 11.258 \\
\hline 0.740 & 0.709 & -1.244 & 3.330 & 0.761 & -1.336 & 1.476 & 0.657 & -1.153 & 7.511 \\
\hline 0.814 & 0.726 & -1.242 & 3.246 & 0.781 & -1.336 & 1.397 & 0.670 & -1.147 & 7.538 \\
\hline 0.895 & 0.688 & -1.266 & 4.775 & 0.739 & -1.364 & 2.003 & 0.633 & $\cdot 1,169$ & 11.381 \\
\hline 0.985 & 0.628 & -1.309 & 7.915 & 0.675 & -1.409 & 3.257 & 0.590 & -1.209 & $19.23 \%$ \\
\hline 1.083 & 0.615 & -1.350 & 9.5 .58 & 0.661 & -1.452 & .8 .855 & 0.568 & -1.248 & 23.695 \\
\hline 1.192 & 0.631 & -1.379 & 9.096 & $0.6 \% 6$ & -1.479 & 3.730 & $0.58 \mathrm{~s}$ & -1.279 & 22.179 \\
\hline 1.311 & 0.677 & -1.405 & 7.122 & 0.72 .5 & -1.503 & 2.972 & 0.630 & -1.307 & $1 \% .071$ \\
\hline 1.442 & 0.696 & -1.419 & 6.542 & 0.745 & -1.519 & 2.700 & 0.647 & -1.320 & 15.850 \\
\hline 1. 586 & 0.652 & -1.427 & 8.481 & 0.699 & -1.530 & 3.308 & 0.60 .5 & -1.324 & 21.173 \\
\hline 1.745 & 0.601 & -1.433 & 1.1 .887 & 0.645 & $\cdot 1.538$ & 4.676 & 0.557 & -1.329 & 30.22 .0 \\
\hline 1.919 & 0.610 & $\cdot 1.416$ & 10.863 & 0.656 & -1.521 & 4.259 & 0.565 & $-1,311$ & 27.708 \\
\hline 2.111 & 0.643 & -1.406 & 8.514 & 0.692 & -1.512 & 3.288 & 0.5994 & -1.299 & 22,018 \\
\hline 2.322 & 0.674 & -1.402 & 6.716 & 0.727 & -1.512 & 2.528 & 0.621 & -1.292 & 17.845 \\
\hline 2.555 & 0.697 & $\cdot 1.398$ & 5.62 .2 & 0.752 & $\cdot 1.510$ & 2.083 & 0.641 & -1.287 & $15.1 \%$ \\
\hline 2.810 & 0.677 & -1.404 & 6.022 & 0.732 & -1.518 & 2.170 & 0.622 & -1.283 & 16.714 \\
\hline 3.091 & $0.6 \% 2$ & -1.392 & 5.641 & 0.728 & -1.500 & 1.974 & 0.615 & -1.274 & 16.118 \\
\hline 3.400 & 0.628 & -1.395 & 6.730 & 0.683 & -1.517 & 2.273 & 0.573 & -1.2 .74 & 19.926 \\
\hline 3.740 & 0.584 & -1.393 & 1.883 & 0.637 & -1.518 & 2. 589 & 0.537 & -1.268 & 2.4 .005 \\
\hline 4.114 & 0.592 & -1.381 & 6.922 & 0.647 & -1.509 & 2.2 .11 & 0.537 & -1.2 .53 & 21.667 \\
\hline 4.526 & 0.588 & -1.376 & 6.620 & 0.5344 & -1.508 & 2.050 & 0.532 & -1.245 & $21.37 \%$ \\
\hline 4.978 & 0.589 & $.1,400$ & 6.176 & 0.645 & -1.534 & 2.04 .3 & $0,5,32$ & $-1.26 \%$ & 2.2 .476 \\
\hline 5,476 & 0.570 & $-.1,45$ & $7.41:$ & 0.626 & $-1.55 \%$ & 2. 181 & 0.515 & $. \cdot 1,2.18$ & 25.119 \\
\hline 6.024 & 0.581 & $\cdot 1,401$ & $6.25,9$ & 0.638 & $\cdot 1.538$ & 1.875 & (). 52.4 & -1.263 & 21.413 \\
\hline 6.626 & 0.601 & -1.369 & 4.681. & 0.662 & $-1,507$ & 1.361 & 0.540 & -1.2 .30 & 16.097 \\
\hline 7.289 & 0.635 & -1.353 & 3.409 & 0.701 & -1.493 & 0.980 & 0.563 & -1.214 & 11.8354 \\
\hline 8.018 & 0.643 & -1.352 & 2.946 & 0.709 & -1.491 & 0.855 & 0.577 & -1.214 & 10.153 \\
\hline 8.820 & 0.613 & $\cdot 1.380$ & 3.342 & 0.674 & 1.519 & $0.9 \%$ & 0.551 & 1.242 & 11.473 \\
\hline 9.702 & 0.604 & -1.397 & 3.213 & $0.66,3$ & -1.634 & 0,947 & 0.545 & -1.260 & 10.899 \\
\hline 10.672 & 0.615 & -1.4012 & 2. $\mathrm{BH} 1$ & $0,6 \%$ & -1.531 & 0.801 & 0.556 & $-1.26 \mathrm{Eg}$ & 8.976 \\
\hline 11.739 & 0.655 & 1.411 & $1.95,1$ & 0.718 & -1.544 & 0.591 & 0.593 & $-1.27 \%$ & 6.447 \\
\hline 12.913 & $0.6 \% 2$ & -1.432 & 1.643 & 0.735 & .1 .566 & 0.4983 & 0.609 & -1.298 & 5.422 \\
\hline 14.204 & 0.676 & $=1.458$ & 1.499 & 0.737 & $\cdot 1.591$ & 0.451 & 0.614 & -1.325 & 4.915 \\
\hline 15.625 & 0.667 & -1.479 & 1,440 & 0.72 .7 & $\cdot 1.611$ & 0.443 & 0.607 & $-1,346$ & 4.688 \\
\hline 17.187 & 0.696 & -1.496 & $1.30 \%$ & 0.72 .4 & $1.628 B$ & 0.405 & $0 .(1,0)$ & $1.36 \%$ & 4.22 .0 \\
\hline 18.906 & 0.663 & $.1,515$ & $1.1 \%$ & 0.227 & 1.6146 & 0.3166 & 0611 & 1.383 & 3.801 \\
\hline 20.796 & $0 . t 933$ & $-1,52.1$ & 0.9633 & 0.742 & $1,6: 3$ & 0.299 & 0.623 & -1.388 & 3.134 \\
\hline 22.876 & 0.682 & -1.535 & 0.880 & 0.74 .1 & - 1. $66 \theta$ & 0.2688 & 0.0 .2 .3 & -1.401 & 2.890 \\
\hline 25.164 & 0.692 & .1 .544 & 0.763 & 0.752 & $\because 1.6>B$ & 0.231 & 0.6312 & -1.410 & 2.528 \\
\hline 27.680 & 0.709 & $-1,542$ & 0.617 & 0.771 & $-1.67 \%$ & 0.1844 & $0.644)$ & $-1,406$ & 2.065 \\
\hline
\end{tabular}


TABLE 4-2 SUMMARY OF PREDICTION COEFFICIENTS FOR VERTICAL, PSRVG FOR STATIONS ON ROCK,

\begin{tabular}{|c|c|c|c|c|c|c|c|c|c|}
\hline \multirow{2}{*}{$\begin{array}{c}\text { Frequanoy } \\
\text { (Hz) }\end{array}$} & \multicolumn{3}{|c|}{ Best Estimate Ecruations } & \multicolumn{3}{|c|}{ Lower: Bound Eguat 1ons } & \multicolumn{3}{|c|}{ Upper: Bound Equat Long } \\
\hline & 9 & $\underline{b}$ & $\mathrm{~K}$ & a & 1) & $\underline{x}$ & 采 & $\underline{b}$ & $\mathrm{k}$ \\
\hline 0.314 & 0.628 & -1.050 & 1.913 & 0.702 & -1.171 & 0.670 & 0.557 & -0.929 & 5.461 \\
\hline 0.345 & 0.582 & $-1,030$ & 2.808 & 0.652 & -1.154 & 0.959 & 0.512 & $-0,006$ & 8.221 \\
\hline 0.380 & 0.535 & -1.030 & 4.078 & 0.602 & $-1,15 \%$ & 1.348 & 0.469 & $-0,902$ & 17.330 \\
\hline 0.418 & 0.510 & -1.038 & 5.231 & 0.574 & $-1,168$ & 1.689 & 0.446 & $-0,908$ & 16.195 \\
\hline 0.459 & 0.498 & -1.065 & 6.430 & 0.558 & $-1,193$ & 2.119 & 0.438 & -0.937 & 19.558 \\
\hline 0.505 & 0.479 & $-1,109$ & 8.169 & 0.533 & $-1,234$ & 2.760 & 0.42 .5 & -0.984 & 24.176 \\
\hline 0.550 & 0.500 & -1.158 & 8.285 & 0.554 & -1.282 & 2,813 & 0.446 & -1.033 & 2.4 .400 \\
\hline 0.612 & 0.569 & -1.211 & 6,394 & 0.627 & -1.332 & 2.212 & 0.512 & -1.088 & 18.487 \\
\hline 0.673 & 0.644 & -1.252 & 4.696 & 0.705 & -1.371 & 1.673 & 0.583 & -1.133 & 13.184 \\
\hline 0.740 & 0.731 & -1.253 & 3.056 & 0.798 & -1.369 & $1,12.4$ & 0.664 & -1.138 & 8.306 \\
\hline 0.814 & 0.766 & -1.242 & 2.633 & 0.839 & $-1,361$ & 0.940 & 0.692 & -1.123 & 7.376 \\
\hline 0.895 & 0.736 & -1.252 & 3.543 & 0,809 & -1.375 & 1.215 & 0.664 & -1.128 & 10.329 \\
\hline 0.985 & 0.680 & -1.282 & 5.642 & 0.747 & -1.410 & 1.873 & 0.613 & -1.155 & 16.998 \\
\hline 1.083 & 0.658 & -1.341 & 7.390 & 0.722 & -1.471 & 2.380 & 0.594 & -1.210 & 22.940 \\
\hline 1.192 & 0.659 & -1.400 & 8.063 & 0.72 .0 & -1.528 & 2.661 & 0.599 & -1.273 & 24,432 \\
\hline 1.311 & 0.698 & -1.442 & 6.818 & 0.759 & -1.568 & 2.282 & 0.637 & -1.316 & 20.366 \\
\hline 1.442 & 0.726 & -1.468 & 6.104 & 0.789 & -1.505 & 2.023 & 0.663 & -1.340 & 18.420 \\
\hline 1.586 & 0,691 & -1.476 & 7.605 & 0.752 & -1.605 & 2.469 & 0.630 & $-1,346$ & 23.424 \\
\hline 1.745 & 0.629 & $-1.47: 3$ & 11.171 & 0.686 & -1.606 & 3.04 & 0.572 & -1.339 & 35,617 \\
\hline 1.919 & 0.629 & -1.449 & 10.606 & 0.687 & -1.584 & 3.306 & $0.5 \%$ & -1.315 & 34.027 \\
\hline 2.111 & 0.659 & -1.449 & 8.589 & 0.120 & -1.584 & $2.6 \%$ & 0.598 & $-1,315$ & 27.633 \\
\hline 2.322 & 0.685 & -1.455 & 7.079 & 0.750 & -1.591 & 2.163 & 0.621 & $-1,318$ & 23.163 \\
\hline 2.555 & 0.726 & -1.455 & 5.382 & 0.794 & -1.592 & 1.642 & 0.658 & -1.318 & 17.635 \\
\hline 2.810 & 0.710 & -1.475 & 5.823 & 0.776 & -1.611 & 1.783 & 0.644 & -1.338 & 19.017 \\
\hline 3.091 & 0.707 & -1.470 & 5.426 & 0.774 & -1.607 & 1.642 & 0.641 & -1.332 & 17.927 \\
\hline 3.400 & 0.659 & -1.479 & 6.726 & 0.722 & -1.619 & 2.006 & 0.597 & -1.340 & 22.549 \\
\hline 3.740 & 0.618 & -1.484 & 7.883 & 0.677 & -1.626 & 2.296 & 0.558 & -1.342 & 27.065 \\
\hline 4.114 & 0.623 & -1.473 & 7.013 & 0.684 & -1.618 & 1.999 & 0.562 & -1.328 & 24.609 \\
\hline 4.526 & 0.622 & -1.466 & 6.590 & 0.684 & -1.614 & 1.828 & 0.559 & -1.319 & 23.761 \\
\hline 4.978 & 0,621 & -1.488 & 6.734 & 0.684 & -1.638 & 1.830 & 0.558 & -1.337 & 24.783 \\
\hline 5.476 & 0.595 & -1.508 & 7.690 & 0.656 & -1.660 & 2.052 & 0.535 & .1 .356 & 28.816 \\
\hline 6.024 & 0.602 & -1.485 & 6.490 & 0.664 & -1.637 & 1.734 & 0.541 & -1.333 & 24.293 \\
\hline 6.626 & 0.614 & -1.454 & 5.099 & 0.678 & -1.606 & 1. 363 & 0.549 & -1.302 & 19.080 \\
\hline 7.289 & 0.642 & $-1,437$ & 3.811 & 0.710 & -1.590 & 1.011 & 0.573 & -1.284 & 14.371 \\
\hline 8.018 & 0.644 & $-1,422$ & 3.290 & 0.714 & -1.574 & 0.874 & 0.575 & -1.269 & 12.379 \\
\hline 8.820 & 0.616 & -1.441 & 3.629 & 0.682 & -1.596 & 0.948 & 0.550 & $-1,286$ & 13.896 \\
\hline 9.702 & 0.608 & -1.455 & 3.448 & 0.672 & -1.609 & 0.901 & 0.543 & $-1,300$ & 13.188 \\
\hline 10.672 & 0.618 & -1.469 & 2.940 & 0.682 & -1.623 & 0.776 & 0.553 & $-1,316$ & 11.139 \\
\hline 11.739 & 0.667 & -1.473 & 1.996 & 0.737 & -1.626 & 0.529 & 0.598 & -1.319 & 7.527 \\
\hline 12.913 & 0.690 & $-1,492$ & 1.614 & 0.781 & -1.646 & 0.424 & 0.619 & -1.338 & 6.135 \\
\hline 14.204 & 0.700 & $-1,518$ & 1,421 & 0.771 & -1.673 & 0.373 & 0.829 & -1.364 & 5.4 .11 \\
\hline 15.625 & 0.692 & -1.535 & 1.350 & 0.761 & -1.6888 & 0.356 & 0.623 & $-1,381$ & 5.117 \\
\hline 17.187 & 0.691 & -1.553 & 1.229 & 0.759 & $\cdot 1.705$ & 0.328 & 0.623 & -1.401 & 4.610 \\
\hline 18,906 & 0.700 & -1.573 & 1.077 & 0.767 & $\cdot 1.724$ & 0.290 & 0.83 .33 & -1.422 & 3.998 \\
\hline 20.796 & 0.714 & -1.589 & 0.900 & 0.783 & -1.741 & 0.240 & 0.646 & $-1.43 \%$ & 3.371 \\
\hline 2.2 .876 & 0.716 & -1.606 & 0.820 & 0.784 & -1.759 & 0.218 & 0.848 & -1.453 & 3.001 \\
\hline 25.164 & 0.727 & -1.622 & 0.713 & 0.797 & -1.776 & 0.187 & 0.658 & $-1,467$ & 2.717 \\
\hline 27.680 & 0.744 & -1.624 & 0.584 & 0.816 & -1.780 & $0.1 \leq 1$ & $0.6 \% 3$ & $-1 \cdot 468$ & 2. 2.54 \\
\hline
\end{tabular}


TABLE 4-3 SUMMARY OF PREDICTION COEFFICIENTS FOR RADIAL, PSRVS FOR STATIONS ON ALLUVIUM.

\begin{tabular}{|c|c|c|c|c|c|c|c|c|c|}
\hline \multirow{2}{*}{$\begin{array}{c}\text { Frequanoy } \\
(\mathrm{Hz})\end{array}$} & \multicolumn{3}{|c|}{ Best Estimate Equations } & \multicolumn{3}{|c|}{ Lower Bound Equations } & \multicolumn{3}{|c|}{ Upper Bound Equations } \\
\hline & a & b & $\underline{\mathbf{K}}$ & a & $\underline{b}$ & $\underline{\underline{K}}$ & $\underline{\mathbf{a}}$ & $\underline{b}$ & $\underline{1}$ \\
\hline 0.314 & 0.658 & $-1,303$ & 4.843 & 0.706 & $-1,400$ & 2,144 & 0.609 & -1.207 & 10.938 \\
\hline 0.345 & 0.617 & -1.246 & 6.232 & 0.666 & -1.346 & 2.680 & 0.567 & $-1,146$ & 14,483 \\
\hline 0.380 & 0.528 & -1.247 & 11.573 & 0.573 & $-1,351$ & 4.808 & 0.485 & -1.142 & 27.865 \\
\hline 0.418 & 0.441 & -1.293 & 23.488 & 0.478 & $-1,401$ & 9.485 & 0.404 & $-1,186$ & 58,163 \\
\hline 0.458 & 0.392 & -1.332 & 36.201 & 0.423 & $-1,439$ & 14.672 & 0,360 & -1.225 & 89,318 \\
\hline 0.505 & 0.390 & $-1,371$ & 41.932 & 0.420 & $.1,476$ & 17.354 & 0.360 & -1.267 & 101,319 \\
\hline 0.556 & 0.427 & -1.382 & 35.502 & 0.458 & -1.484 & 15.092 & 0.396 & $-1,281$ & 83,514 \\
\hline 0,612 & 0.449 & $-1,462$ & 37.576 & 0.480 & -1.563 & 16.025 & 0.418 & -1.361 & 88.114 \\
\hline 0.673 & 0.493 & -1.504 & 31,700 & 0.526 & $-1,605$ & 13,589 & 0.460 & -1.404 & 73.946 \\
\hline 0.740 & 0.507 & -1.484 & 27.297 & 0.541 & $-1,583$ & 11,819 & 0.473 & -1.385 & 63.047 \\
\hline 0.814 & 0.505 & $-1,466$ & 26.348 & 0.539 & -1.564 & 11.510 & 0.471 & -1.368 & 60.313 \\
\hline 0.895 & 0.492 & -1.453 & 28.692 & 0.526 & $\cdot 1,554$ & 12.253 & 0.457 & -1.352 & 67.186 \\
\hline 0.985 & 0.489 & $-1,458$ & 31.210 & 0.523 & -1.559 & 13.316 & 0.455 & -1.358 & 73.153 \\
\hline 1.083 & 0.473 & -1.499 & 39.073 & 0.505 & -1.602 & 16.372 & 0.440 & $-1,396$ & 93,249 \\
\hline 1,192 & 0.457 & $-1,532$ & 44.836 & 0.488 & -1.635 & 18.740 & 0.426 & -1.429 & 107.275 \\
\hline 1.311 & 0.501 & -1.528 & 32.497 & 0.534 & -1.632 & 13.663 & 0.467 & -1.427 & 77.289 \\
\hline 1.442 & 0.540 & -1.495 & 22.689 & 0.577 & -1.599 & 9.452 & 0.502 & -1.391 & 54.461 \\
\hline 1.586 & 0.490 & $-1,498$ & 28.830 & 0.524 & -1.602 & 12.068 & 0.456 & -1.395 & 68.871 \\
\hline 1.745 & 0.462 & -1.507 & 33.437 & 0.493 & -1.608 & 14.271 & 0.431 & -1.406 & 78.345 \\
\hline 1.919. & 0.484 & $-1,483$ & 26.786 & 0.515 & -1.580 & 11.743 & 0.452 & -1.385 & 61.100 \\
\hline $2 . \therefore 11$ & 0,508 & $-1,434$ & 19.354 & 0.543 & -1.534 & 8.344 & 0.472 & -1.334 & 44.894 \\
\hline 2.322 & 0.522 & -1.407 & 15.559 & 0.559 & -1.508 & 6. 652 & 0.485 & -1.307 & 36.389 \\
\hline 2.555 & 0.555 & -1.389 & 11,746 & 0.595 & -1.490 & 5.026 & 0.515 & -1.288 & 27.506 \\
\hline 2.810 & 0.512 & -1.410 & 14.839 & 0.550 & -1.516 & 6.076 & 0.473 & -1.304 & 36.239 \\
\hline 3.091 & 0.504 & -1.434 & 15.725 & 0.543 & -1.543 & 6,249 & 0.466 & -1.325 & 38.570 \\
\hline 3.400 & 0.513 & -1.431 & 13.967 & 0.553 & -1.543 & 5.450 & 0.473 & $-1,320$ & 35,794 \\
\hline 3.740 & 0.515 & -1.401 & 11.999 & 0.556 & -1.514 & 4.650 & 0.474 & -1.289 & 30,962 \\
\hline 4.114 & 0.520 & -1.404 & 11.023 & 0.562 & -1.516 & 4.262 & 0.478 & -1.291 & 28.512 \\
\hline 4.526 & 0.516 & $-1,399$ & 10,463 & 0,560 & $-1,519$ & 3.787 & 0.471 & $-1,279$ & 28,908 \\
\hline 4.978 & 0.511 & -1.409 & 10.469 & 0.557 & $-1,536$ & 3.578 & 0.465 & -1.282 & 30.631 \\
\hline 5.476 & 0.514 & -1.423 & 9.929 & 0.561 & -1.553 & 3.315 & 0.467 & -1.294 & 29.743 \\
\hline 6.024 & 0.534 & -1.397 & 7.408 & 0.583 & -1.528 & 2.460 & 0.484 & -1.267 & 22.302 \\
\hline 6.626 & 0.549 & -1.381 & 5.857 & 0.601 & -1.512 & 1.947 & 0.497 & -1.251 & 17.615 \\
\hline 7.289 & 0.597 & -1.388 & 4.285 & 0.653 & -1.516 & 1.446 & 0.542 & -1.259 & 12.697 \\
\hline 8.018 & 0.607 & -1.381 & 3.540 & 0.663 & -1.508 & 1.211 & 0.552 & -1.254 & 10.345 \\
\hline 8.820 & 0.597 & -1.406 & 3.542 & 0.650 & -1.532 & 1.2 .19 & 0.543 & -1.279 & 10.289 \\
\hline 9.702 & 0.586 & -1.439 & 3.589 & 0.636 & -1.561 & 1.274 & 0.536 & -1.316 & 10.110 \\
\hline 10.672 & 0.608 & -1.451 & 2.915 & 0.660 & -1.574 & 1.032 & 0.556 & -1.328 & 8.232 \\
\hline 11.739 & 0.627 & -1.474 & 2.457 & 0.680 & -1.597 & 0.871 & 0.575 & -1.352 & 6.927 \\
\hline 12.913 & 0.638 & -1.494 & $2.14 \%$ & 0.690 & $-1,616$ & $0.7 \% 0$ & 0.586 & $-1,373$ & 5.985 \\
\hline 14.204 & 0.644 & -1.519 & 1.941 & 0.695 & -1.639 & 0.710 & 0.594 & $-1,400$ & 5.306 \\
\hline 15.625 & 0.635 & -1.540 & 1.880 & 0.684 & -1.658 & 0.696 & 0.587 & $-1,423$ & 5.078 \\
\hline 17.187 & 0.634 & -1.572 & 1.792 & 0.682 & -1.690 & 0.663 & 0.587 & -1.454 & 4.846 \\
\hline 18.906 & 0.637 & -1.593 & 1.624 & 0.683 & -1.710 & 0.607 & 0.590 & -1.476 & 4.347 \\
\hline 20.796 & 0.638 & -1.605 & 1.450 & 0.684 & -1.722 & 0.539 & 0.591 & -1.488 & 3.898 \\
\hline 22.876 & 0.638 & -1.631 & 1.391 & 0.684 & -1.749 & 0.516 & 0.592 & -1.514 & 3.747 \\
\hline $25 \cdot 164$ & 0.649 & -1.644 & 1.220 & 0.685 & -1.762 & 0.450 & 0.602 & -1.526 & 3.312 \\
\hline 27.680 & 0.655 & -1.654 & 1.092 & 0.702 & -1.774 & 0.397 & 0.607 & -1.535 & 3,001 \\
\hline
\end{tabular}


TABLE 4-4 SUMMARY OF PREDICTION COEFETCIENTS FOR RADIAL. PSRVS FOR STATIONS ON ROCK

\begin{tabular}{|c|c|c|c|c|c|c|c|c|c|}
\hline \multirow{2}{*}{$\begin{array}{c}\text { Erequency } \\
\underline{\mathrm{Hz}}\end{array}$} & \multicolumn{2}{|c|}{ Best Estimate } & \multirow{2}{*}{$\begin{array}{c}\text { Equations } \\
\mathrm{K}\end{array}$} & \multicolumn{3}{|c|}{ Lower Bound Equations } & \multicolumn{3}{|c|}{ Upper Bound Equations } \\
\hline & $\underline{a}$ & $\underline{b}$ & & $\underline{a}$ & $\underline{b}$ & $\underline{\mathbf{K}}$ & a & $\underline{b}$ & $\underline{\mathrm{K}}$ \\
\hline 0.314 & 0.713 & -1.233 & 3.089 & 0.778 & -2.344 & 1.240 & 0.649 & -1.121 & 7.604 \\
\hline 0.345 & 0.660 & -1.180 & 4.318 & 0.725 & -1.296 & 1.583 & 0.596 & -1.065 & 12.082 \\
\hline 0.380 & 0.575 & -1.177 & 7.912 & 0.634 & -1.298 & 2.958 & 0.516 & -1.057 & 21.162 \\
\hline 0418 & 0.487 & -1.227 & \pm 6.294 & 0.537 & -1.353 & 5.852 & 0.437 & -1.102 & 45.369 \\
\hline 0.459 & 0.439 & -1.269 & 25.222 & 0.483 & -1.397 & 8.908 & 0.395 & -1.142 & 71.415 \\
\hline 0.505 & 0.430 & -1.310 & 30.450 & 0.471 & -1.435 & 10.974 & 0.389 & -1.184 & 84.494 \\
\hline 0.556 & 0.468 & -1.320 & 25.468 & 0.511 & -1.440 & 9.540 & 0.425 & -1.200 & 67.988 \\
\hline 0.612 & 0.507 & -1.409 & 24.965 & 0.551 & -1.530 & 9.274 & 0.463 & -1.287 & 67.208 \\
\hline 0.673 & 0.545 & -1.457 & 22.042 & 0.591 & $* 1.579$ & 8. 123 & 0.499 & -1.334 & 59.811 \\
\hline 0.740 & 0.558 & -1.434 & 18.881 & 0.504 & -1.553 & 7.147 & 0.511 & -1.315 & 49.883 \\
\hline 0.814 & 0.557 & -1.427 & 18.392 & 0.602 & -1.542 & 7.154 & 0.512 & -1.311 & 47.286 \\
\hline 0.895 & 0.543 & -1.422 & 20.399 & 0.587 & -1.538 & 7.836 & 0.498 & -1.306 & 52.698 \\
\hline 0.985 & 0.527 & -1.432 & 24.097 & 0.571 & -1.551 & 9.154 & 0.483 & -1.313 & 63.431 \\
\hline 1.083 & 0.511 & -1.464 & 29.640 & 0.555 & -1.589 & 10.626 & 0.467 & -1.338 & 82.678 \\
\hline 1.192 & 0.508 & -1.495 & 31.513 & 0.552 & -1.624 & 11.063 & 0.465 & -1.367 & 89.763 \\
\hline 1. 311 & 0.546 & -1.491 & 23.649 & 0.593 & -1.620 & 8.319 & 0.499 & -1.363 & 67.225 \\
\hline 1.442 & 0.579 & -1.455 & 17.084 & 0.631 & -1.585 & 5.949 & 0.528 & -1.326 & 49.062 \\
\hline 1.586 & 0.532 & -1.453 & 21.040 & 0.579 & -1.582 & 7.356 & 0.485 & -1.324 & 60.178 \\
\hline 2.745 & 0.508 & -1.459 & 23.596 & 0.552 & -1.584 & 8.511 & 0.465 & -1.334 & 65.419 \\
\hline 1.919 & 0.519 & -1.446 & 20.615 & 0.562 & -1.566 & 7.764 & 0.476 & -1.326 & 54.736 \\
\hline 2.111 & 0.546 & -1.391 & 14.381 & 0.594 & -1.512 & 5.358 & 0.499 & -1.270 & 38.599 \\
\hline 2.322 & 0.562 & -1.369 & 11.679 & 0.611 & -1.489 & 4.353 & 0.512 & -1.248 & 30.960 \\
\hline 2.555 & 0.590 & -1.362 & $r .161$ & 0.642 & -1.482 & $3.4 /, 3$ & 0.538 & -1.242 & 24.375 \\
\hline 2.810 & 0.557 & -1.408 & 11.472 & 0.606 & -1.530 & 4.209 & 0.500 & -1.285 & 31.263 \\
\hline 3.091 & 0.557 & -1.451 & 12.131 & 0.605 & -1.576 & 4.371 & 0.509 & -1.326 & 33.668 \\
\hline 3.400 & 0.561 & -1.462 & 11.428 & 0.609 & -1.589 & 4.069 & 0.512 & -1.336 & 32.097 \\
\hline 3.740 & 0.570 & -1.436 & 9.51 .3 & 0.620 & -1.562 & 3.405 & 0.520 & -1.310 & 26.579 \\
\hline 4. 114 & 0.573 & -1.446 & 9.025 & 0.623 & -1.572 & 3.237 & 0.523 & -1.321 & 25.164 \\
\hline 4.526 & 1) 566 & -1.446 & 8.725 & 0.619 & -1.581 & 2.905 & 0.513 & -1.311 & 26.208 \\
\hline 4.978 & i. 556 & -1.462 & 9.073 & 0.011 & -1.605 & 2.815 & 0.502 & -1.31 .8 & 29.245 \\
\hline 5.476 & 0.554 & -1.482 & 8.922 & 0.607 & -1.62 .4 & 2.798 & 0.500 & -1.340 & 28.450 \\
\hline 6.024 & 0.562 & -1.480 & $7.39\}$ & 0.615 & -1.618 & 2.334 & 0.510 & -1.341 & 22.914 \\
\hline 6.626 & 0.580 & -1.458 & 5.6832 & 0.636 & -1.598 & 1.807 & 0.524 & -1.317 & 17.868 \\
\hline 7.289 & 0.627 & -1.452 & 4.151 & 0.686 & -1.600 & 1.346 & 0.568 & -1.324 & 12.807 \\
\hline 8.018 & 0.632 & -2.444 & 3.445 & 0.693 & -1.583 & 1.109 & 0.571 & -1.305 & 10.705 \\
\hline 8.820 & 0.621 & -1.472 & 3.4 .45 & 0.881 & -1.612 & 1.098 & 0.562 & -1.331 & $10 \quad 813$ \\
\hline 9.702 & 0.602 & -1.516 & 3.762 & 0.656 & -1.652 & 1.238 & 0.548 & -1.380 & 11.136 \\
\hline 10.672 & 0.630 & -1.522 & 2.919 & 0.687 & -1.659 & 0.952 & 0.573 & -1.384 & 8. 152 \\
\hline 11.739 & 0.651 & -1.542 & 2.419 & 0.709 & -1.681 & 0.781 & 0.592 & -1.404 & 7.491 \\
\hline 12.913 & 0.671 & -1.552 & 1.952 & 0.730 & -1.689 & 0.639 & 0.612 & -1.415 & 5.967 \\
\hline 14.204 & 0.687 & -1.572 & 1.652 & 0.746 & -1.707 & 0.549 & 0.628 & -1.437 & 4. 967 \\
\hline 15.625 & 2.679 & -1.586 & 1.569 & 0.736 & -1.720 & 0.525 & 0.621 & -1.452 & 4.687 \\
\hline 17.187 & 0.682 & -1.615 & 1.465 & 0.739 & -1.751 & $0.4 \$ 2$ & 0.624 & -1.479 & 4.452 \\
\hline 18.906 & 0.687 & -1.638 & 1.319 & 0.743 & -1.773 & 0.440 & 0.630 & -1.504 & 3.949 \\
\hline 20.796 & 0.686 & -1.656 & 1.210 & 0.742 & -1.791 & 0.402 & 0.630 & -1.521 & 3.64 .2 \\
\hline 22.876 & 0.686 & -1.687 & 1.178 & 0.74. & -1.823 & 0.390 & 0.631 & $-1,552$ & 3.559 \\
\hline 25.164 & 0.702 & -1.700 & 1.006 & 0.759 & -1.837 & 0.328 & 0.645 & -1.562 & 3.083 \\
\hline 27.680 & 0.708 & $1-1.712$ & 0.903 & $0.76 t ;$ & -1.851 & 0.289 & 0.650 & -1.572 & 2.321 \\
\hline
\end{tabular}


TAELE 4-5 SUMARY OF FEEDICTION COEEETCIENTS EOR TRANSVERSE PSRVS FOR STATIONS ON ALLUVIJM

\begin{tabular}{|c|c|c|c|c|c|c|c|c|c|}
\hline fuency & st & nate & Eions & wer & 04 & 18 & I & and & \\
\hline$(\mathrm{Ez}$ & $\underline{a}$ & $\underline{b}$ & $\underline{\mathrm{K}}$ & a & $\underline{b}$ & $\underline{k}$ & 3 & b & $\underline{k}$ \\
\hline 0.314 & 0.468 & -0.999 & 5.065 & 0.519 & -1.106 & 2.031 & 0.417 & -0.890 & 12.633 \\
\hline 0.345 & 0.445 & -1.042 & 7.575 & 0.491 & -1.152 & 3.016 & 0.398 & -0.933 & 19.024 \\
\hline 0.380 & 0.448 & -1.080 & 9.111 & 0.493 & -1.187 & 3.674 & 0.403 & -0.972 & 22.593 \\
\hline 0.418 & 0.457 & -1.131 & 10.846 & 0.500 & -1.238 & 4.421 & 0.414 & -1.924 & 26.610 \\
\hline 0.459 & 0.416 & -1.180 & 16.678 & 0.454 & -1.288 & 6.735 & 0.378 & -1.072 & 41.300 \\
\hline 0.505 & 0.389 & $-i .244$ & 24.944 & 0.423 & -1.353 & 9.599 & 0.354 & -1.135 & 60.224 \\
\hline 0.556 & 0405 & -1.291 & 25.304 & 0430 & -1.400 & $10.1: 5$ & 0.371 & $\because 182$ & 63.301 \\
\hline 6. $\$ 12$ & 0.418 & -1365 & 28.958 & 0.451 & -1.471 & 11.776 & 0.355 & -1.25 .5 & 71.207 \\
\hline 0.673 & 0.468 & -1.405 & 24.738 & 0.503 & -1.511 & 10.038 & 0.432 & -1.298 & 60.662 \\
\hline 0.140 & 0.484 & 1.420 & $24.40 !$ & 0.519 & -1.530 & 10.183 & 0.449 & -1.323 & 58.440 \\
\hline 0.814 & 0.520 & -1.418 & 19.855 & 0.558 & -1.522 & 8.242 & 0.432 & -1.313 & 47.832 \\
\hline 0.895 & 0.520 & -1.417 & 20.232 & 0.559 & -1.523 & 8.277 & 0.481 & -1.310 & 49.455 \\
\hline 0.985 & 0.471 & -1.433 & 28.548 & 0.507 & -1.541 & 11.531 & 0.435 & -1.325 & $70 . E 76$ \\
\hline 1.083 & 0.425 & -2.476 & 41.369 & 0.455 & -1.584 & 20.610 & $0.3 y ?$ & $\because 38 ;$ & 103,039 \\
\hline$\therefore .192$ & 0.402 & -1.537 & 53.728 & 0.433 & -1.645 & 21.847 & 0.373 & $\cdot: .429$ & $: 34.345$ \\
\hline 1.311 & 0.437 & -1.550 & 43.051 & 0.467 & $-1 E S 7$ & 17.520 & 0.407 & -1.443 & 105.786 \\
\hline 1.442 & 0.487 & -1.529 & 29.483 & 0.522 & 1.036 & 11.952 & 0.453 & -1.422 & 72732 \\
\hline$\therefore .58 t$ & $0.48 E$ & 2511 & $2 \because 47 \theta$ & 0.522 & $-\therefore .820$ & 10.953 & 0.451 & $\therefore 401$ & 68.059 \\
\hline 1.145 & 0488 & -1431 & 24.723 & 0.523 & $\because 2.587$ & 10.130 & 0453 & -1.375 & 60.376 \\
\hline 1919 & 0.471 & -1.444 & $\therefore 3.967$ & 0595 & -1.548 & 9.982 & 0.47 & .1 .340 & 57.546 \\
\hline$\therefore: 21$ & 0457 & -1.447 & $21.14 ;$ & 0.523 & -1.552 & $8.7: 5$ & .452 & $\because=342$ & 50.832 \\
\hline$\therefore 322$ & 0.519 & -145 & 17408 & $0.5 \leq 8$ & 1502 & 7.25 & 480 & 1. 346 & 42.833 \\
\hline 2.555 & 0.550 & -1.429 & 13.137 & 0.591 & -1.536 & 5.29 & 0.500 & -1.322 & $32.38 \%$ \\
\hline$\therefore 810$ & $0.54 \mathrm{a}$ & -2.620 & 22.372 & $0.59 !$ & $\therefore 531$ & 4.856 & 996 & -2.309 & $31.45 \%$ \\
\hline 3.091 & 0.530 & -1432 & 12.940 & 0.518 & $-1,545$ & 4.947 & 0.493 & -1.318 & 33714 \\
\hline 3.400 & 0.518 & -1.439 & 13.202 & 0560 & -1.553 & $5 \cdot \operatorname{cog}$ & $0.47 \%$ & $-1,324$ & 34.590 \\
\hline$\because 740$ & 0.545 & 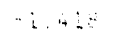 & $1004 ?$ & 0530 & -1.535 & 3.750 & 6507 & -1302 & LE. 59 \\
\hline 4.114 & 0.435 & -1.429 & 12.592 & $0.53 ?$ & $-\therefore \leq 50$ & 4.555 & 0.454 & -1.309 & 34.614 \\
\hline 4526 & 0.475 & -1.430 & 13. 103 & 0.517 & $1.5 \$ 5$ & -343 & 0434 & -1.306 & $3: 4: 1$ \\
\hline 4.378 & 512 & - 139 & 9.200 & 0559 & -1.528 & $3: 108$ & 0.465 & -1270 & 27.29 \\
\hline 5.476 & 0.543 & $\cdot 7,39$ & 7.198 & 0593 & 1.521 & 2.422 & 0.49 & -1205 & 2070 . \\
\hline$\therefore 024$ & $0.58:$ & $-\therefore 386$ & 5.58 & $06: 1$ & 1.511 & 1.99 & 0.510 & $\therefore .2 E L$ & LE.172 \\
\hline 5020 & 255 & $\because 376$ & 5.45 & 0.50 & -1499 & 2.763 & $0.50 \mathrm{E}$ & 1.242 & 14441 \\
\hline 7289 & 0.532 & 1.376 & 3.820 & 0.545 & -1.438 & 2519 & 0538 & 1.249 & 10.902 \\
\hline c. 016 & 0.023 & $\because 35:$ & 2.86 & 0.681 & -1.485 & 0.96. & 0.50 .5 & -1.233 & 8.093 \\
\hline 3. 820 & 0.630 & -1.503 & 2.355 & 0.635 & -1.476 & 0.899 & 0.57 & -1.242 & 6.850 \\
\hline 2702 & 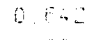 & :.191 & 2.151 & 0.700 & 1.517 & $\square \cdot{ }_{4} E$ & $0.5: 4$ & $\cdot: .360$ & E. 193 \\
\hline 10.572 & 0652 & $-2+21$ & ? 373 & $: 727$ & $\therefore .542$ & $9 \times 49$ & 0.593 & -1.290 & 5403 \\
\hline$\therefore \quad 133$ & 0671 & $7: 43 z$ & 1.72 & 0.73 & -1559 & $0.5+9$ & $\because 11$ & -230 & $455 ?$ \\
\hline 12013 & 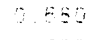 & -1455 & 130 & 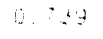 & -1.581 & 0493 & 3.22 & -1.30 & 4.001 \\
\hline 24204 & 0.35 & $\because 445$ & $1: 90$ & 0.752 & .1597 & $04 ! 9$ & 0.35 & 1351 & 3.378 \\
\hline$\therefore \quad 2 \leq$ & $\because \sin$ & $\because 25:$ & 182 & 9733 & $-\vdots \quad 2$ & 045 & $\therefore \quad \therefore 25$ & $: 364$ & 3.504 \\
\hline$\because \quad 197$ & 864 & $\therefore: \because 4$ & $2-43$ & $8 \quad 3$ & $\therefore 5$ & $0 \leq 2$ & $\because$ & 1930 & $3 \quad \therefore$ \\
\hline.$\quad m$ & $\therefore: 3$ & $\therefore \quad \cdots:$ & $\therefore \quad 1$ & $\because:$ & $\therefore \cdots$ & $1 \quad \therefore 6$ & $\therefore \quad \cdots$ & $: \quad+\cdots$ & $3 \ldots$ \\
\hline$\therefore \quad \therefore$ & cro & $\because 5 y$ & $\therefore \because$ & $-\quad 1$, & $\because 720$ & $\therefore \quad 37$ & $\because \cdots$ & $\ddots \cdots$ & $\therefore \quad \cdots$ \\
\hline$\therefore \quad 378$ & $\therefore=3$ & 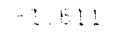 & 9.925 & $\therefore y$ & -1.752 & $0.3+t$ & 0.62 & $2+4$ & $24 r i$ \\
\hline$\therefore \quad: 54$ & $0 \div 32$ & 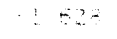 & $\therefore E 73$ & $\therefore \quad \therefore$ & -1.750 & $3 \quad 24=$ & 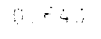 & $\therefore 5 r$ & $\therefore \quad 24$ \\
\hline$\therefore 800$ & 0.52 & $\therefore \quad 5+r$ & $0.79 \%$ & 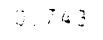 & $\therefore 70$ & 9.232 & $\therefore 40$ & 1523 & 2.25 \\
\hline
\end{tabular}


TABLE 4-6 SUMMAY OF PREDICTION COEFFICIENTS FOR TRANSVERSE PSRVS FOR STATIONS ON ROCR.

\begin{tabular}{|c|c|c|c|c|c|c|c|c|c|}
\hline \multirow{2}{*}{$\begin{array}{c}\text { Erequency } \\
(\mathrm{Hz})\end{array}$} & \multicolumn{3}{|c|}{ Best Estimate Equations } & \multicolumn{3}{|c|}{ Lower Bound Equations } & \multicolumn{3}{|c|}{ Upper Bound Equations } \\
\hline & $\underline{\mathrm{a}}$ & $\underline{b}$ & $\underline{\mathrm{K}}$ & $\underline{a}$ & $\underline{\mathfrak{b}}$ & $\underline{k}$ & $\underline{a}$ & $\underline{b}$ & $\underline{\underline{K}}$ \\
\hline 0.314 & 0.511 & -0.386 & 3.999 & 0.575 & -1.110 & 1.469 & 0.447 & -0.863 & 10.888 \\
\hline 0.345 & 0.489 & -1.035 & 5.986 & 0.548 & -1.150 & 2.159 & 0.429 & -0.910 & 16.595 \\
\hline 0.380 & 0.488 & $-1.07 ?$ & 7.440 & 0.544 & -1.201 & 2.719 & 0.432 & -0.953 & 20.356 \\
\hline 0.418 & 0.480 & -1.128 & 9.779 & 0.533 & -1.251 & 3.571 & $0.42 \%$ & -1.004 & 26.782 \\
\hline 0.459 & 0.449 & -1.173 & 14.200 & 0.497 & -1.299 & 5.119 & 0.401 & -1048 & 39.390 \\
\hline 0.505 & 0.436 & $\cdot 1.226$ & 13.401 & 0.482 & -1.356 & 6.413 & 0.390 & -1.097 & 52.800 \\
\hline 0.556 & 0.454 & -1264 & 18.726 & 0.501 & -1.394 & 6.504 & 0.408 & -1.134 & 53.918 \\
\hline 0.812 & c. 467 & $\cdots 1.324$ & 20.747 & 0.513 & -1.453 & 7.264 & 0.422 & -1.195 & 59.258 \\
\hline 0.673 & 0.515 & -1.309 & 18.092 & 0.564 & -1.499 & 6.237 & 0.456 & -1.238 & 52.479 \\
\hline 0.740 & 0.535 & -1.397 & 17.652 & 0.584 & -1.526 & 6.154 & 0.485 & -1.268 & 50.545 \\
\hline 0.814 & 0.573 & -1.399 & 14.438 & 0.625 & -1.529 & 5.041 & 0.520 & -1.269 & $4 i .350$ \\
\hline 0.895 & 0.563 & -1.409 & 15.813 & 0.617 & -1.542 & 5.356 & 0.510 & -1.276 & 46.690 \\
\hline 0.985 & 0.513 & -1.415 & 21.868 & 0.562 & -1.552 & 7.212 & 0.463 & -1.279 & 66.310 \\
\hline 1.083 & 0.459 & -1.444 & 32.051 & c. $: 02$ & -1.581 & 10.477 & 0.415 & -1.305 & 98.050 \\
\hline 1.192 & 0.443 & -1.502 & 39.729 & 0.484 & -1.639 & 13.036 & 0.403 & -1.365 & 121.075 \\
\hline 1. 311 & 0.478 & -1.519 & 32.222 & 0.520 & -1.655 & 10.671 & 0.435 & -1.383 & $97.30 !$ \\
\hline 1.442 & 0.539 & -1.476 & 20.007 & 0.589 & -1.613 & 5.589 & 0.489 & -1.340 & 60.754 \\
\hline 1. 586 & 0.539 & -1456 & 18.433 & 0.590 & -1.594 & 5.957 & 0.488 & -1.319 & 56.749 \\
\hline 1745 & 0.550 & -1.419 & 15.408 & 0.502 & -1.553 & 5.165 & 0.498 & -1.285 & 45.965 \\
\hline 1.919 & 0.521 & -1.387 & 16.069 & 0.571 & -1.520 & 5.452 & 0.471 & $-i .254$ & 47.358 \\
\hline 2.111 & 0.531 & -1.385 & 14.489 & 0.581 & -1.517 & 4.972 & 0.480 & -2.254 & 42.219 \\
\hline 2. 322 & 0.563 & -1.408 & 12.268 & 0.616 & -1.541 & 4.139 & 0.510 & -1.274 & 36.360 \\
\hline 2.555 & 0.607 & -1.391 & 8.772 & 0.665 & -1.523 & 2.903 & 0.549 & -1.253 & 25.712 \\
\hline 2.810 & 0.609 & -1.393 & 8.296 & 0.668 & -1.528 & 2.771 & 0.550 & -1.258 & 24.833 \\
\hline 3.091 & 0.600 & -1.411 & 8647 & 0.657 & -1.547 & 2.854 & 0.542 & -1.275 & 26.202 \\
\hline 3.400 & 0.582 & $-1,438$ & 9.235 & 0.637 & -1.574 & 3.043 & 0.527 & -1.301 & 28.028 \\
\hline 3740 & 0.611 & -1.432 & 7.132 & 0.669 & -1569 & 2.332 & 0.552 & -1.284 & 21.812 \\
\hline 4.114 & 0.561 & -1.459 & 9.281 & 0.616 & -1.622 & 2.311 & 0.500 & -1.317 & 29.587 \\
\hline 4.326 & 0.530 & $-: 462$ & 10.233 & 0.583 & -1.608 & 3.108 & 0.477 & -1.315 & 33,691 \\
\hline 4.978 & 0.558 & $\because 1.429$ & 7.496 & $0.6: 7$ & -1.581 & 2.172 & 0.498 & -1.2 .77 & 25.856 \\
\hline 5.476 & $0.58 \mathrm{i}$ & -1.428 & 6.079 & 0641 & -1.576 & 1.820 & 0.521 & -1.279 & 20.305 \\
\hline 6.024 & 0.596 & 1427 & 4.900 & 0.859 & -1.570 & 1.526 & 0.538 & -1.284 & 15.739 \\
\hline 0.626 & 0.597 & -2.609 & 4.241 & 0.657 & $-1 \leq 52$ & 1.328 & 0.536 & -1.267 & 13.541 \\
\hline 1.289 & 0.637 & -1.394 & 3.017 & 0.701 & -2.535 & 0.954 & 0.572 & -1.252 & 9.545 \\
\hline 8.018 & 0.661 & -1355 & 2.314 & 0.729 & -1.527 & 0.727 & 0.593 & -1.263 & 7.360 \\
\hline 8.820 & 0.668 & -1.409 & 2.078 & 0.735 & $-i .550$ & 0.650 & 0.601 & -1.268 & 6. 544 \\
\hline 9702 & 0.674 & -1436 & 1.918 & 0.740 & -1.578 & 0.604 & $0.60 ?$ & -1.294 & 6.089 \\
\hline 10.672 & 0.695 & -1.452 & 1.581 & 0.763 & -1.594 & 0.497 & 0.027 & -1.310 & $=034$ \\
\hline 11.739 & 0.710 & $-: 453$ & 1.293 & 0.780 & -1.508 & 0.397 & 0.039 & -1.317 & 4.244 \\
\hline 12.313 & 0.727 & -1.471 & 1.057 & 3.798 & -1.616 & 0.328 & 0.555 & 1.326 & 3.474 \\
\hline 24.204 & 0.743 & -1.482 & 0.676 & 0.815 & -1020 & 0.271 & $0.67 !$ & -1.336 & 2.832 \\
\hline 15.025 & 0.724 & -2.515 & 0.917 & 0.792 & $-\therefore .657$ & 0.288 & 0.650 & $\because 373$ & 2.913 \\
\hline$\therefore: 187$ & 0.699 & -1.557 & 1.017 & 0.763 & $\because .698$ & 0.722 & $0.63 \mathrm{e}$ & $\cdots 1.415$ & 3.222 \\
\hline 19.900 & 0.716 & -1.593 & 0.909 & $0.85 !$ & -1.737 & 0.201 & $0 \quad 051$ & -1.448 & 2.947 \\
\hline$\therefore 76$ & 0.736 & $\because: \cdots$ & $\therefore \% ?$ & 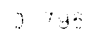 & $\because \quad 33$ & 256 & 1,264 & $: .463$ & $2.53 t$ \\
\hline 22.375 & 3.145 & $-\therefore 5$ & 6. 51 & $\therefore B: 2$ & -1.72 & $2:$ & $\therefore \cdot y$ & $: 480$ & $\therefore 253$ \\
\hline$\therefore \quad 204$ & 0.75 & $\therefore b_{0}$ & $\therefore 583$ & 325 & -1794 & $\because 175$ & 058 & 149 & $\therefore .940$ \\
\hline $27 \quad 000$ & 0.756 & 2001 & 055 & 3,324 & $\because: 2: 0$ & $4 \quad 114$ & $3+4$ & $-1.5: 1$ & 1.801 \\
\hline
\end{tabular}




\section{2 Evaluation of Predictions}

The predictive capability of the derived equations at this point is uproven. In an effort to determine their usefulness as a predictive tool, comparisons of PSRVs calculated from these equations and PSRVs measured in four UNEs were made. These four UNEs were not included in the data base used :c lerive the equations discussed in this report or the surface-downhole ratios derived in Phillips (1987). These comparisons are discussed below.

The first UNE used is a recent event ( 80 to $150 \mathrm{kt}$ yield) recorded at the rucca Mountain stations (source-to-station distances between 40 and $50 \mathrm{~km}$ ). Monsured and predicted PSRV for this event are shown in Figures 4-1 through 1.8 . The predictions are shown on these plots as a solid line (best estimate) ind dashed lines ( 95 confidence intervals). The data are shown as the chain c..shed lines. All three components for a particular station are shown on a single figure. The conclusions drawn from these figures are listed below.

1. In general, the prediction procedure accurately describes the observed ground motions at Yucca Mountain. A11 measured PSRVs are within the 55* confidence intervals of the best estimate of the predictions.

2. Of all Yucca Mountain stations active on this UNE, station $W-25$ had the largest deviation between measured and predicted PSRVs. This deviation occurred in frequencies greater than $2 \mathrm{~Hz}$. At frequencies less than $2 \mathrm{~Hz}$, the data and the prediction are in reasonable agreement. Additional study needs to be done to understand the station effects at this location.

3. The technique used to predict downhole PSRVs produces satisfactory results. Predicted spectra shapes and amplitudes agree reasonably we 11 with the observed values.

The second UNE used for evaluation purposes was also a recent event with the same general parameters as the UNE discussed above. The comparisons of the predicted and measured values are shown in Figures 4-9 and 4-16. The conclusions reached from these figures are similar to those listed above. The alictions for this UNE do not compare as favorably with the measured PSRVs. $\therefore$ ver. In general, the measured surface PSRVs have a higher frequency went and greater amplitudes than the predictions. The largest difference cen measured and predicted PSRVs occurred at $W-25$ again. The predicted cnhole PSRVs mirror the shape of the measured PSRVs, but are lower in litude, due in part to the underprediction of the surface amplitudes. In cases, the measured PSRVs are within the $95 \%$ confidence intervals. 

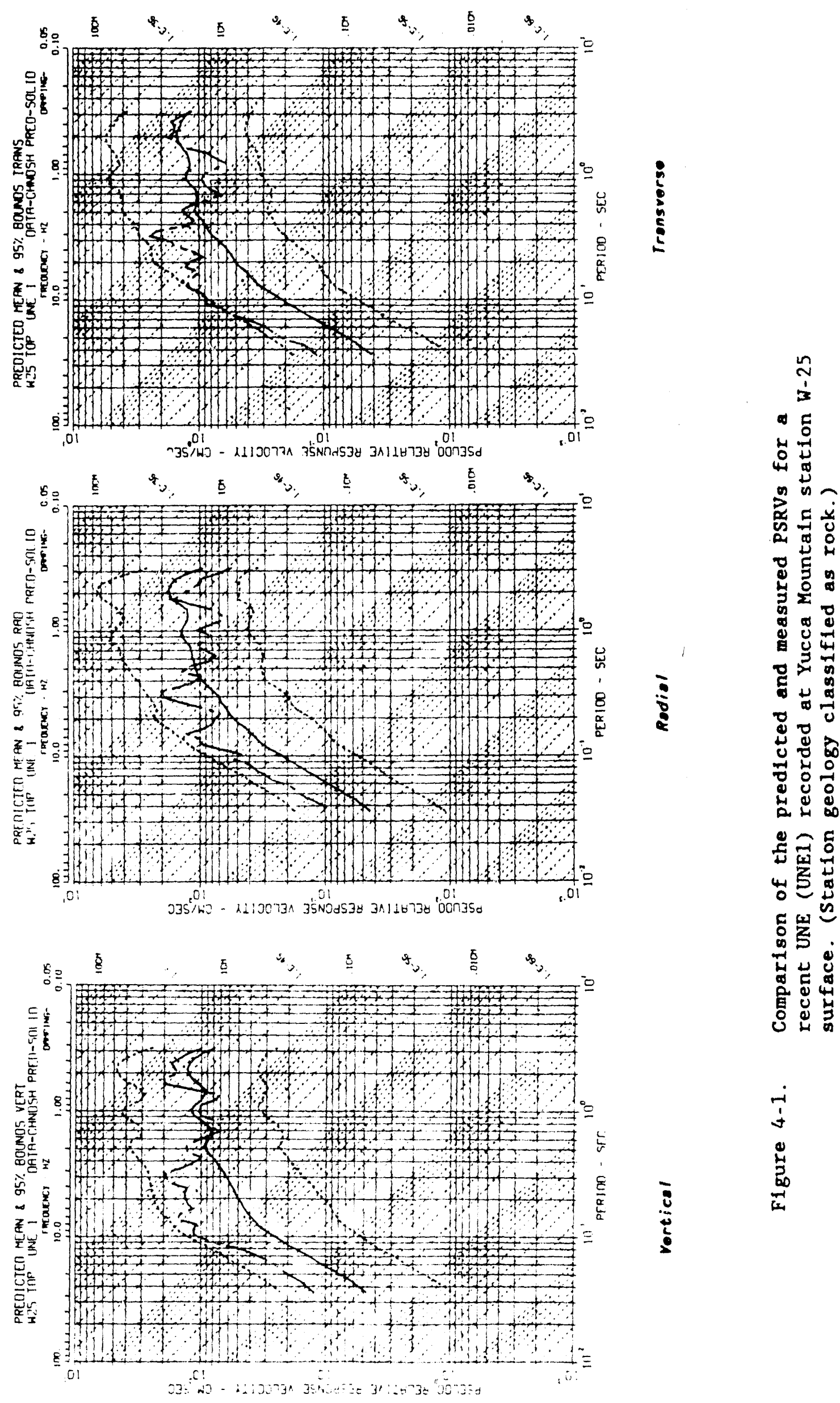

$\underset{j}{-1}$ 

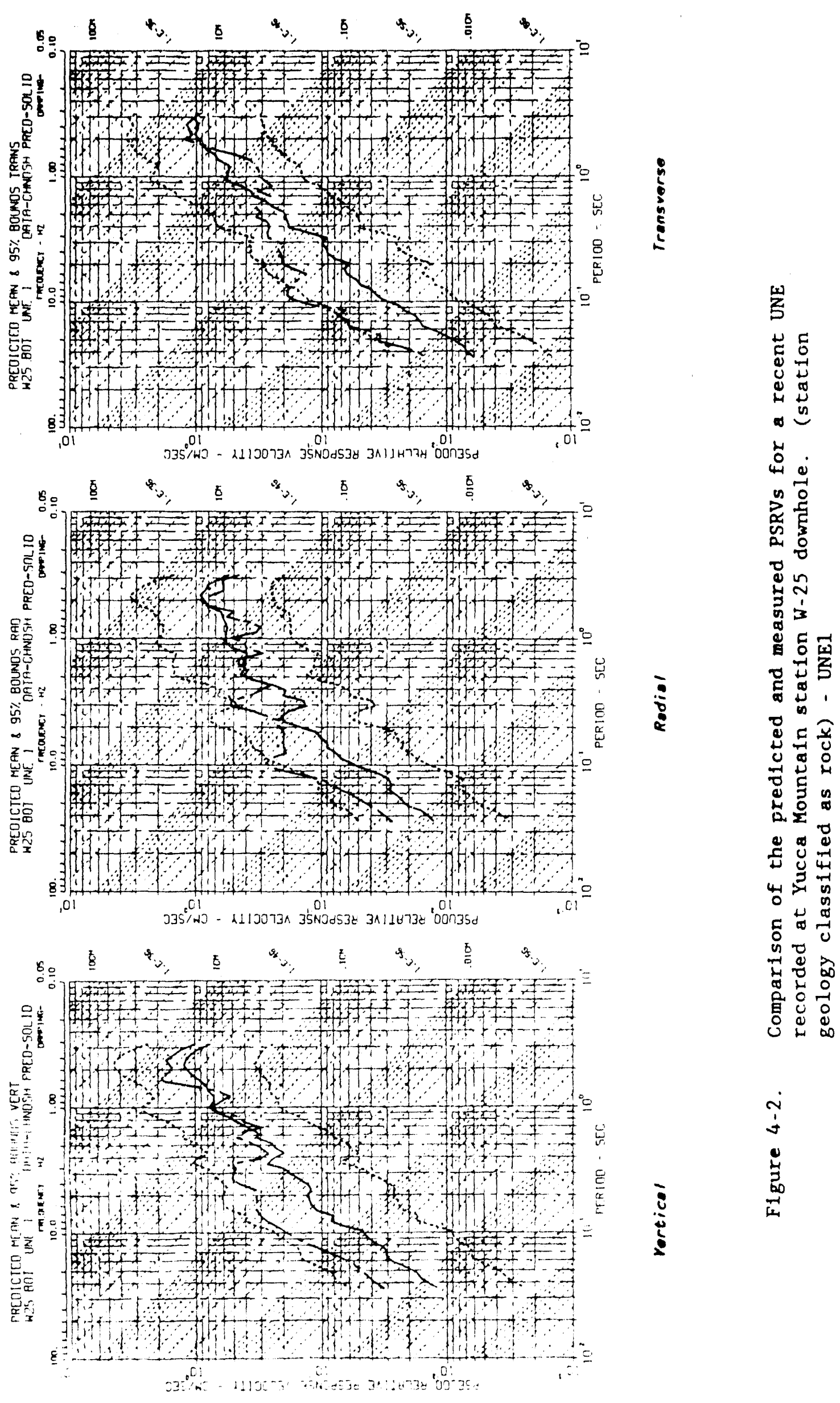

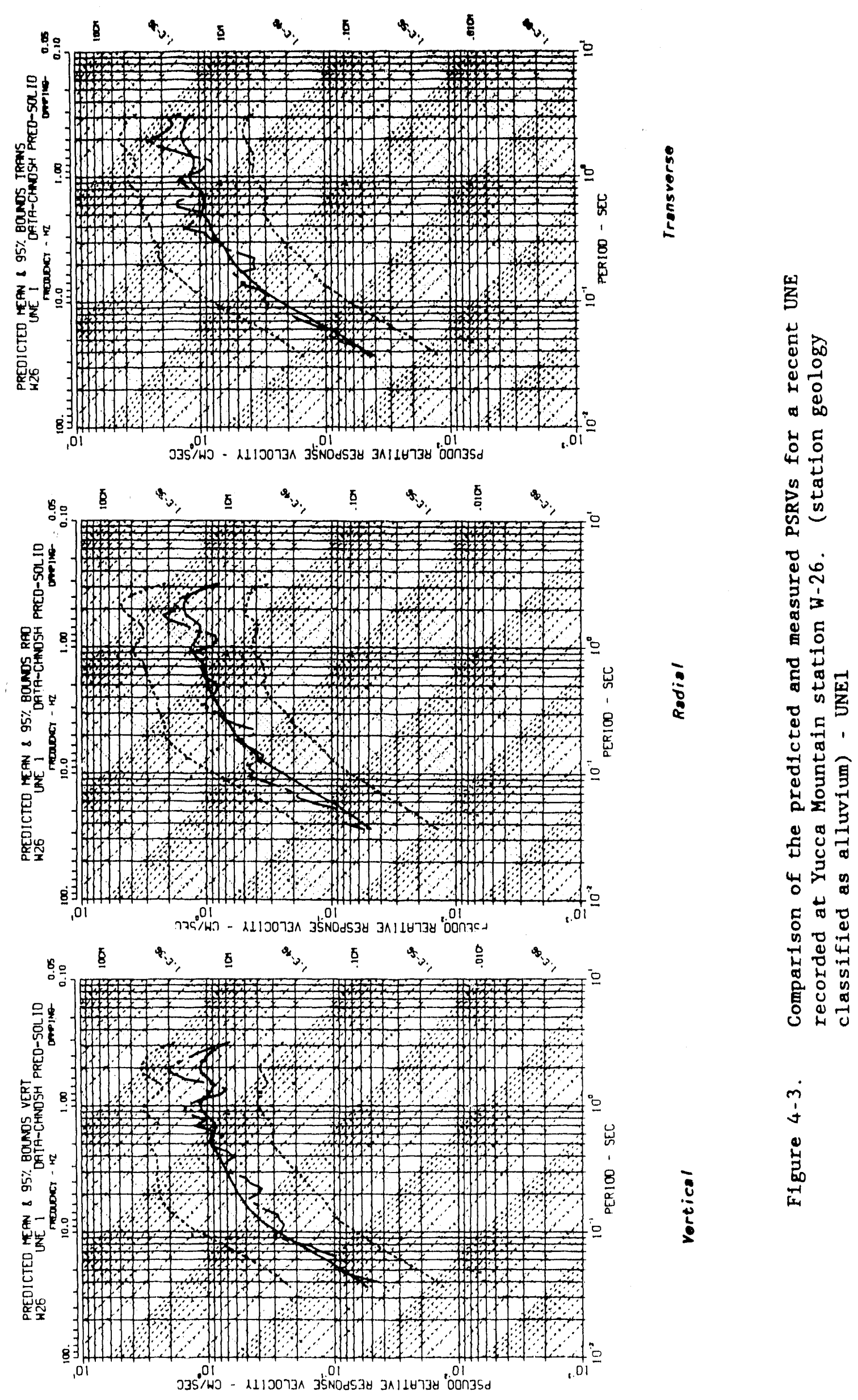

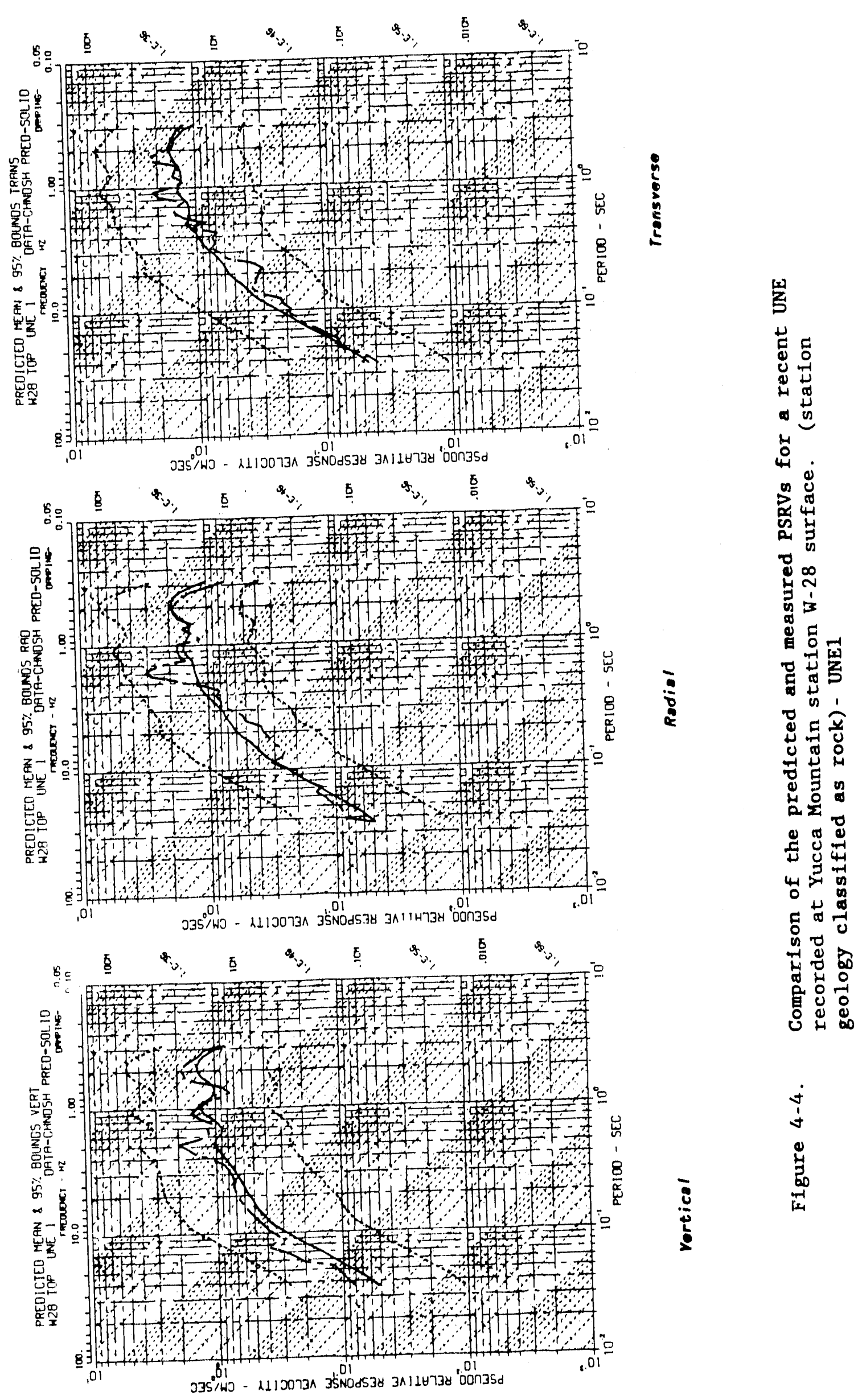

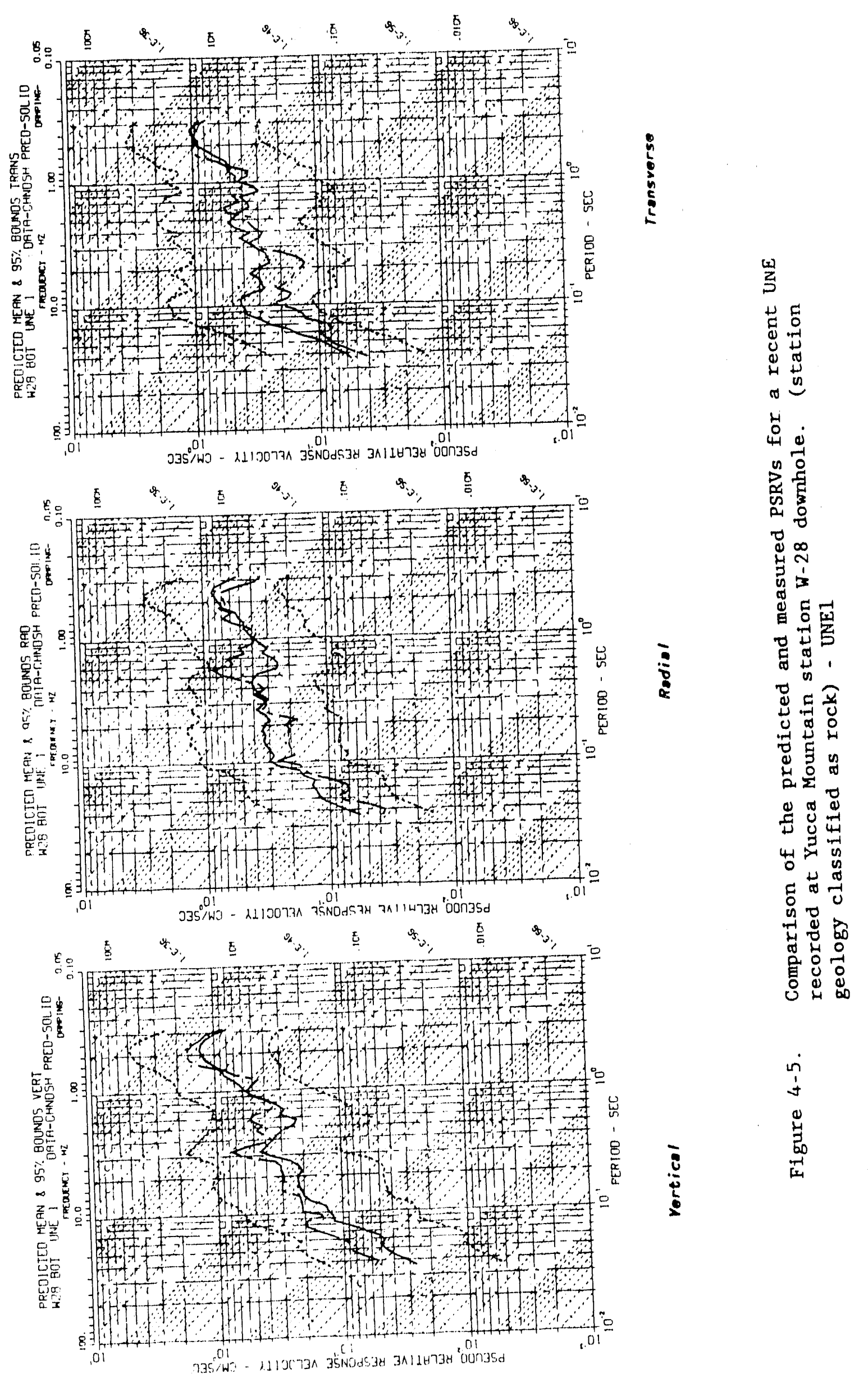

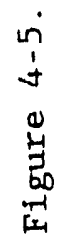



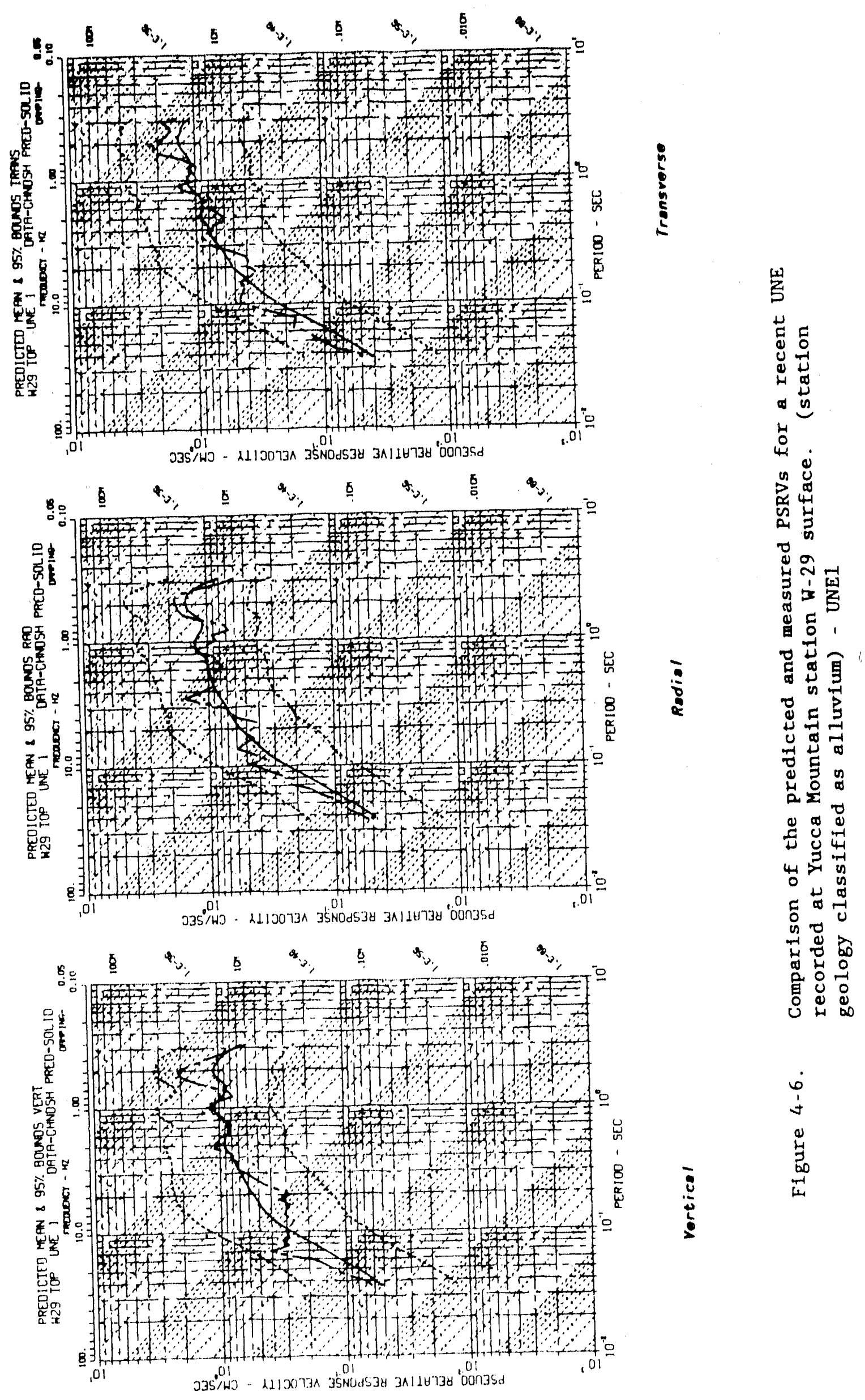

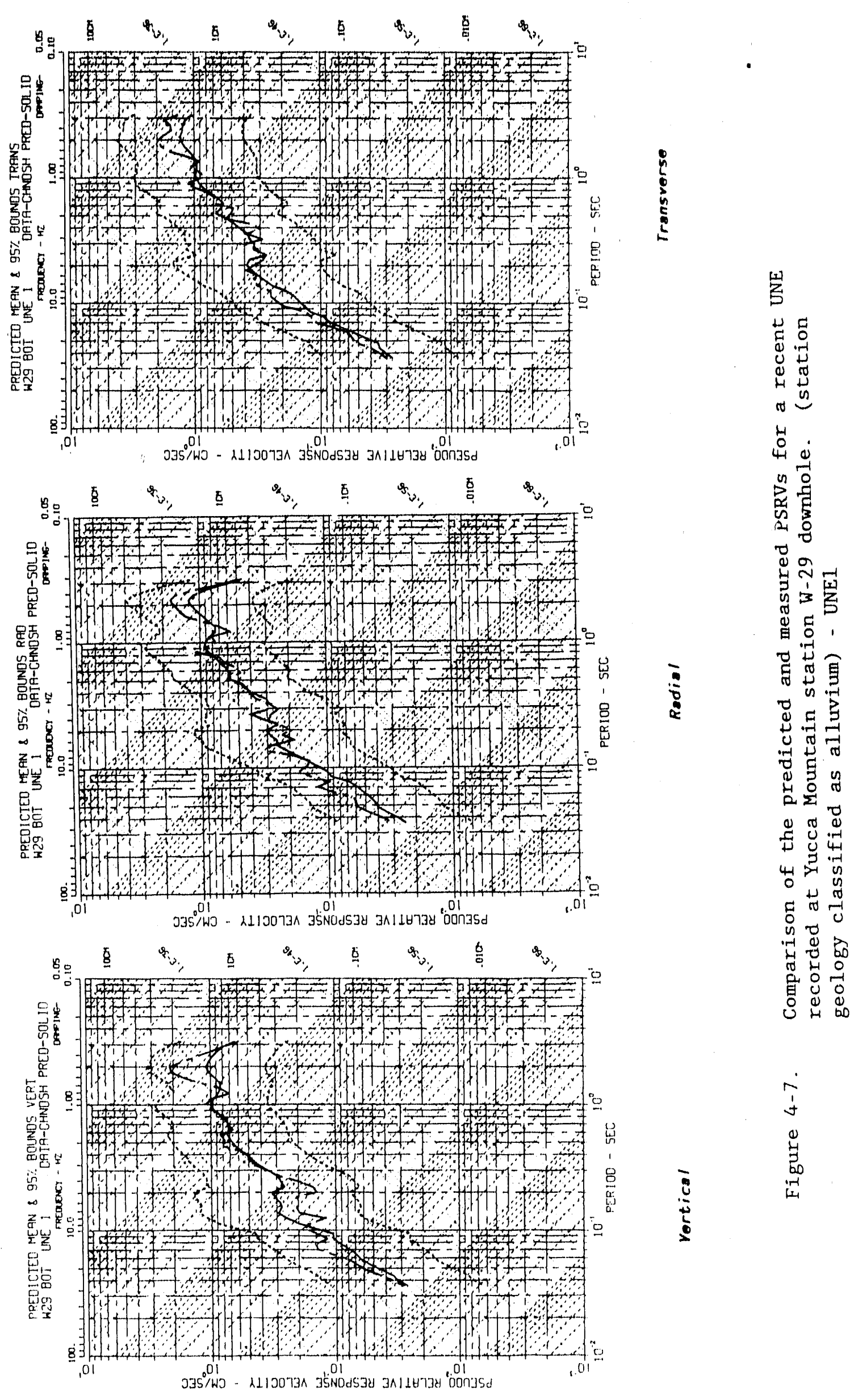

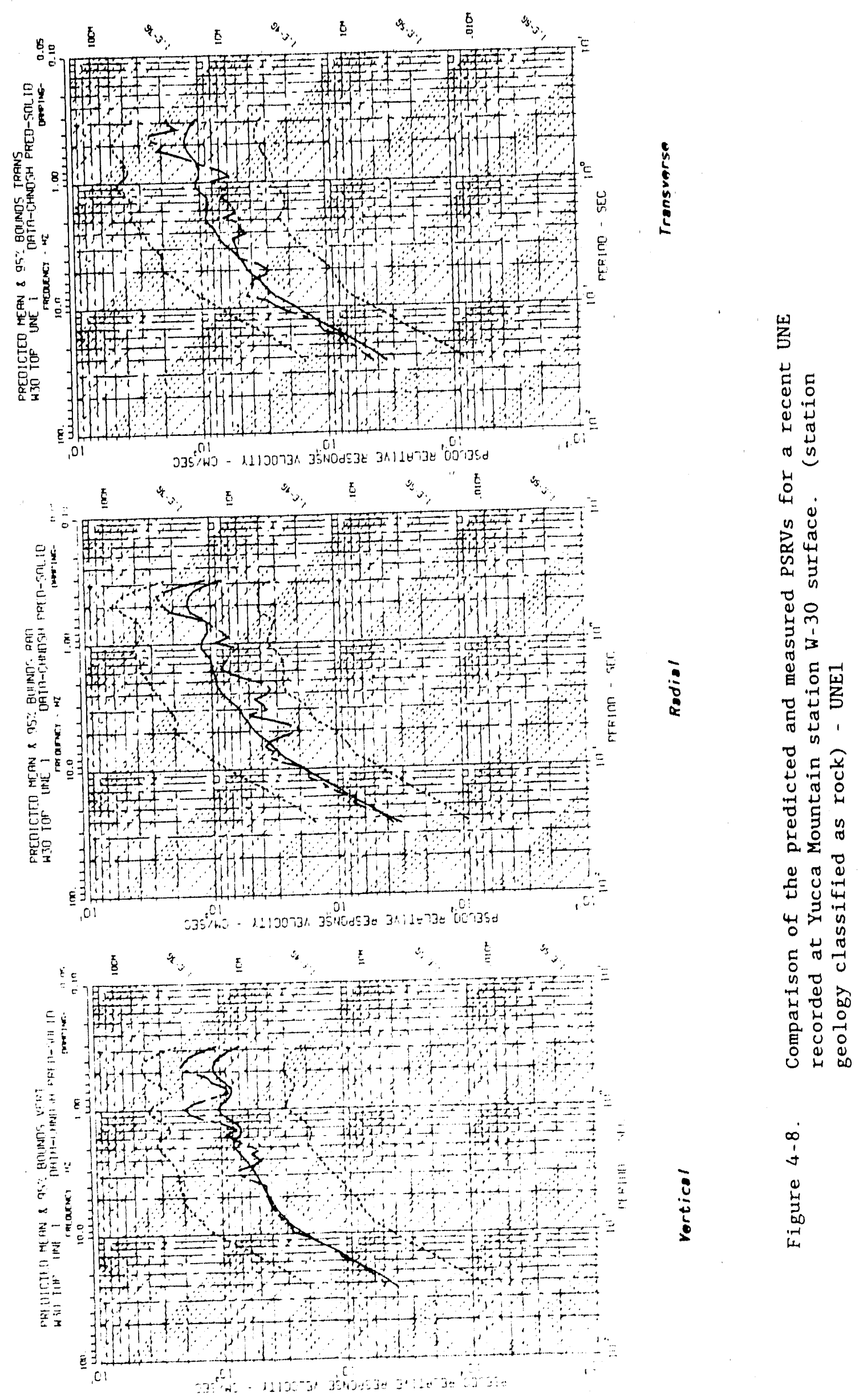

$n$
$\vdots$
$c$
$c$ 

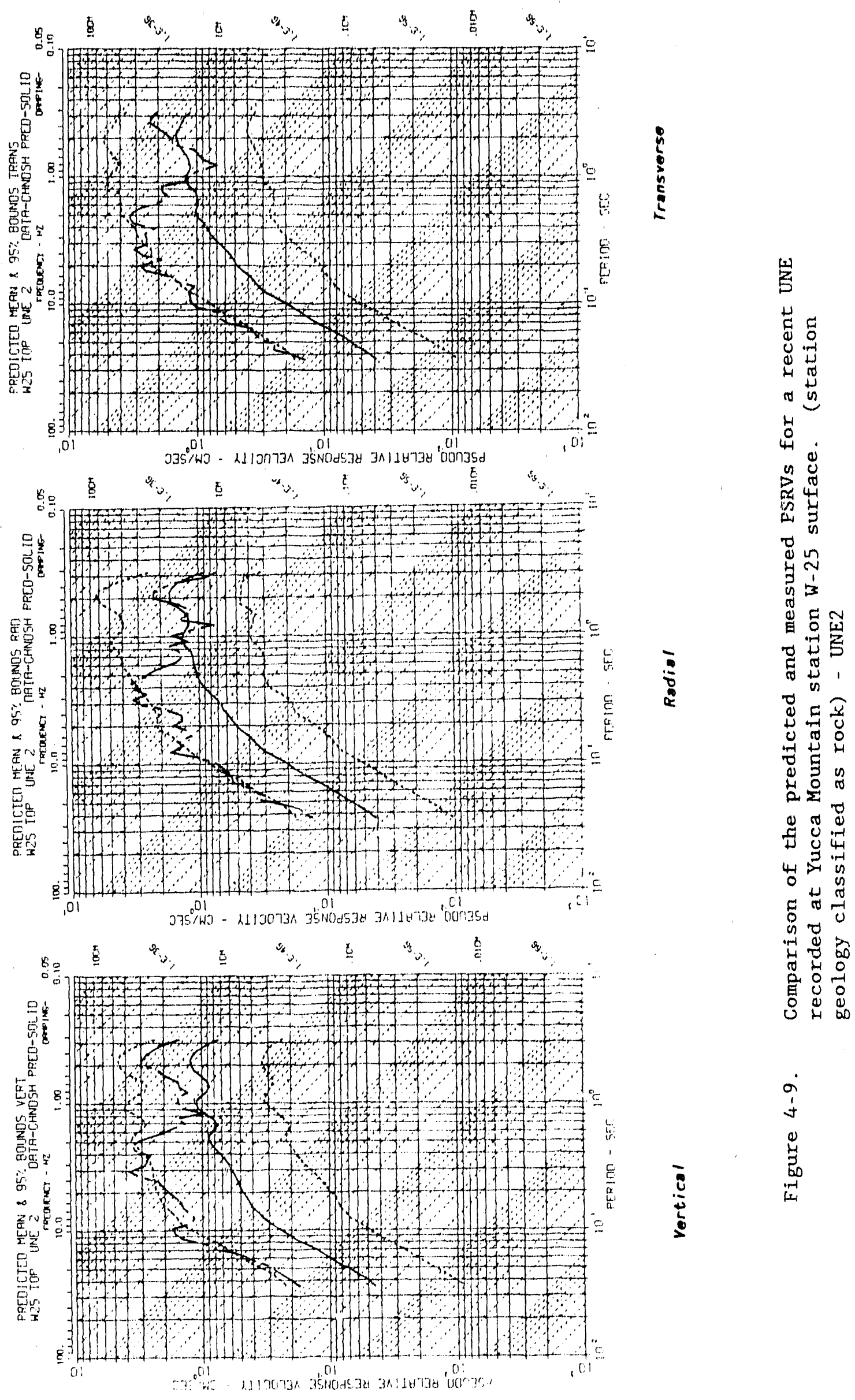


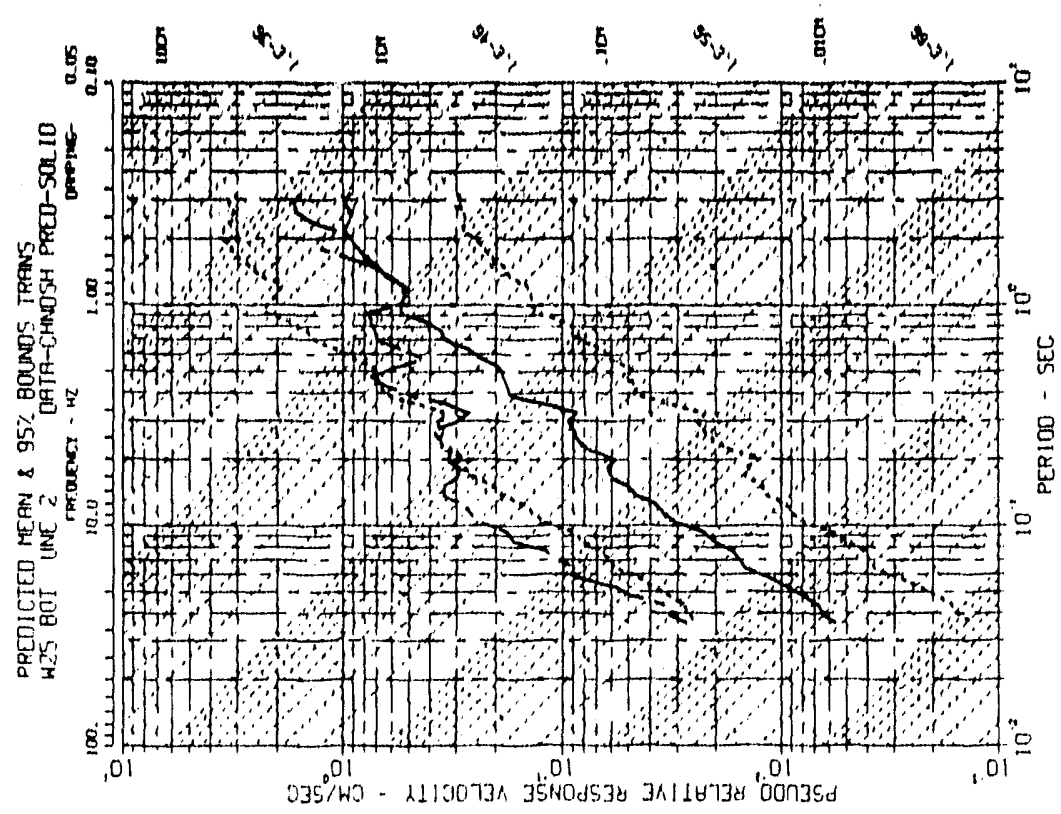

$\frac{n}{5}$
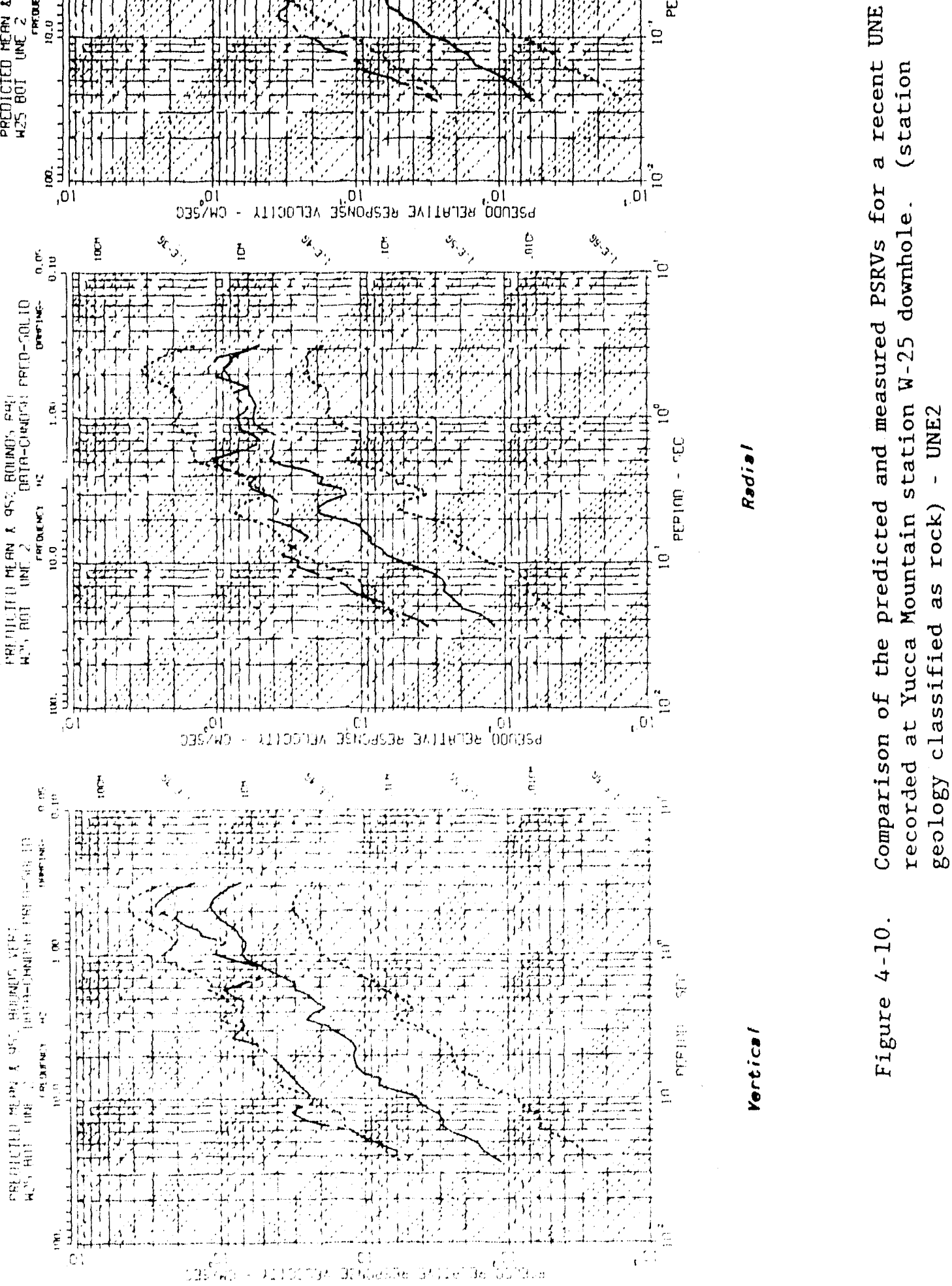

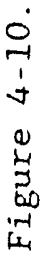



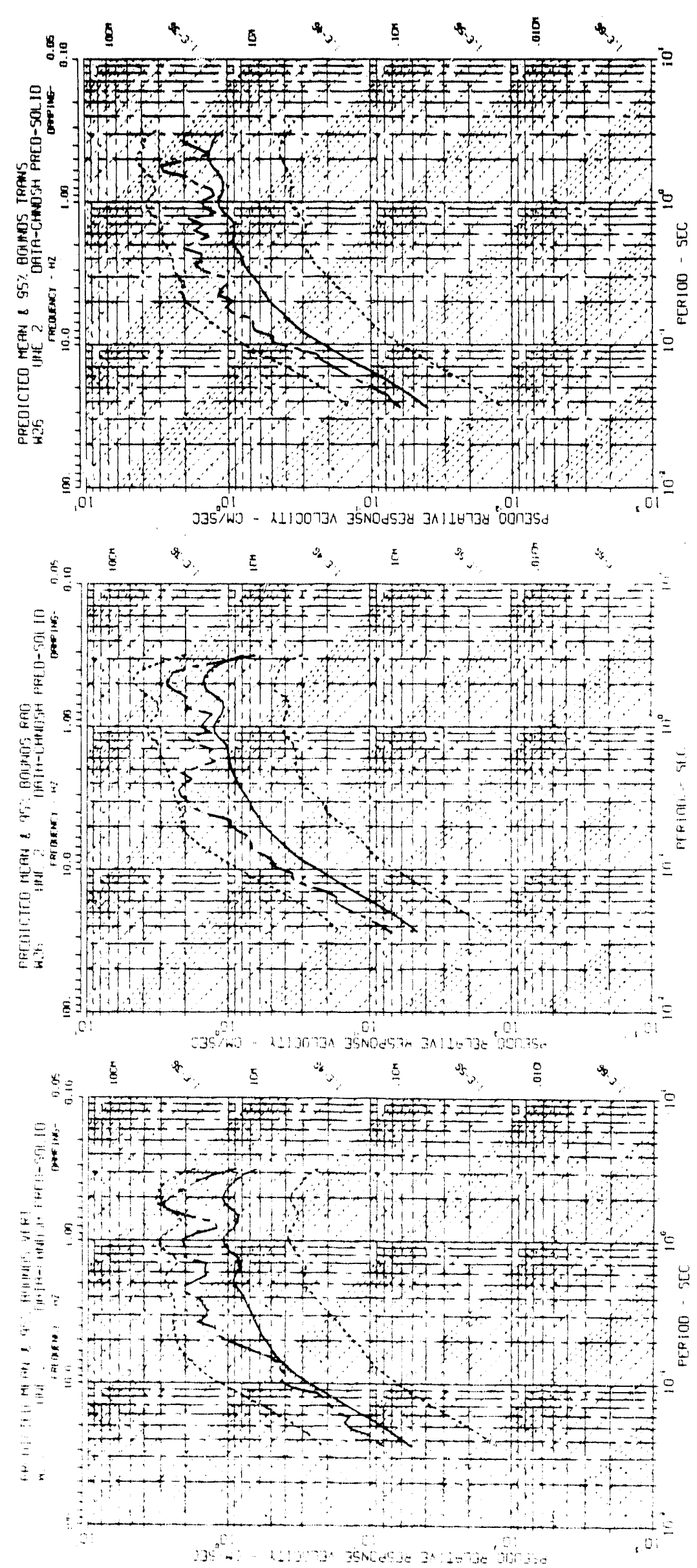

잉

站 $\frac{1}{3}$ 

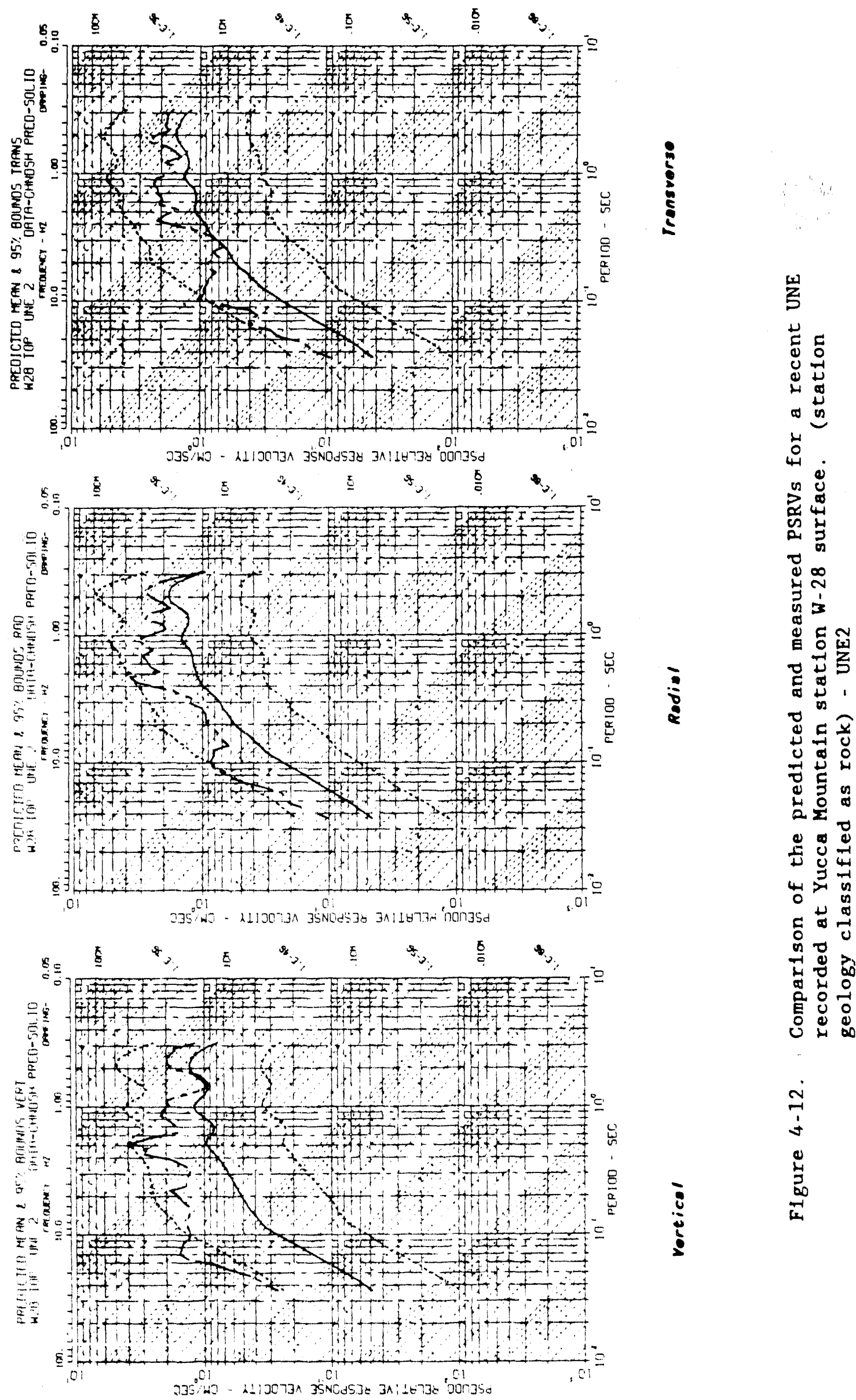

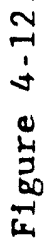



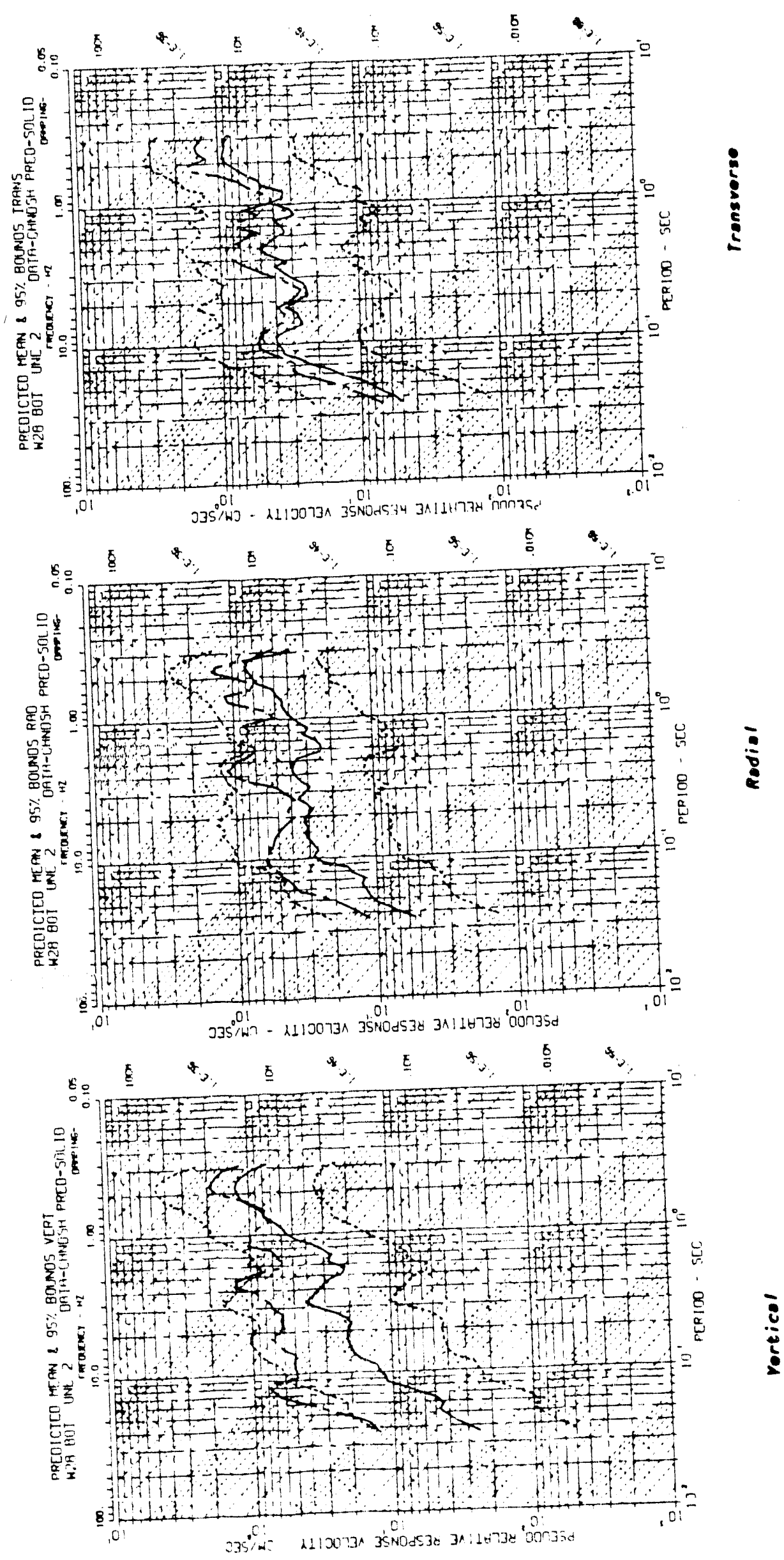

岁

0 10 - 

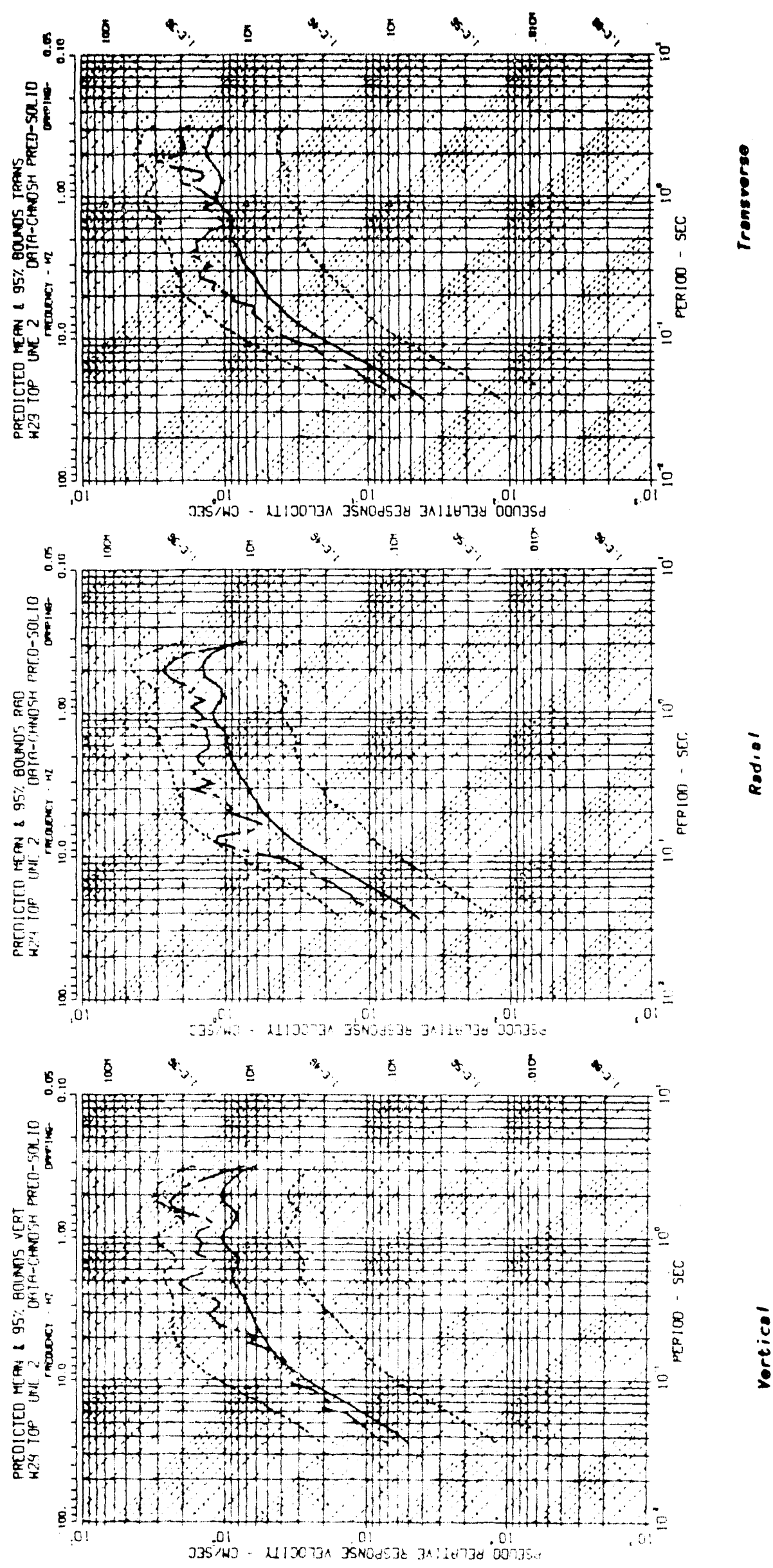

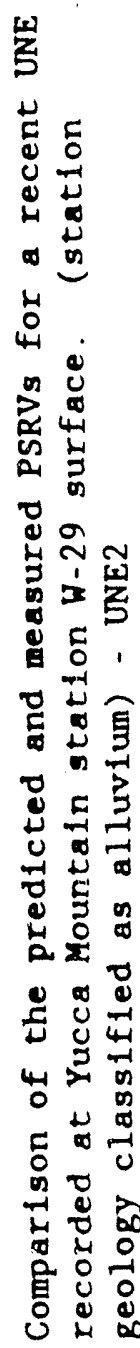

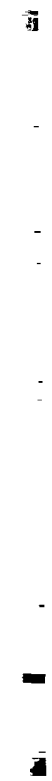



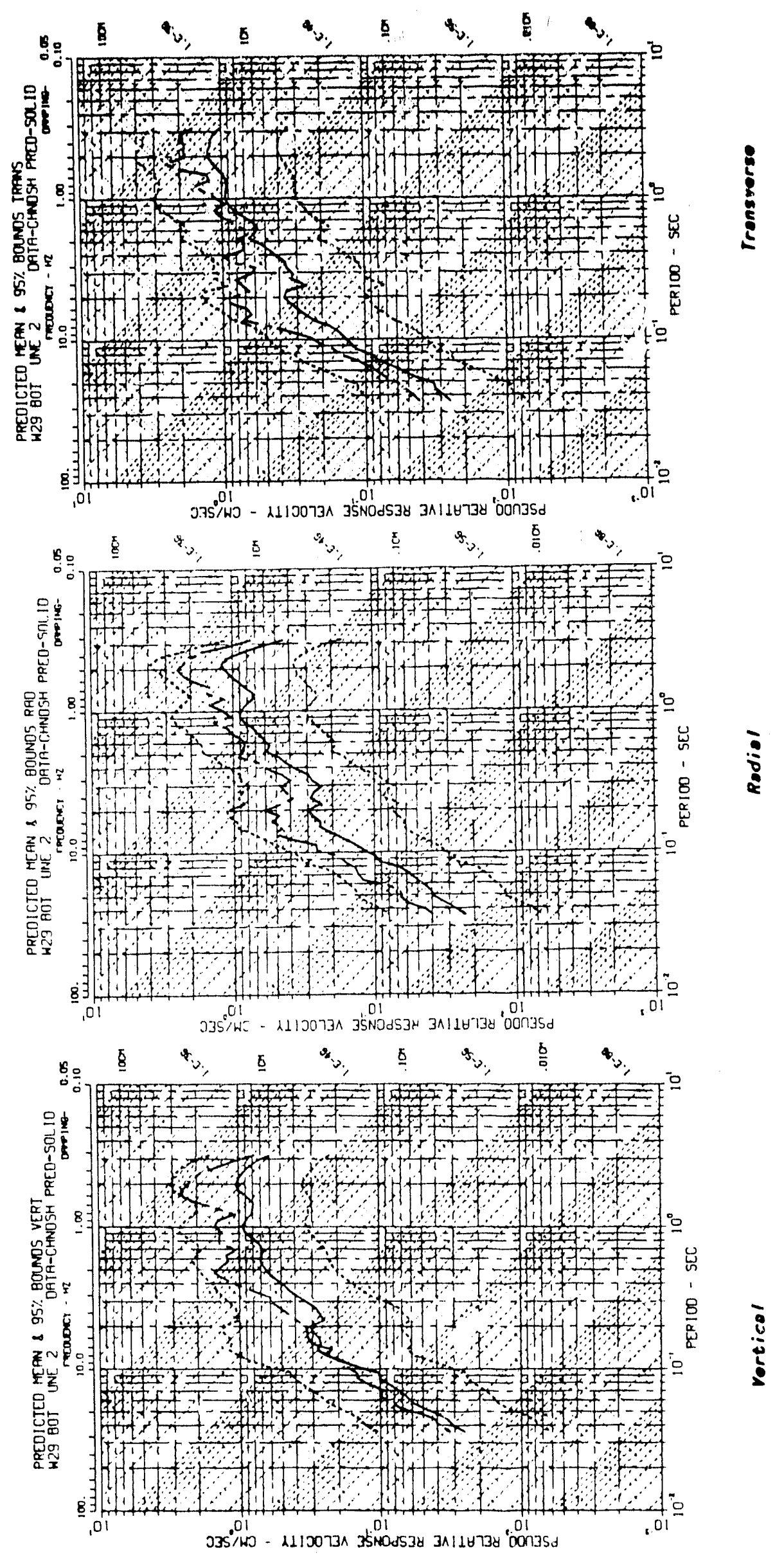

恣

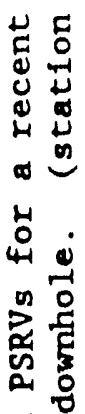

do

곡 ิㅗㄴ

忽方点

总焉

o

足

ํㅝㅁ

岂远

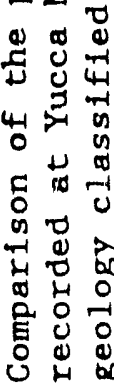

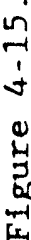



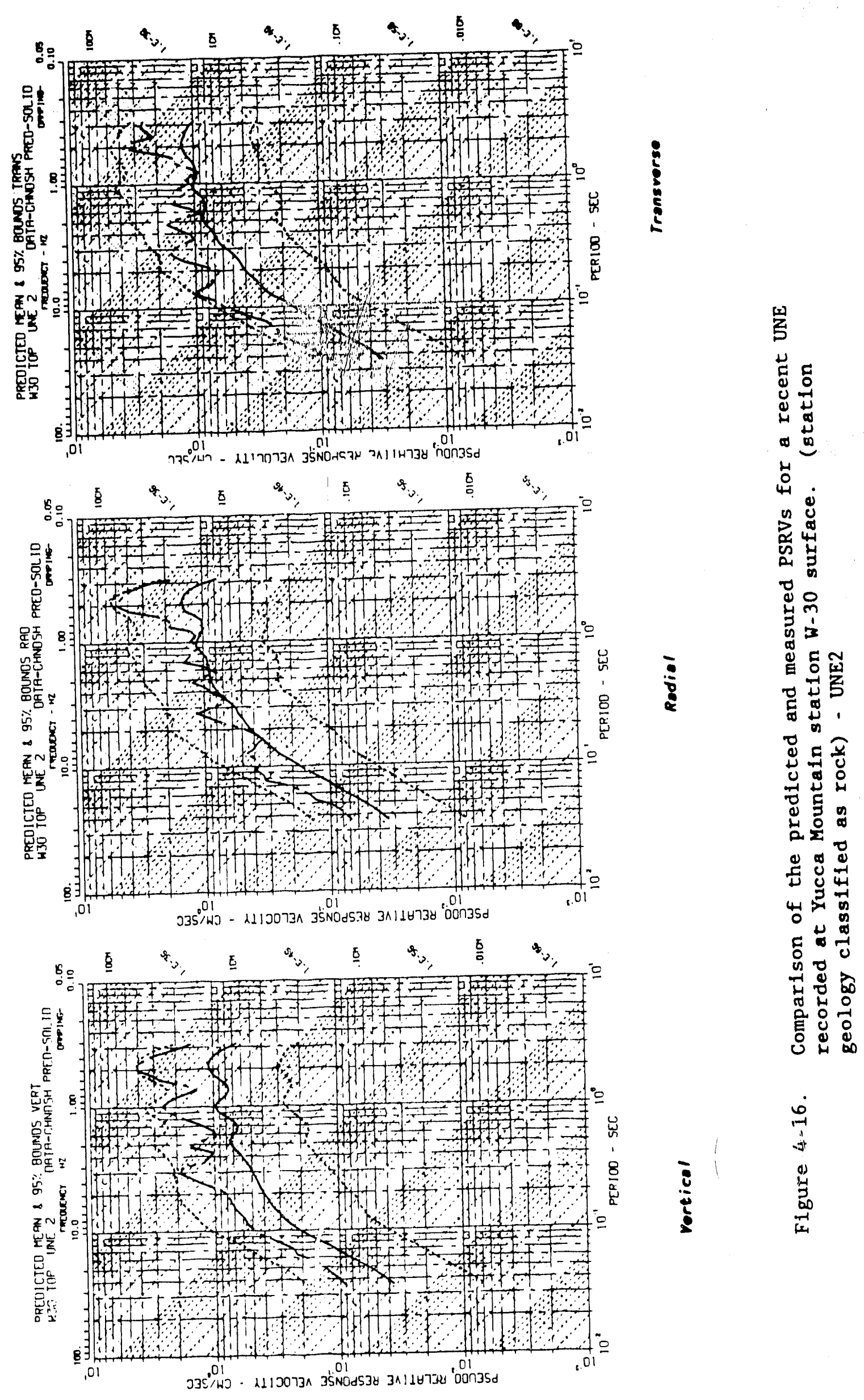
The third event used for evaluation of the prediction equations was also a recent event. The comparisons of the predicted and measured values are shown in Figures 4-17 through 4-24. As in the other comparisons, the measured ISRVs always fall within the $95 \%$ confidence interval on the prediction. In genera1, the predicted surface PSRVs compare favorably with the measured PSRVs. Downhole PSRVs at Stations W25 and W29 (Figure $4-18$ and $4-23$ ) are fairly wel1 predicted. The downhole behavjor at W28 (Figure 4-21) was poorly predicted. Inspection of the time histories racorded at this station for this event revealed that the surface and the downhole ground motions were essentially the same amplitude for the entire waveform for all three components. Downhole ground motions observed at this station have shown an amplification in radial and transverse components at the higher frequencies of $8.20 \mathrm{~Hz}$ (Philitips, 1987). The behavior observed in this event is different in that it affects all. components for all frequencies. The field and digitiuing records for this station have been checked and the data are apparently correct. This behavior is curious and will receive further study. It should be remembered that an empirical prediction will predict the "average" event. A substantial deviation from the average will not be accurately predicted by the empirical method.

The overall conclusion from these comparisons is that the prediction procedure for PSRVs produces reasonably accurate predictions for this event.

The fourth UNE used for the evaluation of the PSRV prediction procedure was an older large yleld event ( $>500$ ) event with a station at a distance similar to the design basis UNE. This comparison is shown in Figure 4-25. The symbols and format of this figure are the same as defined for the previous figures. The same general conclusions made above for the recent events are noted here (note the PSRV amplitudes are an order of magnitude larger than those shown in previous comparisons). The prediction procedure developed fol: PSRVs is reasonably accurate.

The objective of this effort was to develop a credible empirical prediction technique for PSRVs from underground nuclear explosions. An empirical prediction consists of a west estimate (a measure of the average of a collection of data) and an estimate of the uncertainty (standard deviation) on that estimate. The measure of the credibility of a prodiction procedure is how well the predicted values (both best estimate and uncertainties) compare to the measured values. The comparisons shown in this section indicate that, for the most part, predicted values compare reasonably well with the observed values. In most cases the observed PSRVs are within the 95 o confidence intervals on the best estimate. The data base used to develop this procedure had a larger number of low-yield events than high-yield events. Some effort was made to use as many high-yield events as possible in the data base to avoid biasing the prediction procedures to these low-yield events. The lact that the procedure works as well for the low-yield event at the larger distances ( 40 to $50 \mathrm{~km}$ ) as it does for an event similar to the design hasis UNE indicates that this bias has been avoided. 

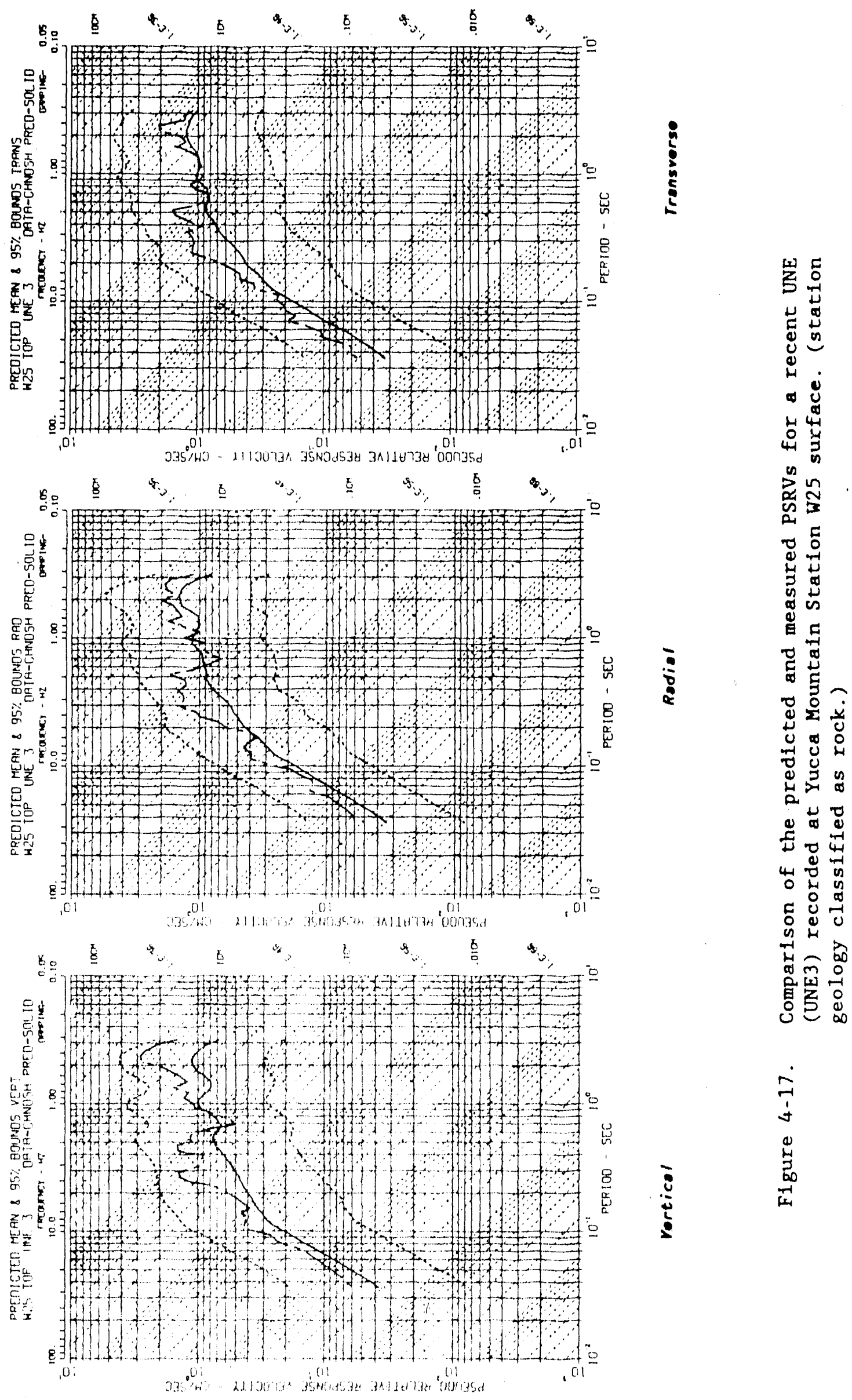

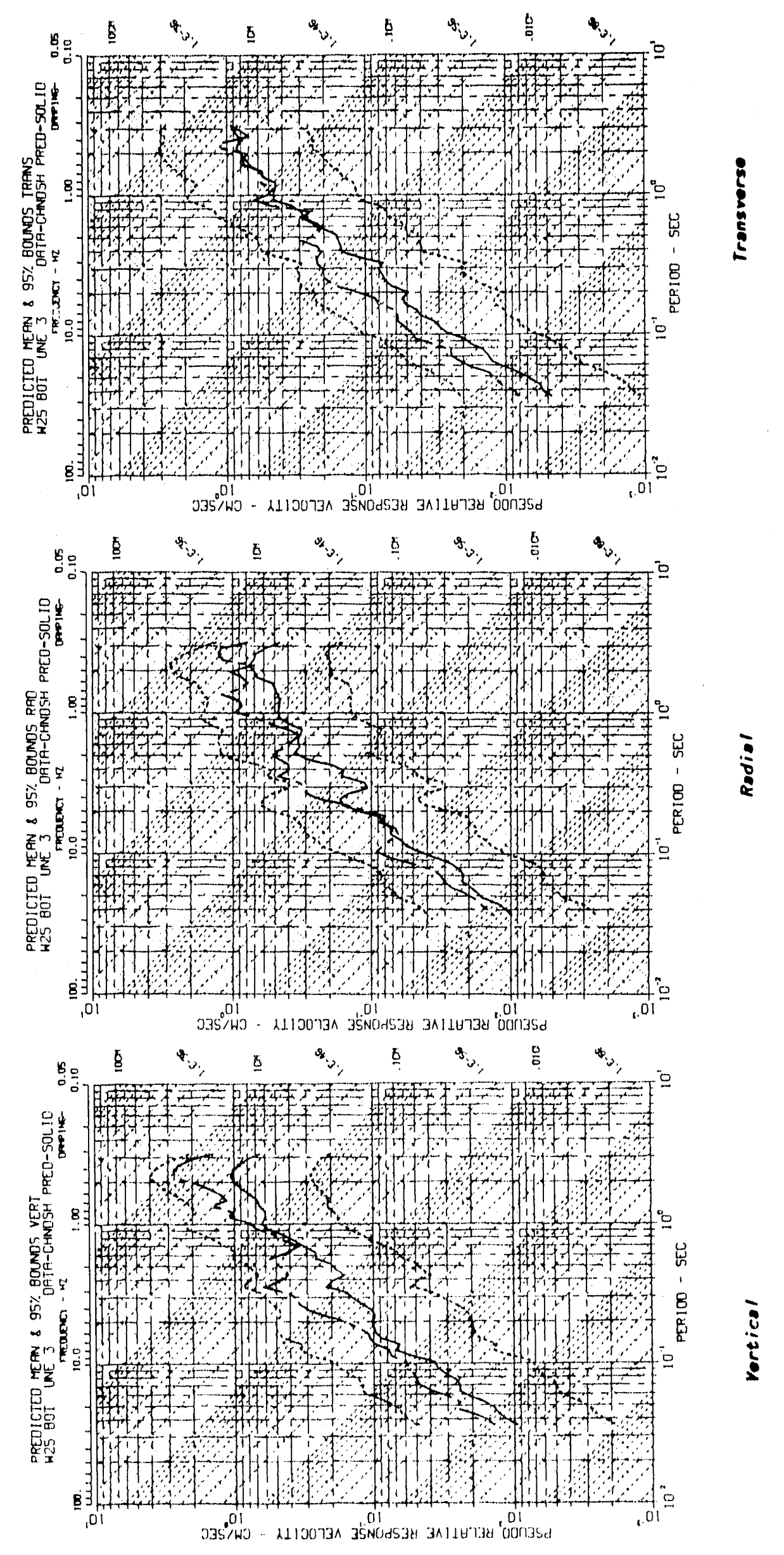

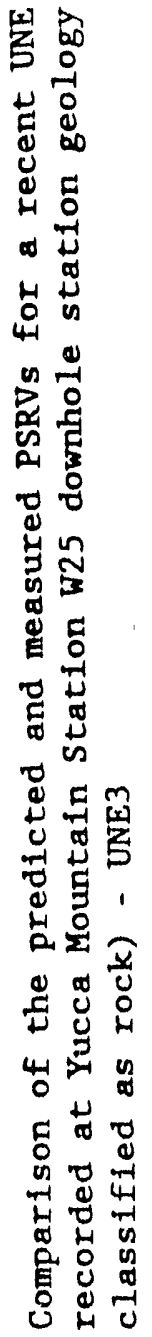

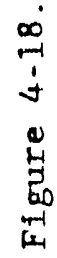



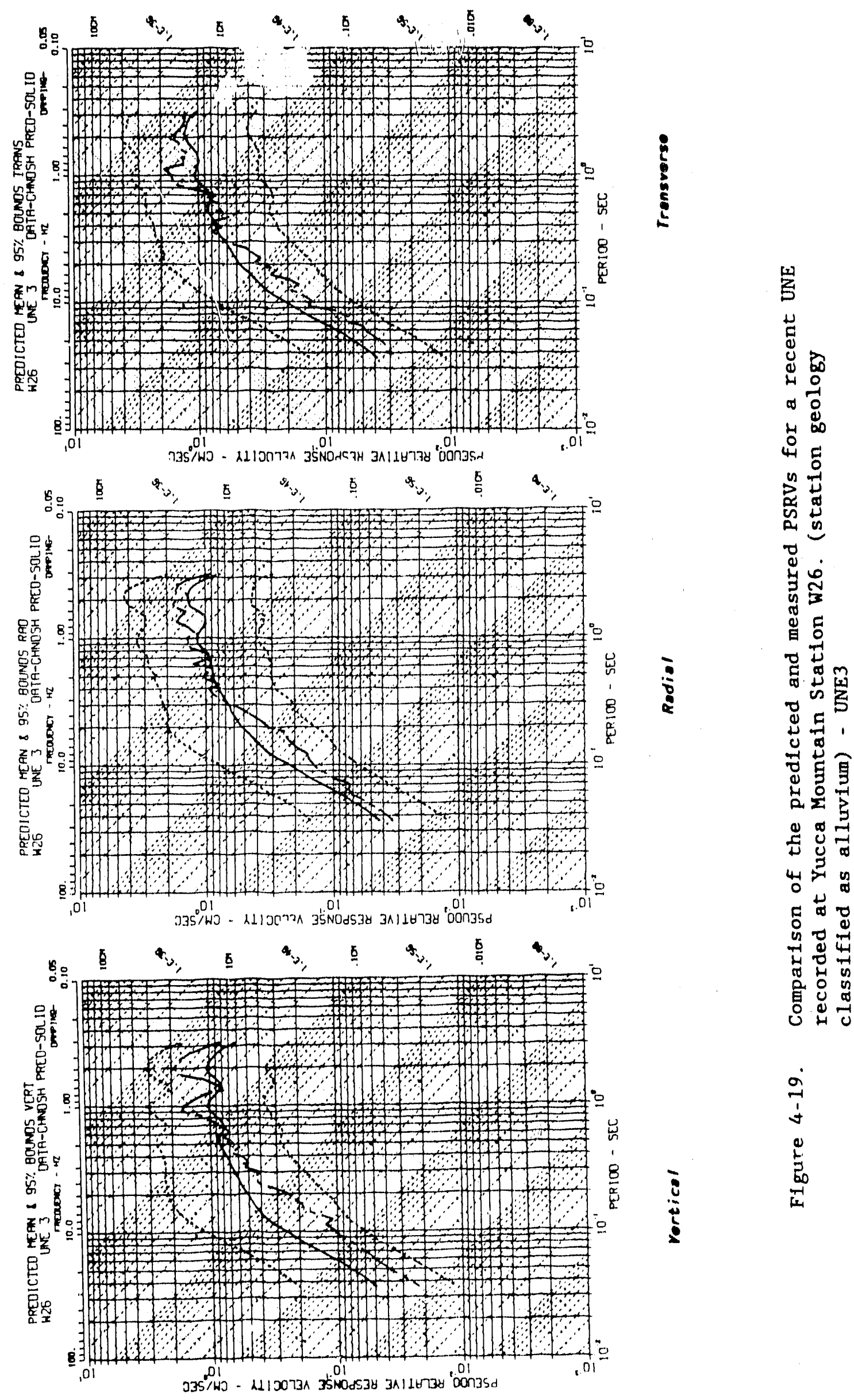

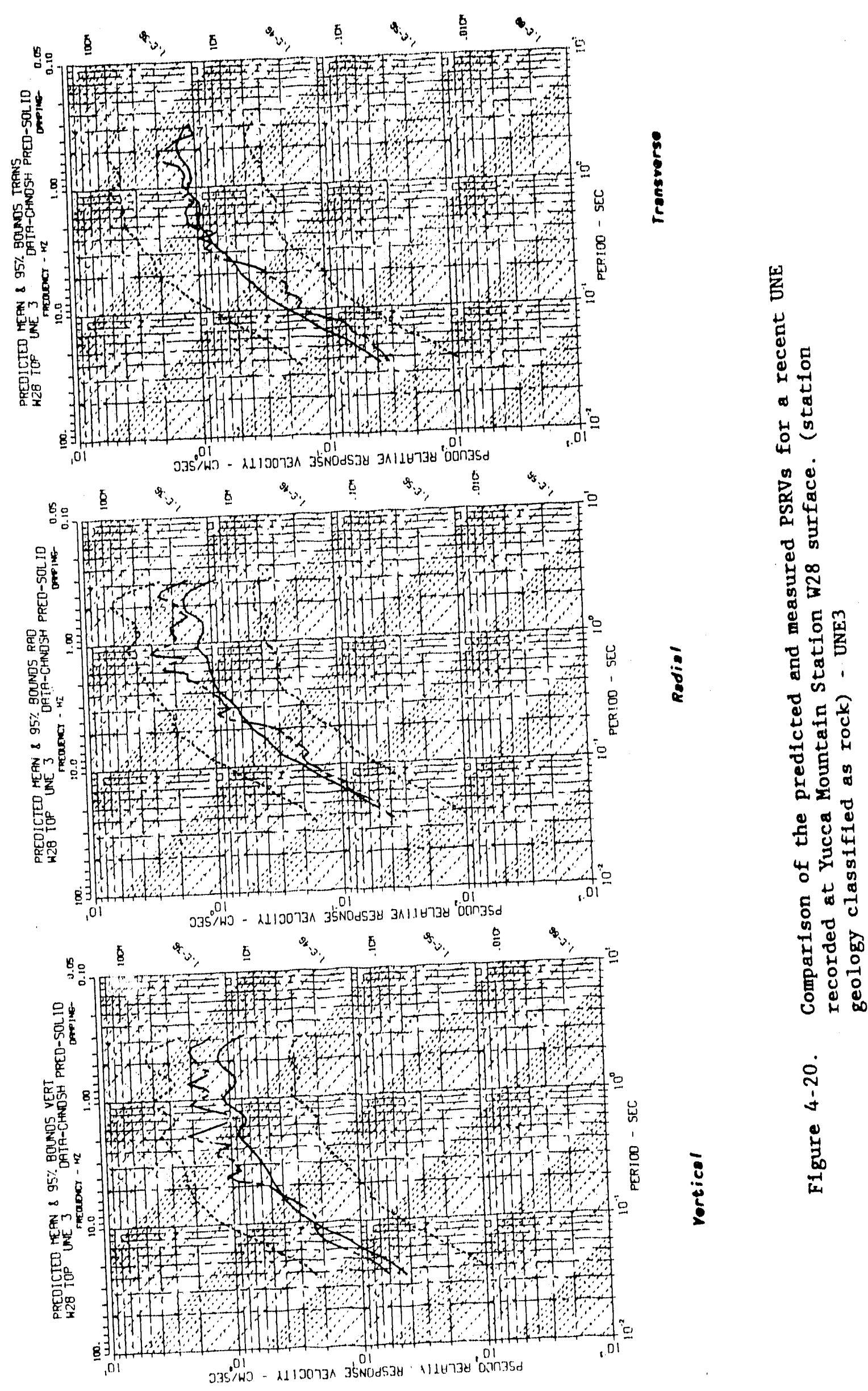

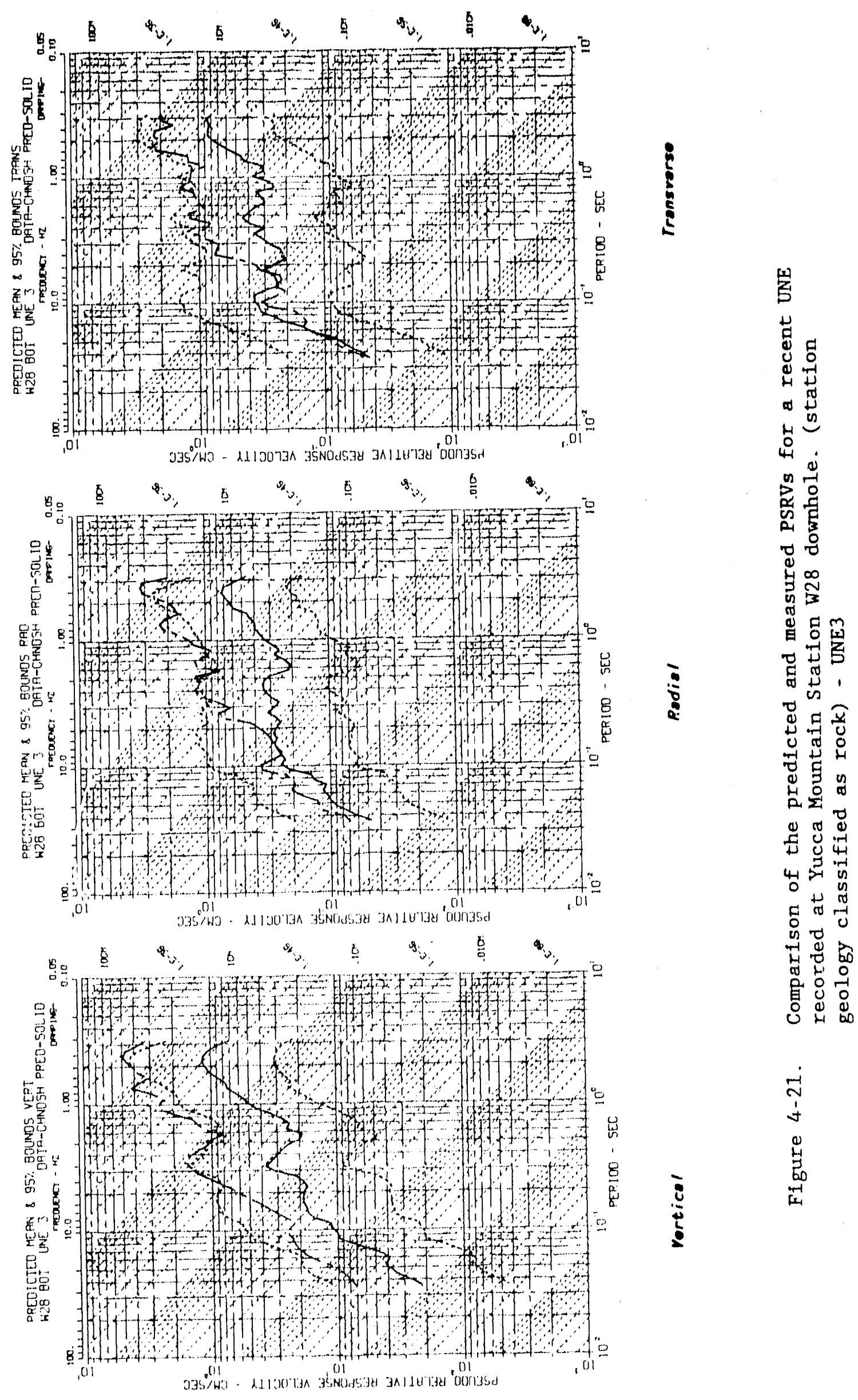

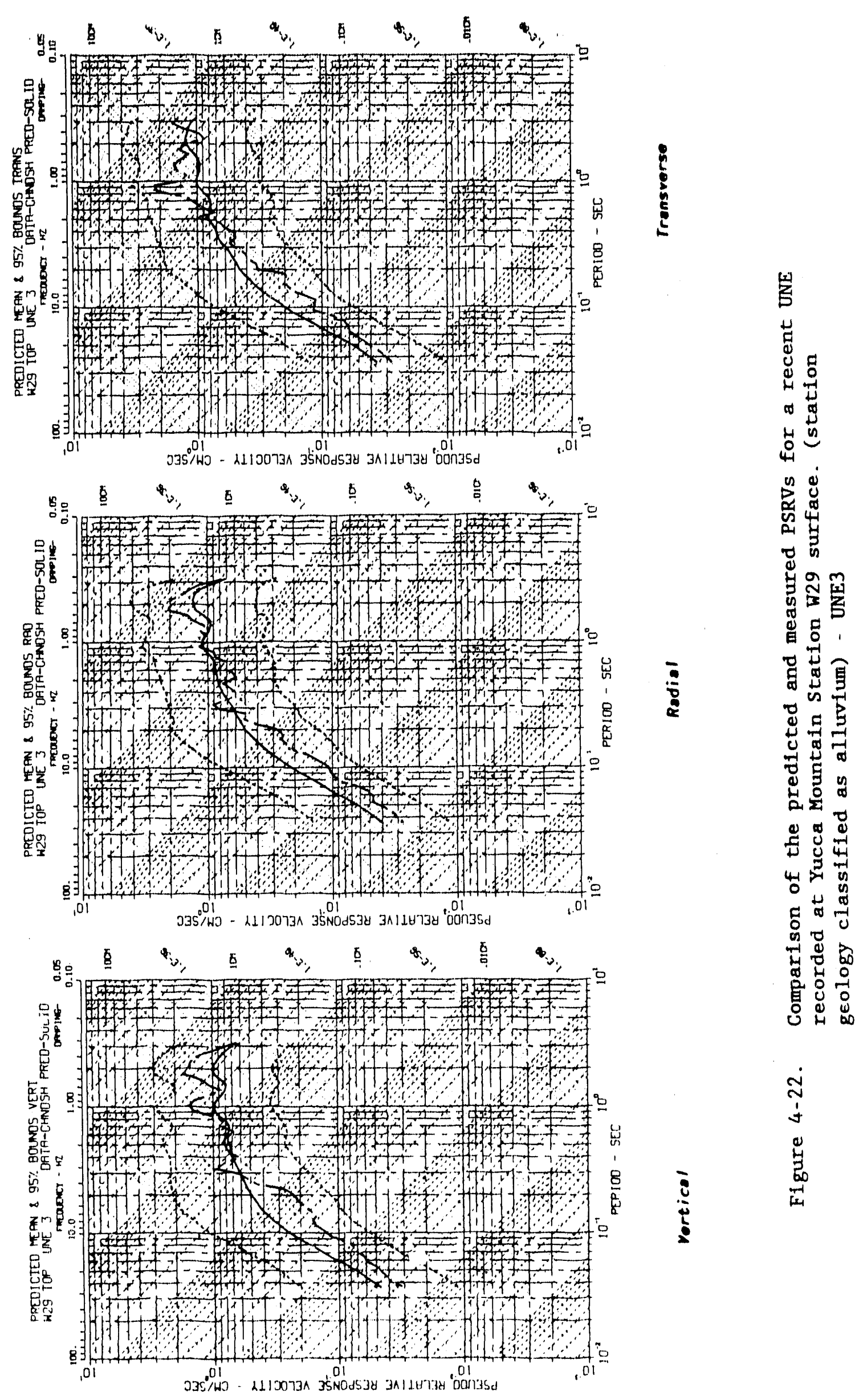

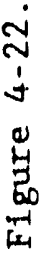



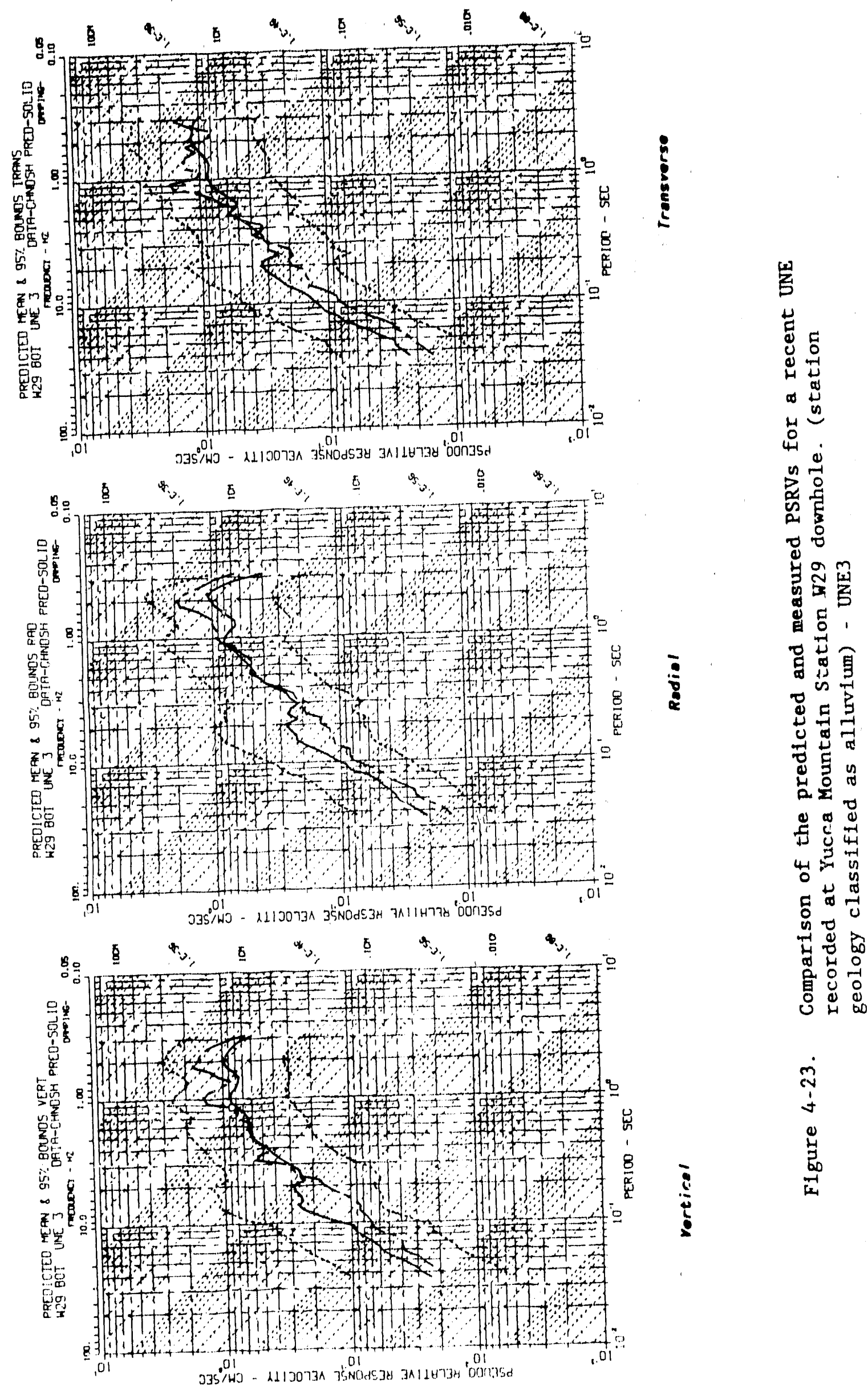

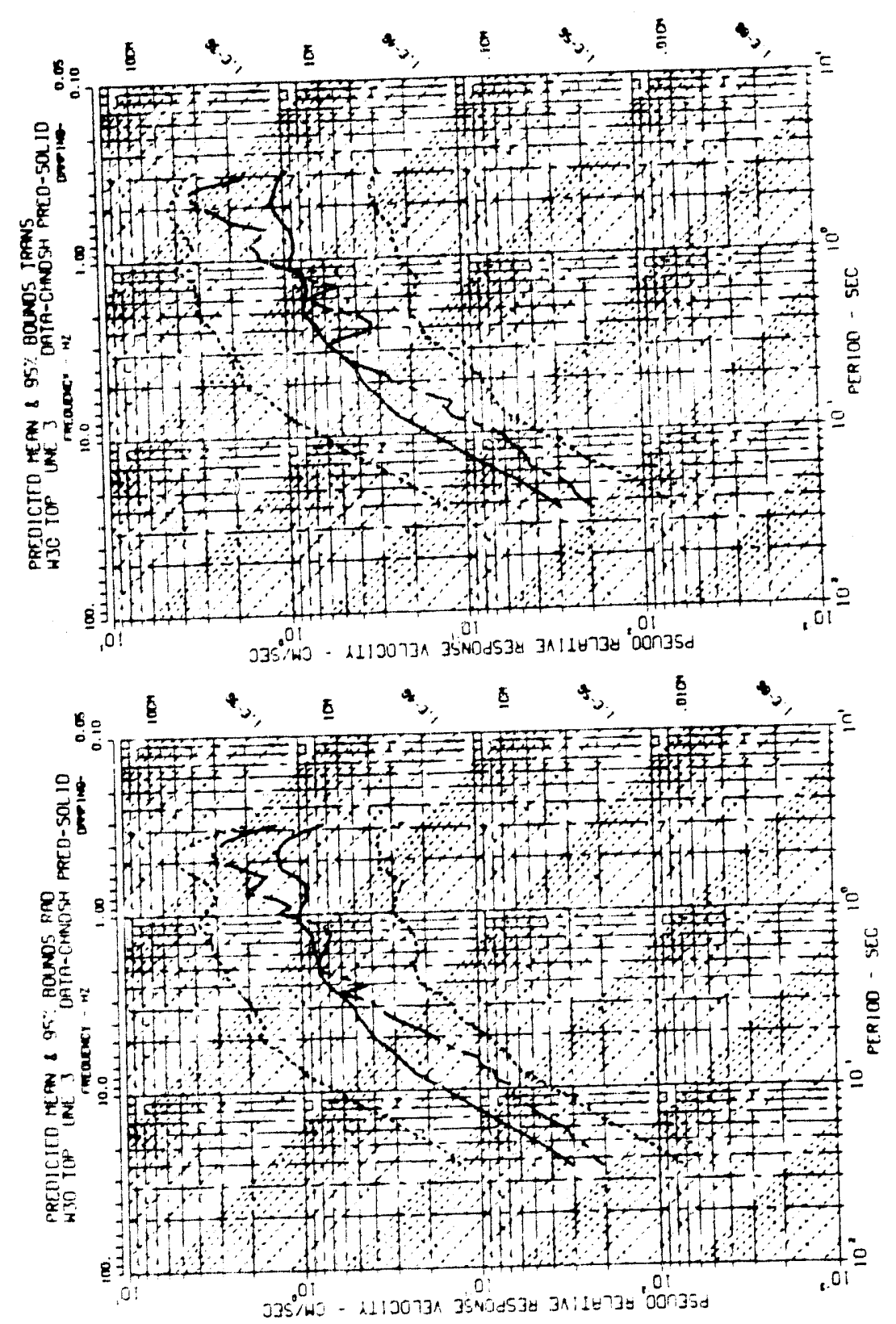

8
5
5
5
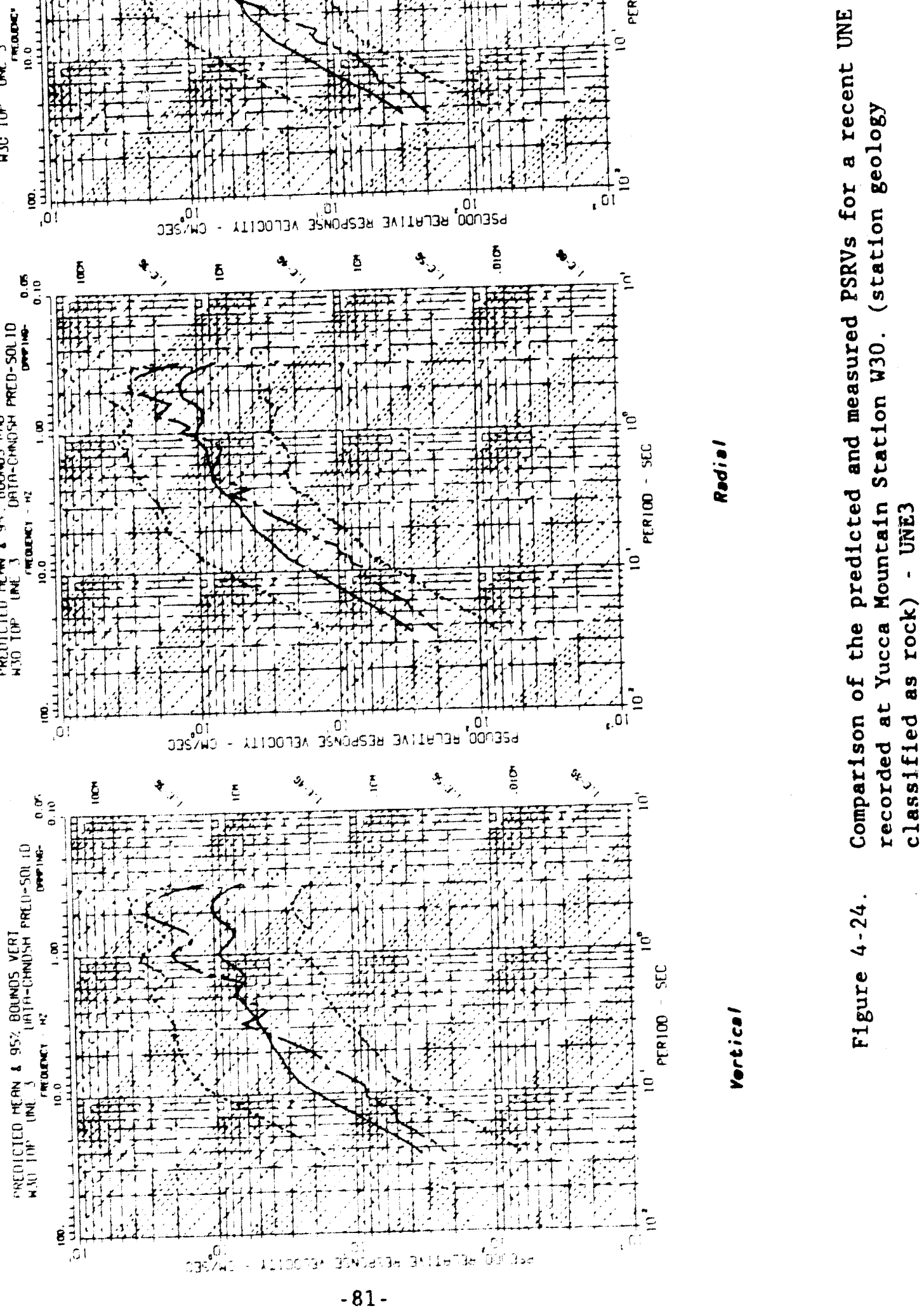

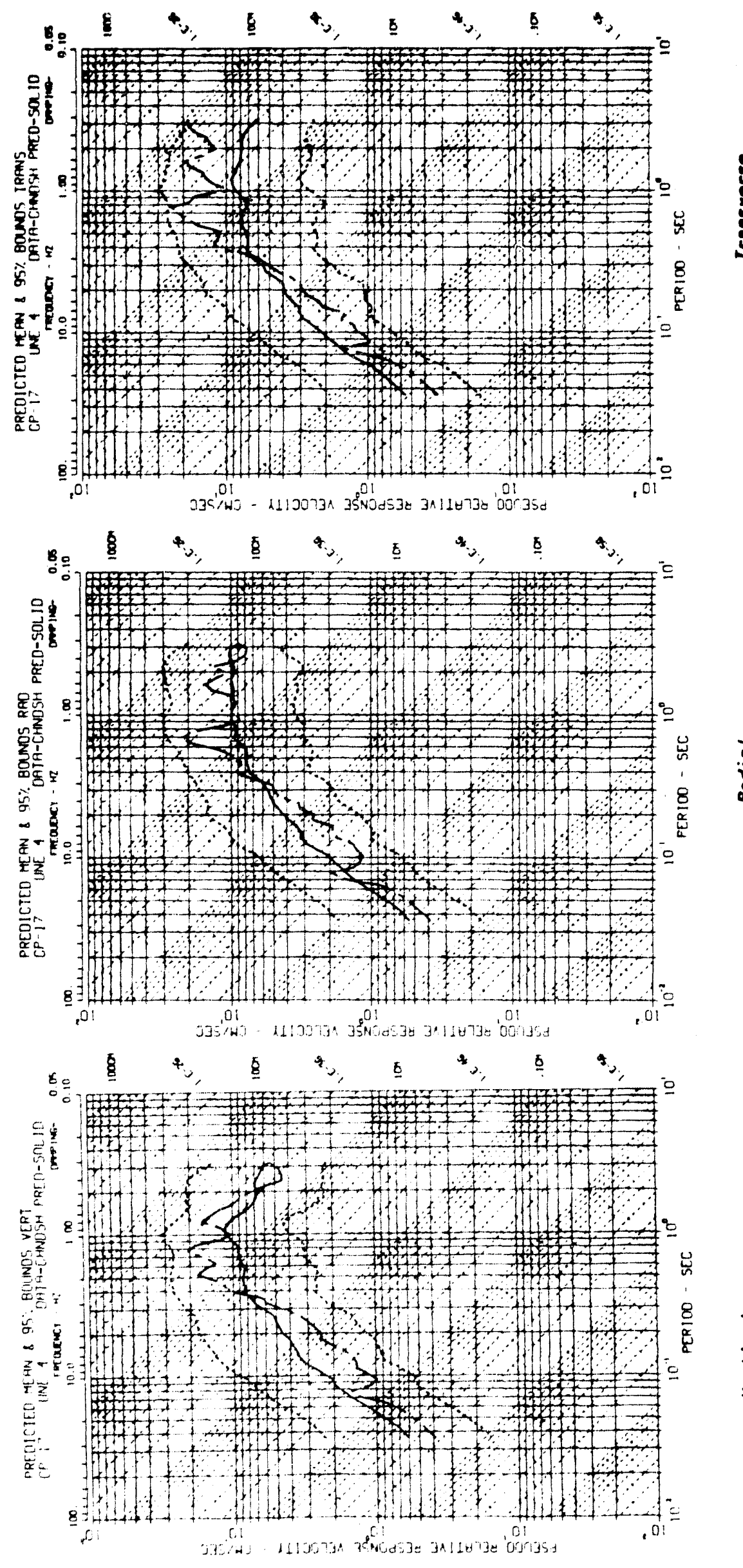

8

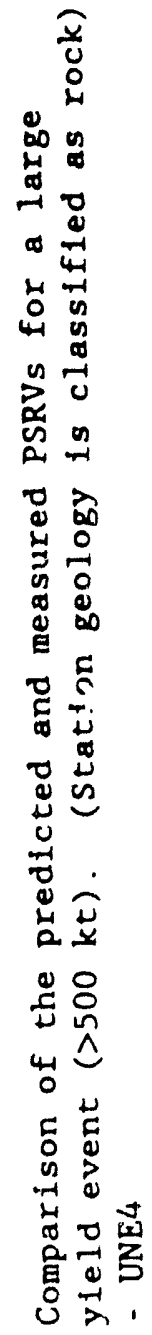

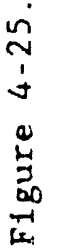




\subsection{Comparison of the Prediction of the Design Ground Motions}

The predicted PSRVs for the design hasis lut ale shown in figure $4-26$. These predictions were performed for a rock geology. To provide a frame of reference, the design earthquakes determined in an earlier study of ground motion at rucca Mountain (URS/Blume \& Associates, 1986) are also shown on this: figure. These earthquakes were determined via probabilistic mothods. inesign Farthquate 1 (DE-1) was based on a return period of 2000 years. The peat: horieontal ground acceleration was estimated to be $0.4 \mathrm{~g}$ and $0.2 / \mathrm{g}$ was the est inated value of the peak vertical ground acceleration. Design Farthquate? (DE-2) was based on a return period of 500 years. The peak horizontal and vertical ground accelerations were estimated to be 0.25 and $0.17 \mathrm{~g}$,

respectively. Both DE-1 and DE-2 spectra have greater amplitudes (by factois of 3 to 4) than the best estimate UNE spectrum. UNE grenerated ground motions generally have larger (relative to horizontal components) vertical components than do earthquake generated ground motions. This is observed in Figure $4-26$. DE- 1 is generally greater than or equal to the upper bound of the UNE production. DE-2 falls within the upper bound value of the vertical UNE production, but generally above the upper bound on the horizontal UNE predictions. The shape of the earthquate and UNE spectra are similar. The. earthquake spectra contain more high frequencies than the UNE spectrum.

Based on these comparisons, it is clear that the earthquake motions will govern the design of the repository facilities. This is especially true when it is considered that only the best estimate earthquake spectra is presented. This spectrum has uncertainties associated with it that will more than lik.y drive the design earthquake motions even higher, creating a larger separation between UNE and earthquake motions. 

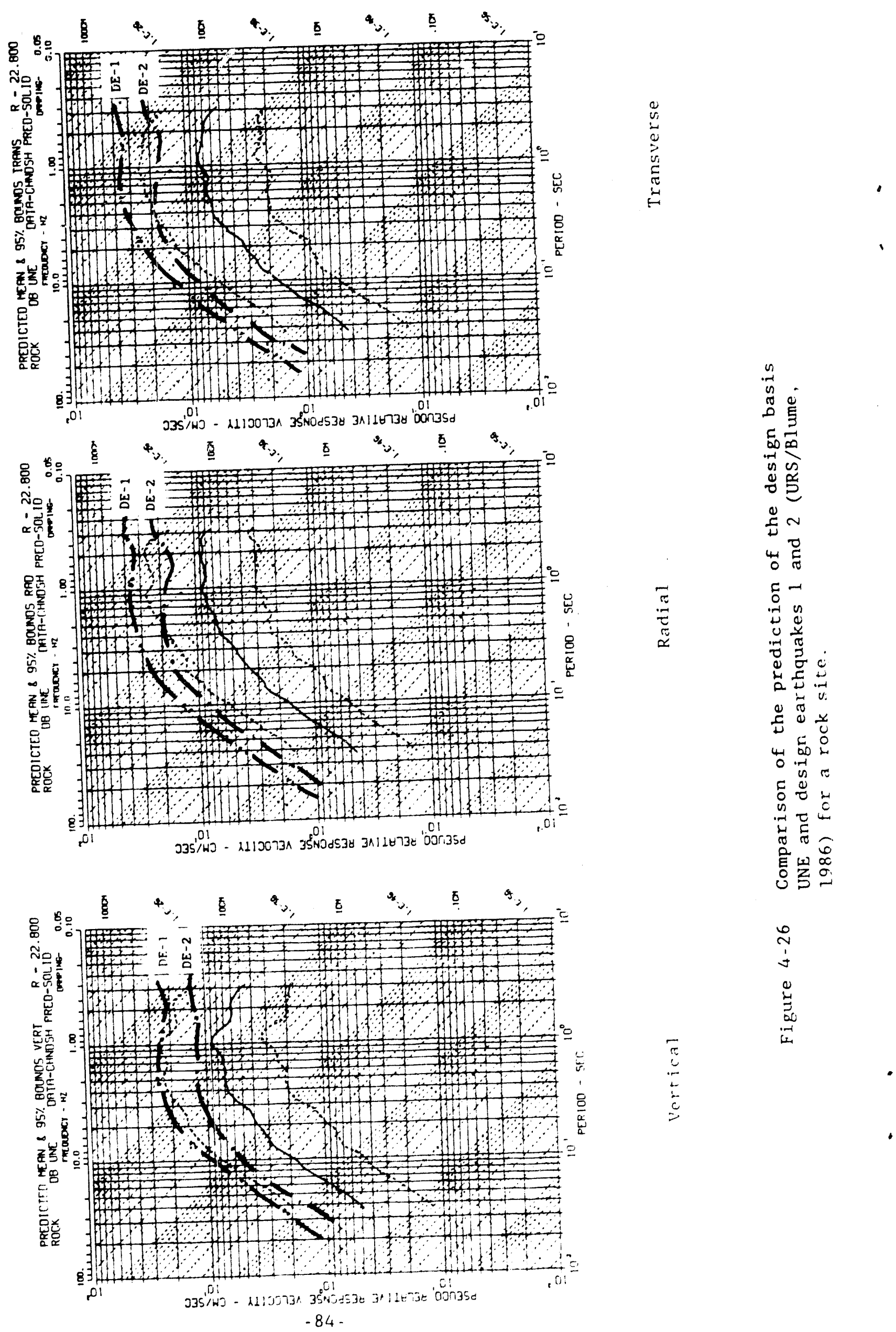


\subsection{Comparison of UNE and Earthquake PSRVs}

In an effort to determine the similarities and differences in earthquake and UNE ground motions, a comparison of predicted PSRVs for an "equivalent" UNE earthquake pair was made. The equivalency between the two sources was determined in the following manner. First the explosion energy had to be expressed in terms of earthquake magnitude. This was accomplished by use of equation 4-2 from Vortman (1991). This equation was derived from a fit of announced Pahute Mesa UNEs (the limits on this equation are yields from 20 to $1200 \mathrm{kt}$ and magnitudes from 4.7 to 6.2 ).

$$
m=3.603+0.3774 \ln W
$$

where

$$
m \text { is equivalent body wave magnitude }
$$

$W$ is the yield of the explosion.

The body wave magnitude was then converted to a moment magnitude by use of the following relationship (Houston and Kanamori, 1986):

$$
M_{w}=\left(m^{\prime}-2.7\right) / 0.53
$$

where

$$
\begin{aligned}
& M_{w} \text { is the moment magnitude } \\
& m^{\prime} \text { is the body wave magnitude. }
\end{aligned}
$$

( $m$ ' is determined from the entire short period P-Wave train rather thar the maximum amplitude of the first few cycles (as is $m$ ). For explosions, these two magnitudes should be similar.)

To calculate the earthquake PSRV the technique from Joyner and Bonre (1982) was used. This procedure was developed from analys is of earthquakes in western North America with moment magnitudes greater than 5.0 and fault ruptures less than $20 \mathrm{~km}$ deep. The prediction equations were developed for $5 \%$ damped PSRVs for periods between 0.1 and $4.0 \mathrm{~s}$ $(0.25$ to $10 \mathrm{hz})$. In addition, predictions may be made for either rock or soil sites. The predictions made for the comparisons shown here are for the "larger of the two horizontal components" (which compares to the INN radial motion) at a rock site.

For convenience, the design basis UNE was chosen for this comparison. The key parameters are the yield (700 kt) and the sourceto-station distance $(22.8 \mathrm{~km})$. Using Equations $4-2$ and $4-3$, the $700 \mathrm{kt}$ yield converts to an equivalent moment magnitude earthquake of 6.37 . These parameters were used in both prediction techniques to produce the romparisons shown in Figure 4-27 and 4-28. 


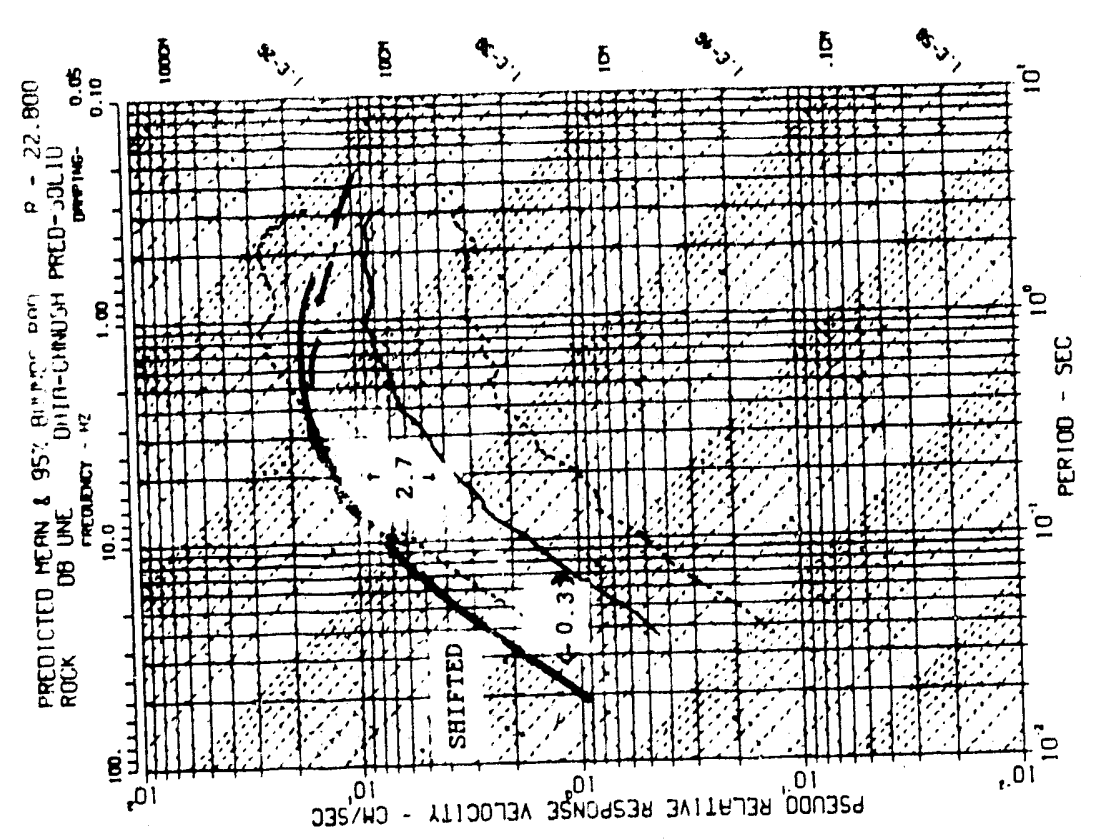

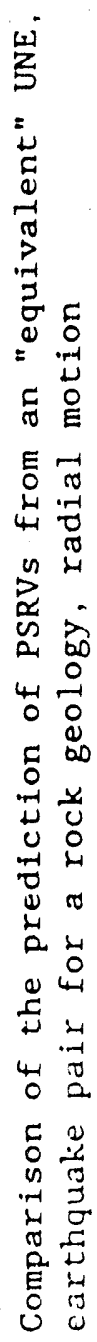

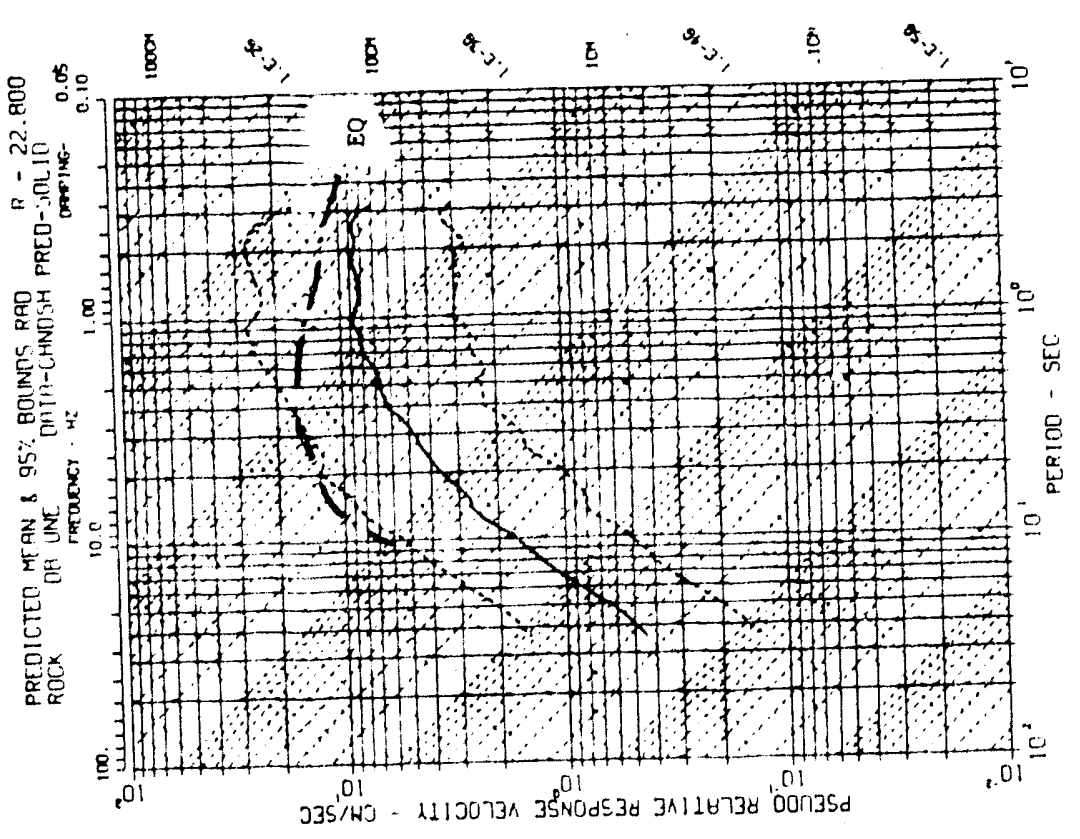

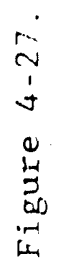




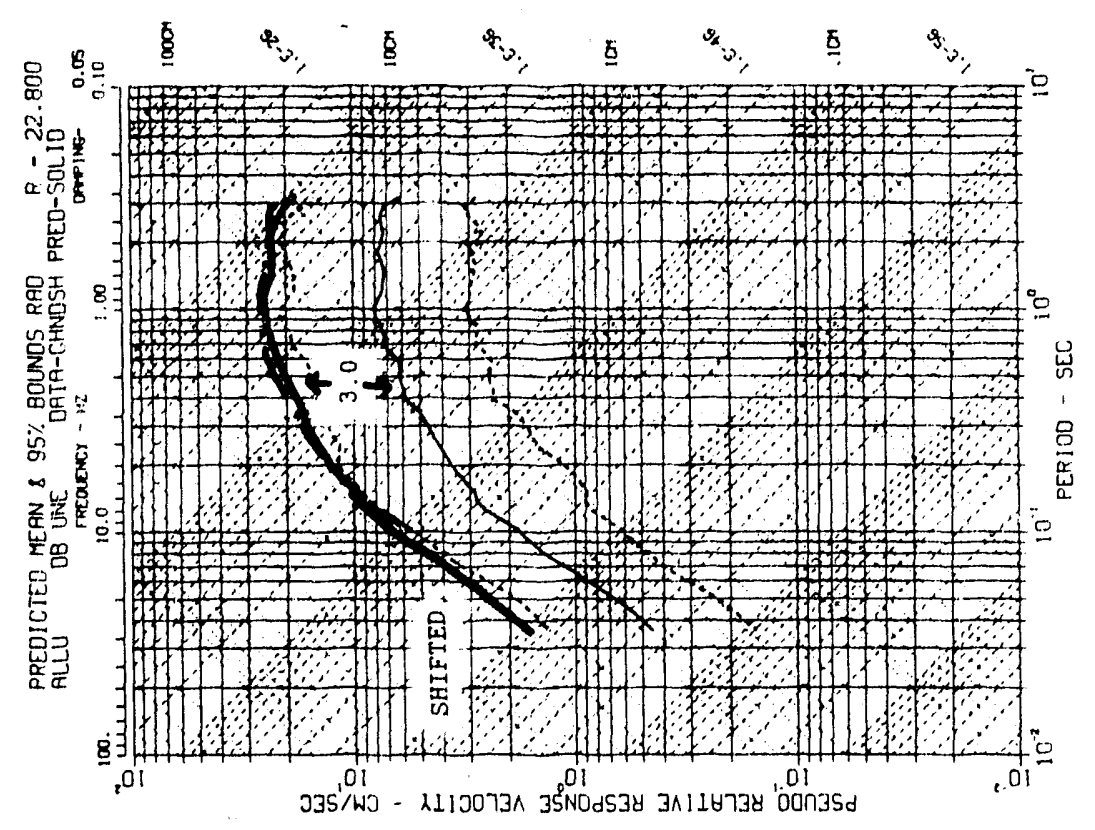

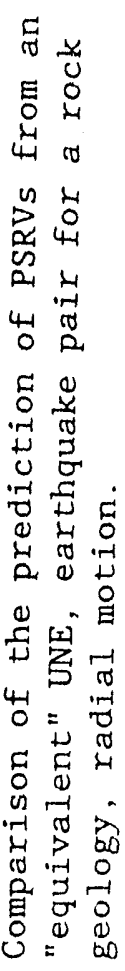

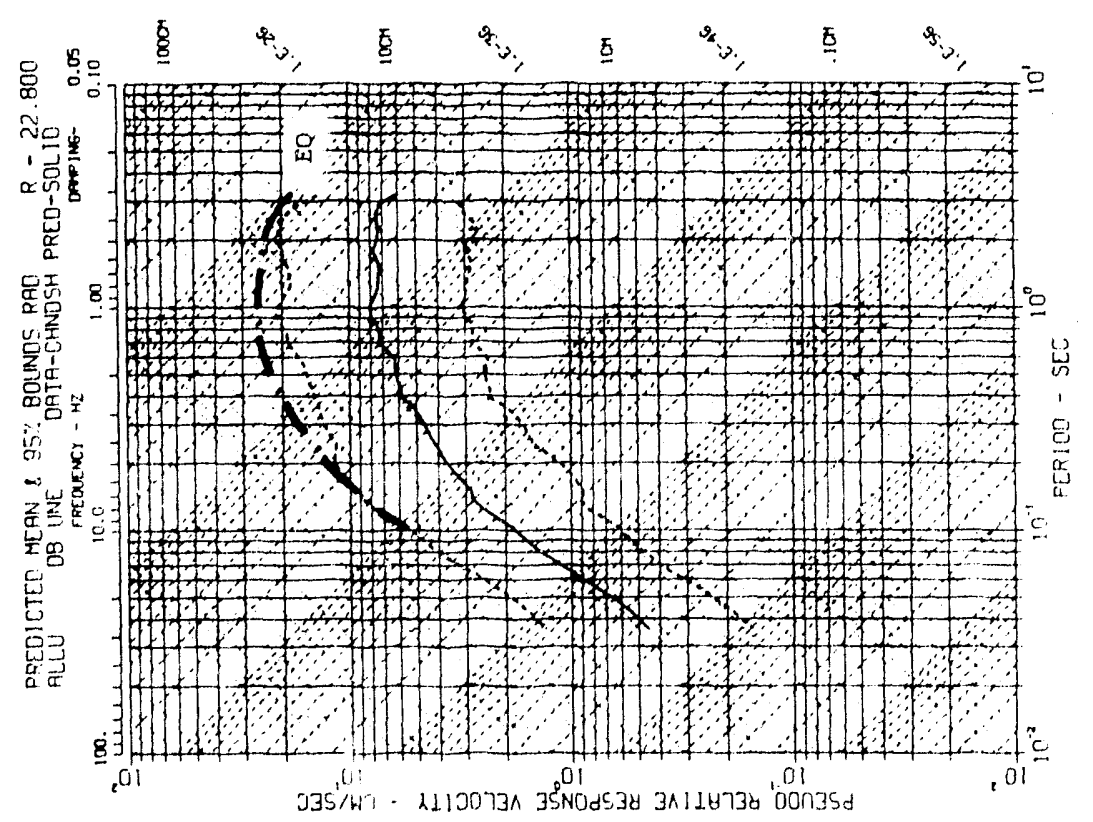

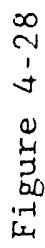


For the rock geology, the predicted earthquake PSRV is of greater amplitude but similar in shape to the UNE PSRV. The UNE PSRV can be modificed to agree with the earthquake PSRV by multiplying the period by 0.3 and the amplitude by about 2.7. The shifted UNE prediction is also shown in Figure 4. $2 \%$

Figure 4-28 shows the comparisons of the predicted earthquake and U!NF PSKV for an alluvial or soil station geology. As was the case with the previous comparisons, the earthquake PSRV is of larger amplitude than the UNE. PSPV. The frequency contents of the two predictions are more similar, lowever. The UNE PSRV can be modified to agree with the earthquake PSRV by multiplying the aniplitude by about 3.0. The shifted UNE PSRV is also shown in Figure $4-28$.

Assuming that the earthquake PSRV prediction procedure is representative of the actual earthquake ground motion in western North America (including Nevada) and the UNE prediction procedure is representative of actual ground motion behavior at NTS, these comparisons are interesting in that they imicate the possibility of a simple shift between UNE and earthquake PSRVs. 11. this shift was determined to be systematic over a wide range of "rquivalent" UNE earthquake pairs, then an empirical method could be clevel pcrl to generate "equivalent NTS earthquake" PSRVs from the UNE data base. Further study is required to determine the feasibility of further analysis along these lines. 


\subsection{CONCLUSIONS AND RECOMMTNDATIONS}

The conclusions from this study are as follows:

(1). A credible prediction procedure for UNE PSRV has been developed. This procedure provides reasonable predictions at: Yucca Mountain and for NTS in general. This procedure also provides results consistent with earlier work.

(2). Observed amplification at Yucca Mountain stations W-14, W-21, $W-22$, and $W-23$ may be explained, at least in part, by topography near the stations. All of these stations were installed on ridges. Ground motions with wavelengths on the order of mountain width were amplified at these stations. Significant amplification of ground motions at the other Yucca Mountain stations was not observed in this study.

(3). Prediction of downhole PSRVs can be accomplished at specific stations by use of the surface/downhole ratios developed in an earlier study. A general depth attenuation model for Yucca Mountain does not exist at this point.

(4). Comparison of predictions of earthquake PSRVs from earlier work and UNE PSRV for design basis events at Yucca Mountain indicate that the hest estimate of the UNE ground motion is a factor of 3 to 4 below the earthquake motion. Predicted earthquake motions wore generally at or above the upper $95 \%$ confidence bound ( 97.58 non-exceedance probability level) of the UNE prediction.

The recommendations that result from this study are as follows:

(1). A general depth attenuation model for the Yucca Mountain area should be developed.

(2). Topographic and other site effects at Yucca Mountain should be studied in more detail and quantified.

(3). More detailed study is needed to determine the feasibility of developing a method to modify UNE- generated ground motions to simulate earthquake- generated ground motions for the Yucca Mountain area. 


\subsection{REFERENCES}

Christiansen, R. L., and P. W. Lipman, Geologic Map of the Topopah Spring NW Quadrangle, Nye County, Nevada, MAP GQ-444, Departiment of the Interior, United States Geological Survey (HQS.880517.1118)

Crawford, R. E., C. J. Higgins and E. H. Bultmann, 1974. The Air Force Manual for Design and Analysis of Hardened Structures, AFWL-TR-74102, Air Force Weapons Laboratory, Kirtland Air Force Base, NM.

(NNA. 891208.0047)

Environmental Research Corporation, 1984. Prediction of Ground Motion Characteristics of Underground Nuclear Detonations, NVO-1163-239 (NNA.870406.0100)

Geli, L., P. Bard, and B. Jullien, 1988. "The Effect of Topography on Earthquake Ground Motion: A Review and New Results, "Bulletin of the Seismological Society of America, Vol. 78, No. 1, pp. 42-63 (NNA.890713.0234)

Higgins, C. J., R. L. Johnson and G. E. Triandafilidis, 1978. The Simulation of Earthquake-Like Ground Motions with High Explosives, CE-48(78) NSF-507-1, Vol. 1, University of New Mexico Department of $\mathrm{Civil}$ Engineering and Bureau of Engineering Research, Albuquerque, NM (NNA.891107.0100)

Houston, H. and H. Kanamori, 1986. "Source Spectra of Great; Earthquakes: Teleseismic Constraints on Rupture Process and Strong Motion," Bulletin of the Seismological Society of America, Vol. 76, No. 1, pp. 19-42 (NNA.890713.0238)

Joyner, W. B. and D. M. Boore, 1982. Prediction of Earthquake Response Spectra, OFR82-977, U. S. Geological Survey, Menlo Park, California (HQS.880517.1286)

Lipman, P.W. and E. ‥Kay, 1965. Geologic Map of the Topopah Spring SW Quadrangle, Nye County, Nevada, MAP GQ-439, Department of the Interior, United States Geological Survey (HQS.880517.1317)

Iyuch, R. D., 1969. "Response Spertra for Pahute Mesa Events," Bulletin of the Seismological Society of Anerica, Vol. 59 (NNÄ. 890714.0073 )

Newmark, N. M., and E. Rosenbluth, 1971. Fundamentials of Earthquake Engineering, Prentice-Hall, Tm, , lnglewond Cliffe, N. I (NNA.891106.0212)

Phillips, J. S., 1991, Analysis of Component. Surface/Downhole Coround Motions at Yucca Mountain from Underground Nuc lear Explosions in Pahute Mesa, SAND) 87.2381 , Sandia National Laboratories.

Albuquerque, NM (NNA.901127.0287)

URS:John A. Blume \& Associates, Engineers, 1986. Ground Motion Evaluations at Yucca Mountitin, Nevada, with Applicatios to Repositor Conceptual Design and Siting, SANDB5-7104, for Sandia National Laboratories, Albuquerque, NM (NNA.8712(;4 (O)() 
Vortman, L. J., 1986, Ground Motion Produced at Yucca Mounta in from Pahute Mesa Underground Nuclear Explosions, SAND85-1605, Sandia National Laboratories, Albuquerque, NM (HQS. 880517.2986)

Vortman, L. J., 1991, in review, An Evaluation of the Seismicity of the Nevada Test Site and Vicinity, SAND86-7006, Sandia National Laboratories, Albuquerque, NM (NNA.911118.0084)

Walck, M. C., 1988, Modeling of Anomalous Ground Motion Observed at Jackass Flats, Nevada Test Site, Seismological Research Letters (NNA. 891106.0220)

Walck, M. C., 1989, Two-Dimensional Velocity Models for Paths from Pahute Mesa and Yucca Flat to Yucca Mountain, SAND88-3033, Sandia National Laboratories, Albuquerque, NM (NNA.901005.0051) 


\section{A. 1 Introduction}

The purpose of this appendix is to provide the background information on the codes used to develop the prediction procedure discussed in the main body of this report. Included here will be a short description of the processing scheme used as well as source code listings and verification and validation studies.

The procedure used to process these data is summarized as follows. In general, PSRVs were calculated on an event-by-event, component-by-component basis. The disk files containing the PSRV amplitudes calculated for individual events were stored off-line on a Compaq 286 system until all calculations were completed. These numerous output files were then combined into one file for each component (vertical, radial, or transverse) by use of the COPY utility in MS/DOS (Version 3) or the APPEND utility on the VAX 8650. (These large files are now stored on magnetic tape through the use of the BACKUP utility on the VAX 8650.) These large files are the input files for the FIT program.

The overall logic used in processing these data is shown in the flow chart in Figure A-1. The digital UNE ground motion are stored on magnetic tape at Sandia National Laboratories. These data were read onto a disk file on a VAX 8650. This, file along with an input file that provides the sourceto-station distance, is used by the PSRV code to calculate and plot PSRVs. In addition, the PSRV code saves the psuedo velocity amplitudes on disk file for incorporation into the data base. This amplitude file may be further processed by the SORT code or used directly in the PREPRO code. The SORT code can be used to sort the data by station geology or to eliminate stations. The PREPRO code converts the PSRV data from a station/event basis to a format where all amplitudes, yields, and distances for a specific frequency are listed together. The output of the PREPRO code is used directly as input into the FIT code. The FIT code performs the linear regression for each input frequency and plots and lists the results (these are listed in Appendix $C$ ). In addition, FIT creates a disk file that contains the equation coefficients in a format readable by the predicition code (discussed in Appendix B). A code named COMPARE was used to compare regression results with observed data. This code evolved into the prediction code. Separate versions of FIT, SORT and PREPRO were written to handle the single-event analysis.

The codes SORT, PREPRO, and COMPARE are considered to be auxiliary software (or calculational non.SES codes, as defined in Green (1988). The results of these codes were checked by visual inspection of the files they produced during the initial debug phase 
PROBLEM INPUT

SHOT \# ASSIGNED

Input Range
DIGITAL GROUND

MOTION DATA

(Shot Nare)

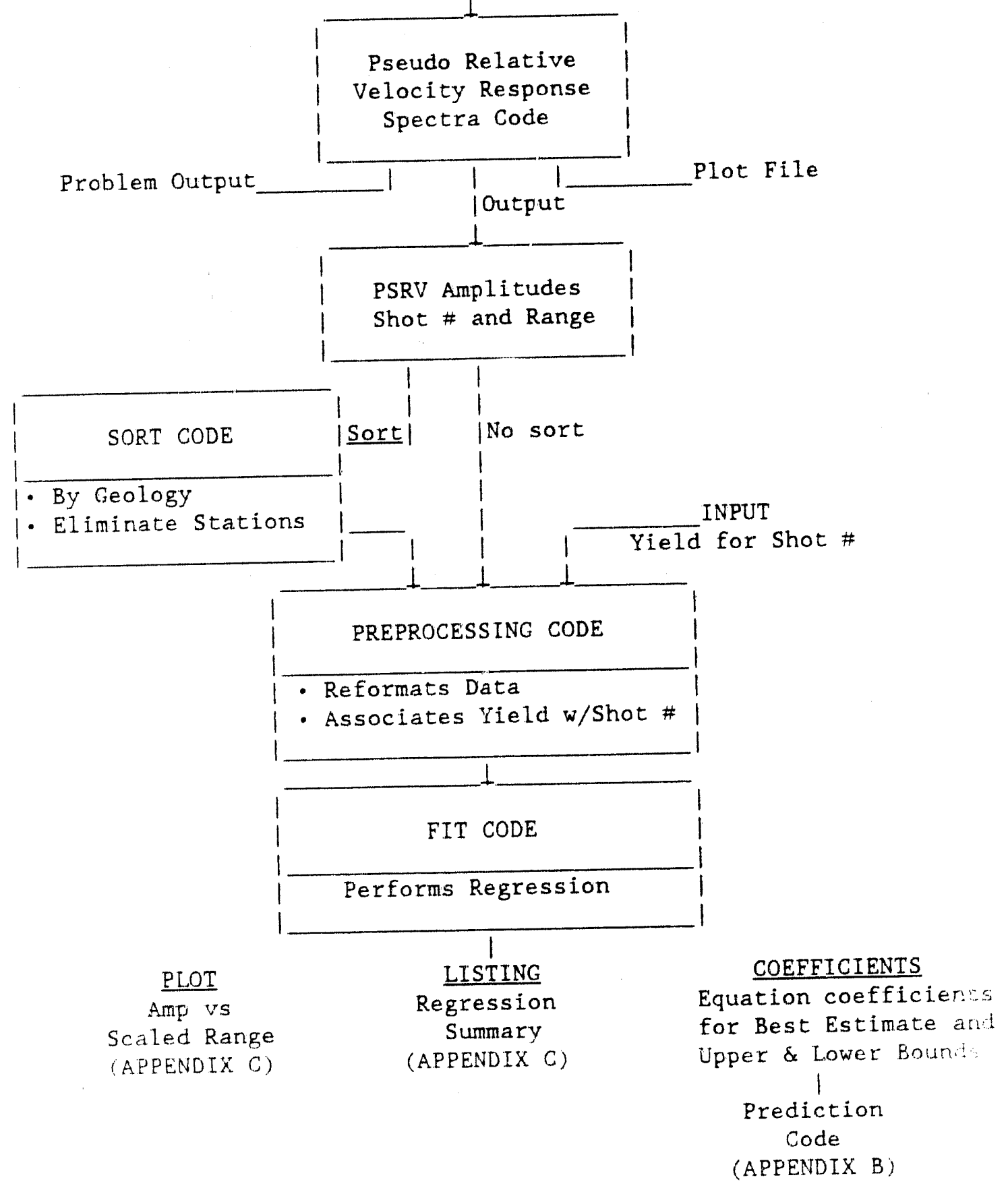

Figure A.I Processing Scheme Used for Handling Ground Motion Data in It:! Study 
as well as during the actual analysis effort. There jas no documentation of this check as such, but when errors were found they were corrected. Because these programs only manipulate data and do not calculate any values they will not be discussed further. The source code listings for these codes are given in Section $A$ of this appendix.

The PSRV and FIT codes fit the definition of Scientific and Engineering Software (SES) as given in Green (1988). These codes perform calculations with the data and will require verification and validation to ensure that they provide correct results. Documentation for these codes is given in Section $A$ and the source code listings are given in Section $A$. 


\section{A Verification and Validation of PSRV and FIT}

\section{A. 2.1 PSRV Code}

The calculational aspects of this code were documented and verified in Sanders (1987). S, changes were made specifically for this study, however. The major modification was to move the code from the computer system described in Sanders (1987) (NOS/NE) to the VAX 8650. Other modifications concerned the input/output ( $1 / 0$ ) sepects of the program. None of the calculational routines were modified. These changes are discussed below.

The PSRV code is written in ANSI standard FORTRAN 5. Because both computers (NOS/VE and VAX) both have FORTRAN 5 compilers, this consisted of changing minor details in the coding (e.g," "was changed to' and the format of some of the plotting commands was changed). The primary concern was of numerical accuracy. To determine the difference in the numerical results from one machine to another the same data file was run through both systems. A plot of the two PSRVs and the difference between them is shown in Figure A-2. Figure A-3 shows an enlarged plot of the differences. The maximum difference is about 78 at $14 \mathrm{~Hz}$. This problem is associated with the numerical precision (rounding off) of the individual machines and was considered to be within acceptable accuracy for this study.

The modifications to the $I / O$ aspects of the program consisted of addition of station name, source-to-station distance and station geology as input parameters. In addition, an output file containing the PSRV amplitudes was created and saved on disk, for further manipulation.

PSRVs have been used in building codes and by structural designers as a way to specify seismic ground motions for several years. Using PSRVs in the study of UNE-generated ground motions has been done for several years as well and this work is an extension of well accepted engineering practice. 


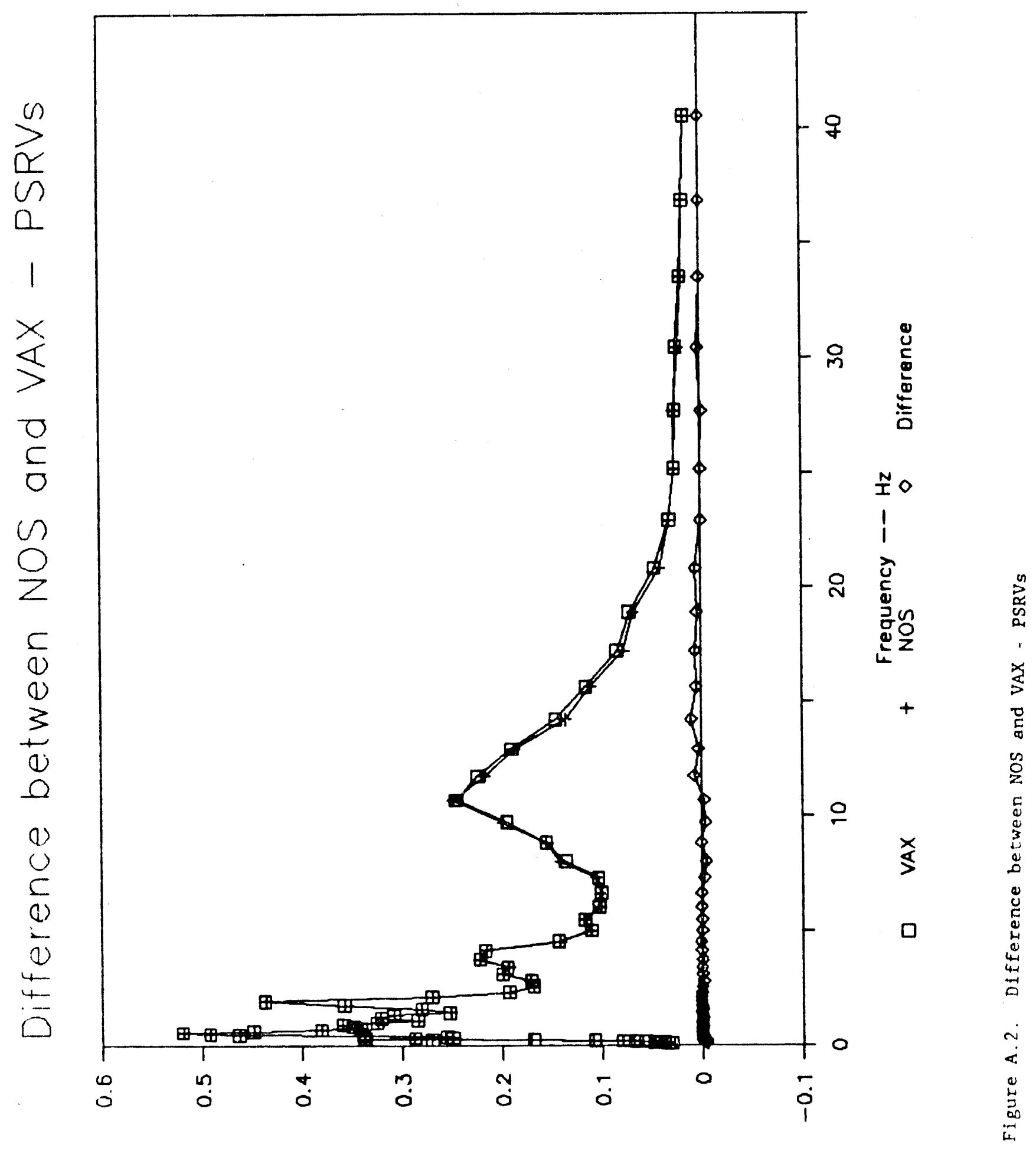

Kt!oolan opnasd 


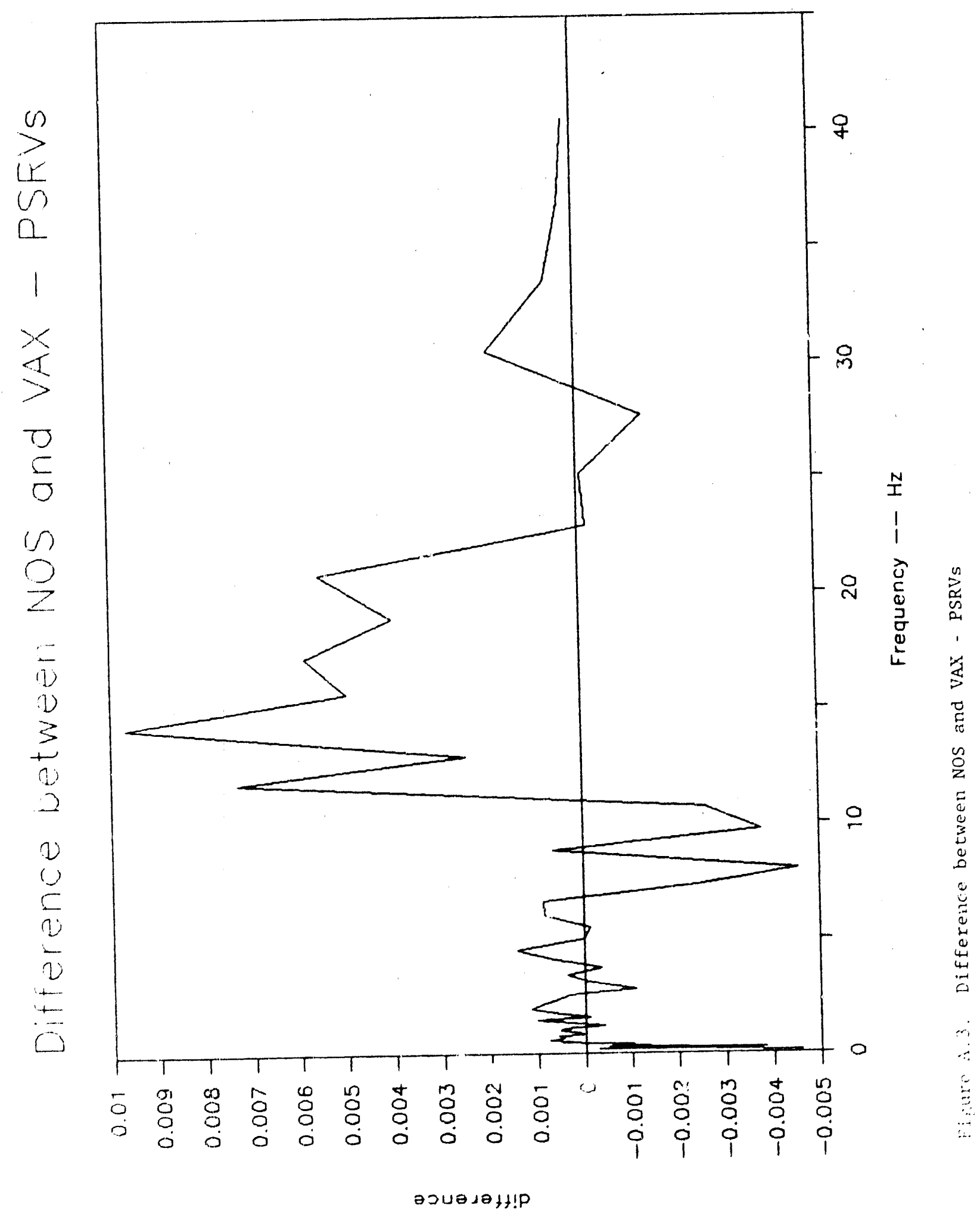




\section{A2. 2 EIT Code}

The FIT code was written specifically for this effort. Existing programs were not used because they would have required extensive revision to meet the requirements of this study. This code was built around subroutines from

International Mathematical and Statistical Libraries, Inc. (IMSL, 1984). The logic flow, subroutines and their function is shown in Figure A-4. The verification of the results generated by this code was acomplished by inputing data known to regress to a line. The equation of this line was:

$$
A=10.0 W^{0.333} R^{-1.0}
$$

The program used to generate the data file is shown in Figure

A-5. The output of FIT from this file is shown in Figure A-6 (Note that the format of this listing is somewhat different than those shown in Appendix $C$, further refinements were accomplished after this check was done.) The FIT program calculated the coefficient on $W$ as 0.332979 , the coefficient on $R$ as 0.999838 , and the constant as 10.0481 . The plot of the regression is shown in Figure A-7. These results verify that this program is operating correctly.

This approach is the standard method used in the analysis of UNE ground motion data (See Environmental Research Corporation, 1984, for good example of the use of this approach.) Therefore, validation of this approach and use of the FIT code for this work is based on past work by many analysts. 
1. READ in all data and set up arrays.

2. For a single frequency

a. CALL Subroutine TOLOG

Transform data to $\log -\log$ space

b. CALL IMSL Subroutine BECOVM

Sets up matrix of the independent and dependent variables.

c. CALL IMSL Subroutine RLMUL

Performs multiple regression at the 958 confidence level

d. CALL Subroutine FROMLOG

Transforms regression coefficients to arithmetic values

e. CALL Subroutine OUT

Prints regression information to output file and regression coefficients to a separate file

f. CALL Subroutine SETPLOT

Sets up plotting

i) CALL Subroutine PREDICT

Determines points on the best fit, upper bound and lower bound for plotting

ii) CALL Subroutine PLT

Plots data and regression lines

3. Loop through 2. for all frequencies

Figure A-4. Logic Flow and Subroutine Description of FIT 


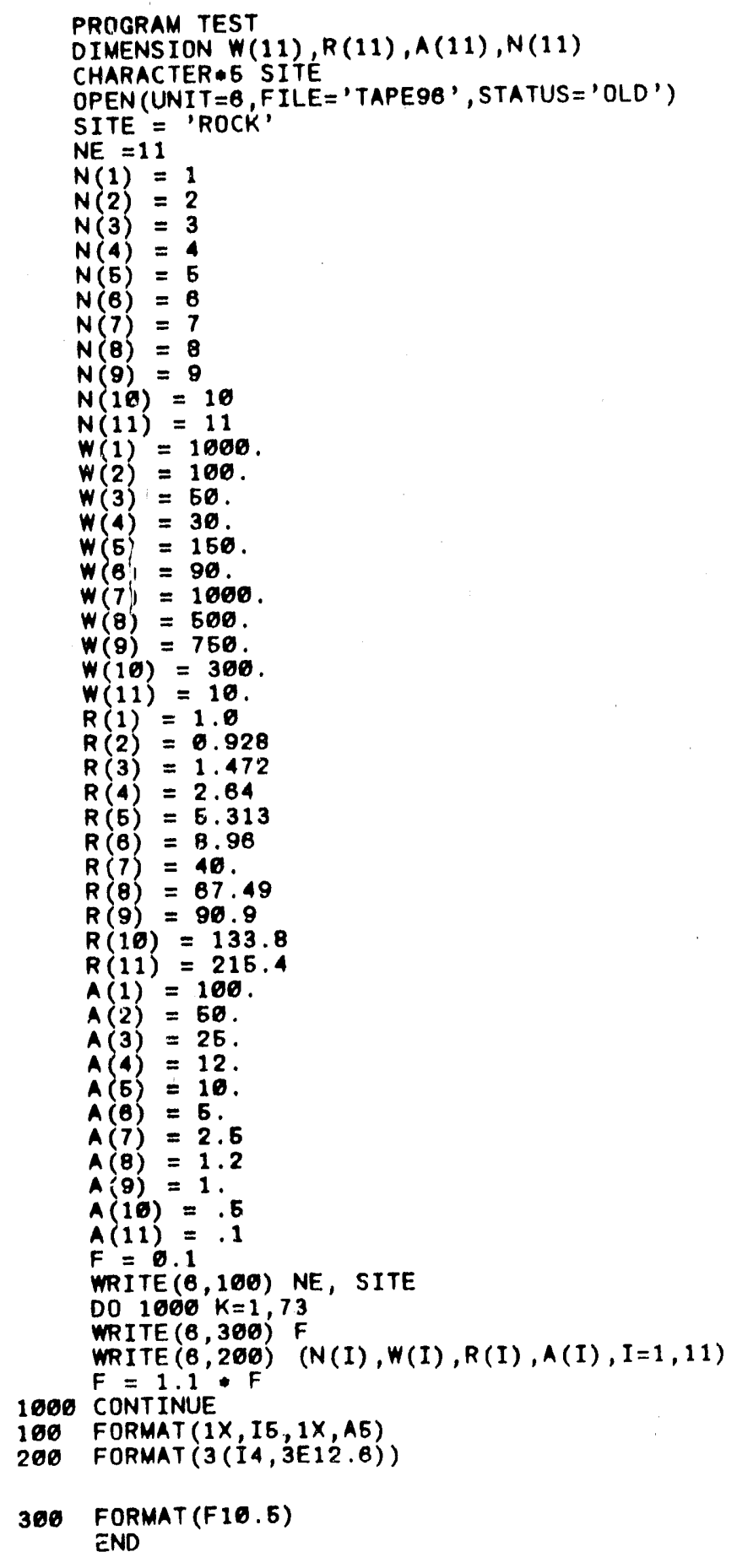

Fifm: A.5. Test data used for FIT 
FREQUENCY IS $\quad 0.10000$

REGRESSION COEFFICIENTS CALCULATED FOR THIS FREQUENCY

YIELD COEFFICIENT $=0.332 \$ 79 E+\infty 6$

RANGE COEFFICIENT $=-0.99,3838 E+\varnothing \varnothing$

INTERCEPT $=\emptyset .100481 E+\emptyset 2$

LOWER CONFIDENCE LIMITS FOR:

YIELD $=0.329466 E+00$ RANGE $=-0.100242 E+01$ INTERCEPT $=0.965671 E+01$

UPPER CONFIDENCE LIMITS FOR:

YIELD $=\emptyset .336492 E+00 \quad$ RANGE $=-\varnothing .997253 E+\emptyset 0 \quad$ INTERCEPT $=\emptyset .102431 E+02$

STANDARD ERROR FOR:

YIELD $=\emptyset .188901 E-02$ RANGE $=0.138989 E-02 \quad$ INTERCEPT $=0.101039 E+01$

ADJUSTED SUMS OF SQUARES FOR:

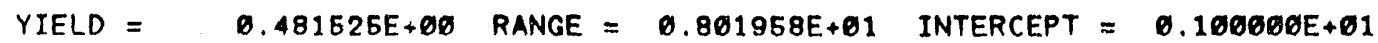

PARTIAL F-TEST VALUES FOR:

YIEI.D $=\emptyset .310717 E+05$ RANGE $=\emptyset .517486 E+08$ INTERCEPT $=\emptyset .100000 E+\emptyset 1$

$P$ (EXCEEDING F UNDER HO)

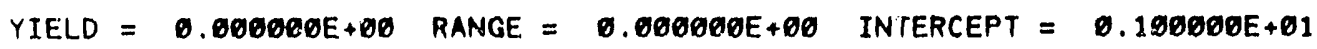

ANALYSIS OF VARIANCE

DEGREES OF FREEDOM

REGRESSION $=0.200000 E+01$ RESIDUAL $=0.800000 E+01$ CORRECTED TOTAL $=0.100000 E+02$

UMS OF SQUARES

REGRESSION $=\varnothing .822916 E+\emptyset 1$ RESIDUAL $=\varnothing .123978 E-63$ CORRECTED TOTAL $=0.822929 E+\emptyset 1$.

EAN SQUARES

REGRESSION $=0.411468 E+01$ RESIDUAL $=0.164872 E-04$

-VALUE

REGRESSION $=0.286596 E+66$

(EXCEEOING F UNDER HO)

REGRESSION $=\emptyset . \emptyset \boxminus \boxminus \boxminus \boxminus \boxminus E+\emptyset \emptyset$

PERCENTAGE VARIATION EXPLAINED BY THE ESTIMATED MODEL IS $\boldsymbol{0 . 9 9 9 9 8 6 E + \emptyset 2}$

STANDARD DEVIATION OF THE RESIDUALSIS

RESIDUAL STANDARO DEVIATION AS A $\pi$ OF THE RESFONSEMEAN IS $0.614129 E+\emptyset 0$

NUMBER OF DECIMAL DIGITS OF ACCURACY IN THEREGRESSION COEFFICIENTS IS $\emptyset .4 \varnothing \emptyset \boxminus \boxminus \theta E+\emptyset 1$

Figure A.6. Output from Problem FIT 


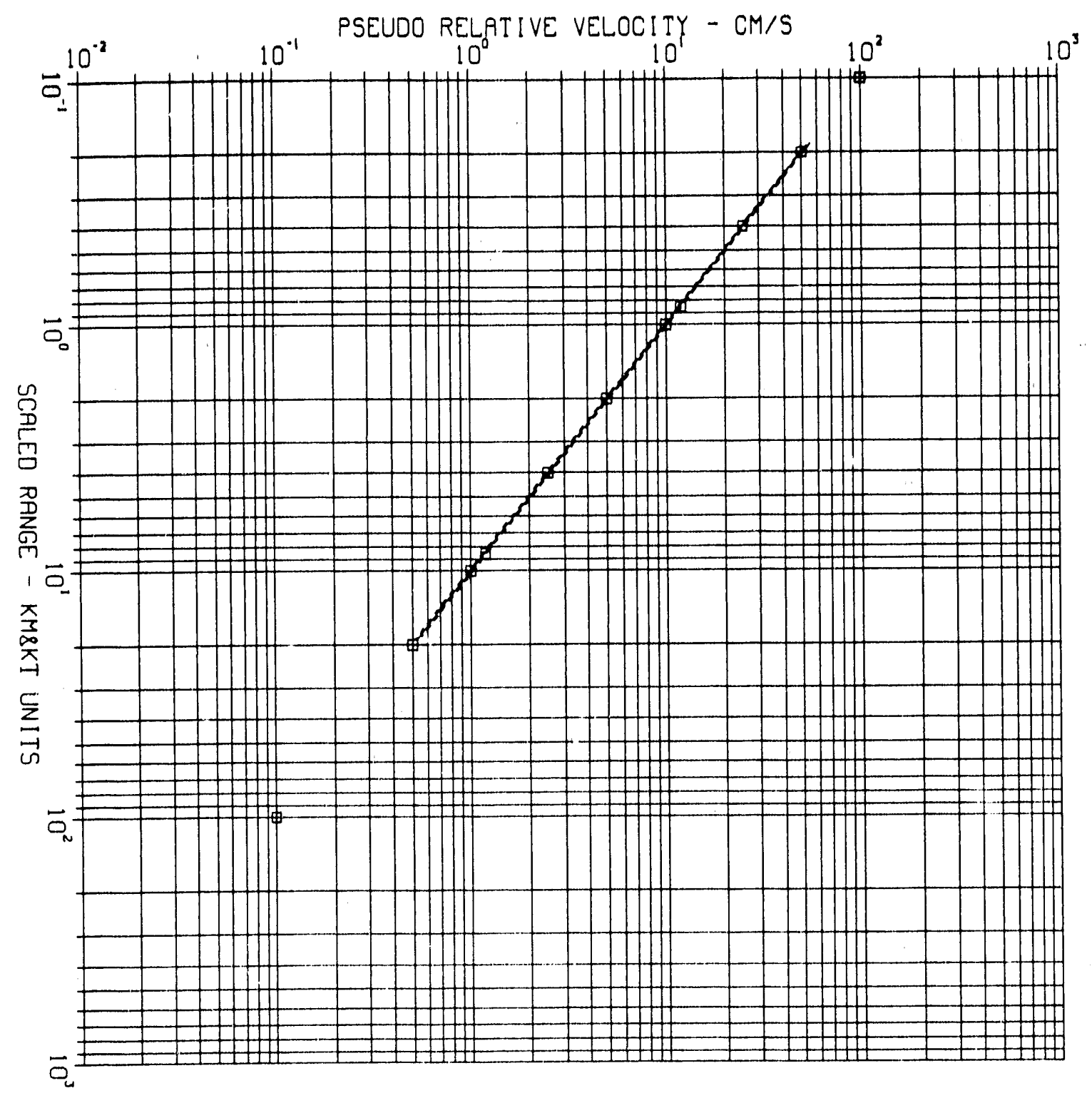

Figute A.7. Plot of results from test run on FIT code 


\section{A. 3 Source Code L1stings}

The source code listings for the programs discussed in this appendix are glven in this Appendix. These codes are presented in the following order:

1. PSRV

2. FIT Multiple Event Version

3. FIT Single Event Version

4. SORT

5. PREPRO

6. COMPARE 
"PSRV CODE" 


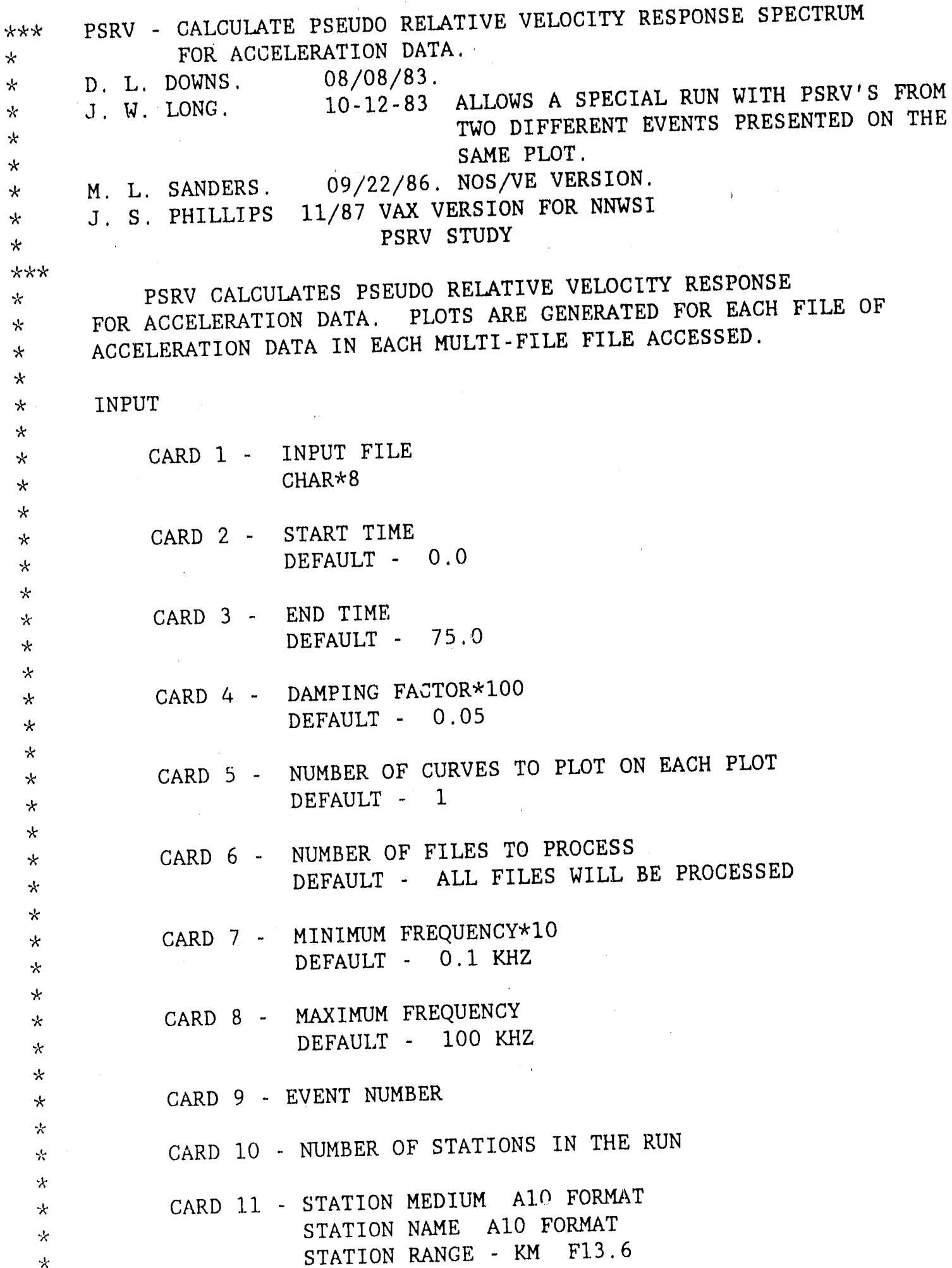


ON INPUT, ONLY 1 CARD IS REQUIRED. IF CARDS $2-8$ ARE OMITTED, THE DEFAULT VALUES WILL BE USED. ANY OF THE PARAMETERS ON CARDS 2-8 MAY BE CHANGED; HOWEVER, ANY PRECEDING DATA CARDS MUST BE PRESENT. ANY INTERVENING DATA VALUES THAT ARE DESIRED TO DEFAULT MUST BE REPRESENTED BY NULLS.

NOTE : CARE MUST BE TAKEN WHEN CHANGING THE VALUES OF FREQMN AND FREQMX. THEY BOTH SHOULD BE INTEGER POWERS OF 10. FURTHER, FREQMX SHOULD BE 1000 TIMES AS LARGE AS FREQMN. OTHERWISE, THE PLOTTING ROUTINE RESULTS ARE UNPREDICTABLE.

OUTPUT

TAPE77 - PLOT FILE GENERATED. THIS FILE MUST BE DISPOSED TO A PLOTTER.

ERRORS

FILE I/O ERRORS

CALLS VSTART, VDESCP, CHKDATA, READIN, INDEX, EXPAND, SPEC, OUTPSRV, SCALE, LGLGLG, DRWCUR, ENDPL, DONEPL, ABORT.

LOGICAL ACCDATA, ALLDONE

CHARACTER $* 8$ AMPFAC, DATAOUT (200), INFIL, GAUGEOR.

CHARACTER $* 8$ ROTANG, STA'TNUM, NEWVALU

CHARACTER*10 EVNTNAM, FREQUEN, TRACK, STAMED (30), STANAM(30)

DIMENSION PERIOD(200), PSRVAL(200), DVAL(100000), STARNG(30)

INTEGER IVAL (100000), EVNTNUM

$* * * * * * *$

$* \quad$ INITIALIZE DISPLAY ROUTINES

$* x * x * x$

CALL VSTART $(0.0,0)$

DISABLE BLANK PAGE BETWEEN PLOTS. REFERENCE: DISSPLA JSER'S GUIDE FOR NOS/VE, MARCH 1.986, P.17,19.

CALL VDESCP $(900,0,0)$ 


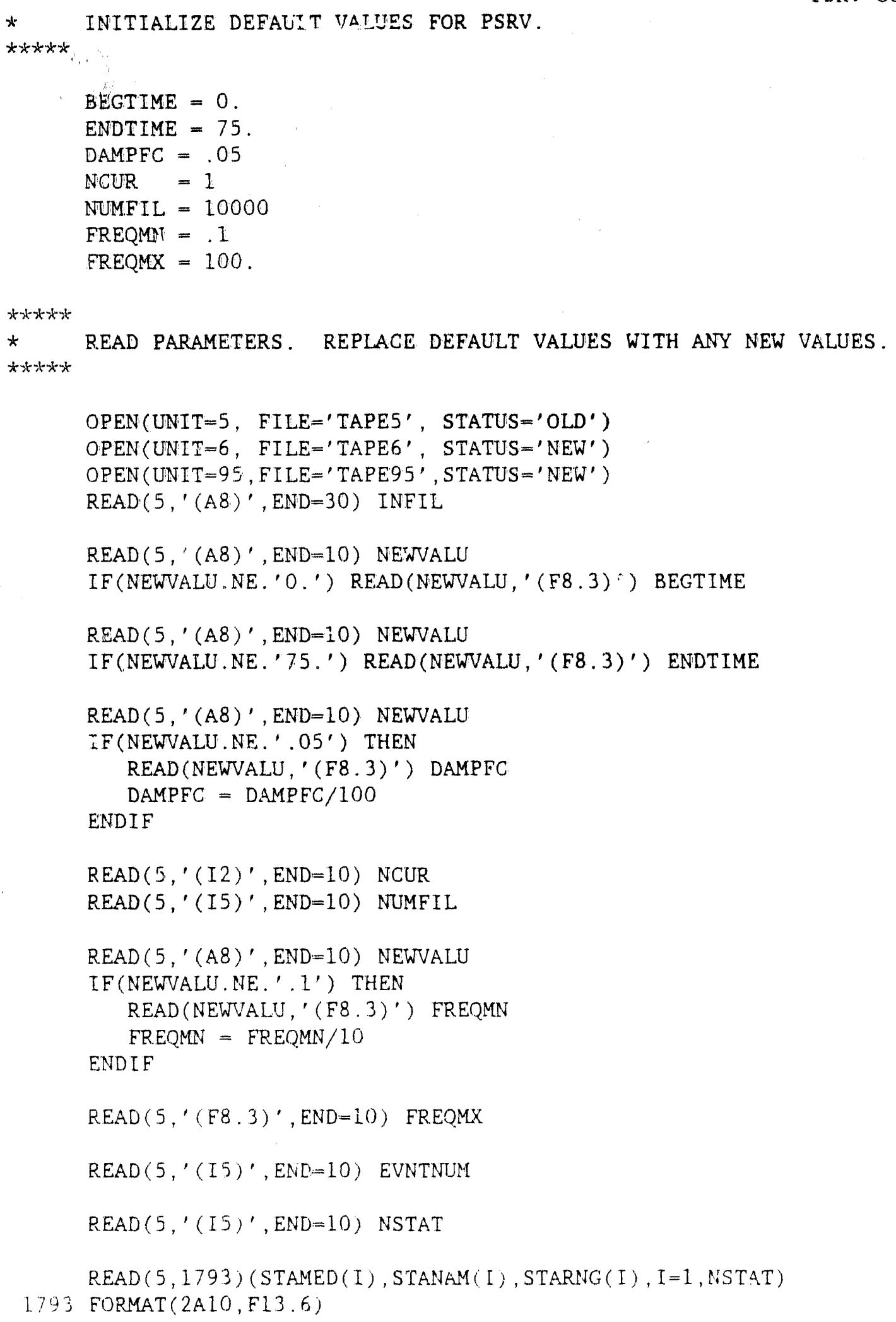


WRITE $(6,1794)$ EVNTNUM

1794 FORMAT $(2 X, '$ EVENT NUMBER $=$ ', I5)

WRITE $(6,1795)$

1795 FORMAT $(/ /, 2 \mathrm{X}$, 'STATIONS AND RANGES USED IN THIS RUN',//)

WRITE $(6,1796)(\operatorname{STANAM}(I), \operatorname{STARNG}(I), \operatorname{STAMED}(I), I=1$, NSTAT)

1796 FORMAT $(1 X, A 10,1 X, F 13.6,1 X, A 10)$

$10 \quad$ ICUR $=$ NCUR

$x+x+x$

$*$ CHECK FOR REASONABLE VALUES. SET THOSE THAT ARE NOT

$*$ TO DEFAULT VALUES AND WRITE ERROR MESSAGES.

this

CALL CHKDATA (BEGTIME, ENDTIME, NUMFIL, FREQMN, FREQMX, IERR)

IF (IERR.NE. O) THEN

WRITE $(6,200)$ IERR

CALL EXIT

ENDIF

$x+4 x$

$* \quad$ ECHO PARAMETERS.

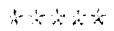

WR ITE $(6,210)$

WRITE $(6,215)$ INFIL, BEGTIME, ENDTIME, DAMPFC,

- NUMFIL, FREQMN , FREQMX

$\therefore x+x$

CALCULATE MINIMUM AND MAXIMUM PERIODS FROM

MXIMUM AYD MIUIMUA FREQUENCIES.

$\dddot{X} \mathrm{~L}=1.0 /$ FREQMX

$\mathrm{XR}=1.0 /$ FREQMN

OPEN INPUT FILE

JPEN UNIT $=11$, FILE='INFIL', STATUS $='$ OLD'

QEAD INPUT DATA 


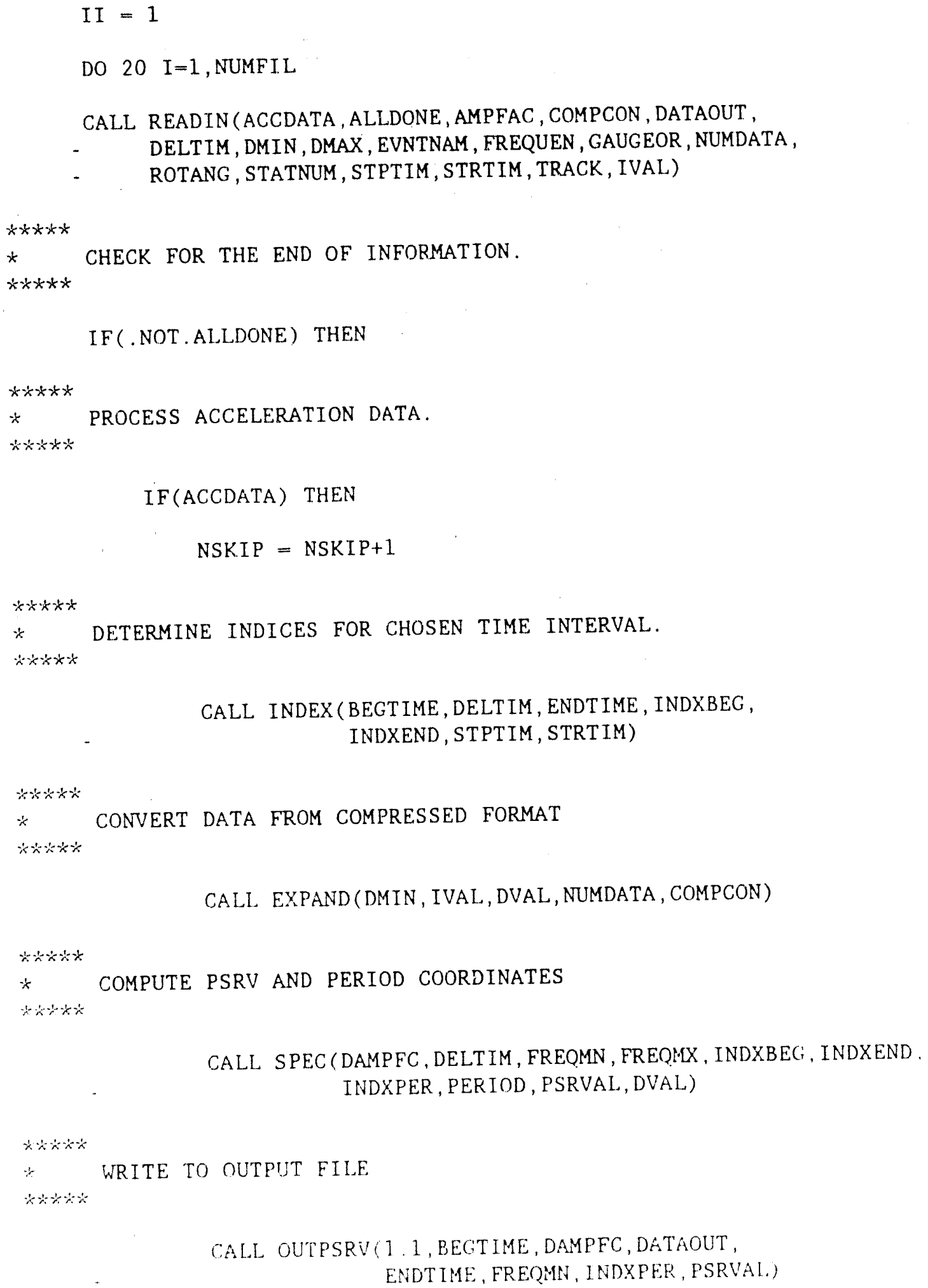




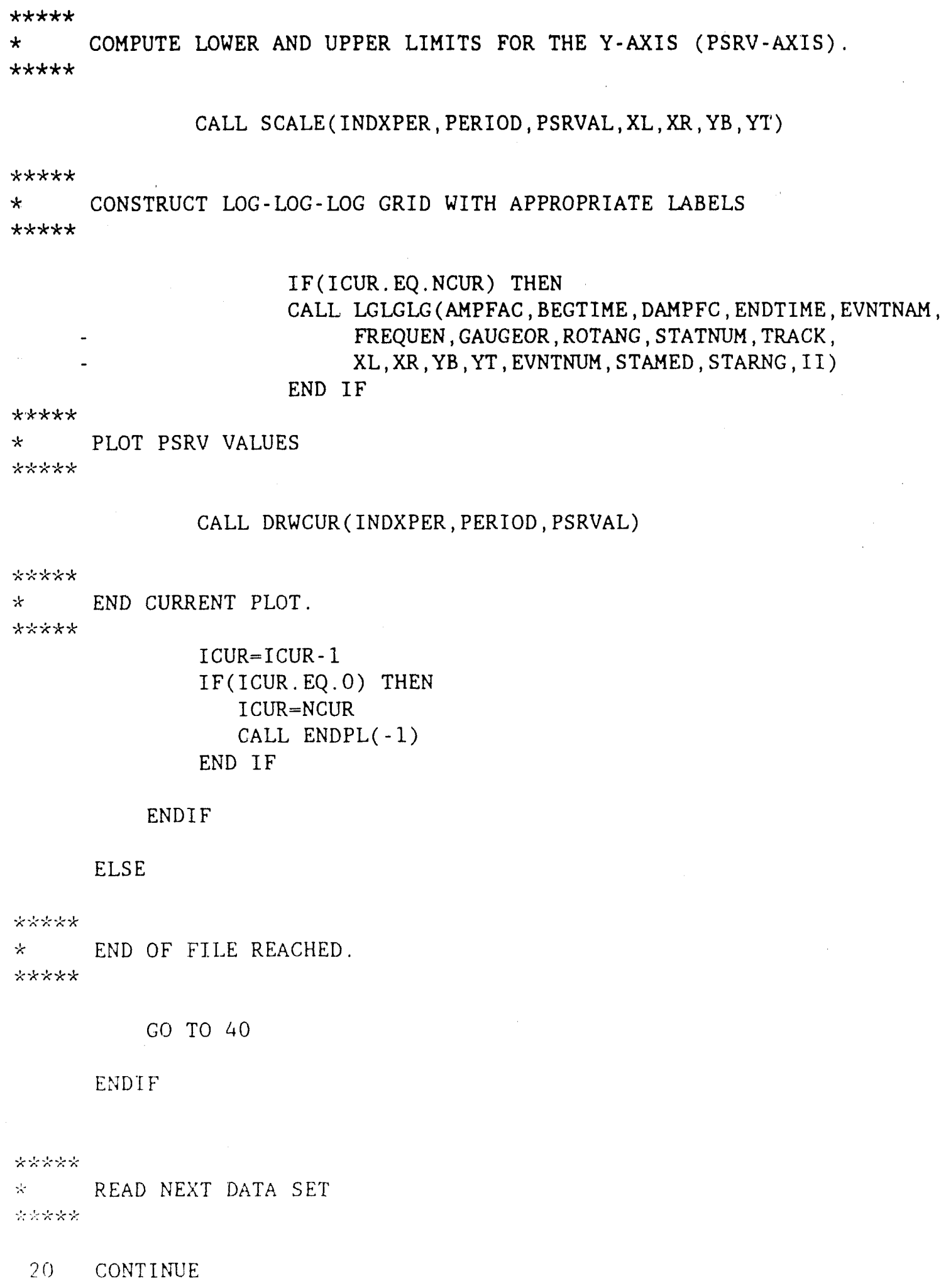


GO TO 40

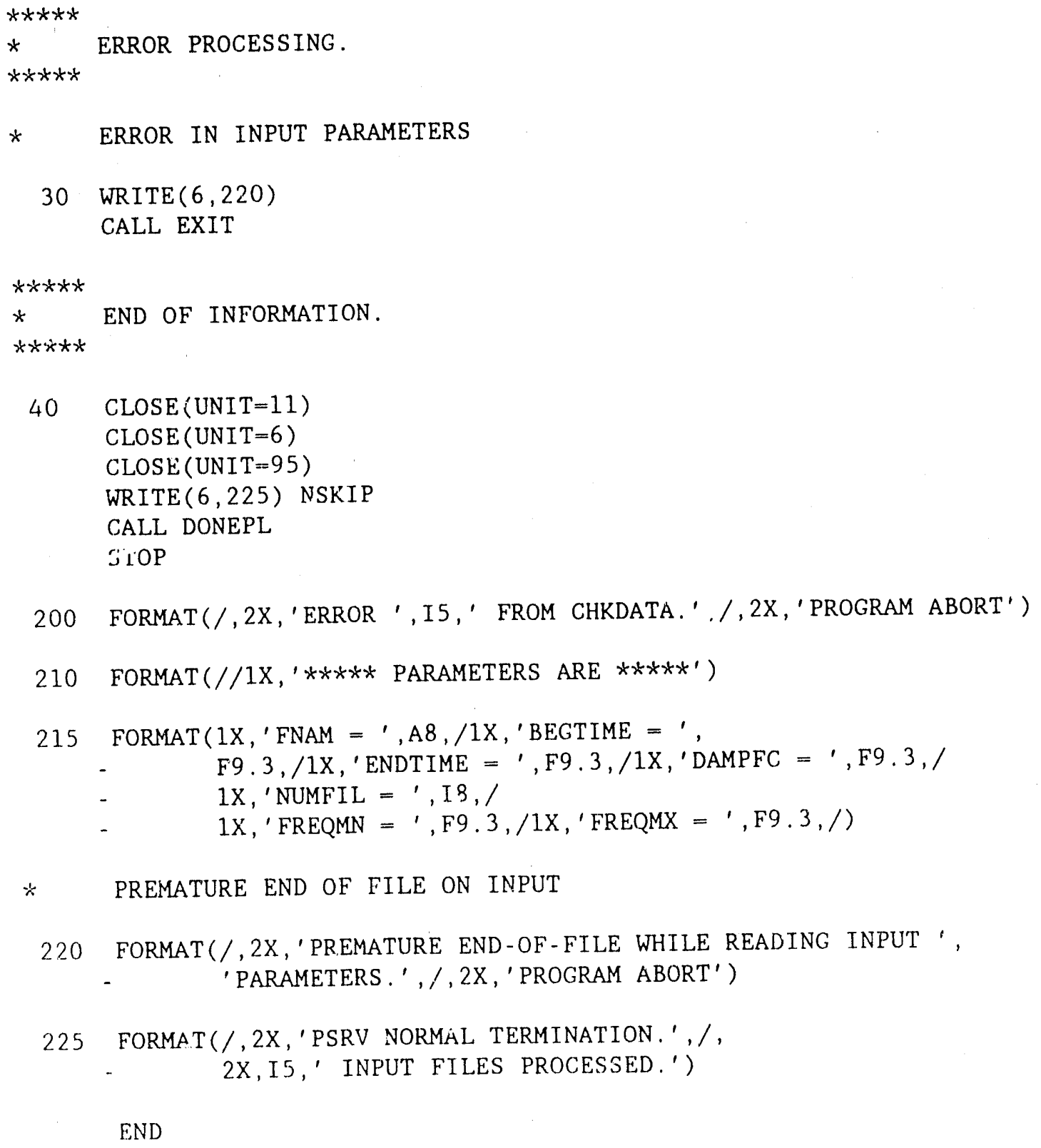


SUBROUTINE CHKDATA (BEGTIME, END'ITME, NUMFIL, FREQMN, FREQMX)

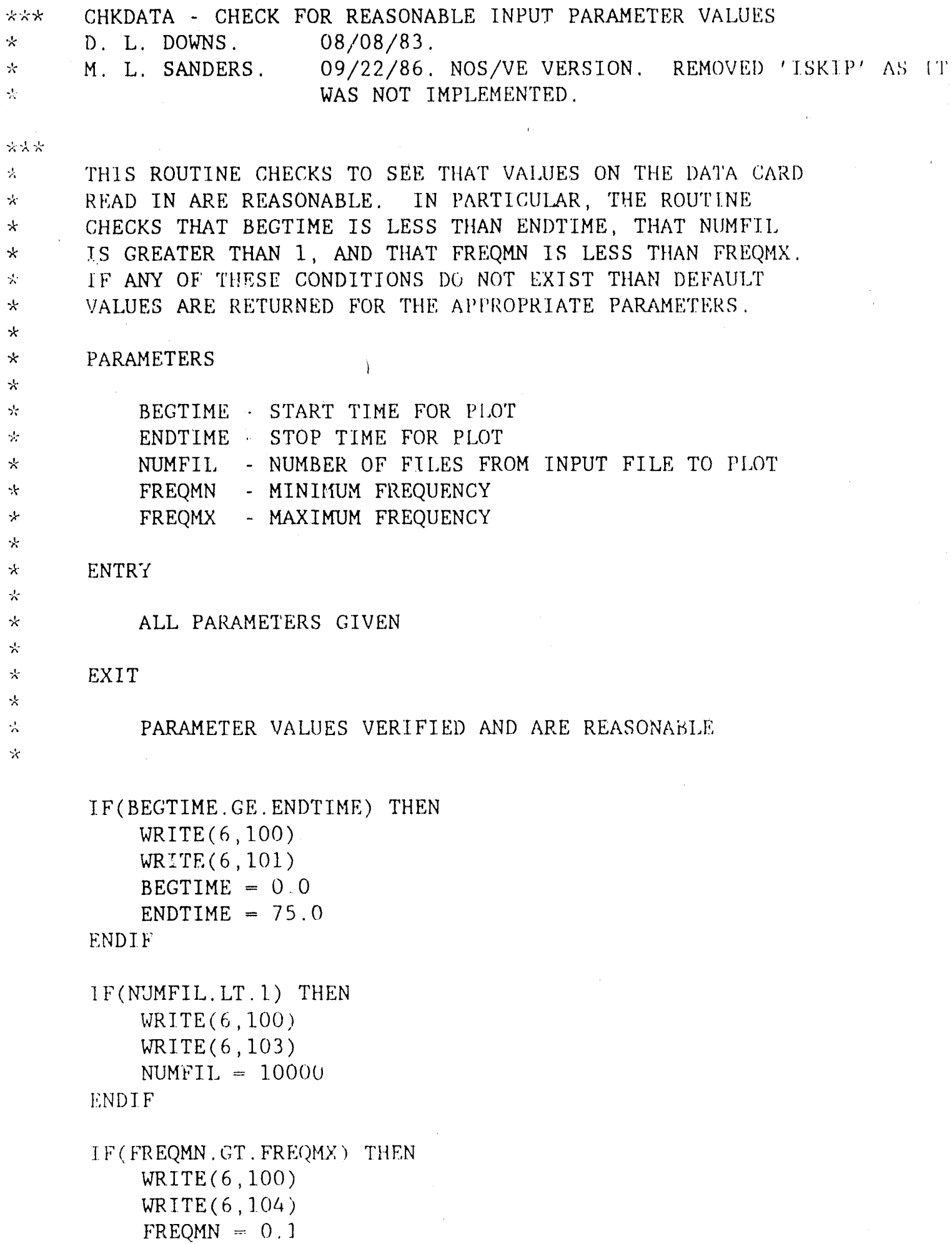




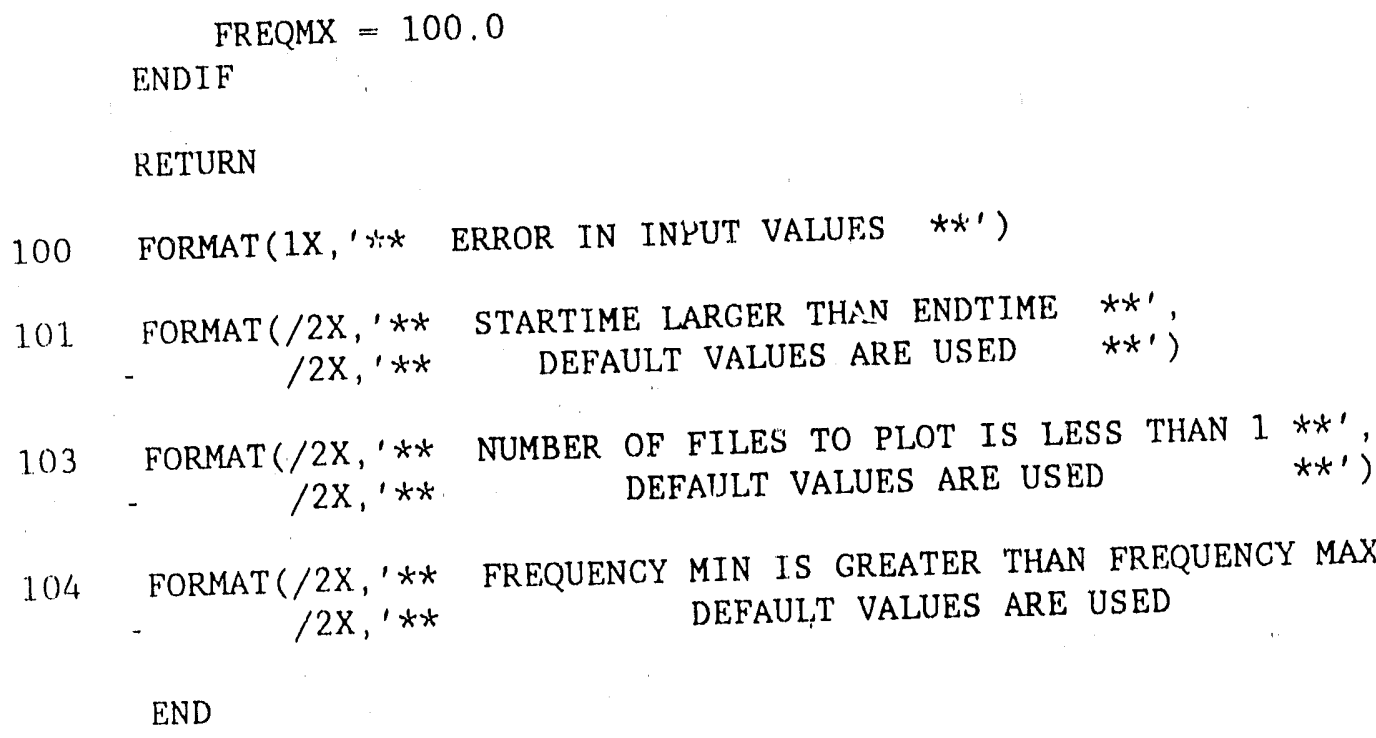


PSRV Code

SUBROUTINE READIN (ACCDATA, ALLDONE, AMPFAC, COMPCON, DATAOUT, DELTIM, DMIN , DMAX, EVN'TNAM, FREQUEN, GAUGEOR, NUMDATA, ROTANG, STATNUM, STPTIM, STRTIM, TRACK, IVAL)

READIN - CHECK FOR REASONABLE INPUT PARAMETER VALUES

D. L. DOWNS . 08/08/83.

M. L. SANDERS. 09/22/86. NOS/VE VERSION. REMOVED THE COMMON AND NOW PASS THE DATA ARRAY AS A PARAMTER.

THIS PROCEDURE READS IN THE ID SECTION AND DATA SECTION OF OF AN INPUT FILE. THE ID SECTION IS ASSUMED TO HAVE 10-80 CHARACTER RECORDS WITH 8 CHARACTERS PER WORD. FROM THE ID SECTION THE FOLLOWING WORDS ARE READ, CONVERTED INTO THEIR PROPER FORMATS, AND PASSED BACK

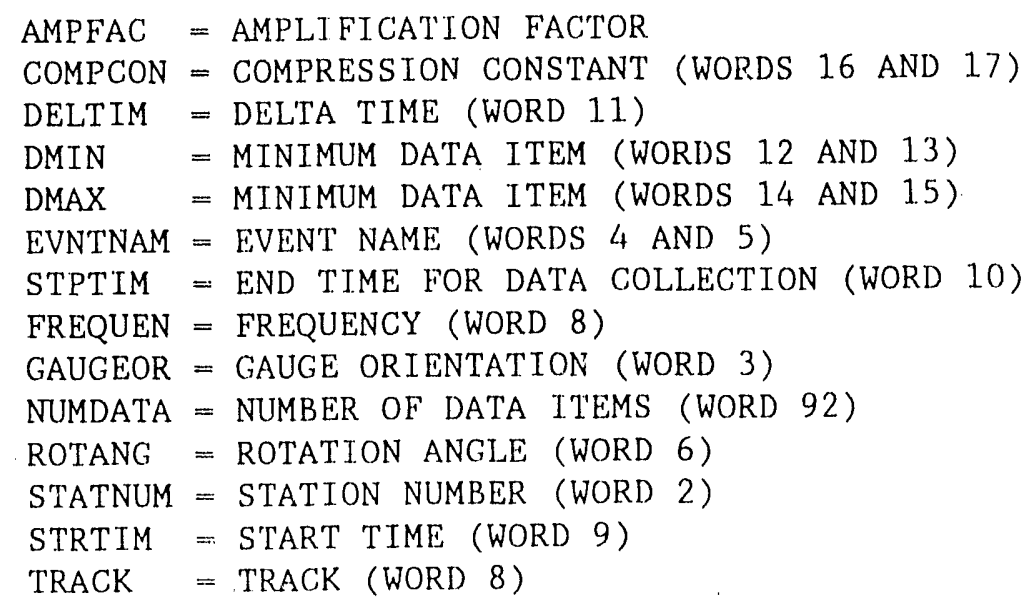

THE COMPRESSED FORM OF THE DATA IS ALSO RETURNED

IVAL $\quad=$ DATA VAI JES

ALSO RETURNED ARE TWO LOGICAL VARIABLLES

ACCDATA = TRUE IF DATA IS ACCELERATTON DATA

ALLDONE = TRUE [F ENI) OF INFORMATTON IS REACHED

INTEGER IVAL(100000)

CHARACTER *8 AMPFAC, IJA'TAOUT (200), GAUGEOR, I DBLOCK(100)

CHARACTER*8 RO'TANG, S'TATNUM, MOI)RECS (500)

CHARACTER $* 10$ FVN'TNAM, FREQUEN, S'TRING, 'TRACK

LOGICAL ACCDATA, ALLDONE. 
DATA INTEG/'INTEG $/ /$, INTEG $2 / /$ INTEG $2 / /$

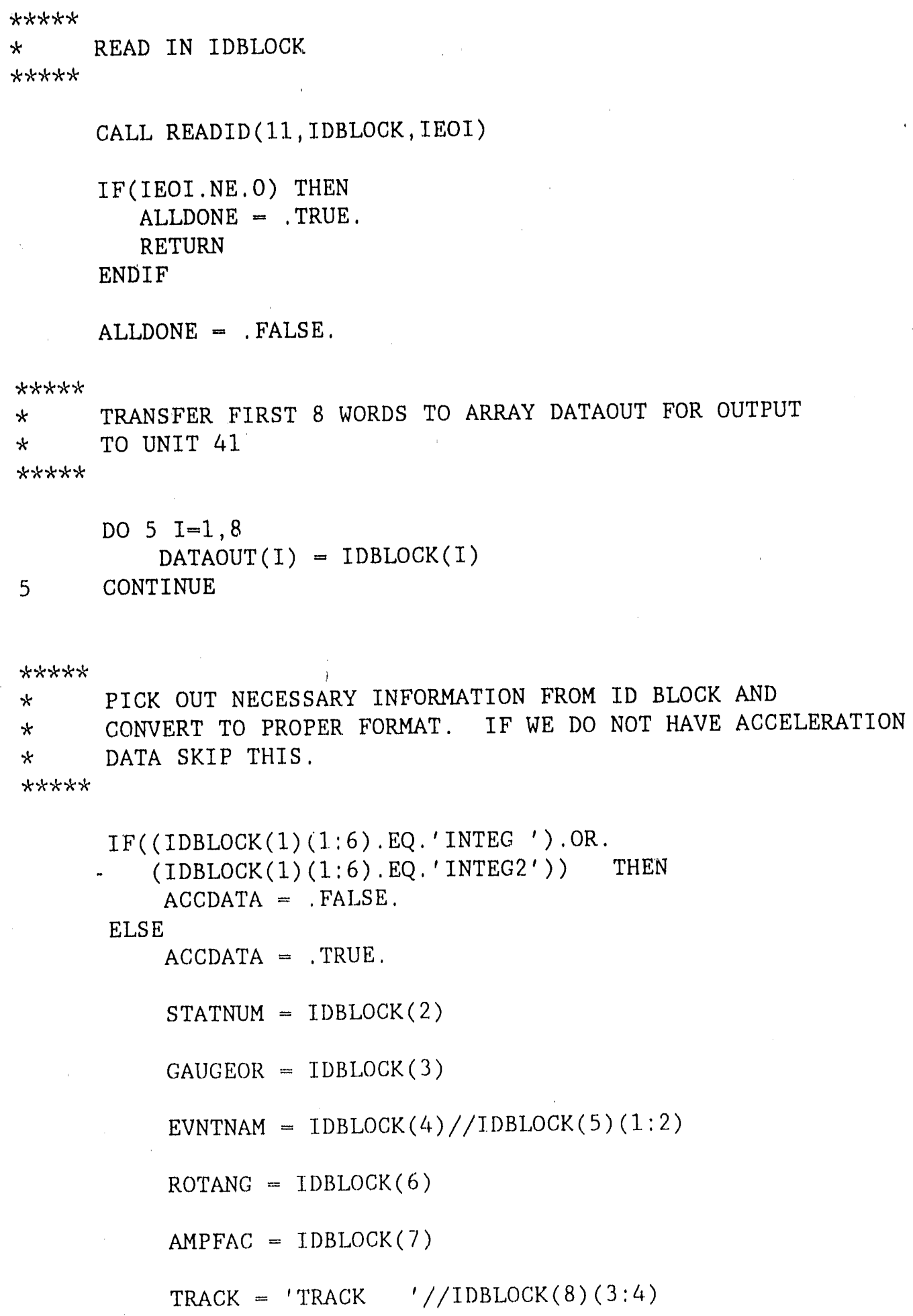




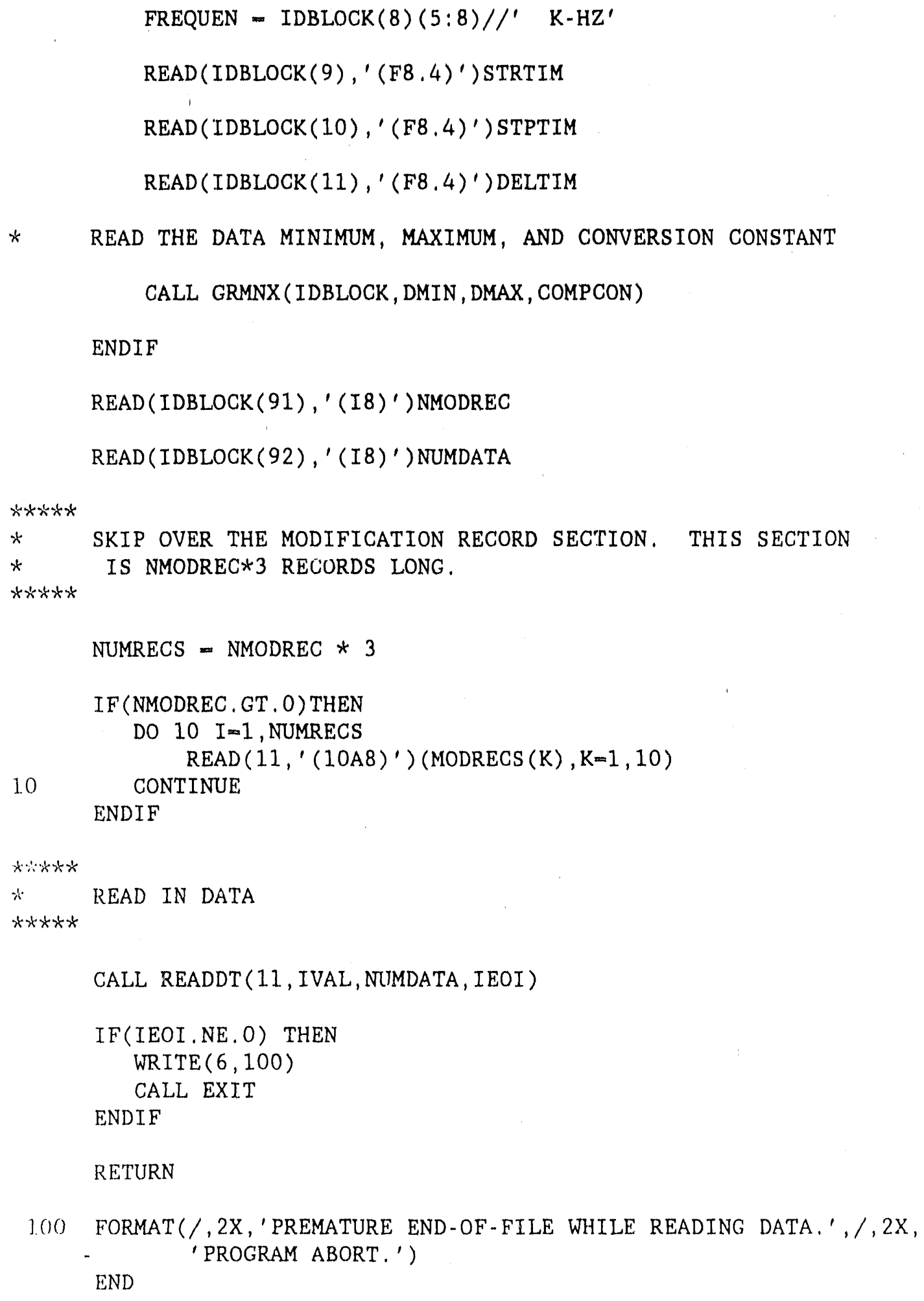


SUBROUTINE INDEX (BEGTIME, DELTIM, ENDTIME, INDXBEG, INDXEND, STPTIM , S'TRTIM)

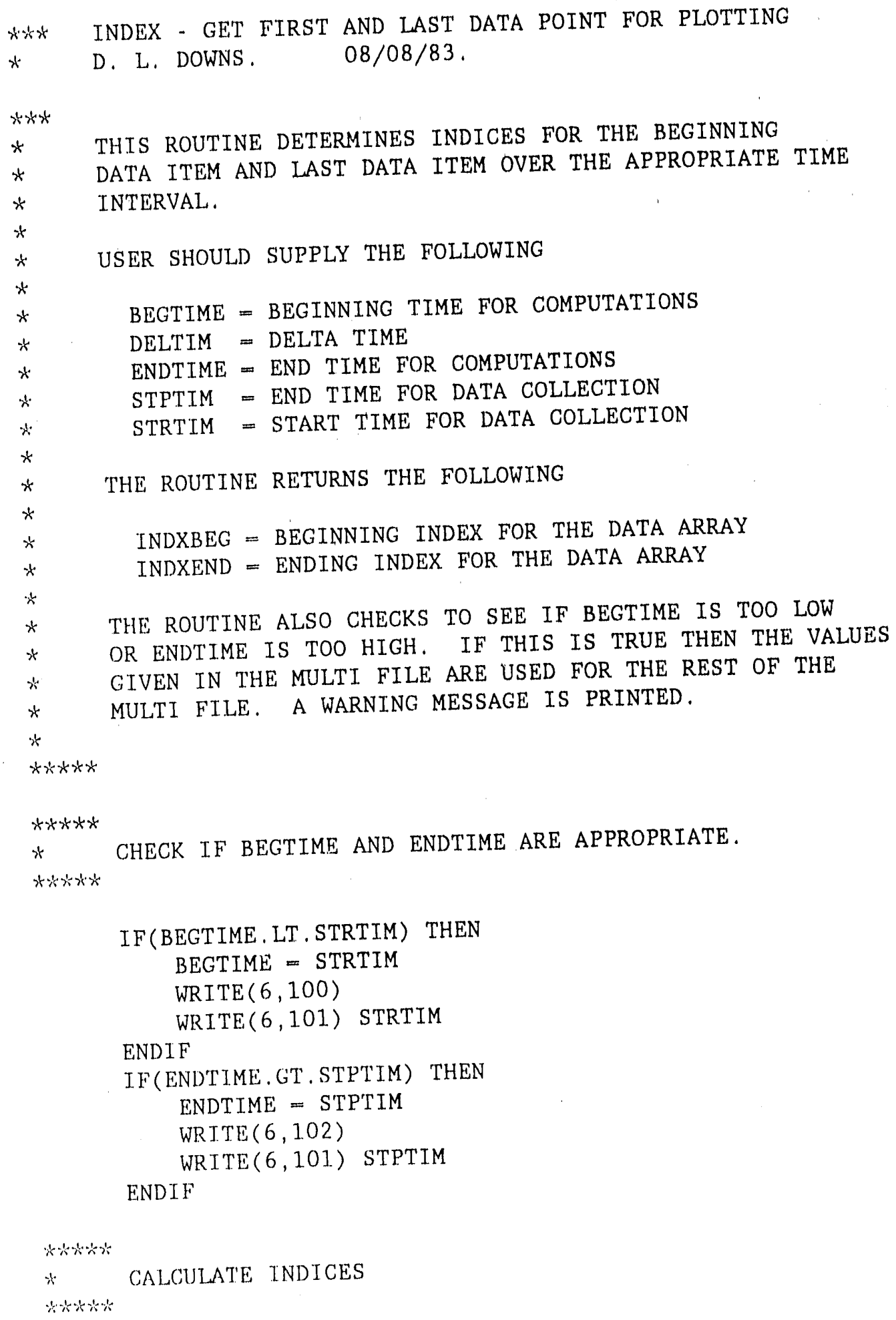


INDXBEG $=\operatorname{INT}(($ BEGTIME-STRTIM $) /$ DELTIM $)+1$

INDXEND $=$ INDXBES + INT (ENDTIME/DELTIM)

RETURN

100 FORMAT ( $1 \mathrm{X},{ }^{\prime}$ CHOSEN BEGTIME TOO SMALL FOR THIS FILE')

101 FORMAT (1X,'DEFAULT OF ',E9. $3,{ }^{\prime}$ WILL BE USED')

102 FORMAT ( $1 \mathrm{X},{ }^{\prime}$ CHOSEN ENDTIME TOO LARGE FOR THIS FILE')

END 
SUBROUTINE SPEC (DAMPFC, DELTIM, FREQMN, FREQMX, INDXBEG, INDXEND, INDXPER, PERIOD, PSRVAL, DAT)

SPEC - CALCULATE PSRV'S

D. L. DOWNS . $08 / 08 / 83$.

M. L. SANDERS. 09/22/86. NOS/VE VERSION. REMOVED THE COMMON AND NOW PASS THE DATA ARRAY AS A PARAMTER.

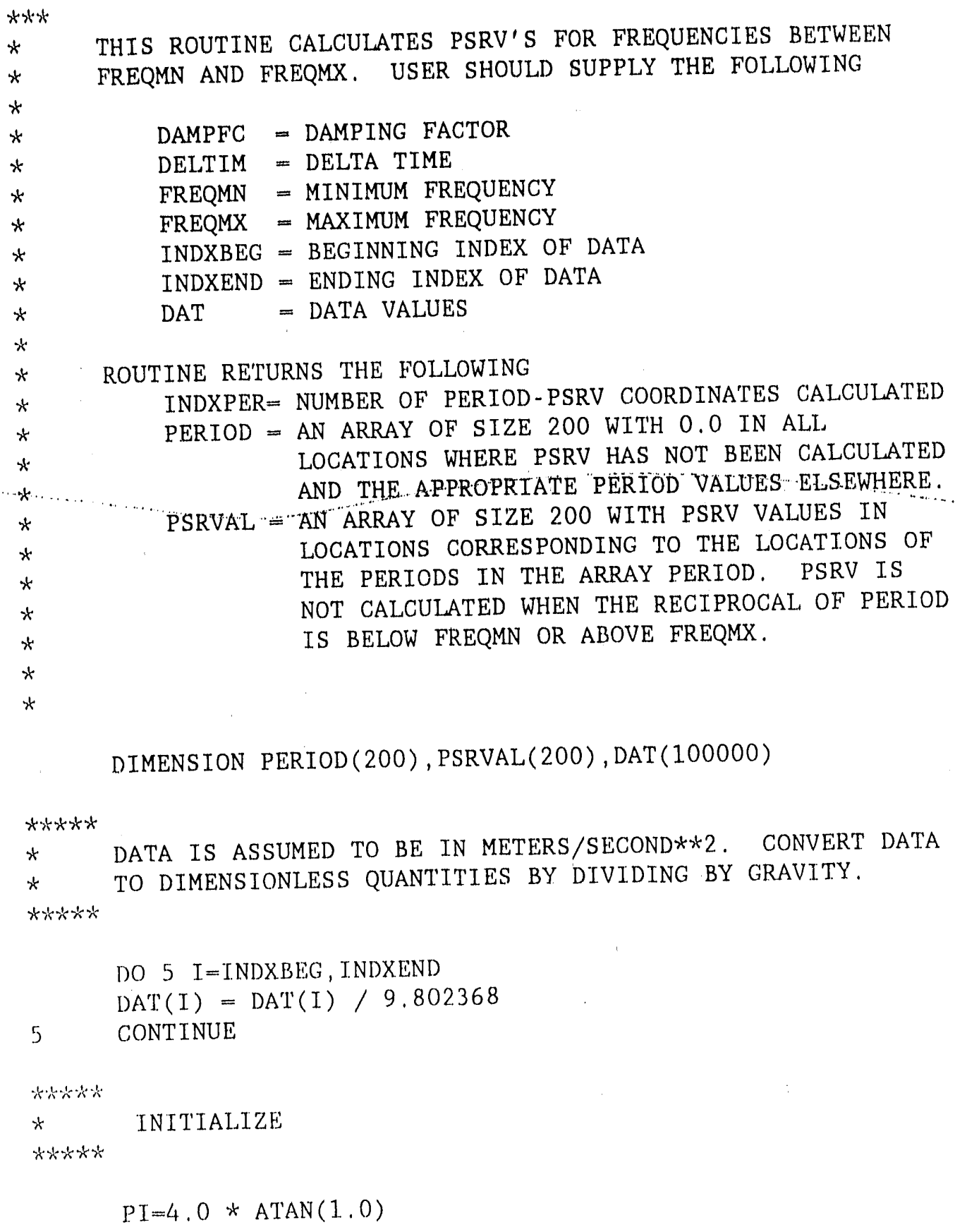

DAMPFC = DAMPING FACTOR

DELTIM DELTA TIME

FREQMN = MINIMUM FREQUENCY

FREQMX $=$ MAXIMUM FREQUENCY

INDXBEG $=$ BEGINNING INDEX OF DATA

INDXEND $=$ ENDING INDEX OF DATA

DAT $=$ DATA VALUES

ROUTINE RE'TURNS THE FOLLOWING

INDXPER $=$ NUMBER OF PERIOD - PSRV COORDINATES CALCULATED

PERIOD = AN ARRAY OF SIZE 200 WITH 0.0 IN ALI. LOCATIONS WHERE PSRV HAS NOT BEEN CALCULATED AND THE A.PPROPRIATE PERTOOD VALUES ELSEWHERE.

PSRVAL " "AN ARRAY OF SIZE 200 WITH PSRV VALUES IN LOCATIONS CORRESPONDING TO THE LOCATIONS OF THE PERIODS IN THE ARRAY PERIOD. PSRV IS NOT CALCULATED WHEN THE RECIPROCAL OF PERIOD IS BELOW FREQMN OR ABOVE FREQMX.

DIMENSION PERIOD(200), PSRVAL(200), DAT(100000) 
$O M E G A=$ FREQMN $* 2.0 * \mathrm{PI}$

OMEGHI $=$ FREQMX $* 2.0 * \mathrm{PI}$

FREQ=FREQMN

PSRV cincle

$x+x+x$

$x$

$x$

$x$

$x$

$x+x+x$

USE NEWMARK BETA PARAMETER METHOD OF NUMERICAL INTEGRATION TO SOLVE T'HE DIFERENTIAL EQUATION FOR DISPIACEMEN'T USING DIFFERENT VALUES OF OMEGA, OMEGA REPRESENTS $2 *$ PI/PERTOD ANI) RANGES BETWEEN FREQMN * $2 *$ PI AND FREQMX * $2 *$ PI.

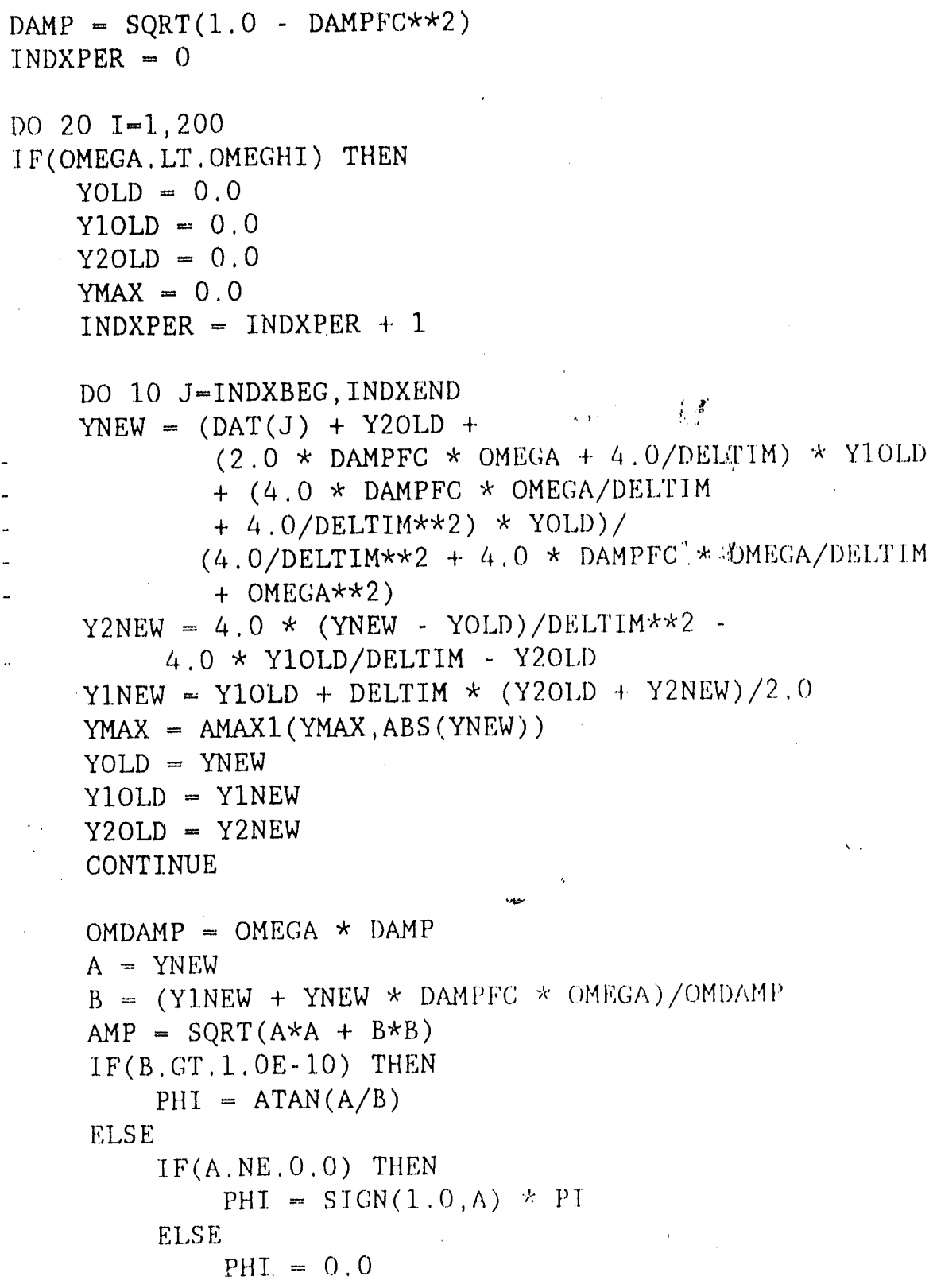




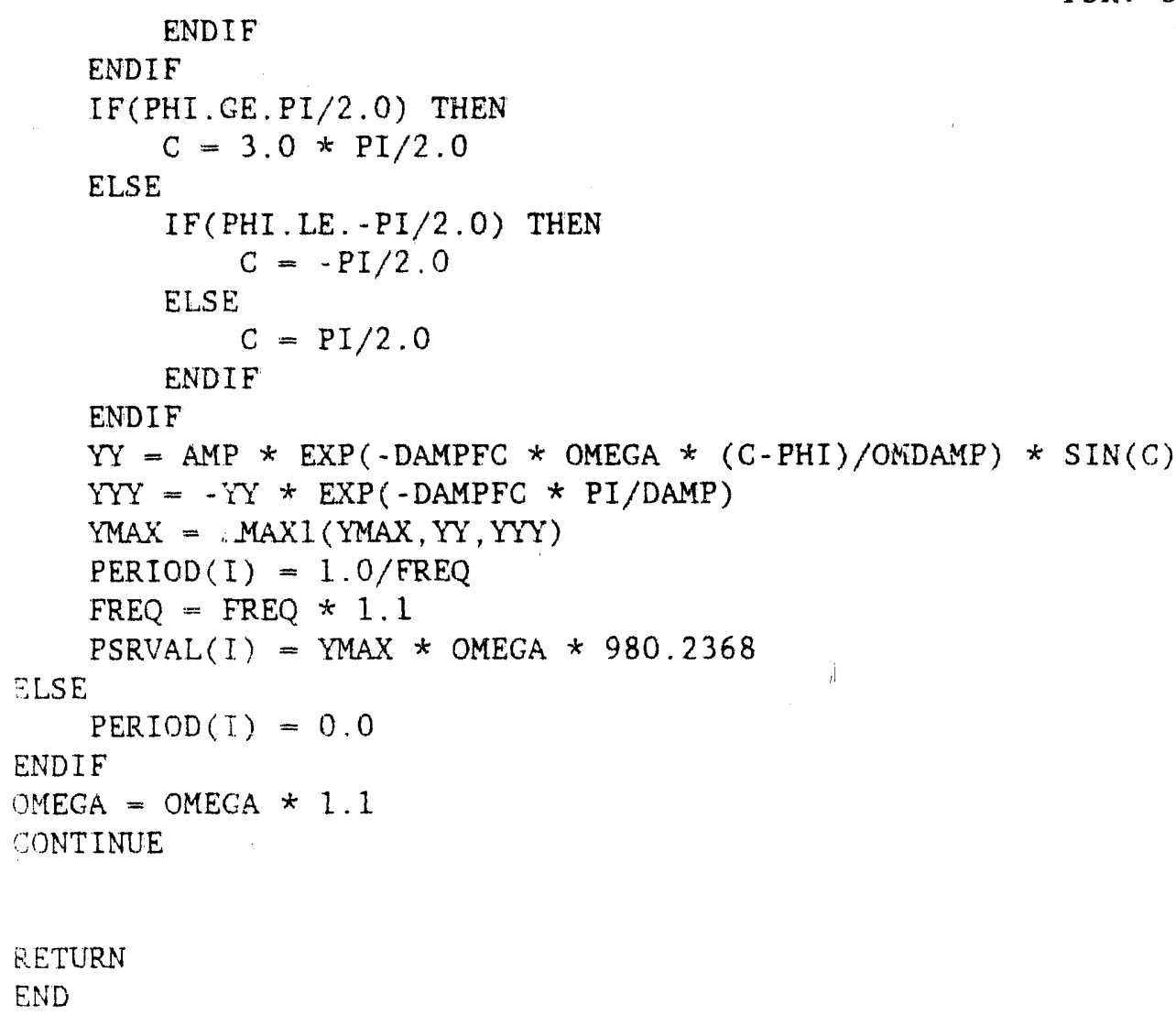


SUBROUTINE OUTPSRV (AMULT, BEGTIME, DAMPFC, DATAOUT,

\section{- $\quad$ ENDTIME, FREQMN, INDXPER, PSRVAL)}

OUTPSRV - CONSTRUCTS OUTPUT ARRAY

D. L. DOWNS. 08/08/83.

M. L. SANDERS. 09/22/86. NOS/NE VERSION.

REPLACE 'DATE(DAY)' WITH 'DATE ( )'.

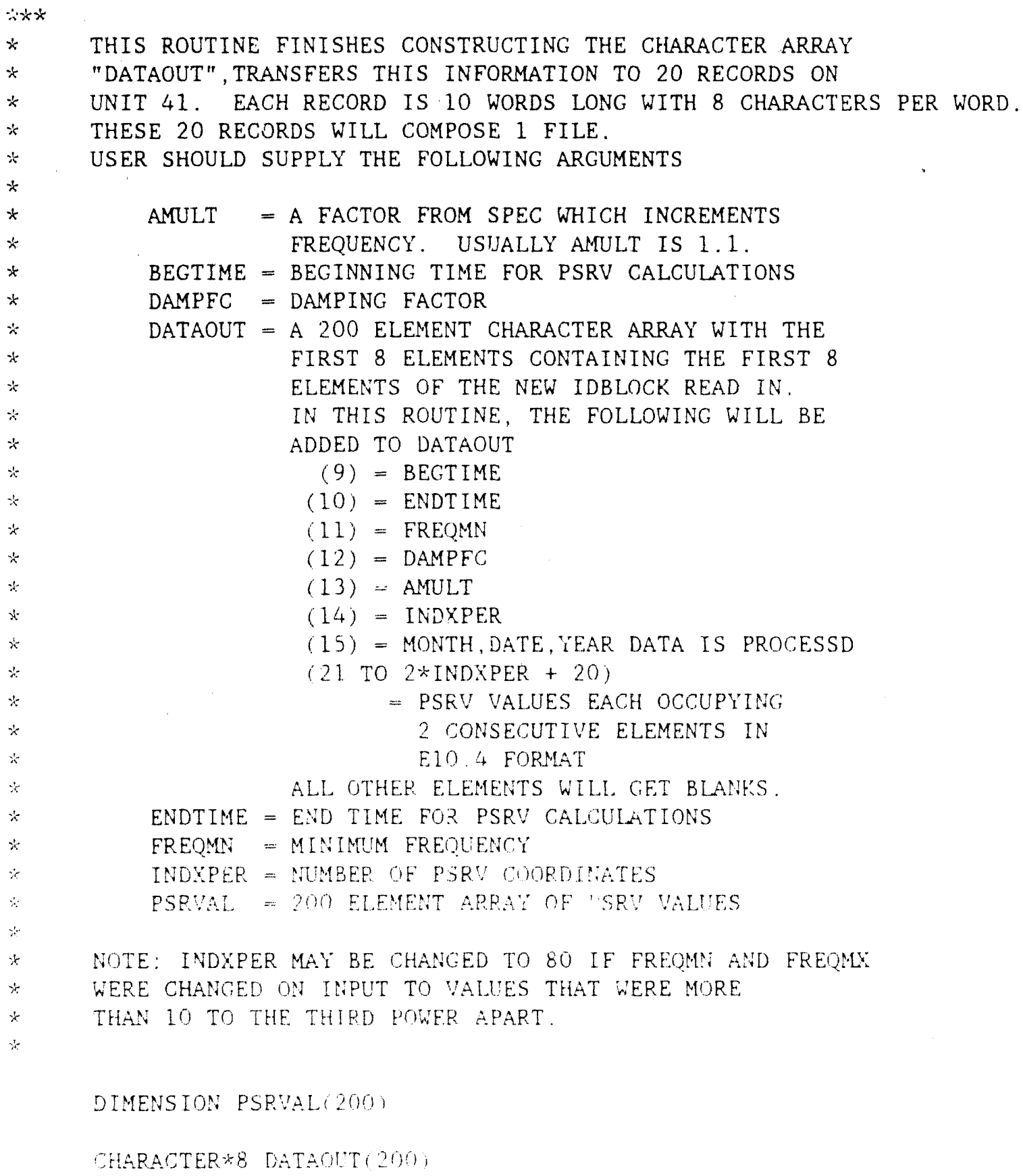


CHARACTER *10 STRING, DAT

$* * * * *$

* TRANSFER data to arRay dataout

$x+2 x * x$

WRITE (DATAOUT (9), '(F8.3)') BEGTIME

WRITE (DATAOUT (10), '(F8.3)') ENDTIME

WRITE (DATAOUT (11), ' (F8.2)') FREQMN

WRITE(DATAOUT (12),' (F8.4)') DAMPFC

WRITE (DATAOUT (13), ' (F8.2)') AMULT

* IF INDXPER IS LARGER THAN 80 , THEN IT GETS SET TO 80 ,

* A WARNING MESSAGE IS PRINTED, AND ONLY THE FIRST 80

* PSRV VALUES ARE SAVED. NORMALly THIS WILl NOT HAPPEN.

$* x * x * x$

IF (INDXPER.GT . 80) THEN

INDXPER $=80$

$\operatorname{WRITE}(6,101)$

ENDIF

WRITE(DATAOUT (14), ' (I8)') INDXPER

CALL DATE(DAT)

STRING $=$ DAT

$\operatorname{DATAOUT}(15)=\operatorname{STRING}(1: 4) / / \operatorname{STRING}(6: 7) / / \operatorname{STRING}(9: 10)$

DO $5 \mathrm{I}=16,200$

$\operatorname{DATAOUT}(I)=$,

5 CONTINUE

DO $10 \quad I=1$, INDXPER

WRITE (STRING , '(E10.4)') PSRVAL(I)

DATAOUT $(2 * I+19)=\operatorname{STRING}(1: 8)$

$\operatorname{DATAOUT}(2 * I+20)=\operatorname{STRING}(9: 10)$

10 CONTINUE

RETURN

101 FORMAT $\left(/ / 1 \mathrm{X},{ }^{\prime} * * * * * *\right.$ TOO MANY PSRV VALUES $* * * * * \cdots$,

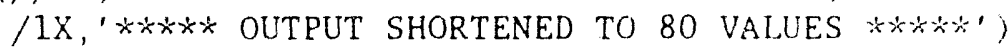

END 
SUBROUTINE SCALE (INDXPER, PERIOD, PSRVAL, XL, XR, YB , YT)

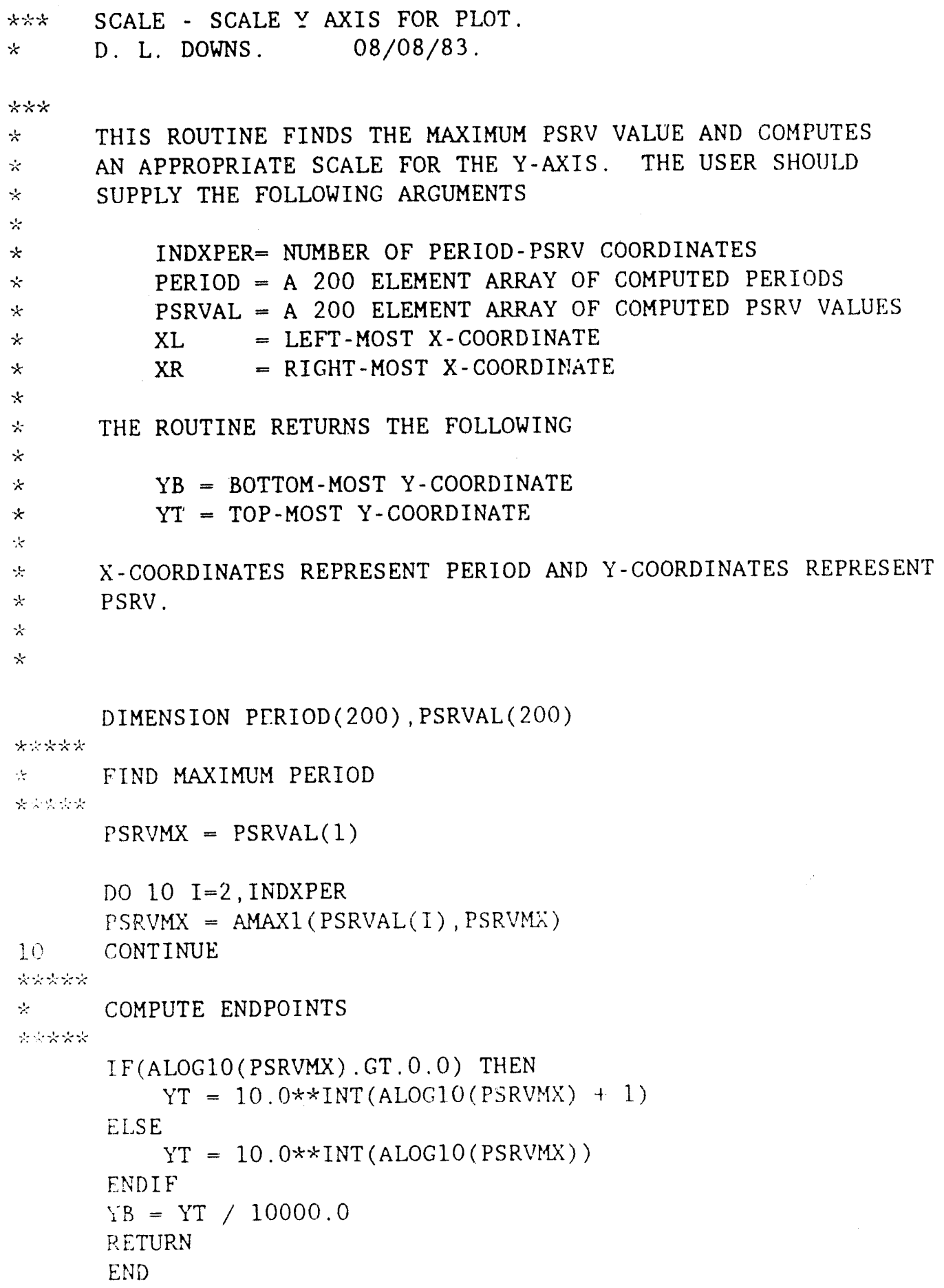


SUBROUTINE DRWCUR (INDXPER, PERIOD, PSRVAL)

$x *$ DRWCUR - PLOTS THE CURVE.

$*$ D. L. DOWNS. 08/08/83.

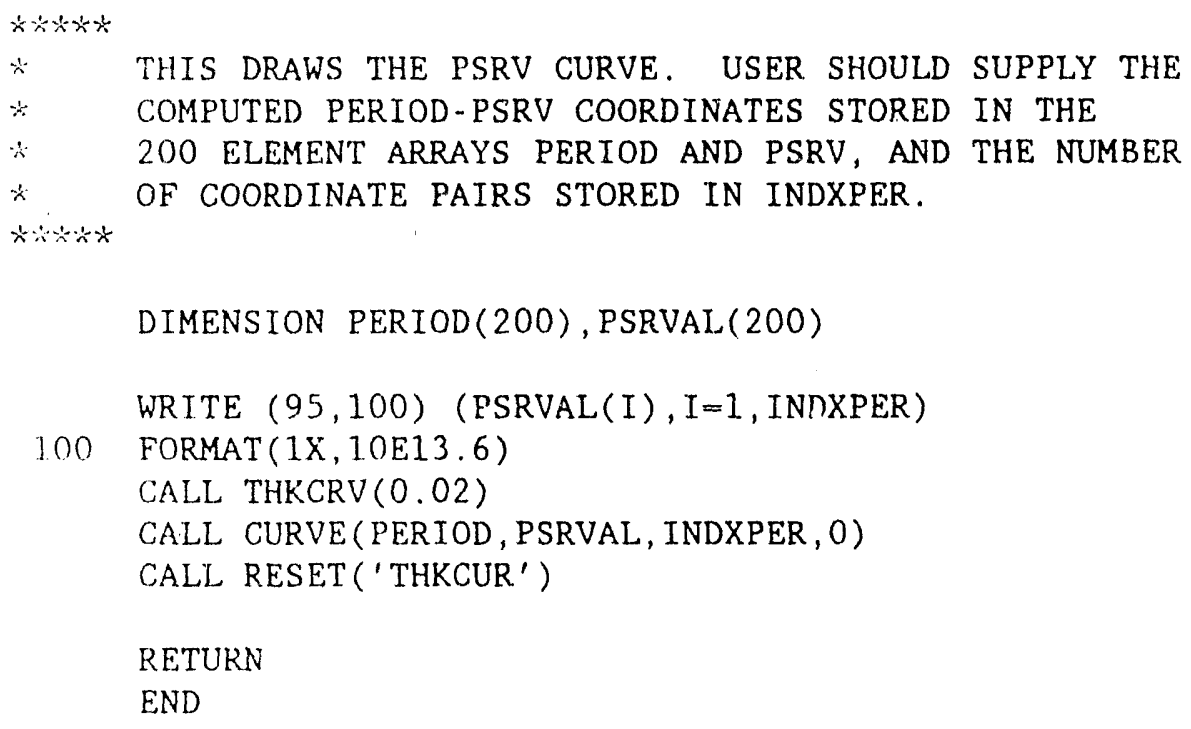


SUBROUTINE LGLGLG (AMPFAC, BEGTIME, DAMPFG, ENDTIME, EVNTNAM,

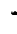
FREQUEN, GAUGEOR, ROTANG , STATNUM, TRACK, XL, XR, YB , YT , EVNTNUM, STAMED, STARNG , I I)

LGLGLG - CONSTRUCTS A GRID.

D. L. DOWNS . $08 / 08 / 83$.

M. L. SANDERS. 09/22/86. NOS/VE VERSION.

REPLACE 'DATE(DAY)' WITH 'DATE()',

THIS ROUTINE CONSTRUCTS A LOG-LOG-LOG GRID. THE USER SHOULD SUPPLY THE FOLLOWING ARGUMENTS

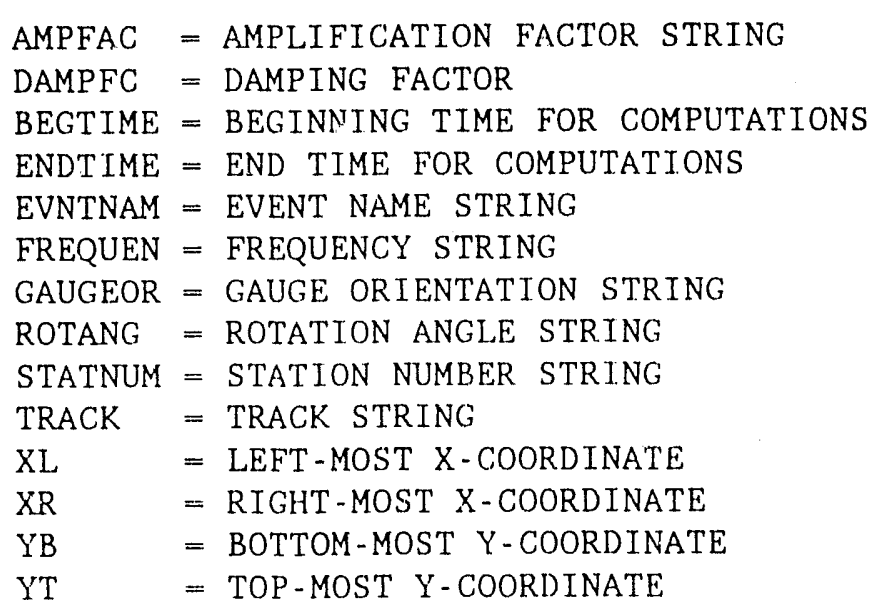


DATA LXNAME/'PERIOD - SEC'/,'IXNAME/12/, IYNAME/42/

DATA LYNAME/'PSEUDO RELATIVE RESPONSE VELOCITY - CM/SEC'/

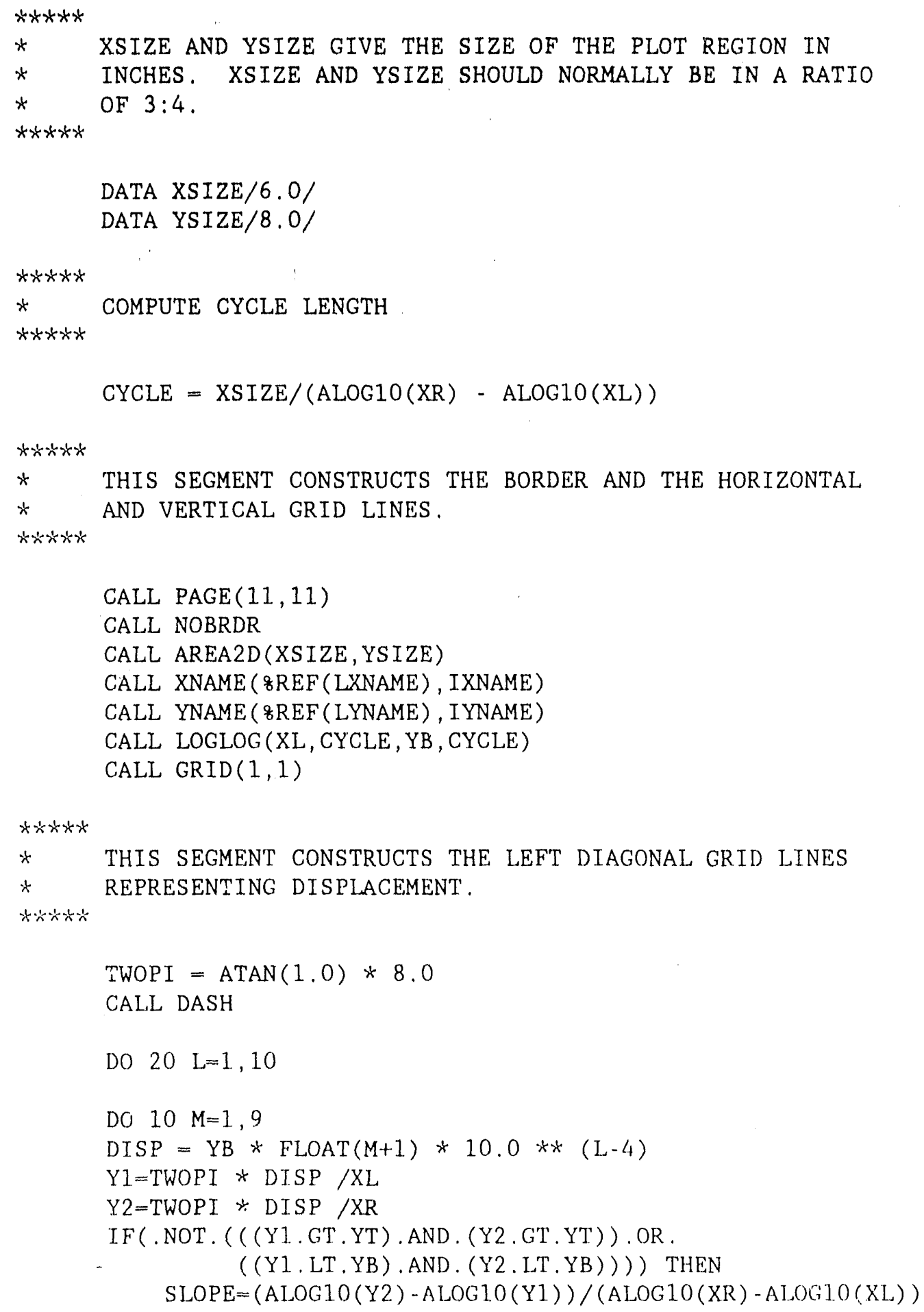




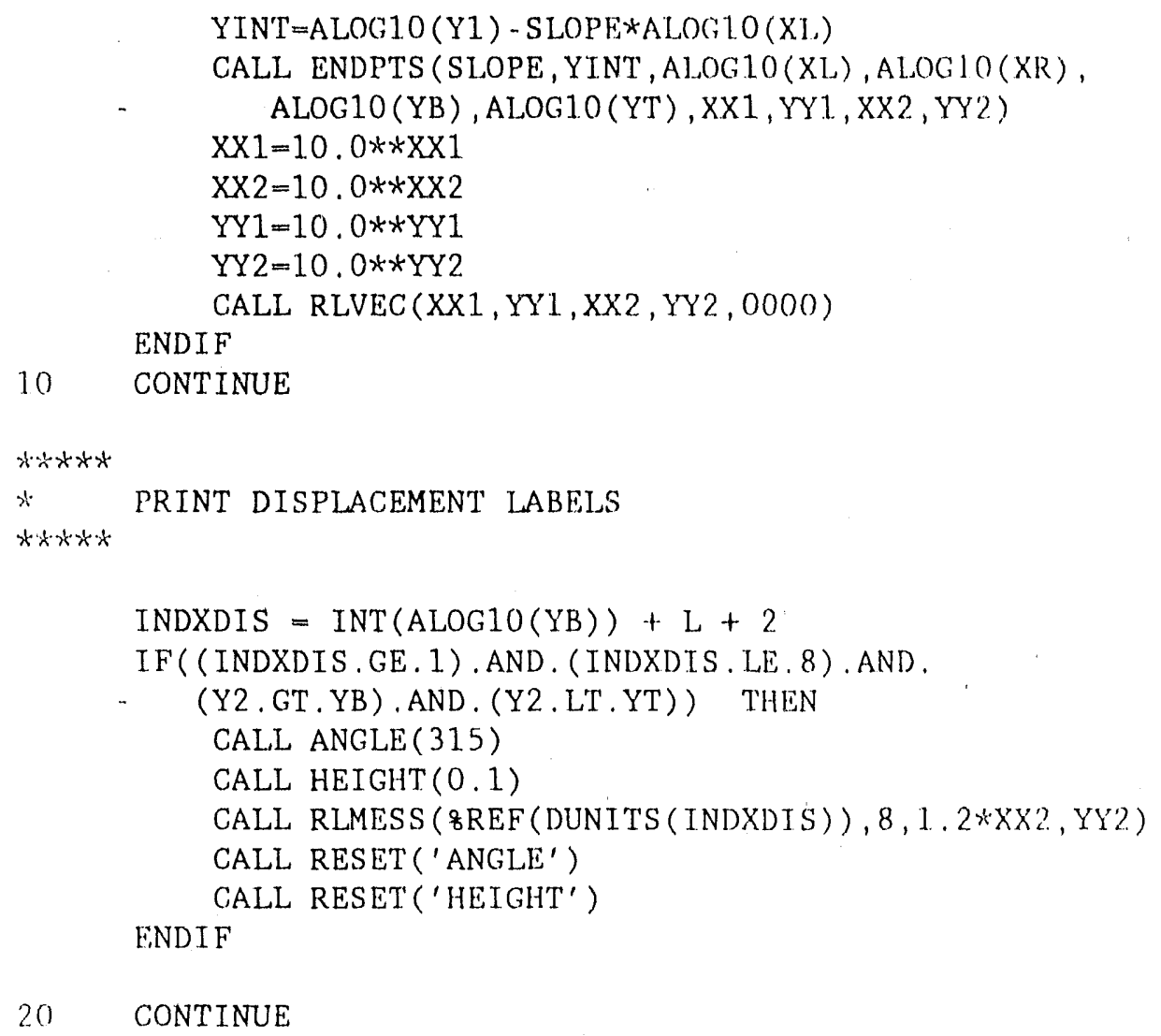




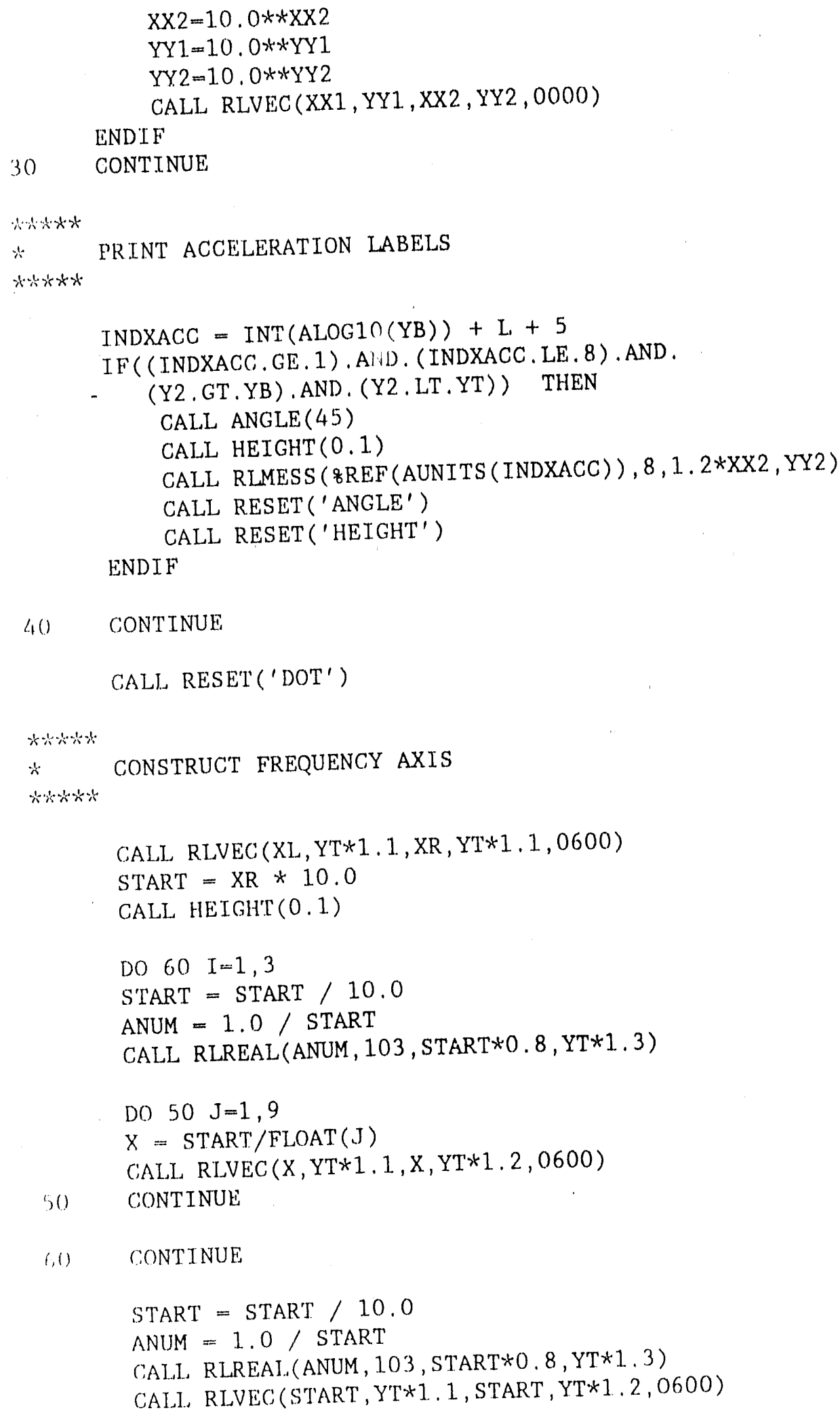


CALL RESET ('HEIGHT')

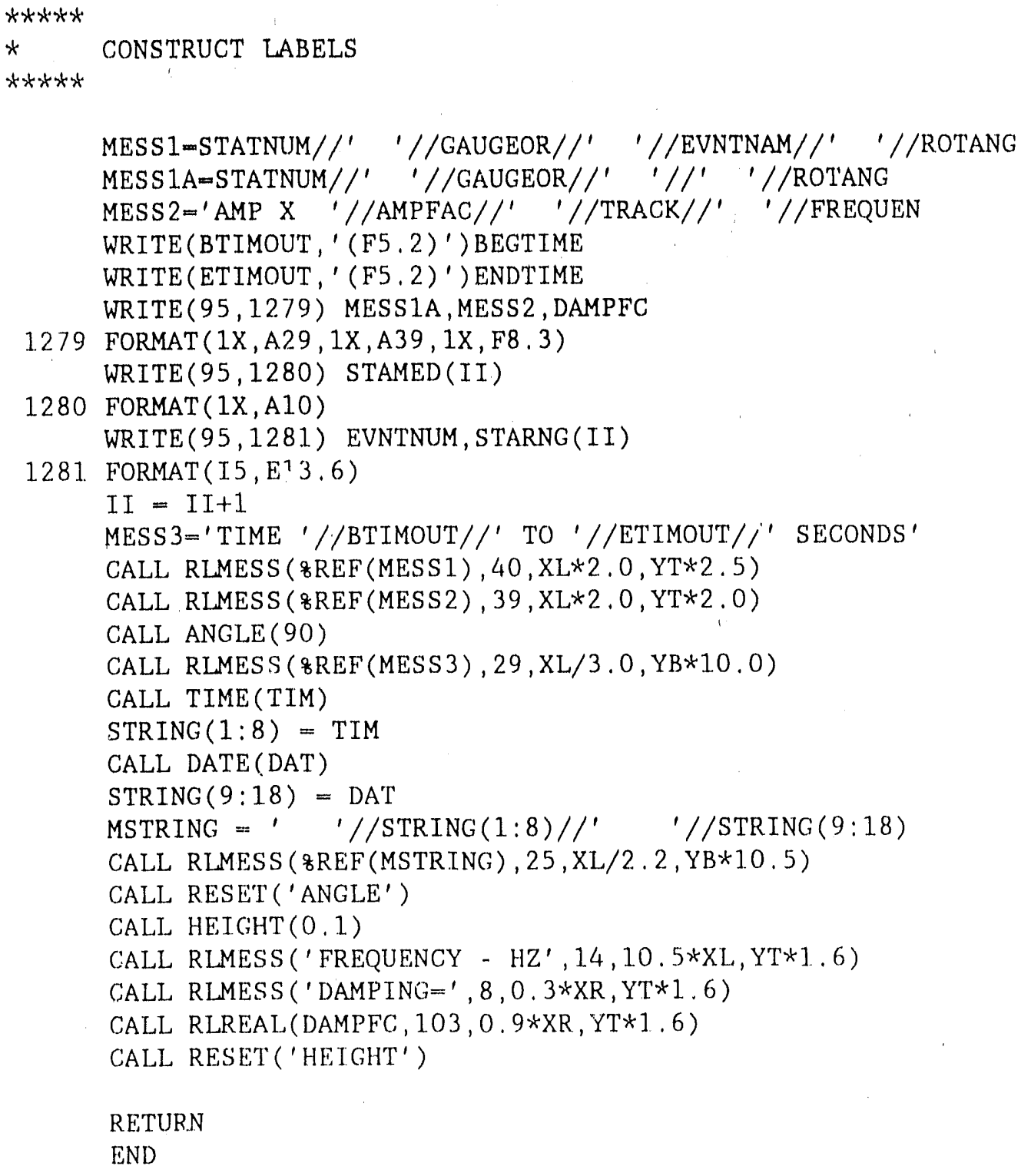


SUBROUTINE ENDPTS (SLOPE, YINT, XLEFT, XRIGHT, YBOT, YTOP,

$X X 1, Y Y 1, X X 2, Y Y 2)$

ENDPTS - DETERMINE ENDPOINTS FOR THE AXIES.

D. L. DOWNS . 08/08/83.

M. L. SANDERS. 09/22/86, NOS/VE VERSION.

$3 * x+4 x$

$\ddot{k}$

THIS ROUTINE RETURNS THE ENDPOINTS OF A GRAPH WITH $X$-SCALE FROM "XLEFT" TO "XRIGHT" AND Y-SCALE FROM "YBOT" TO "YTOP". USER MUST SUPPLY THE FOLLOWING ARGUMENTS ON INPUT

SLOPE = SLOPE OF THE LINE SEGMENT

YINT $=$ Y-INTERCEPT OF THE LINE SEGMENT

XLEFT $=$ LEFT-MOST X-COORDINATE

XRIGHT $=$ RIGHT-MOST X-COORDINATE

YBOT $=$ BOTTOM-MOST Y-COORDINATE

YTOP $=$ TOP-MOST Y-COORDINATE

THE ROUTINE RETURNS THE FOLLOWING

$X X 1=X$-COORDINATE OF LEFT ENDPOINT

$\mathrm{YY} 1=\mathrm{Y}$-COORDINATE OF LEFT ENDPOINT

$\mathrm{XX} 2=\mathrm{X}$-COORDINATE OF RIGHT ENDPOINT

$\mathrm{XX} 3=\mathrm{Y}$-COORDINATE OF RIGHT ENDPOINT

$Y Y=S L O P E * X L E F T+Y I N T$

IF (YY.LT.YBOT) THEN

$X X 1=(Y B O T-Y I N T) / S L O P E$

$Y Y 1=Y^{\prime}{ }^{\prime}{ }^{\prime}$

ELSE

IF (YY.GT . YTOE) THEN

$X X I=(Y T O P-Y I N T) / S L O P E$

$Y Y 1=Y T O P$

ELSE

$X X 1=X L E F T$

ENDIF

$Y Y 1=Y Y$

ENDIF

$Y Y=S L O P E * X R I G H T+Y I N T$

IF (YY.LT.YBOT) THEN

$X X 2=(Y B O T-Y I N T) / S L O P E$

$Y Y 2=Y B O T$

ELSE

IF (YY.GT.YTOP) THEN

$X X 2=(Y T O P-Y I N T) / S L O P E$ 


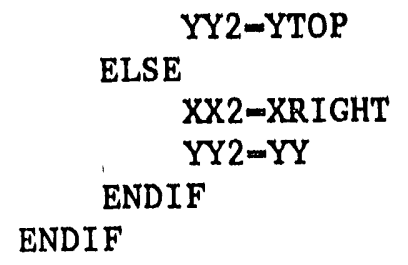

END 
SUBROUTINE READID(LUI, IDBUF, IEOI)

$* * *$ READID - READ CHANNEL ID BLOCK.

* T. L. P. BUTLER, 12/16/83.

READID READS A CHANNEL ID BLOCK FROM A GIVEN INPUT

UNIT. READID PERFORMS A FORMATTED READ.

PARAMETERS

$$
\begin{array}{ll}
\text { LUI } & \text { INPUT LOGICAL UNIT } \\
\text { IDBUF - } & \text { CHANNEL ID BUFFER } \\
\text { IEOI } & \text { END OF INFORMATION FLAG } \\
& 0, \text { NORMAL RETURN } \\
& 1, \text { END OF FILE ENCOUNTERED }
\end{array}
$$

ENTRY INPUT UNIT GIVEN, UNIT MUST BE OPEN AND CORRECTLY POSITIONED ON ENTRY.

EXIT' CHANNEL ID BLOCK RETURNED IN ID BUFFER. IF END OF FILE ENCOUNTERED END OF INFORMATION

FLAG IS SET, AND ID BUFFER CONTENTS ARE UNDEFINED.

ERRORS

FILE I/O ERROR

CALLS NONE.

CHARACTER $* 8$ IDBUF (100)

$J E O I=0$

$\operatorname{READ}(L U 1, '(10 A 8) ', E R R=20$, IOSTAT $=$ IOERR, $E N D=10)$ IDBUF

RETURN

w

END OF INFORMATION

1.) $\quad \mathrm{IEOI}=1$

RETURN

$\dot{x}$

ERROR ON FILE READ

20 WRITE $(6,100)$ IOERR

CALL EXIT

$100 \operatorname{FORMAT}(/, 2 \mathrm{X}$, ' ERROR ', I5,' ON INPUT FILE READ IN READID. ')

END 
SUBROUTINE READDT (LUI, IVAL, NDVAL, IEOI)

‘*** READDT - READ CHANNEL DATA.

* T. L. P. BUTLER, 1.2/16/83.

*** READDT READS THE COMPRESSED DATA VECTOR FOR A

* channel from a given input unit. REAdd't performs

* A FORMATTED READ.

$*$

PARAMETERS

LUI - INPUT LOGICAL UNIT

IVAL - CHANNEL DATA VECTOR

NDVAL - CHANNEL DATA VECTOR LENGTH

IEOI - END OF INFORMATION FLAG

0 , NORMAL RETURN

1. END OF FILE ENCOUNTERED

EN'TRY INPUT UNIT AND VECTOR LENCTH GIVEN, UNIT MUS'T BE OPEN AND CORRECTLY POSITIONED ON ENTRY.

EXIT CHANNEL DATA VECTOR RETURNED. IF END OF FILE ENCOUNTERED, END OF INFORMATIION FLAG IS SET

AND CONTENTS OF DATA VECTOR ARE UNDEFINED.

ERRORS

FILE I/O ERROR

CALLS NONE.

DIMENSION IVAL(NDVAL)

$I E O I=0$

$*$

DETERMINE NUMBER OF RECORDS TO READ FROM FILE

$\mathrm{NREC}=\mathrm{NDVAL} / 1.6$

NLFT' $=$ MOD $($ NDVAL, 16$)$

$I N X=1$

*

READ TNTEGRAL, RECORDS

IF(NREG,G'T,O) THEN

DO $10 T=1$, NREC;

$\operatorname{READ}\left(\right.$ LUT, , $(1615)^{\prime}$, END $\left.=15\right)$ 


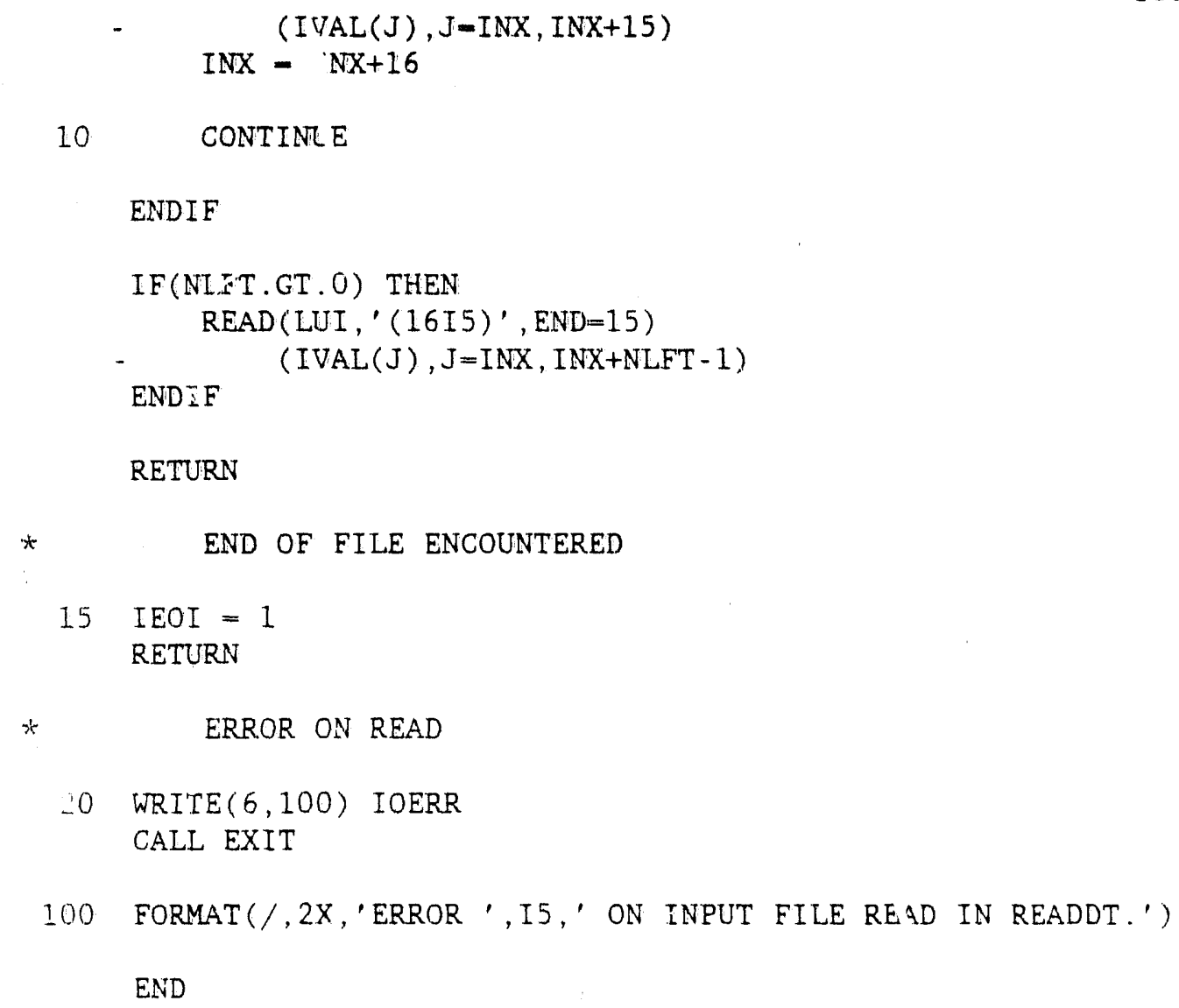


SUBROUTINE GRMNX (IDBUF, DMIN, DMAX, CCONST) 
SUBROUTINE EXPAND(DMIN, IVAL, DVAL, NSIZ, CCONST)

$*:$ EXPAND - EXPAND COMPRESSED DATA VALUES.

T. L. P. BUTLER. 08/02/83.

EXPAND PERFORMS A REVERSE TRANSFORM ON DATA THAT HAS BEEN COMPRESSED USING *COMPRESS*. EXPAND WILI PROCESS A BLOCK OF ANY GIVEN SIZE WITHIN THE MEMORY CONSTRAINTS OF THE MACHINE. THE REAL RESULTS ARE RETURNED IN DVAL.

THE REVERSE TRANSFORM IS AS FOLLOWS -

DVAL $=($ IVAL $*$ COMPRESSION CONSTANT $)+$ DMIN

\section{PARAMETERS}

DMIN - DATA SET MINIMUM VALUE

IVAL - INPUT VECTOR OF INTEGER VALUES

DVAL - OUTPUT VECTOR OF REAL VALUES

NSIZ - INPUT VECTOR LENGTH

CCONST - COMPRESSION CONSTANT

ENTRY DATA MINIMUM, DATA VECTOR, VECTOR LENGTH, AND COMPRESSION CONSTANT GIVEN.

EXIT

EXPANDED REAL VALUES RETURNED.

ERRORS NONE.

CALLS NONE.

DIMENSION DVAL(NSIZ), IVAL(NSIZ)

EXPAND DATA BLOCK

DO $10 I=1$, NSIZ

$\operatorname{DVAL}(I)=\operatorname{REAL}(\operatorname{IVAL}(I)) * \operatorname{CCONST}+\operatorname{DMIN}$

10 CONTINUE

RETURN

END 
"FIT - MULTIPLE EVENT VERSION" 
C

$\mathrm{C}$

C

$\mathrm{C}$

C

$\mathrm{C}$

C

C

$\mathrm{C}$

THIS PROGRAM IS USED TO DO MILTIPLE LINEAR REGRESSIONS ON THE PSRV DATA CALCULATED FROM THE PSRV CODE AND PROCESSED THE PREPRO CODE. THE PROGRAM USES ROUTINES FROM THE IMSL MATH LIBRARY.

THE INPUT DATA IS ON TAPE 96 REGRESSION PARAMETERS ARE OUTPUT ON 'FITOUT'. THE DATA ARE PLOTTED USING DISSPLA ROUTINES.

INTEGER EVNTNUM $(80,1500)$

DIMENSION WEVENT $(80,1500), \operatorname{STARNG}(80,1500), \operatorname{AMP}(80,1500)$, $\& \operatorname{NBR}(6), \operatorname{TEMP}(3), \mathrm{XM}(3), \mathrm{X}(1500,3), \mathrm{Y}(1500,3), \mathrm{A}(6)$, $\&$ ANOVA $(14), B(3,7), \operatorname{VARB}(3), \mathrm{X} 1(1500), \mathrm{X} 2(1500), \mathrm{RS}(1500)$, $\& \mathrm{PV}(1500), \mathrm{FP}(80)$

CHARACTER $* 10$ FREQ $(80)$

CHARACTER $* 5$ SITE

CHARACTER $* 8$ GAGEOR

OPEN (UNIT $=96$, FILE $=$ ' TAPE96' $^{\prime}$, STATUS $={ }^{\prime}$ OLD' $)$

OPEN (UNIT $=6$, FILE $=$ 'FITOUT' , STATUS $=$ ' NEW' $)$

OPEN (UNIT $=98$, FILE $=$ ' FITCOEF' , STATUS $=$ 'NEW' $)$

CALL VSTART $(0.0,0)$

C

$\mathrm{C}$

C

C

C

C

READ INPUT

READ $(96,100)$ NTOT, SITE, GAGEOR

WRITE $(6,800)$ NTOT, SITE, GAGEOR

SET UP THE NBR ARRAY FOR THE BECOVM ARRAY

$\operatorname{NBR}(1)=3$

$\operatorname{NBR}(2)=$ NTOT

$\operatorname{NBR}(3)=$ NTOT

$\operatorname{NBR}(4)=1$

$\operatorname{NBR}(5)=1$

$\operatorname{NBR}(6)=1$

C

C SET UP FREQUENCY ARRAY FOR SORTING

$\mathrm{FP}(1)=0.1$

DO $1234 \quad I=2,73$

$F P(I)=F P(I-1) * 1.1$

1234 CONTINUE

DO $1000 \quad I=1,73$

$\operatorname{READ}(96,200)$ FREQ(I)

$\&$

$\operatorname{REAd}(96,300)(\operatorname{EvNTNUM}(I, J), \operatorname{WEV} \operatorname{ent}(I, J), \operatorname{STARNG}(I, J), \operatorname{AMP}(I, J)$, $\mathrm{J}=1$, NTOT) 


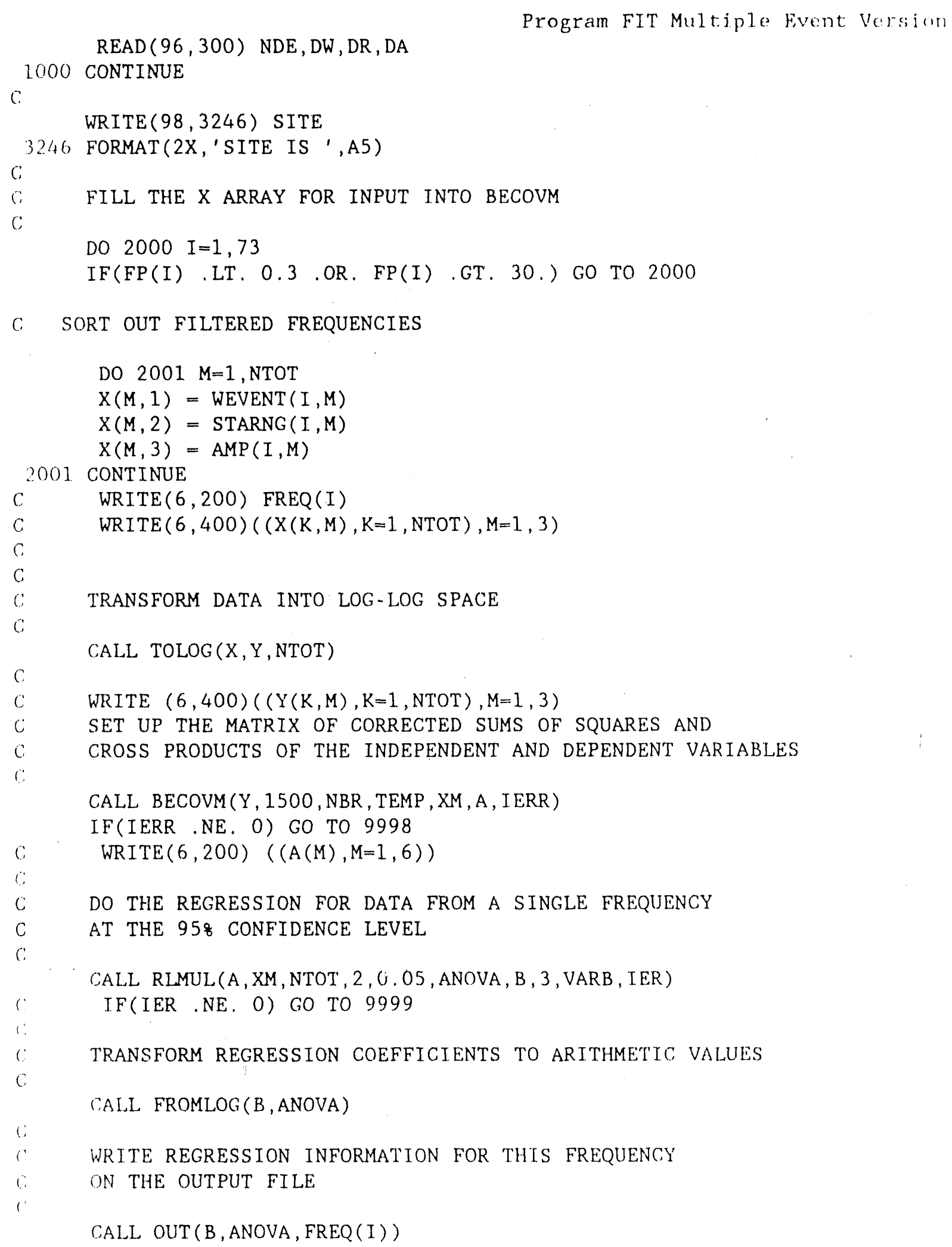


(:) SET UP DATA FOR PLOTTING AND PLOT RESULTS FOR THIS FREQUENCY

C

CALL SETPLOT (X, B, NTOT, FREQ (I), SITE, GAGEOR)

(: $\quad \mathrm{IF}(\mathrm{I}, \mathrm{EQ}, 1)$ GO TO 999

2000 CONTINUE

GO TO 999

m98 WRITE $(6,600)$ IERR

CO TO 999

1,999 $\operatorname{WRITE}(6,700)$ IER

GO TO 999

100 FORMAT $(1 \mathrm{X}, \mathrm{I} 5,1 \mathrm{X}, \mathrm{A} 5,1 \mathrm{X}, \mathrm{A} 8)$

200 FORMAT (A10)

300 FORMAT (T 4, 3E12.6)

$4(10)$ FORMAT $(3(3 \mathrm{E} 12.6))$

$1,00) \operatorname{FORMAT}(/ /, 2 \mathrm{X}$, 'ERROR IN BECOVM', I10)

$100 \operatorname{FORMAT}(/ /, 2 \mathrm{X}$, ' ERROR IN RLMUL', I10)

800 FORMAT $(2 \mathrm{X}$, TOTAL NUMBER OF DATA POINTS ANALYZED IN THIS

\&RUN $=1$, I5,$/ /, 2 \mathrm{X}$, 'RECORDING SITE GEOLOGY IS ' , A5, //, $2 \mathrm{X}$, \&'GAGE ORIENTATION OF THESE DATA IS ', A $8, / /$ )

y9? CALL DONEPL

END 


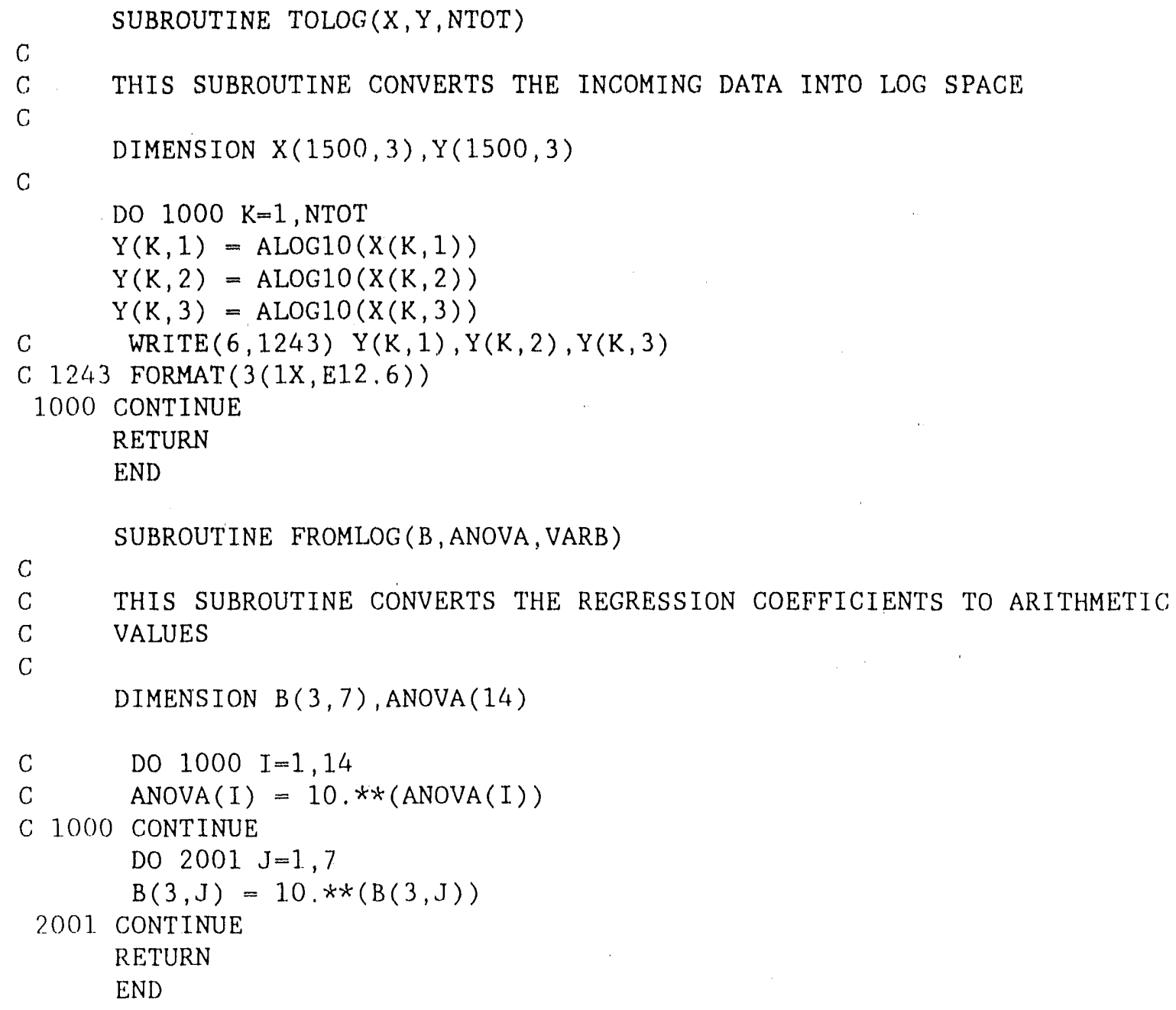


SUBROUTINE OUT (B, ANOVA, FREQ)

C

$\&$

THIS SUBROUTINE WRITES THE CALCULATED REGRESSION COEFFICIENTS

IN A READABLE FORMAT ON THE OUTPUT FILE

DIMENSION B $(3,7)$, ANOVA (14)

CHARACTER $* 10$ FREQ

$\operatorname{WRITE}(6,100)$ FREQ

$\operatorname{WRITE}(6,200)$

$\operatorname{WRITE}(6,300) \quad(B(I, 1), I=1,3)$

$\operatorname{EXPO}=\operatorname{ABS}(B(2,2) * B(1,1) / B(2,1))$

$\operatorname{EXPO1}=\operatorname{ABS}(B(2,3) * B(1,1) / B(2,1))$

$\operatorname{WRITE}(98,1100)(B(I, 1), I=1,3), \operatorname{EXPO},(B(J, 2), J=2,3)$,

$\operatorname{EXPO1},(B(K, 3), K=2,3)$

WRITE $(6,400) \quad(B(I, 2), I=1,3)$

$\operatorname{WRITE}(6,500) \quad(B(I, 3), I=1,3)$

$\operatorname{WRITE}(6,600) \quad(B(I, 4), I=1,3)$

$\operatorname{WRITE}(6,700) \quad(B(I, 5), I=1,3)$

$\operatorname{WRITE}(6,800) \quad(B(I, 6), I=1,3)$

$\operatorname{WRITE}(6,900) \quad(B(I, 7), I=1,3)$

$\operatorname{WRITE}(6,1000)(\operatorname{ANOVA}(I), I=1,14)$

FORMAT' $(/ / /, 2 \mathrm{X}$, ' FREQUENCY IS ' , $2 \mathrm{X}, \mathrm{A} 10)$

FORMAT $(/ /, 2 \mathrm{X}, '$ REGRESSION COEFFICIENTS CALCULATED FOR THIS

\& FREQUENCY',$/ /$ )

FORMAT (2X, ' YIELD COEFFICIENT $=1$, E13 $.6, / /, 2 \mathrm{X},{ }^{\prime}$ RANGE

$\&$ COEFFICIENT $='$, E13.6, $/ /$,

$\& 2 \mathrm{X},{ }^{\prime}$ INTERCEPT $=1$, E13.6, //)

400 FORMAT (2X, 'LOWER CONFIDENCE LIMITS FOR:',$/ /, 2 \mathrm{X}$,

$\&^{\prime}$ YIELD $=1$, E13.6,2X, ${ }^{\prime}$ RANGE $=1$, E13.6

$\&, 2 \mathrm{X},{ }^{\prime}$ INTERCEPT $={ }^{\prime}$, E13.6)

500 FORMAT $\left(/ /, 2 \mathrm{X},{ }^{\prime}\right.$ UPPER CONFIDENCE LIMITS FOR:',$/ /, 2 \mathrm{X}$

$\&,{ }^{\prime}$ YIELD $=$ ', E13 $, 6,2 \mathrm{X},{ }^{\prime}$ RANGE $=$ ', E13.6, $2 \mathrm{X}$,

\&'INTERCEPT $=\prime$, E13.6)

600 FORMAT $\left(/ /, 2 \mathrm{X},{ }^{\prime}\right.$ STANDARD ERROR FOR: ${ }^{\prime}, / /, 2 \mathrm{X}$, $\&^{\prime}$ YIELD $=\prime$, E13 $.6,2 \mathrm{X},{ }^{\prime}$ RANGE $='$, E13.6, $2 \mathrm{X}$,

$\&^{\prime}$ INTERCEPT $=\prime$, E13,6)

700 FORMAT $\left(/ /, 2 \mathrm{X},{ }^{\prime}\right.$ ADJUSTED SUMS OF SQUARES FOR:',$/ /, 2 \mathrm{X}$, $\&^{\prime}$ YIELD $=\prime$, E16. $6,2 X,{ }^{\prime}$ RANGE $='$, E13.6, $2 X$,

$\&^{\prime}$ INTERCEPT $='$, E13.6)

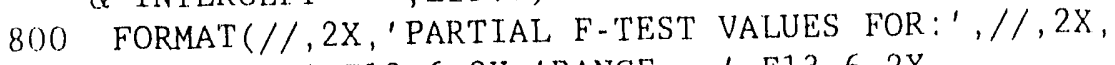
$\&^{\prime}$ YIELD $=\prime$, E13 $, 6,2 \mathrm{X},{ }^{\prime}$ RANGE $={ }^{\prime}$, E13 $, 6,2 \mathrm{X}$,

$\&^{\prime}$ IN'TERCEPT $=\prime$, E13.6)

900 FORMAT $\left(/ /, 2 \mathrm{X},{ }^{\prime} \mathrm{P}(\right.$ EXCEEDTNG F UNDER HO)',$/ /, 2 \mathrm{X}$, $\&^{\prime}$ YIELD $='$, E13 $, 6,2 \mathrm{X},{ }^{\prime}$ RANGE $='$, E13.6, $\& 2 X,{ }^{\prime}$ INTERCEPT $=$ ', E13.6)

1000 FORMAT $(/ /, 2 \mathrm{X}$, 'ANALYSIS OF VARIANCE',$/ /, 2 \mathrm{X}$, \&'DEGREES OF FREEDOM' $, / / 2 \mathrm{X},{ }^{\prime}$ REGRESSION $=$ ', E1.3.6, $2 \mathrm{X}$, 
Program FTT Multiple fivent Versijull

\&'RESIDUAL $=\prime$, E1.3.6,' CORRECTED TO'TAL $=$ ',

\&E13.6,//,' SUMS OF SQUARES',//,2X,

$\&^{\prime}$ REGRESSION $=\prime$, E13.6, $2 \mathrm{X},{ }^{\prime}$ RESTDUAL $=$

$\&, \mathrm{E} 13,6,2 \mathrm{X},{ }^{\prime}$ CORRECTED TOTAL $=', \mathrm{E} 13.6, / /$,

\&'MEAN SQUARES' $/ /, 2 \mathrm{X},{ }^{\prime}$ REGRESSION $=\prime$, E13.6, $2 \mathrm{X}$,

$\&^{\prime}$ RESIDUAL $=\prime$, E13.6,//,'F-VALUE',$/ /, 2 \mathrm{X}$,

\&'REGRESSION $=\prime$, E13 $, 6, / /,{ }^{\prime}$ P(EXCEEDTNG F UNDER HO) ',

$\& / /, 2 \mathrm{X},{ }^{\prime}$ REGRESSION $=1$, E13.6, $/ /, 2 \mathrm{X}$,

$\&$ 'PERCENTAGE VARIATION EXPLAINED BY 'THE ESTIMA'TED MODEL IS '

$\&$, E13,6,//,2X, 'STANDARD DEVIATION OF THE RESTDUALS

\&IS ', E13.6, //,2X,

\&'RESIDUAL STANDARD DEVIATION AS A \& OF THE RESPONSE

\&MEAN IS ', E13.6, //,2X,'NUMBFR OF DECIMAL DIGITS

$\& O F$ ACCURACY IN THE

\&REGRESSION COEFFICTENTS IS ', E13.6)

1.1.00 FORMAT $(1 \mathrm{X}, 9 \mathrm{E}, 13,6)$

RETURN

END 


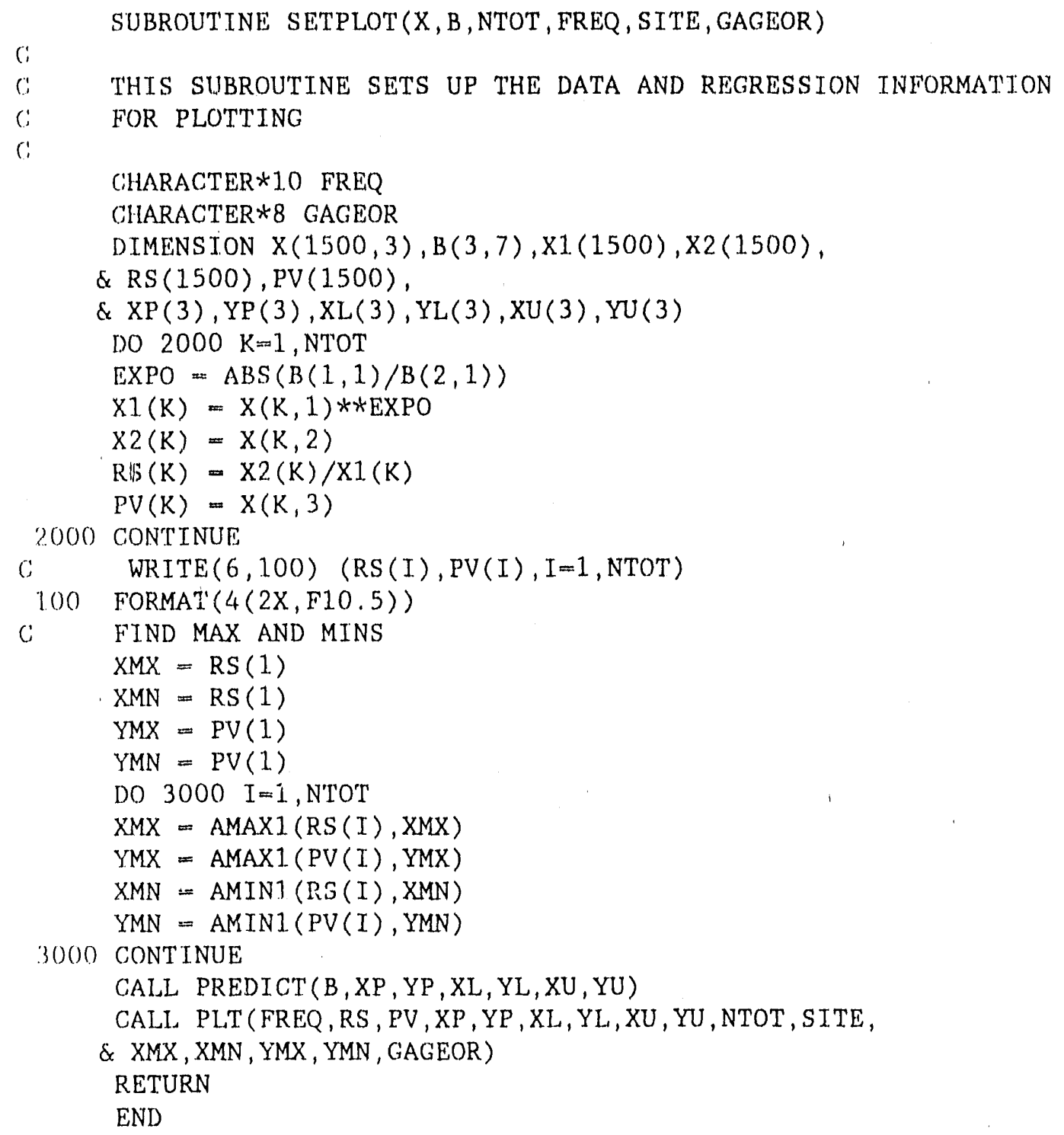


$\mathrm{C}$

C

C

C

SUBROUTINE PREDICT ( $B, X P, Y P, X L, Y L, X U, Y U)$

THIS SUBROUTINE USES THE REGRESSION EQUATION TO PRODUCE THE BF.ST FIR LINE AND THE UPPER AND LOWER BOUNDS FOR THE PLOT]

DIMENSION $B(3,7), X P(3), Y P(3), X L(3), Y L(3), X U(3), Y U(3), R(3)$

$R(1)=10$.

$R(2)=1.0$

$R(3)=100.0$

$\mathrm{W}=150$.

$\operatorname{EXPO1}=\operatorname{ABS}(B(1,1) / B(2,1))$

$\operatorname{EXPO2}=\operatorname{ABS}(B(1,2) / B(2,2))$

$\operatorname{EXPO3}=\operatorname{ABS}(B(1,3) / B(2,3))$

DO $1000 \quad I=1,3$

$\mathrm{XP}(\mathrm{I})=\mathrm{R}(\mathrm{I}) / \mathrm{W} * * \mathrm{EXPO1}$

$\operatorname{IF}(B(2,2), E Q, 0,0, O R, B(2,3), E Q, 0.0)$ GO TO 1234

$\mathrm{XL}(\mathrm{I})=\mathrm{R}(\mathrm{I}) *(\mathrm{~W} * * \mathrm{EXPO} 2 /(\mathrm{W} * * \mathrm{EXPO}) /(\mathrm{W} * * \mathrm{EXPO}))$

$X U(I)=R(I) *(W * * E X P O 3 / W * * E X P 01 / W * * E X P O 3)$

$Y L(I)=B(3,2) *(X L(I) * * B(2,2))$

$Y U(I)=B(3,3) *(X U(I) * * B(2,3))$

$1234 \mathrm{YP}(\mathrm{I})=\mathrm{B}(3,1) *(\mathrm{XP}(\mathrm{I}) * * \mathrm{~B}(2,1))$

1000 CONTINUE

RETURN

END 
SUBROUTINE PLT (FREQ, RS , PV, XP, YP , XL, YL , XU, YU, NTOT

$\&$, SITE , XMX, XMN; YMX, YMN , GAGEOR)

C

C

C

G

'THIS SUBROUTINE PLOTS THE DATA AND THE BEST FIT LINE

WITH THE UPPER AND LOWER BOUNDS

CHARACTER $* 8$ GAGEOR

CHARACTER $* 10$ FREQ

CHARACTER $* 5$ SITE

CHARACTER $* 60$ MESS

DATA XSIZE/8,0/

DAT'A YSIZE/8.0/

CALL RESET ('ALL')

CALL NOBRDR

CALI PAGE $(11.0,11.0)$

CALL AREA2D (XSIZE, YSIZE)

$\mathrm{XR}=10.0 * * \operatorname{INT}($ ALOG $10(\mathrm{XMX})+1)$

$\mathrm{XLP}=10.0 * * \operatorname{INT}($ ALOG10 $(\mathrm{XMN})-1)$

$\mathrm{YT}=10.0 * * \operatorname{INT}(\mathrm{ALOGIO}(\mathrm{YMX})+1)$

$\mathrm{YB}=10.0 * * \operatorname{INT}($ ALOGIO $(\mathrm{YMN})-1)$

$X C Y C L E=X S I Z E /(A L O G 10(X R)-A L O G 10(X L P))$

YCYCLE $=$ YSIZE / (ALOG10(YT) - ALOG10(YB) $)$

C $\operatorname{WRITE}(6,1247) \mathrm{XR}, \mathrm{XLP}, \mathrm{YT}, \mathrm{YB}, \mathrm{XCYCLE}, \mathrm{YCYCLE}$

C 1247 FORMAT $(/ /, 6(2 X F 10.5))$

CALL YNAME ('PSEUDO RELATIVE VELOCITY - CM/S\$',31)

CALL XNAME ('SCALED RANGE - KM\&K'T UNITS\$', 26)

CALL HEADIN ( $\$$ REF (FREQ) $, 10,1.0,3$ )

CALL HEADIN ( 8 REF (SITE) , 5, 1. 0, 3)

CALL HEADIN ( 8 REF (GAGEOR) , 8, 1.0,3)

CALL LOGLOG (XLP, XCYCLE, YB, YCYCLE)

$\operatorname{CALL} \operatorname{GRID}(1,1)$

CALL CURVE (RS, PV, NTOT , - 1)

CALL CURVE (XP, YP , 3, 0)

CALL DASH

CALL CURVE (XL, YL , 3, 0)

CALL CURVE (XU, YU, 3,0$)$

CALL ENDPL(0)

RETURN

END 
"FIT - SINGLE EVENT VERSION 
THIS PROGRAM IS USED TO DO MULTIPLE LINEAR REGRESSIONS ON THE PSRV DATA CALCULATED FROM THE PSRV CODE AND PROCESSED THE PREPRO CODE. THE PROGRAM USES ROUTINES FROM THE IMSL MATH LIBRARY. This version is for a single event.

THE INPUT DATA IS ON TAPE 96 REGRESSION PARAMETERS ARE OUTPUT ON 'FITOUT'. THE DATA ARE PLOTTED USING DISSPLA ROUTINES.

INTEGER EVNTNUM $(80,1500)$

DIMENS ION WEVENT $(80,1500), \operatorname{STARNG}(80,1500), \operatorname{AMP}(80,1500)$,

\& $\operatorname{NBR}(6), \operatorname{TEMP}(2), \mathrm{XM}(2), \mathrm{X}(1500,2), \mathrm{Y}(1500,2), \mathrm{A}(6)$,

\& ANOVA (14), B(2,7), $\operatorname{VARB}(3), \mathrm{X} 1(1500), \mathrm{X} 2(1500), \mathrm{RS}(1500)$,

\& PV (1500)

CHARACTER* 10 FREQ (80)

CHARACTER $\div 5$ SITE, EVNTNUM $(80,1500)$, ENO

CHARACTER $* 8$ GAGEOR

OPEN (UNIT $=96$, FILE $={ }^{\prime}$ TAPE96 $96^{\prime}$, STATUS $\left.==^{\prime} \mathrm{OLD}^{\prime}\right)$

OPEN $\left(\right.$ UNIT $=6$, FILE $=$ ' FITOUT' , STATUS $=$ ' $\left.\mathrm{NEW}^{\prime}\right)$

OPEN (UNIT $=98$, FILE $=$ 'FITCOEF' $^{\prime}$, STAT' ${ }^{\prime}={ }^{\prime}$ NEW' $)$

CALL VSTART $(0.0,0)$

READ INPUT

READ $(96,100)$ NTOT, SITE, GAGEOR

WRITE $(6,800)$ NTOT, SITE, GAGEOR

SET UP THE NBR ARRAY FOR THE BECOVM ARRAY

$\operatorname{NBR}(1)=2$

$\operatorname{NBR}(2)=\operatorname{NTOT}$

$\operatorname{NBR}(3)=\mathrm{NTOT}$

$\operatorname{NBR}(4)=1$

$\operatorname{NBR}(5)=1$

$\operatorname{NBR}(6)=1$

DO $1000 \quad I=1,73$

$\operatorname{READ}(96,200)$ FREQ(I)

$\operatorname{READ}(96,300)$ (EVNTNUM(I , J ), WEVENT (I , J ), STARNG (I , J ), AMP (I , J ), $\dot{\varepsilon}$ $\mathrm{J}=1, \mathrm{NTOT}$ )

READ $(96,300)$ NDE, DW, DR, DA.

UUO CONTINUE

WRITE $(98,3245)$ EVNTNUM( 1,1$)$ 
WRITE $(98,3246)$ SITE

WRITE $(98,3247)$ GAGEOR

3247 FORMAT ( $2 X$, 'GAGE ORIENTATION IS ',A8)

3246 FORMAT (2X,'SITE IS ', A5)

C

C

FILL THE X ARRAY FOR INPUT INTO BECOVM

C

DO $2000 \mathrm{I}=1,73$

DO $2001 \mathrm{M}=1$, NTOT

c

$X(M, 1)=\operatorname{WEVENT}(I, M)$

$X(M, 1)=\operatorname{STARNG}(I, M)$

$X(M, 2)=\operatorname{AMP}(I, M)$

2001 CONTINUE

C WRITE $(6,200)$ FREQ (I)

C WRITE $(6,400)((X(K, M), K=1, N T O T), M=1,3)$

C

$\mathrm{C}$

TRANSFORM DATA INTO LOG-LOG SPACE

CALL TOLOG $(X, Y, N T O T)$

WRITE $(6,400)((\mathrm{Y}(K, M), K=1$, NTOT $), M=1,3)$

SET UP THE MATRIX OF CORRECTED SUMS OF SQUARES AND

CROSS PRODUCTS OF THE INDEPENDENT AND DEPENDENT VARIABLES

CALL BECOVM(Y, 1500, NBR, TEMP, XM, A, IERR)

IF(IERR , NE. O) GO TO 9998

$\operatorname{WRITE}(6,200)((A(M), M=1,6))$

DO THE REGRESSION FOR DATA FROM A SINGLE FREQUENCY

CALL RLMUL (A, XM, NTOT , 1,0.1, ANOVA, B , 2, VARB, IER)

IF(IER . NE. O) GO TO 9999

TRANSFORM REGRESION COEFEICIENTS TO ARITHMETIC VALUES

CALL EROMLOG(B, ANOVA)

WRITE $(6,3245)$ EVNTNUM $(1,1)$

$3 ?-5$ FORMAT $/ / 2 X$, 'EVENT ANLYZED IN THIS RUN IS ', A4

WRITE REGRESSIOI INEORHATION FOR THIS FREQUENCY

ON THE OUTPUT FILE

CALI OUTIB, ANOVA, FREQ(I)

SET UE DATA FOR PLOTTING AND PLOT RESULTS FOR THIS FREQUENCY

ENO = EVNTNUM $(1,1)$

GALL SETPLOT (X,B, NTOT, FREO(I), SITE, ENO, GAGEOR) 


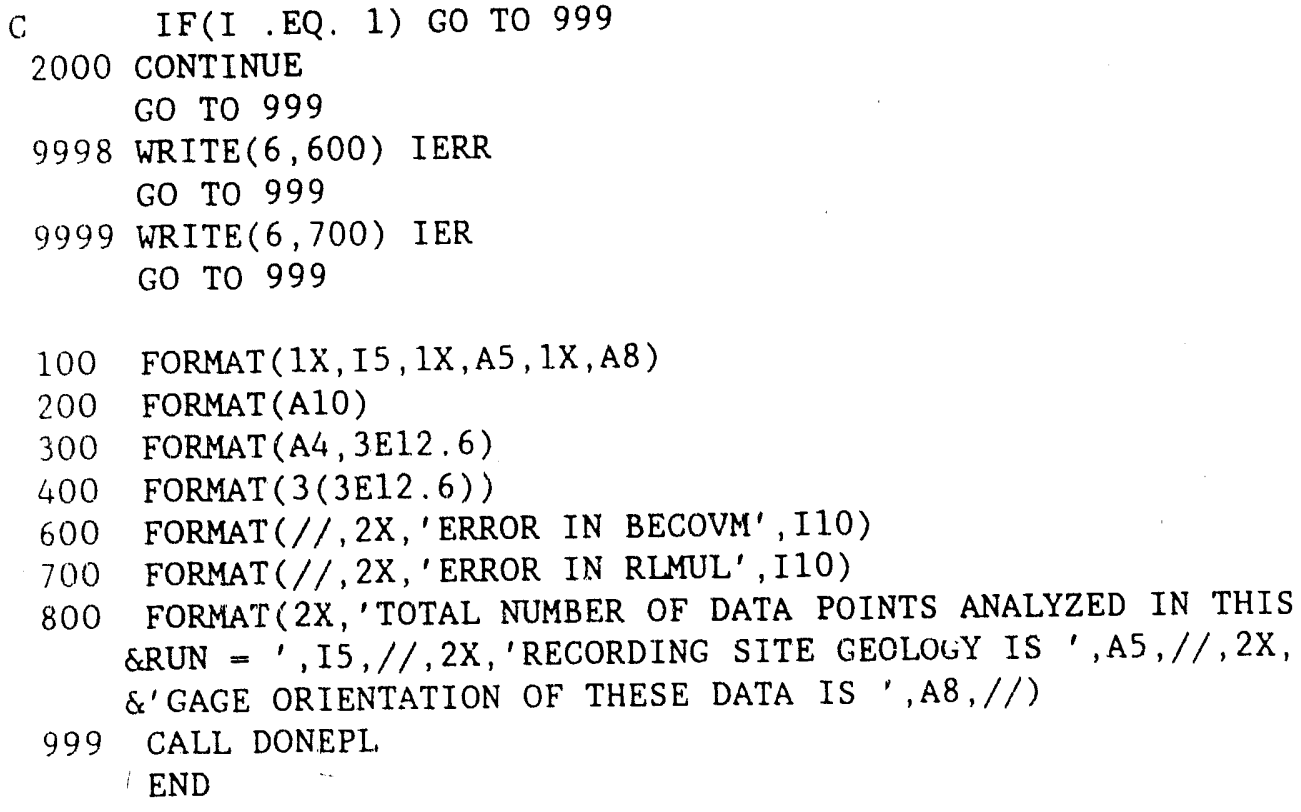




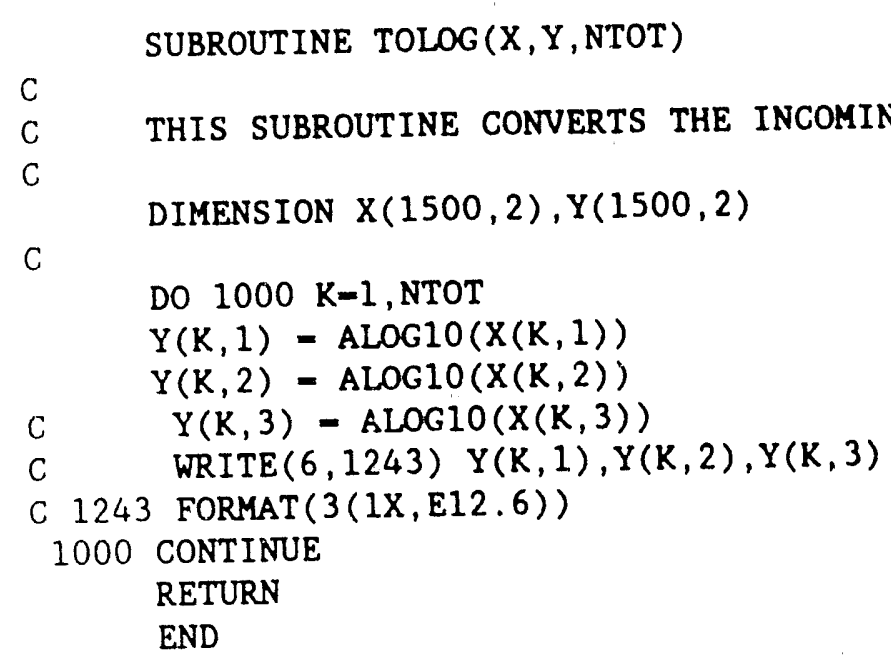


SUBROUTINE FROMLOG (B, ANOVA, VARB)

Program FIT Single Event Version

C

C THIS SUBROUTINE CONVERTS THE REGRESSION COEFFICIENTS TO ARITHMETIC

C VALUES

C DIMENSION $B(2,7)$, ANOVA (14)

C DO $1000 \quad I=1,14$

C $\operatorname{ANOVA}(I)=10 . * *(\operatorname{ANOVA}(I))$

C 1000 CONTINUE

DO $2001 \mathrm{~J}=1,7$

$B(2, J)=10 . * *(B(2, J))$

2001 CONTINUE

RETURN

END 
SUBROUTINE OUT ( $B$, ANOVA, FREQ)

Program FIT Single Event Version

C
C
C
C

THIS SUBROUTINE WRITES THE CALCULATED REGRESSION COEFFICIENTS

IN A READABLE FORMAT ON THE OUTPUT FILE

DIMENSION $B(2,7)$, ANOVA (14)

CHARACTER * 10 FREQ

$\operatorname{WRITE}(6,100)$ FREQ

$\operatorname{WRITE}(6,200)$

$\operatorname{WRITE}(6,300) \quad(B(I, 1), I=1,2)$

$\operatorname{WRITE}(98,1100)(B(I, 1), I=1,2)$

$\operatorname{WRITE}(6,400) \quad(B(I, 2), I=1,2)$

$\operatorname{WRITE}(6,500)(B(I, 3), I=1,2)$

$\operatorname{WRITE}(6,600),(B(I, 4), I=1,2)$

$\operatorname{WRITE}(6,700) \quad(B(I, 5), I=1,2)$

$\operatorname{WRITE}(6,800) \quad(B(I, 6), I=1,2)$

$\operatorname{WRITE}(6,900) \quad(B(I, 7), I=1,2)$

$\operatorname{WRITE}(6,1000)(\operatorname{ANOVA}(I), I=1,14)$

100 FORMAT $\left(/ / /, 2 \mathrm{X},{ }^{\prime}\right.$ FREQUENCY IS ' , $2 \mathrm{X}, \mathrm{A} 10$ )

200 FORMAT $(/ /, 2 \mathrm{X}$, 'REGRESSION COEFFICIENTS CALCULATED FOR THIS

\& FREQUENCY', //)

300 FORMAT ( $2 X,{ }^{\prime}$ RANGE

$\&$ COEFFICIENT $=$, E13.6, $/ /$,

$\& 2 \mathrm{X},{ }^{\prime}$ INTERCEPT $='$, E13.6, //)

400 FORMAT ( $2 \mathrm{X}$, 'LOWER CONFIDENCE LIMITS FOR:',$/ /, 2 \mathrm{X}$,

\&'RANGE $=$ ', E13.6

$\&, 2 \mathrm{X}$, INTERCEPT $=$ ', E13.6)

500 FORMAT $\left(/ /, 2 X, X^{\prime}\right.$ UPPER CONFIDENCE LIMITS FOR:' $/ / /, 2 X$

$\&, '$ RANGE $=$ ', E13,6,2X,

$\&^{\prime}$ INTERCEPT $=\prime$, E13,6)

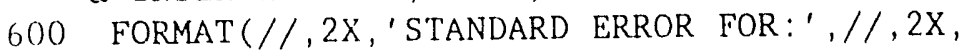

$\&^{\prime}$ RANGE $='$, E $13.6,2 X$,

$\&^{\prime}$ INTERCEPT $=\prime$, E13.6)

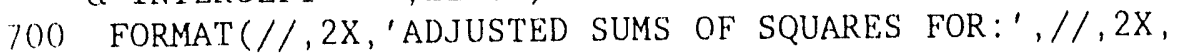
$\&^{\prime}$ RANGE $=', E 13.6,2 X$,

$\&^{\prime}$ INTERCEP'T $=$ ', E13.6)

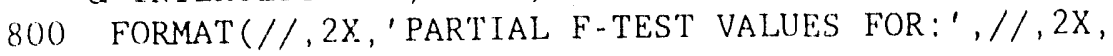
$\&^{\prime}$ RANGE $='$, E13.6, $2 \mathrm{X}$,

$\&^{\prime}$ INTERCEPT $=$ ',E13.6)

9)O FORMAT $\left(/ /, 2 X,{ }^{\prime}\right.$ P(EXCEEDING F UNDER HO),,$/ /, 2 X$,

$\varepsilon^{\prime}$ RANGE $=$ ', E13.6,

$\& 2 X,{ }^{\prime}$ INTERCEPT $='$, E1.3.6)

1000 FORMAT $(/ /, 2 \mathrm{X}$, 'ANALYSIS OF VARIANCE',$/ /, 2 \mathrm{X}$,

\&'DEGREES OF FREEDOM' $, / / 2 \mathrm{X},{ }^{\prime}$ REGRESSION $='$, E1 $3.6,2 \mathrm{X}$,

$\&^{\prime}$ RESIDUAL $='$, E13.6, 'CORRECTED TOTAL $='$,

\&E13.6, $/ /$, ' SUMS OF SQUARES', //,2X,

$\&^{\prime}$ REGRESSION $={ }^{\prime}$, E13 $, 6,2 X,{ }^{\prime}$ RESTDUAL $=$ '

$\&$, E13.6,2X, 'CORREC'TED TOTAL $=$ ' E13.6,//. 
$\| \quad$ Program FIT Single Event Version

\&'MEAN SQUARES' $, / /, 2 \mathrm{X},{ }^{\prime}$ REGRESSION $=$ ', E13.6, $2 \mathrm{X}$,

\&'RESIDUAL = ',E13.6, //, 'F-VALUE',$/ /, 2 \mathrm{X}$,

$\&^{\prime}$ REGRESSION $=1$, E13.6, //, P(EXCEEDING F UNDER HO $)^{\prime}$,

$\& / /, 2 \mathrm{X},{ }^{\prime}$ REGRESSION $='$, E13.6, $/ /, 2 \mathrm{X}$,

$\&$ 'PERCENTAGE VARIATION EXPLAINED BY THE ESTIMATED MODEL IS '

$\&, E 13.6, / /, 2 X, '$ STANDARD DEVIATION OF THE RESIDUALS

\&IS ', E13 . 6, //,2X,

\&'RESIDUAL STANDARD DEVIATION AS A \& OF THE RESPONSE

\&MEAN IS ',E13.6, $/ /, 2 \mathrm{X},{ }^{\prime}$ NUMBER OF DECIMAL DIGITS

$\& O F$ ACCURACY IN THE

\&REGRESSION COEFFICIENTS IS ',E13.6)

1100 FORMAT $(1 \mathrm{X}, 2 \mathrm{E} 13.6)$

RETURN

END 
Program FIT Single Event Version SUBROUTINE SETPLOT (X , B , NTOT , FREQ, SITE, ENO, GAGEOR)

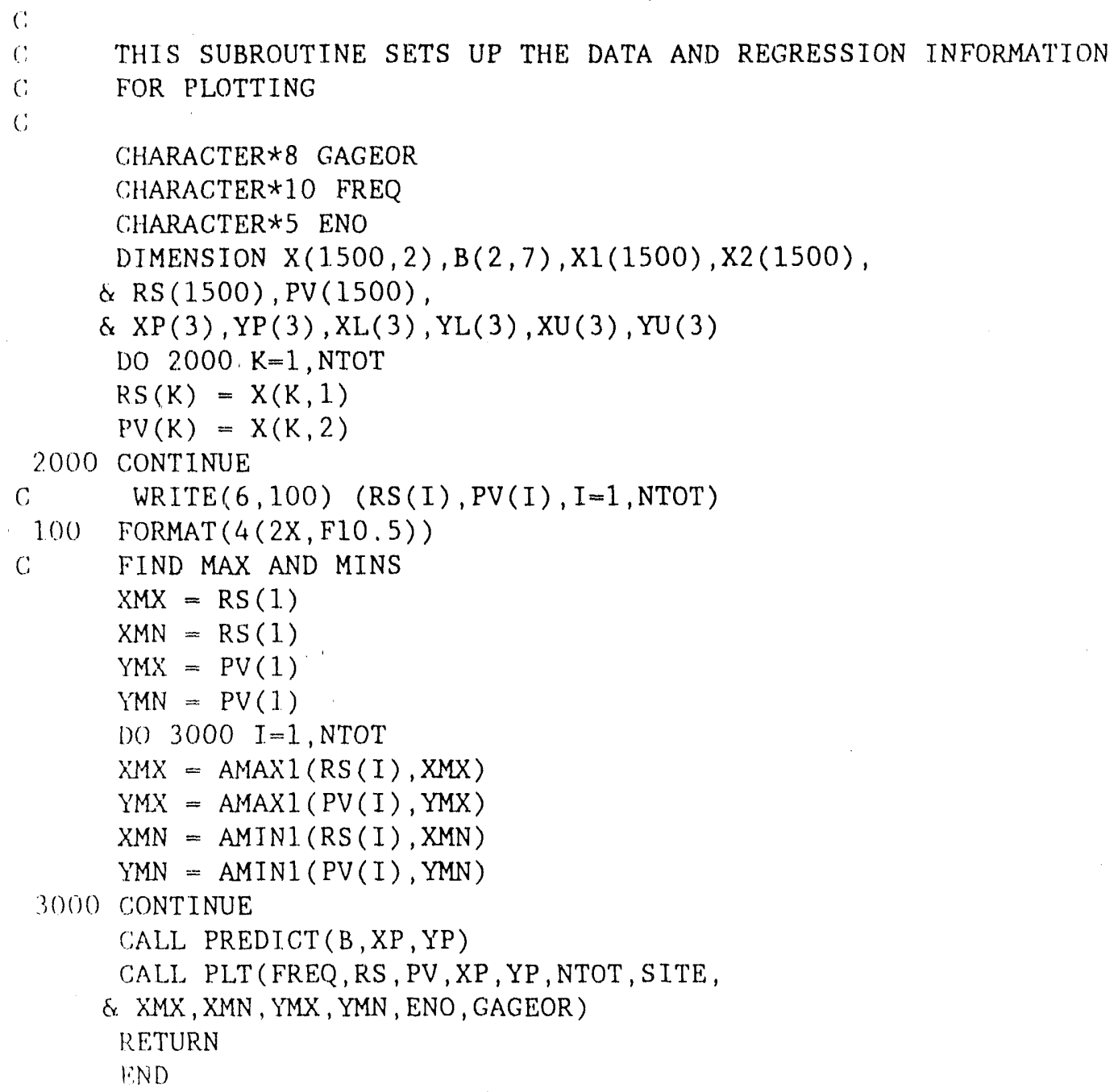


SUBROUTINE PREDICT(B, XP, YP)

Program FIT Single Event Version

C

(.) THIS SUBROUTINE USES THE REGRESSION EQUATION TO PRODUCE THE

(: BEST FIR LINE AND THE UPPER AND LOWER BOUNDS FOR THE PLOT]

(:

DIMENSION $B(2,7), X P(3), Y P(3), X L(3), Y L(3), X U(3), Y U(3), R(3)$

$R(1)=10.0$

$R(2)=20.0$

$R(3)=100.0$

$\mathrm{W}=150$.

DO $1000 \quad I=1,3$

$\mathrm{XI} .(\mathrm{I})=\mathrm{R}(\mathrm{I})$

$X U(I)=R(I)$

$X P(I)=R(I)$

$Y I(I)=B(2,2) *(R(I) * * B(1,2))$

$Y U(I)=B(2,3) *(R .(I) * * B(1,3))$

$1234 \mathrm{YP}(\mathrm{I})=\mathrm{B}(2,1) *(\mathrm{R}(\mathrm{I}) * * \mathrm{~B}(1,1))$

1000 CONTINUE

RETURN

END 
SUBROUTINE PLTS(FREQ, RS, PV, XP, YP, NTOT

C $\&$, SITE , XMX, XMN , YMX, YMN , ENO , GAGEOR)

C THIS SUBROU'TTE PLO'TS THE DATA AND THE BES'T FI'T LINE

C WITH THE UPPER AND LOWER BOUNDS

C

CHARACTER $* 10$ FREQ

CHARACTER $* 8$ GAGEOR

CHARACTER $* 5$ SITE, ENO

CHARACTER $* 60$ MESS

DATA XSIZE/8.0/

DATA YSIZE $/ 8.0 /$

CALL RESET ('ALL')

CALL NOBRDR

CALL PAGE $(11.0,11.0)$

CALL AREA2D (XSIZE, YSIZE)

$\mathrm{XR}=10.0 * *$ INT $(\operatorname{ALOG} 10(\mathrm{XMX})+1)$

$\mathrm{XLP}=10.0 * * \operatorname{INT}(\operatorname{ALOG10}(\mathrm{XMN})-1)$

$\mathrm{YT}=10.0 * *$ INT $($ ALOG10 $(\mathrm{YMX})+1)$

$\mathrm{YB}=10.0 * * \operatorname{INT}($ ALOG10 (YMN) - 1.)

XCYCLE $=$ XSIZE $/(\operatorname{ALOG10}(X R)-\operatorname{ALOG} 10(X L P))$

YCYCLE $=$ YSIZE $/\left(\right.$ ALOG1O $\left.\left(Y^{\prime} T\right)-A L O G 10(Y B)\right)$

C WRITE $(6,1247) X R, X L P, Y T, Y B, X C Y C L E, Y C Y C L E$

C 1247 FORMAT $(/ /, 6(2 X F 10.5))$

CALL YNAME('PSEUDO RELATIVE VELOCTTY - CM/S\$', 31.)

CALL XNAME ('RANGE - km\$', 10)

CALL HEADIN ( 8 REF (FREQ) $1.0,1.0,4$ )

CALL HEADIN ( 8 REF (SITE) $, 5,1.01,4$ )

CALL HEADIN ( 8 REF (ENO) $, 5,1.0,4)$

CALL HEADIN ( \&REF (GAGEOR) , 8, 1.0,4)

CALL LOGLOG (XLP, XCYCLE, YB, YCYCLE)

CALL GRID $(1,1)$

CALL CURVE (RS, PV, NTOT, - 1.)

CALL CURVE (XP, Y'P $, 3,0)$

CALL ENDPL( $(0)$

RETURN

END 
"SORT CODE" 
(:) THIS SORTS THROUGH THE PSRV DATA FILES PRIOR TO

(c) USE OF THE 'PREPRO' PROGRAM

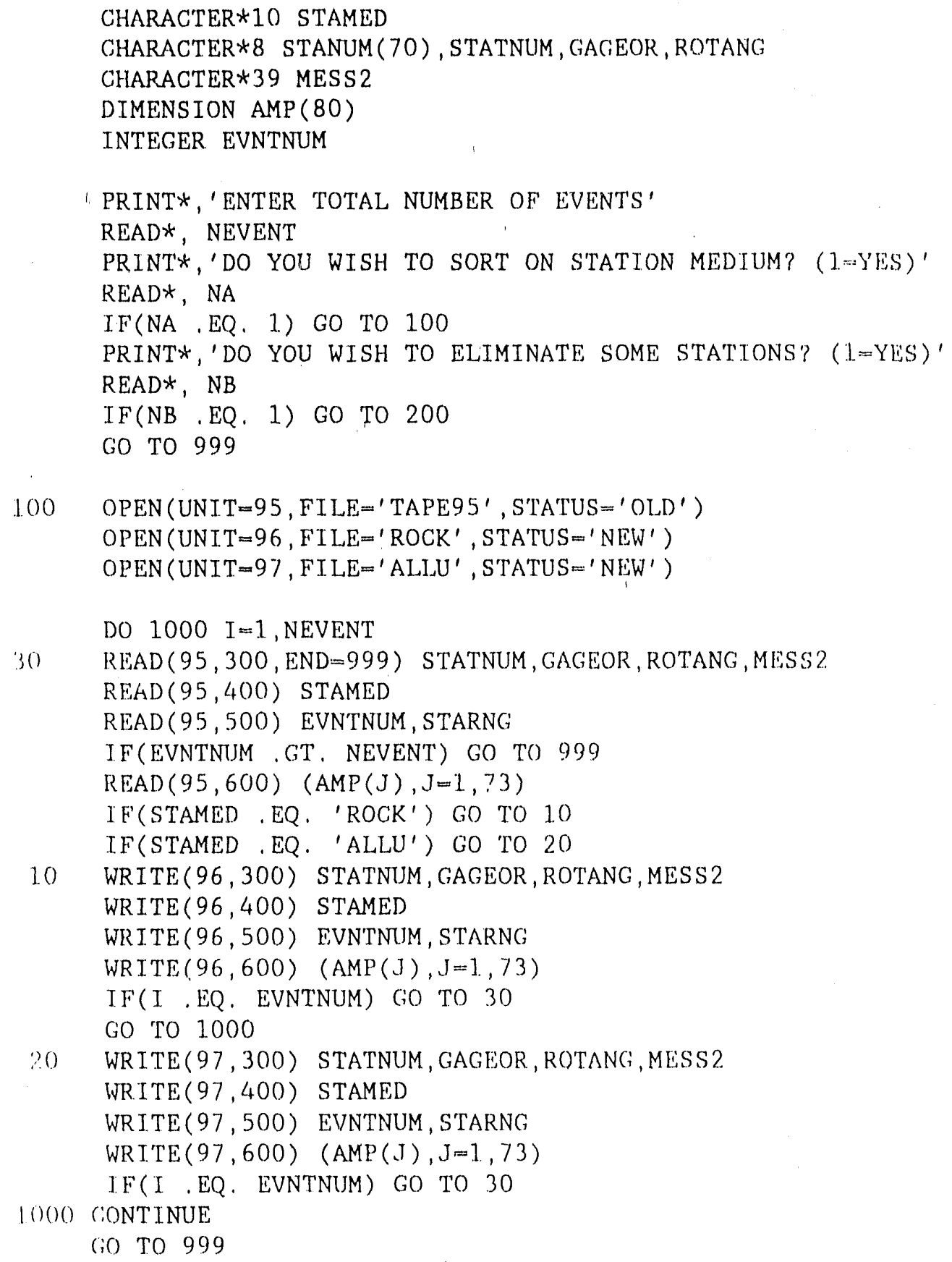


PRINT*, 'HOW MANY STATIONS WIIL BE ELIMINATED?'

READ*, N

PRINT*, 'WHICH STATIONS WILL BE ELTMINATED? (USE APOSTRAPHES)

\& INCLUDE FULL NAME'

READ* , (STANUM (I), I $=1, N$ )

OPEN (UNIT $=95$, FILE $=$ 'TAPE95', STATUS $=$ 'OLD')

OPEN (UNIT $=98$, FILE 'STASORT' , STATUS $=$ 'NEW')

D) $2000 \quad I=1$, NEVENT

$40 \operatorname{READ}(95,300$, END $=999)$ STATNUM, GAGEOR, ROTANG , MESS 2

$\operatorname{READ}(95,400)$ STAMED

$\operatorname{READ}(95,500)$ EVNTNUM, STARNG

IF (EVNTNUM . GT. NEVENT') GO TO 999

$\operatorname{READ}(95,600)(\operatorname{AMP}(K), K=1,73)$

DO 2001. $\mathrm{J}=1, \mathrm{~N}$

$\operatorname{IF}(\operatorname{STANUM}(\mathrm{J})$. EQ. STATNUM) GO TO 40

2001 CONTINUE

WRI'TE $(98,300)$ STATNUM, GAGEOR, RO'TANG, MESS2

WRITE $(98,400)$ STAMED

WRITE $(98,500)$ EVNTNUM, STARNG

WRITE $(98,600)$ (AMP (K), K=1, 73)

IF(I. EQ. EVNTNUM) "(GO TO 40

2000 CONTINUE

300 FORMAT (1X, A8, 2X, A8, 2X, A8, 1X, A39)

400 FORMAT $(1 X, A 10)$

500 FORMAT $([5, \mathrm{E} 13,6)$

600) FORMAT $(1 \mathrm{X}, 10 \mathrm{E} 13.6)$

909 END 
"PREPRO CODE" 


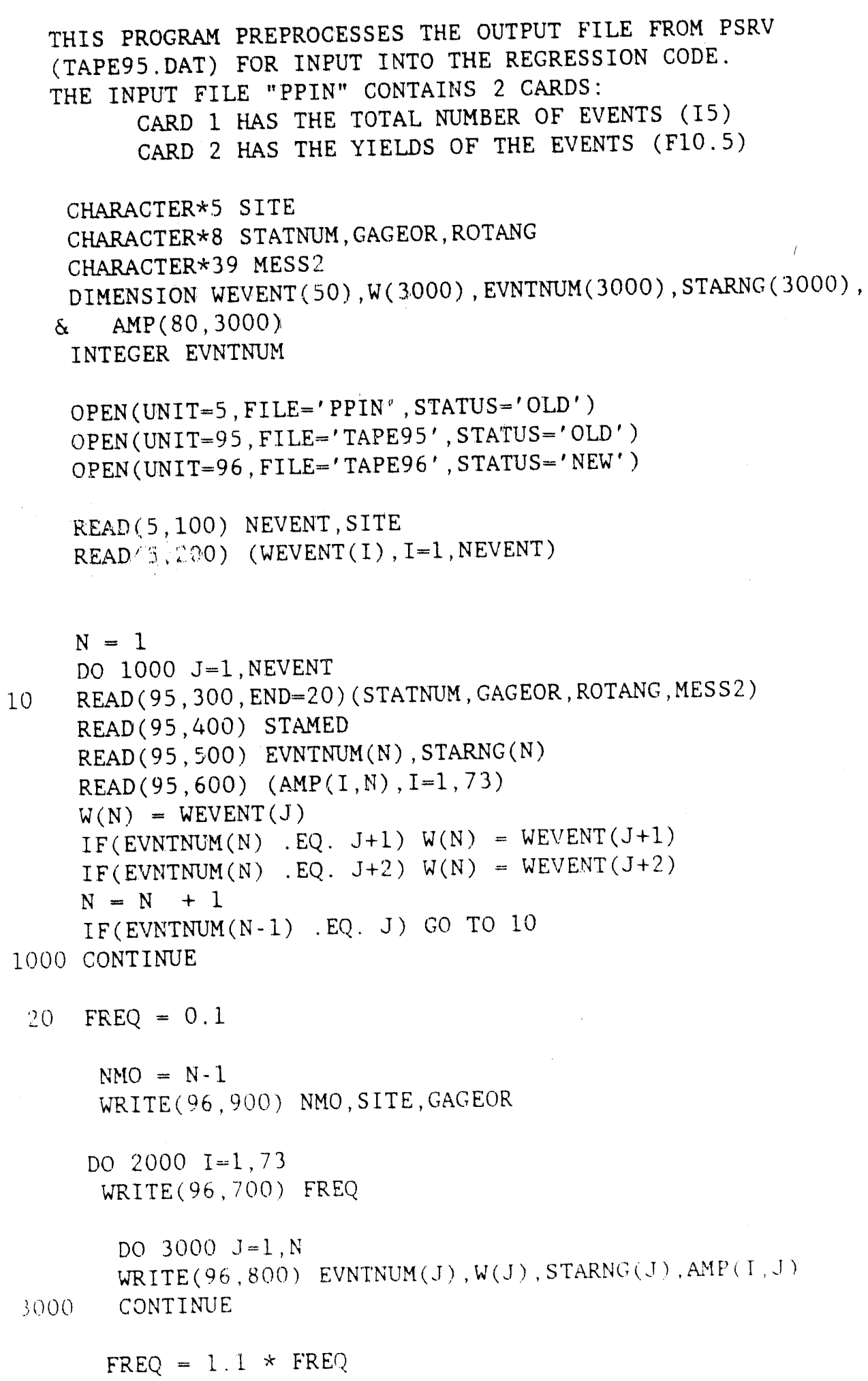




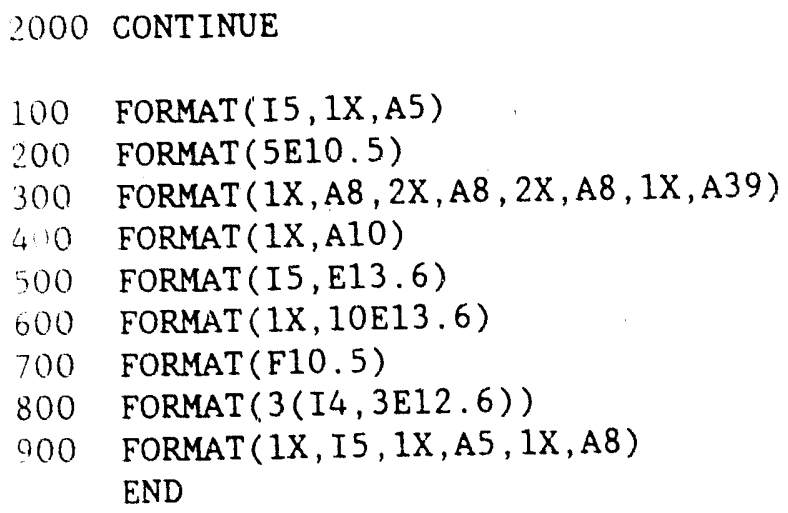


"PROGRAM COMPARE" 


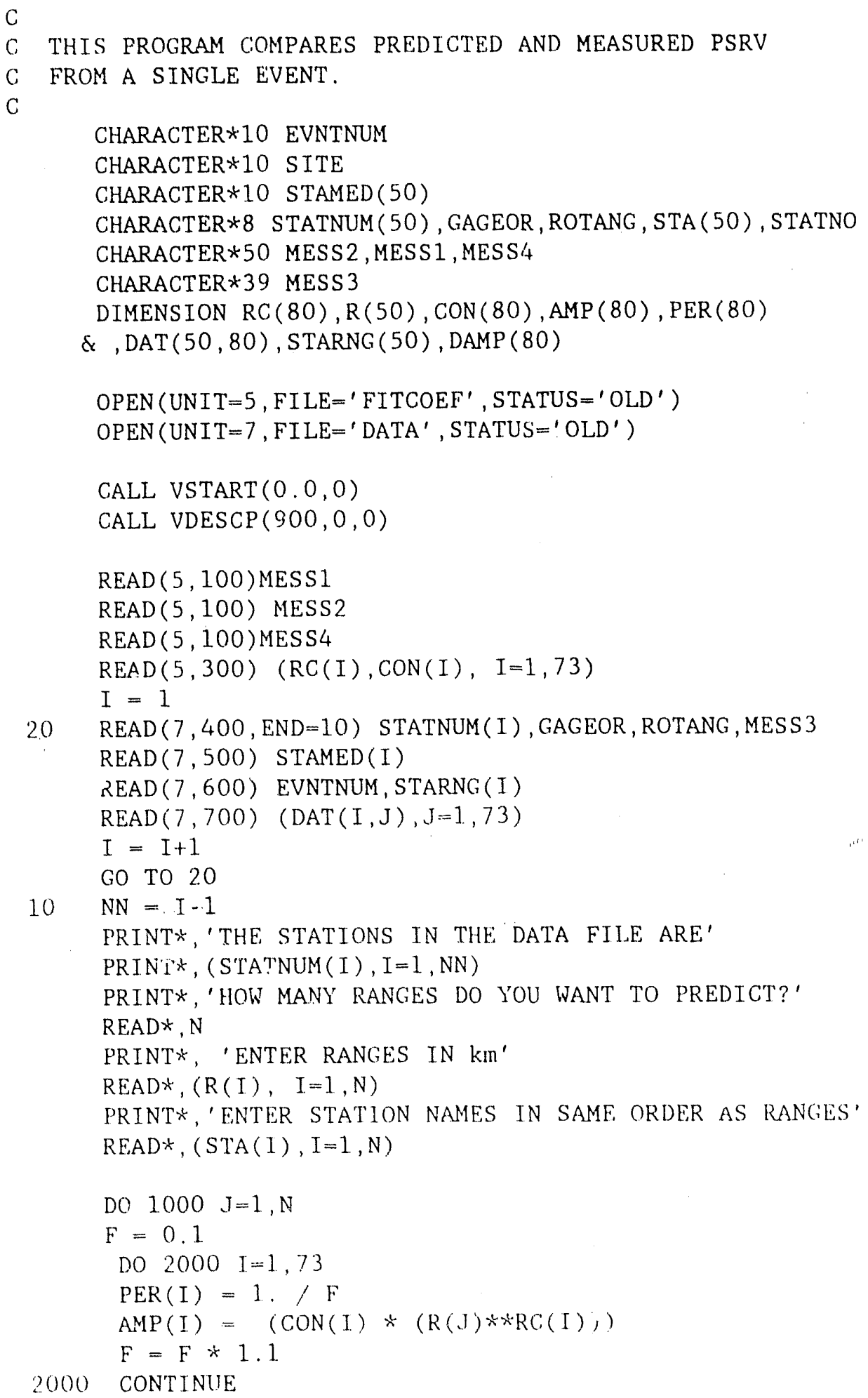




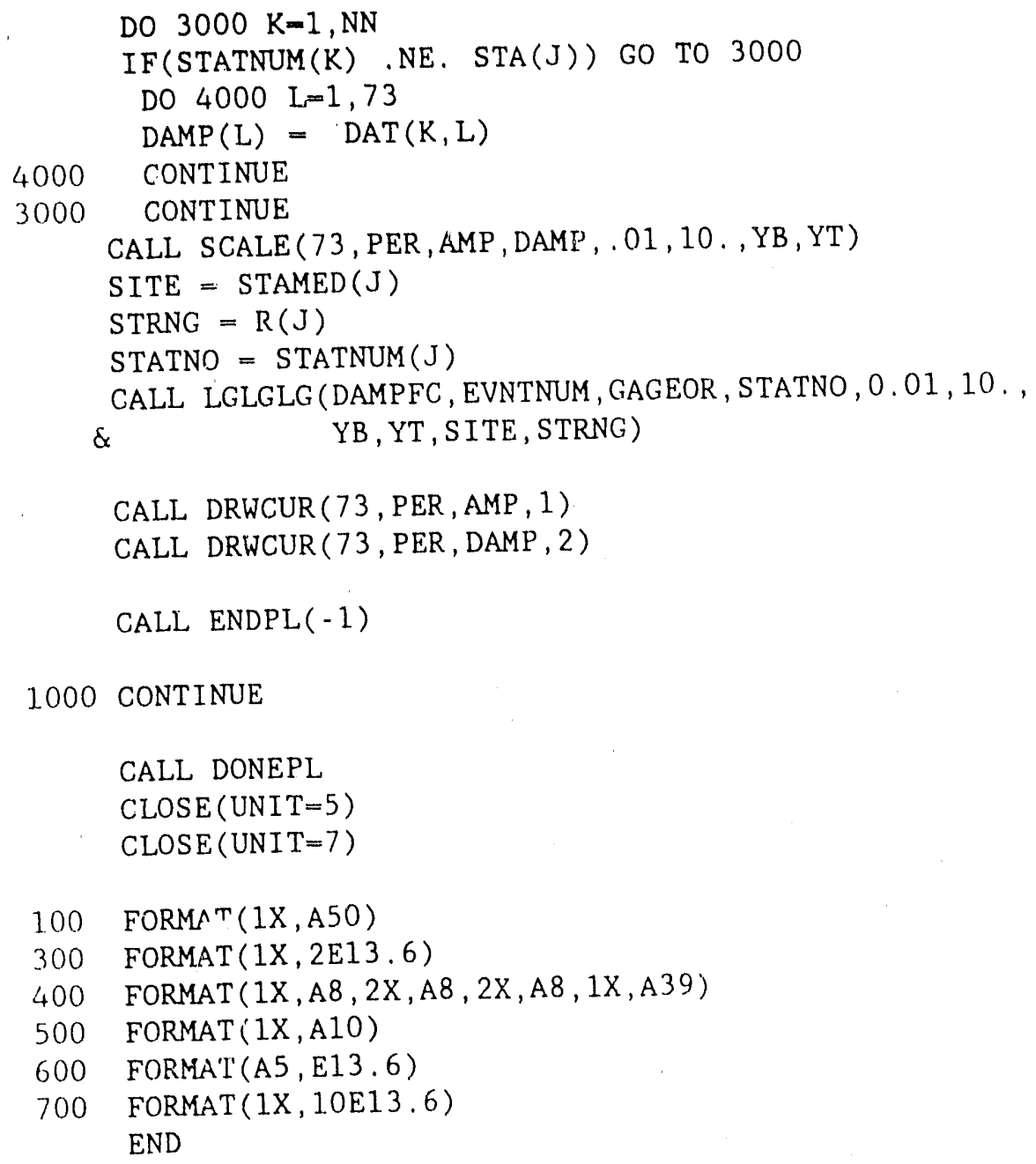


SUBROUTINE SCALE(INDXPER, PERIOD, PSRVAL, DPSRVAL $\S$ $, X L, X R, Y B, Y T$ )

SCALE - SCALE Y AXIS FOR PLOT.
D. L. DOWNS .
$08 / 08 / 83$

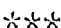

THIS ROUTINE FINDS THE MAXIMUM PSR MALWE AND COMPUTES AN APPROPRIATE SCALE FOR THE Y-AXIS THE USER SHOULD SUPPLY THE FOLLOWING ARGUMENTS

INDXPER = NUMBER OF PERIOD-PSRV COORDINATES

PERIOD $=$ A 200 ELEMENT ARRAY OF COMPUTED PERIODS

PSRVAL $=$ A 200 ELEMENT ARRAY OF PREDICTED PSRV VALUES

DPSRVAL = ARRAY OF CALCULATED PSRVS FROM DATA

XL = LEFT-MOST X-COORDINATE

$\mathrm{XR} \quad=$ RIGHT-MOST $X$-COORDINATE

THE ROUTINE RETURNS THE FOLLOWING

$Y B=$ BOTTOM-MOST Y-COORDINATE

$\mathrm{YT}=$ TOP-MOST Y-COORDINATE

$X$-COORDINATES REPRESENT PERIOD AND Y-COORDINATES REPRESENT PSRV.

DIMENSION PERIOD(80), PSRVAL(80), DPSRVAL(80)

$\sin x+x$

$* \quad$ FIND MAXIMUM PERIOD

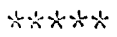

PSRVMX $=$ PSRVAL $(1)$

DPSRVMX $=$ DPSRVAL (1)

DO $10 I=2$, INDXPER

PSRVMX $=$ AMAX1 (PSRVAL $(I)$, PSRVMX)

DPSRVMX $=$ AMAXI $($ DPSRVAL $(I)$, DPSRVMX)

10 CONTINUE

PSRVMX $=$ AMAX1 $($ PSRVMX, DPSRVMX $)$

$+2 x+2 x$

$* \quad$ COMPUTE ENDPOINTS

$\therefore+2 \times x$

IF (ALOG10(PSRVMX) .GT .0.0) THEN

$\mathrm{YT}=10.0 * *$ INT $($ ALOG10 $($ PSRVMX $)+1)$ 
ELSE

$Y T=10.0 * * \operatorname{INT}($ ALOG10 $($ PSRVMX $))$

ENDIF

$Y B=Y T / 10000.0$

RETURN

END 
SUBROUTINE DRWCUR (INDXPER, PERIOD, PSRVAL, II)

$* * *$ DRWCUR - PLOTS THE CURVE.

* D. L. DOWNS. 08/08/83.

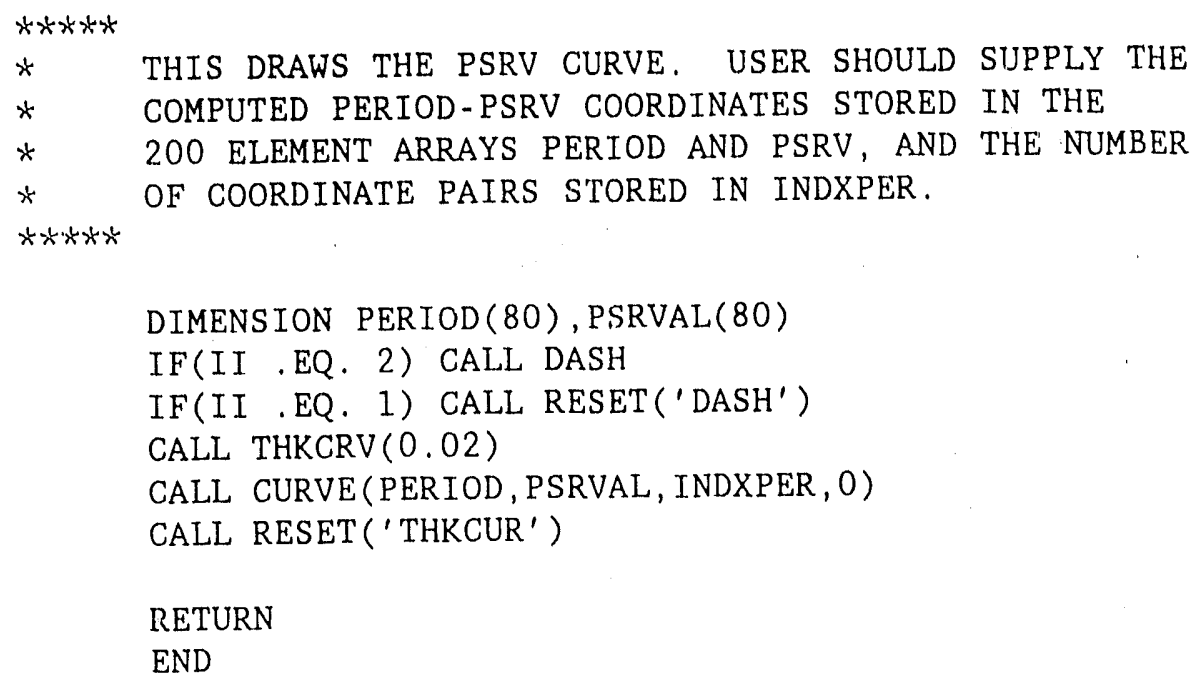


SUBROUTINE LGLGLG (DAMPFC, EVNTNAM,

LGLGLG - CONSTRUCTS A GRID.

D. L. DOWNS . $08 / 08 / 83$.

M. L. SANDERS. 09/22/86. NOS/VE VERSION.

REPLACE 'DATE(DAY)' WITH 'DATE()'.

THIS ROUTINE CONSTRUCTS A LOG-LOG-LOG GRID. THE USER SHOULD SUPPLY THE FOLLOWING ARGUMENTS

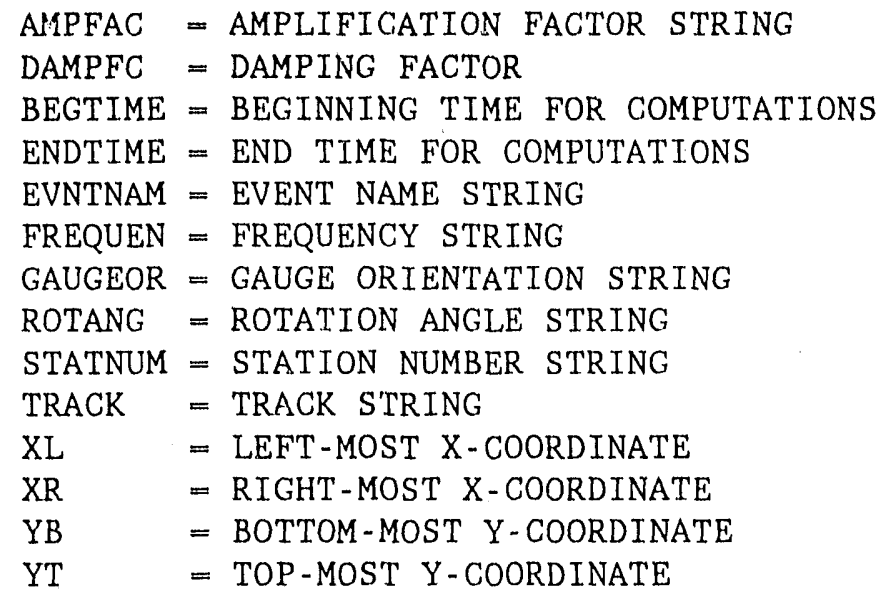


DATA LXNAME/'PERIOD - SEC'/,IXNAME/12/,IYNAME/42/

DATk. LYNAME/'PSEUDO RELATIVE RESPONSE VELOCITY - CM/SEC'/

$x+x+x+x$

* XSIZE AND YSIZE GIVE THE SIZE OF THE PLOT REgION IN

* INCHES. XSIZE AND YSIZE SHOULD NORMALLY BE IN A RATIO

$* \quad$ OF $3: 4$.

$* * * * * * *$

DATA XSIZE $/ 6.0 /$

DATA YSIZE/8.0/

$x^{2}+x^{2}+x \times 4$

* COMPUTE CYClE LENGTH

$* x * * x \cdot 6$

$\mathrm{CYCLE}=\mathrm{XSIZE} /(\operatorname{ALOG} 10(\mathrm{XR})-\operatorname{ALOG} 10(\mathrm{XL}))$

$x \cdot x * x \cdot x$

$*$

$* \quad$ AN

$x * 2 * x+2$

THIS SEGMENT CONSTRUCTS THE BORDER AND THE HORIZONTAL AND VERTICAL GRID LINES.

CALL PAGE $(11,11)$

CALL NOBRDR

CALL AREA2D (XSIZE, YSIZE)

CALL XNAME (\&REF (LXNAME), IXNAME)

CALL YNAME ( $\$ R E F$ (LYNAME), IYNAME)

CALL LOGLOG (XL, CYCLE, YB, CYCLE)

CALL $\operatorname{GRID}(1,1)$

$x \cdot 2 x+x$

* THIS SEGMENT CONSTRUCTS THE LEFT DIAGONAL GRID LINES

* REPRESENTING DISPLACEMENT.

$\dot{x} x^{2} * x * x$

TWOPI $=\operatorname{ATAN}(1.0) * 8.0$

CALL DASH

DO $20 \mathrm{~L}=1,10$

DO $10 M=1,9$

DT.SP $=\mathrm{YB} * \operatorname{FLOAT}(\mathrm{M}+1) * 10.0 * *(\mathrm{~L}-4)$

$Y L=T W O P I * D I S P / X L$

$\mathrm{Y} 2=\mathrm{TWOPI} * \mathrm{DISP} / \mathrm{XR}$

IF (.NOT . (( (Y1.GT . YT) . AND . (Y2 .GT . YT ) ) . OR .

$((Y 1, L T \cdot Y B) \cdot A N D \cdot(Y 2 \cdot L T \cdot Y B))))$ THEN 
$\operatorname{SLOPE}=(\operatorname{ALOG} 10(\mathrm{Y} 2)-\operatorname{ALOG10}(\mathrm{Y} 1)) /(\operatorname{ALOG} 10(\mathrm{XR})-\operatorname{ALOG10}(\mathrm{XL}))$

YINT $=$ ALOG10 (Y1) - SLOPE*ALOG1.0(XL)

CALL ENDPTS (SLOPE, YINT, ALOG1O(XL), ALOG10(XR), ALOG10 (YB), ALOG10 (YT), XX1, YY1, XX2, YY2)

$X X 1=10,0 * * X X 1$

$X X 2=10,0 * * X X 2$

$\mathrm{YY} 1=10,0 * * \mathrm{YY} i$

$Y Y 2=10,0 * * Y Y 2$

ENDIF

CALL RLVEC (XX1, YY1, XX2, YY2, 0000)

10 CONTINUE

$x * x * x$

$*$

PRINT DISPLACEMENT LABELS

$* * * * * x$

INDXDIS $=\operatorname{INT}(A L O G 10(Y B))+\mathrm{L}+2$

IF ( (INDXDIS . GE . 1) , AND. (INDXDIS . LE . 8) , AND .

- (Y2.GT.YB).AND. (Y2.LT.YT)) THEN

CALL ANGLE (315)

CALL HEIGHT (0.1)

CALL RLMESS (8REF(DUNITS (INDXDIS)) , 8, 1.2*XX2,YY2)

CALL RESET ('ANGLE')

ENDIF

CALL RESET ('HEIGHT')

20 CONTINUE

CALL RESET ('DASH')

$2+2 x+3 x+4$

\section{$*$}

* REPRESENTING ACCELERATION.

$* * * * * * x$

CALL DOT

DO $40 \mathrm{~L}=1,10$

DO $30 \quad M=1,9$

ACCEL $=\mathrm{YB} * \mathrm{FLOAT}(\mathrm{M}+1) * 980.2368 * 10.0 * *(\mathrm{~L}-5)$

$Y 1=A C C E L * X L / T W O P I$

$\mathrm{Y} 2=\mathrm{ACCEL} * \mathrm{XR} / \mathrm{TWOPI}$

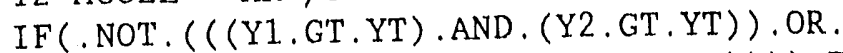

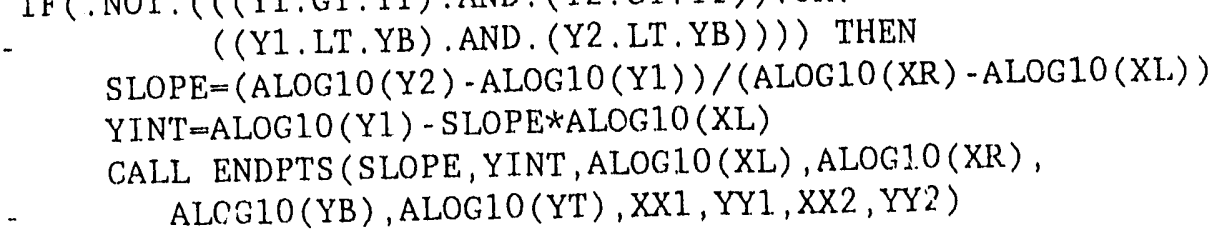




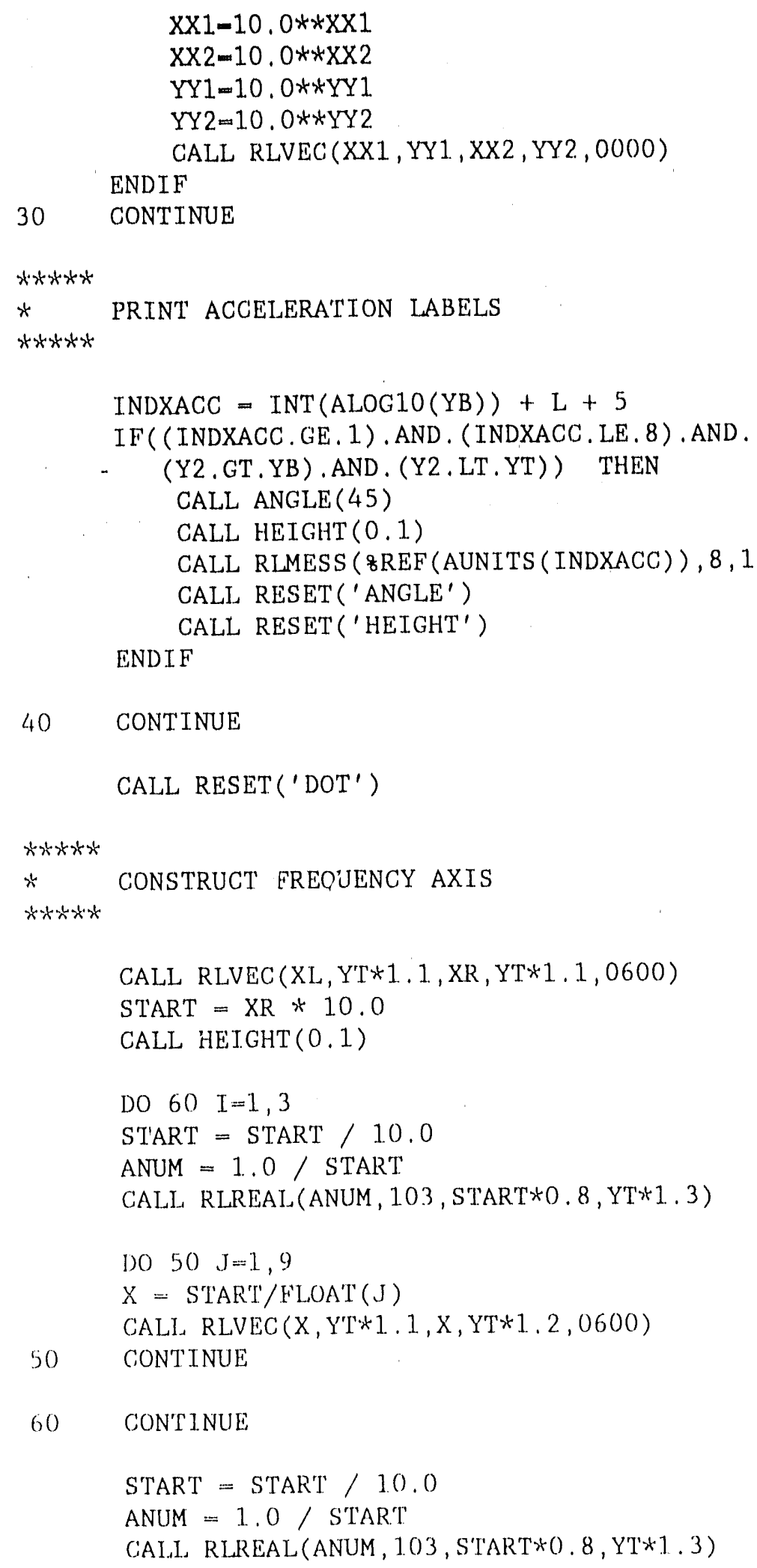


CALL RLVEC (START, YT*1, 1, START, YT*1,2,0600)

CALL RESET ('HEIGHT')

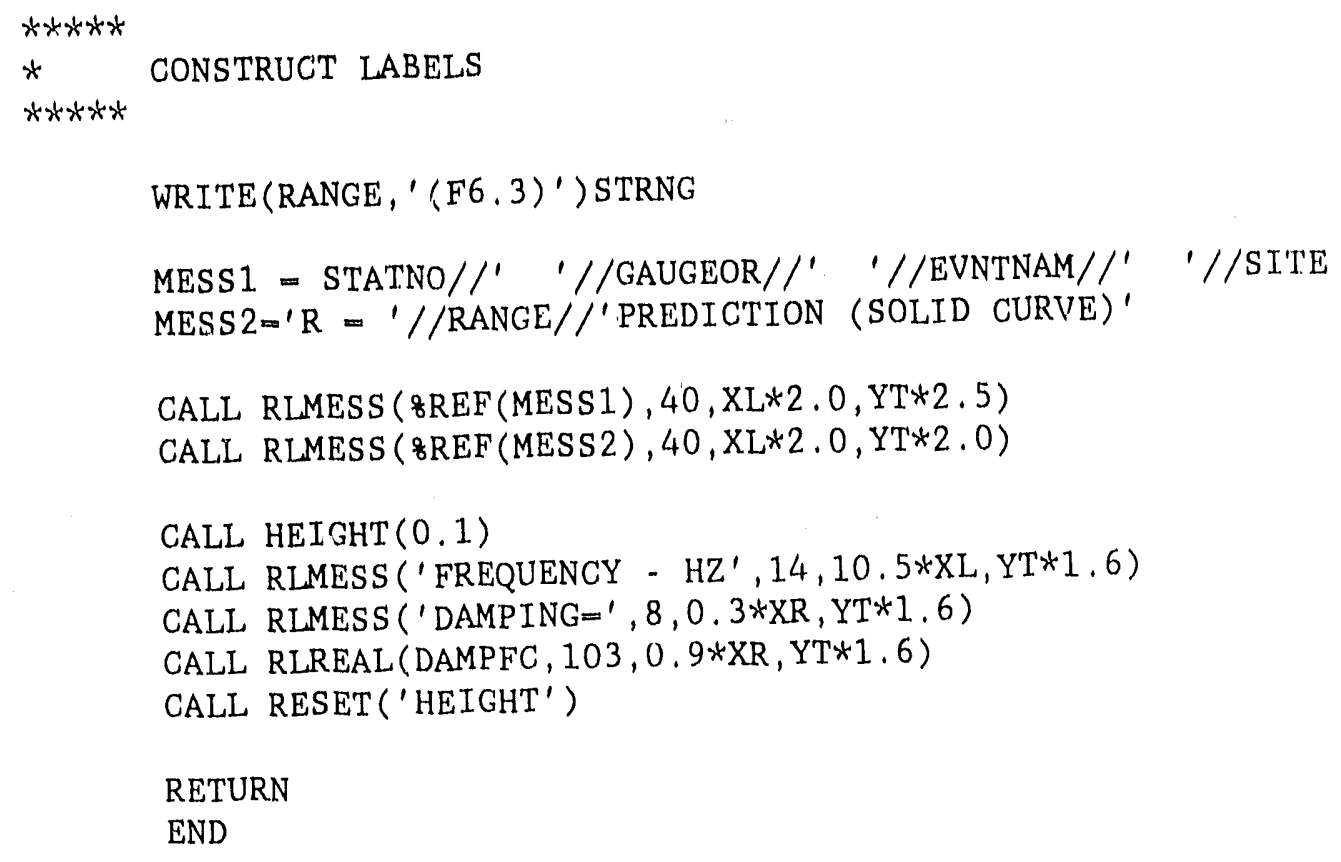


SUBROUTINE ENDPTS (SLOPE, YINT, XLEFT, XRIGHT, YBOT, YTOP,

- $\quad X X 1, Y Y 1, X X 2, Y Y 2)$

*** ENDPTS - DETERMINE ENDPOINTS FOR THE AXIES.

$*$ D. L. DOWNS. 08/08/83.

* M. L. SANDERS. 09/22/86. NOS/VE VERSION.

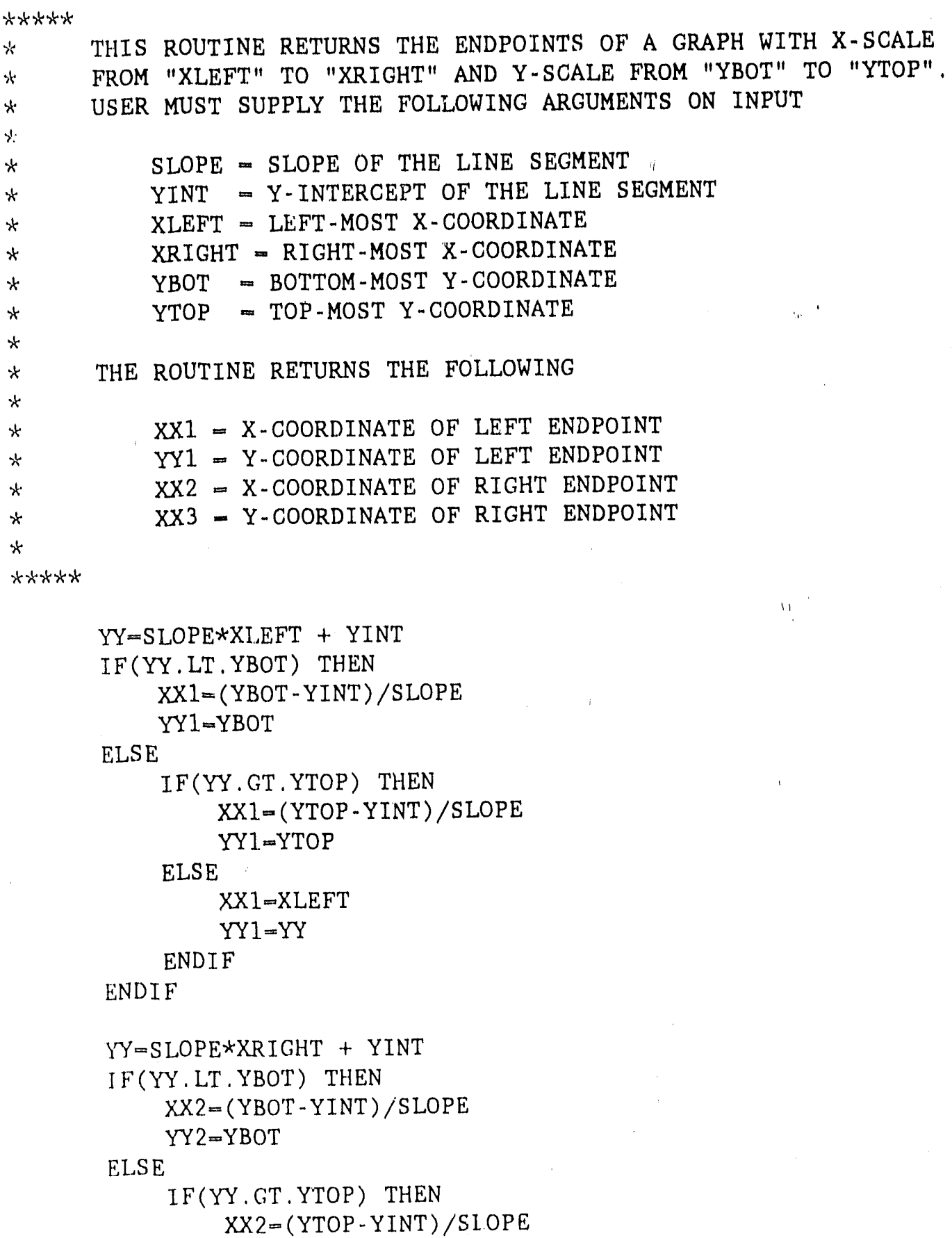




\author{
$Y Y 2=Y T O P$ \\ ELSE \\ XX2-XKIGHT \\ $Y Y 2=Y Y$ \\ ENDIF \\ RETURN \\ END
}




\section{REFERENCES FOR APPENDIX A}

Environmental Research Corporation, 1984, Prediction of Ground Motion Characteristics of Underground Nuclear Detonations, NVO-1163-239 (NNA.870406.0100)

Green, M. W., 1988, Software Quality Assurance Requirements, SNL NNWSI Project Department Operating Procedure, DOP 3-2, Rev. A, Szildia National Laboratories, Albuquerque, NM (NNA.880518.003)

International Mathematical and Statistical Libraries, Inc., 1984, IMSL Library, FORTRAN Subroutines for Mathematics and Statistics, Edition 9.2., Houston, TX (NNA.901127.0196)

Sanders, M. L., 1987, Description of Ground Motion Data Processing Codes, SAND87-1176, Vol. I, Sandia National Laboratories, Albuquerque, NM (NNA.890713.0182) 


\section{APPENDIX B: PREDICTION PROCEDURE FOR PSRVS}

This appendix contains a description of the automated version of the prediction procedure developed in this study. This description includes a discussion of the logic, information on the individual subroutines used, and instructions for use of the program. Also included is the source code listing. This code is written in FORTRAN 5 and uses Dissplay plot routines (Integrated Software Systems Corp., 1984). The equations used to predict the PSRVs were derived with the following units; distance is in $\mathrm{km}$, yield is in $\mathrm{kt}$, pseudo velocity is in $\mathrm{cm} / \mathrm{s}$, acceleration in $\mathrm{gs}$ and displacement in $\mathrm{cm}$.

Program PREDICT will perform predictions of surface PSRVs at any location and downhole PSRVs at stations W12/30, W25, W28 or W29. In addition, the prediction may be compared to observed data or to the prediction procedure developed by Lynch (Environmental Research Corporation, 1984 and Lynch, 1969), main body of the report). An overview of the structure of PREDICT is shown in Figure B-1.

External files required for the operation of the code are the equation coefficient files (a total of 6 ) and a data file (if one exists). The coefficient file contains a header and the coefficients in the formats shown. The numerical coefficients in these files were given in Tables 4-1 through 4-6. The data file consists of three 1 ines of header information and the numerical values in the formats shown. The numerical values in this file are pseudo velocity amplitudes only. The associated frequencies are matched to these amplitudes in the logic of the PREDICT code. The final product of a prediction is the PSRV plot.

The major components of the code and a description of their function are listed in Table B-1. Problem setup and calculations are done in the main program. Plotting is set up and done in subroutines SCALE, LGLGLG, DRWCUR and ENDPTS (these routines wer z taken from the PSRV code). Coefficients and logic necessary to predict the downhole PSRV are located in subroutine DWNHOLE. The Lynch prediction procedure is implemented in subroutine ERCSPEC.

The logic of the input sequence of the program is shown in Figure $\mathrm{B}-2$. The program runs in an interactive mode. The user is prompted with questions which set up a particular run. Numerical values are input in free format (i.e., no specific format, multiple values separated by commas). Character values are input enclosed in single quotation marks ('). There are two primary options in this code. The first option is prediction. The second option is the comparison of predicted values to observed values. Both options require the same initial definition of site geology and gage orientation. After this information is input, the code asks slightly different questions of the user. These will be summarized below. 


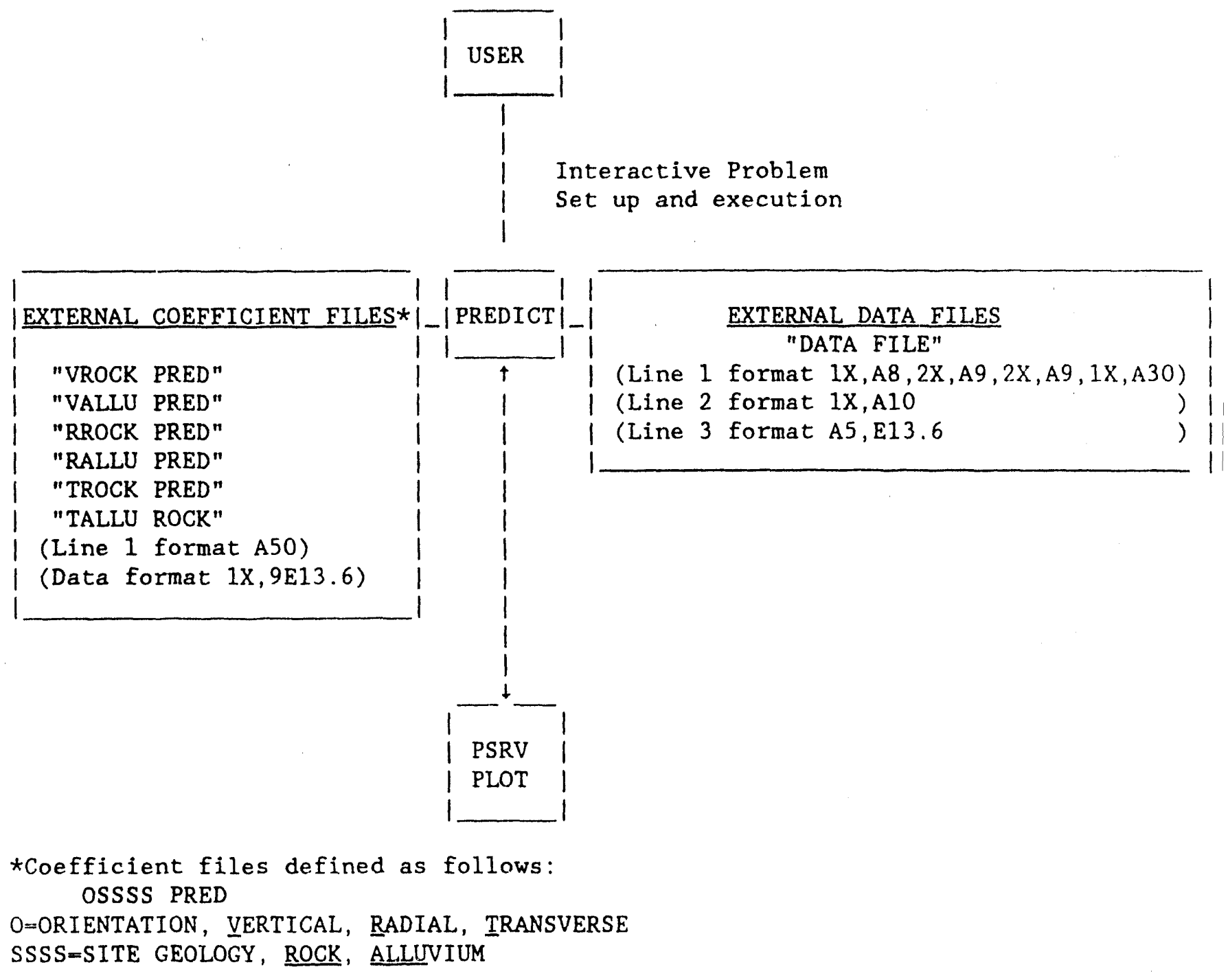

Figure B-1. Block Diagram Showing Overall Structure of PREDICT Code 
TABLE B. 1 Description of the Major Components of the PSRV Prediction Code.

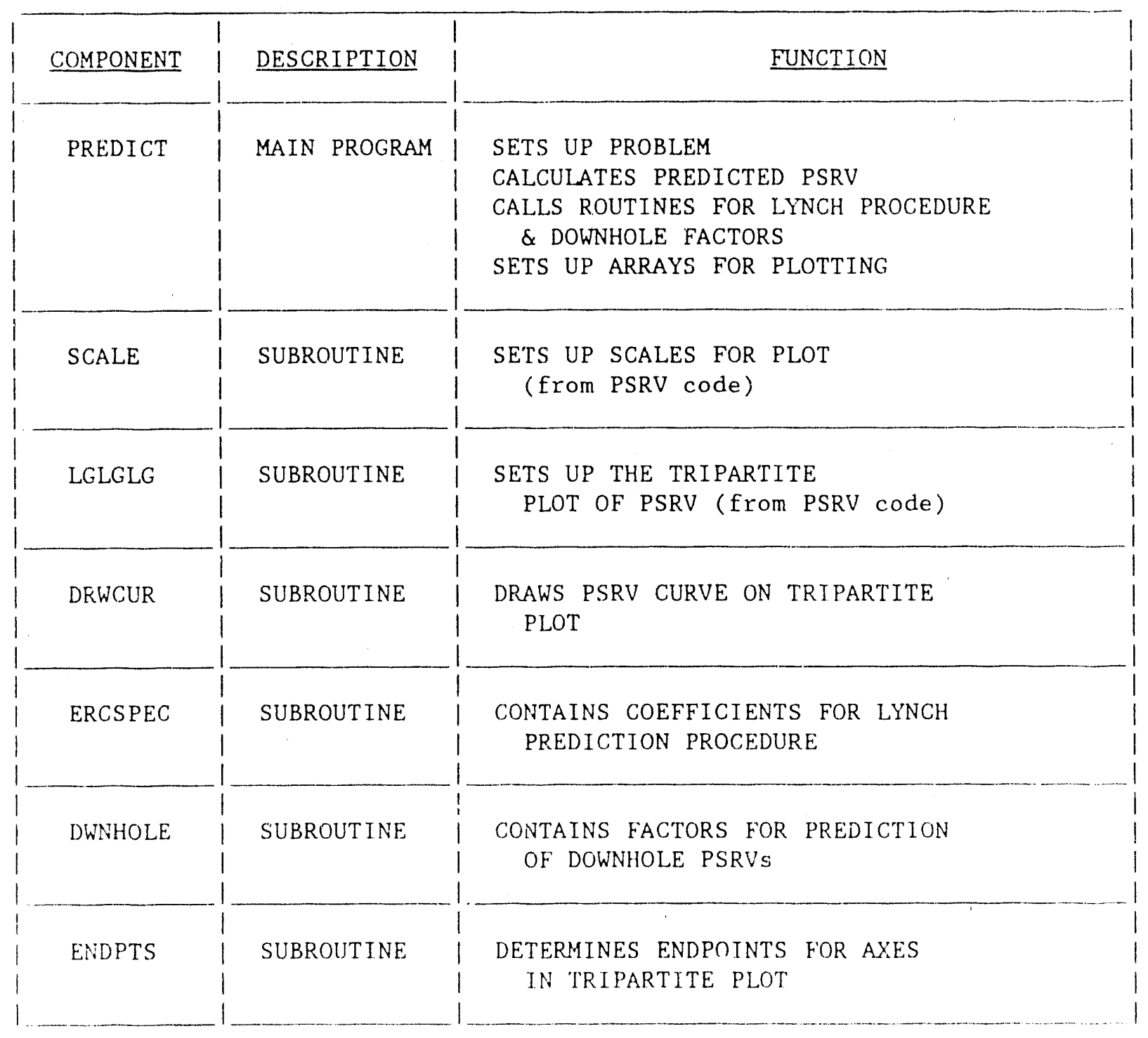




\section{DEFINE STATION GEOLOGY \& GAGE ORIENTATION \\ COMPARE PREDICTION TO D.ATA? \\ (determine appropriate coefficient filo)}

NO DATA FILE

Define labels for plot title Downhole PSRVs?

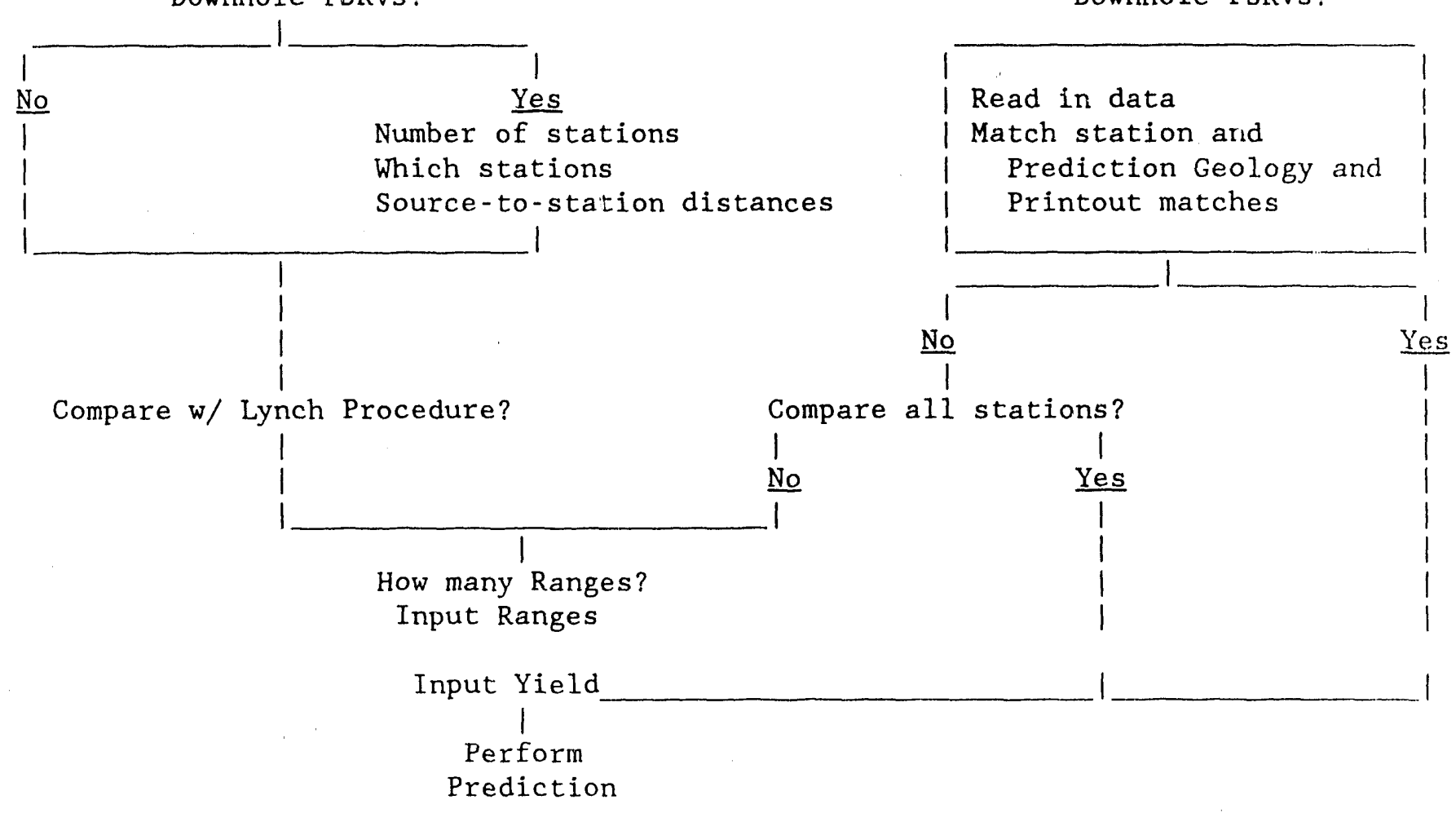

DATA FILE

Define labels for plot title Downhole PSRVs?

atch station and Prediction Geology and Yes
Read in data

Figure B.2. Input sequence for PSRV predicti 1 code 
Option 1 Prediction: After site geology and gage orientation are selected the user is queried about performing downhole predictions. If downhole predictions are desired, the user must supply the number of downhole stations ( 4 max.), the station name (W25 BOT, W28 BOT, W29 BOT or W3O BOT) and the source-to-station distance (range in $\mathrm{km}$ ). The user is given the option to compare the predicted results of this procedure with that of Lynch (ERC). (Note that the Lynch procedure is for surface stations only.) The next parameters the user must specify are the number and the values of range and the yield. If no downhole PSRVs are requested the user is given the option of comparing the current prediction with the Lynch prediction and then must supply the number and value of ranges and the yield.

Option 2 Prediction and Comparison: After site geology and gage orientation are selected the program will search all records in the data file to match the site ,eology of the station with that specified in the initial setup. The user is then queried about performing downhole predictions. If downhole predictions are desired, the program will ask for the yield ( $k t$ ) and predict and compare all stations included in the data file. For the prediction of surface PSRVs, the user may compare all data in the file or selected stations. For all stations the user only specifies the yield. For the selected station option, the user must specify the number and value of the ranges and the yield.

The basic instructions for use of this code are summarized above, in the documentation of the source code and through the interactive input sequence. Additional "rules" are summarized here.

- Only one site type and gage orientation is allowed per run.

- Site geology must be specified in this code and in a data file used for comparison as either ROCK or ALLU.

- Gage orientation must be specified as VERT, RAD, or TRANS.

- Pseudo velocities in the data file are assumed to be at the same frequencies as the prediction procedure.

- Downhole predictions can only be made for four stations: W25 BOT, W28 BOT, W29 BOT and W30 BOT. When option 1 is used companion surface PSRVs will also be calculated. For option 2, all data will be compared.

The listing of the source code is given below. 
PROGRAM PREDICT

$\mathrm{C}$

C THIS PROGRAM PROVIDES MEAN AND THE UPPER AND LOWER $95 \%$ CONFIDENCE

C INTERVALS FOR PREDICTED PSRV.

C

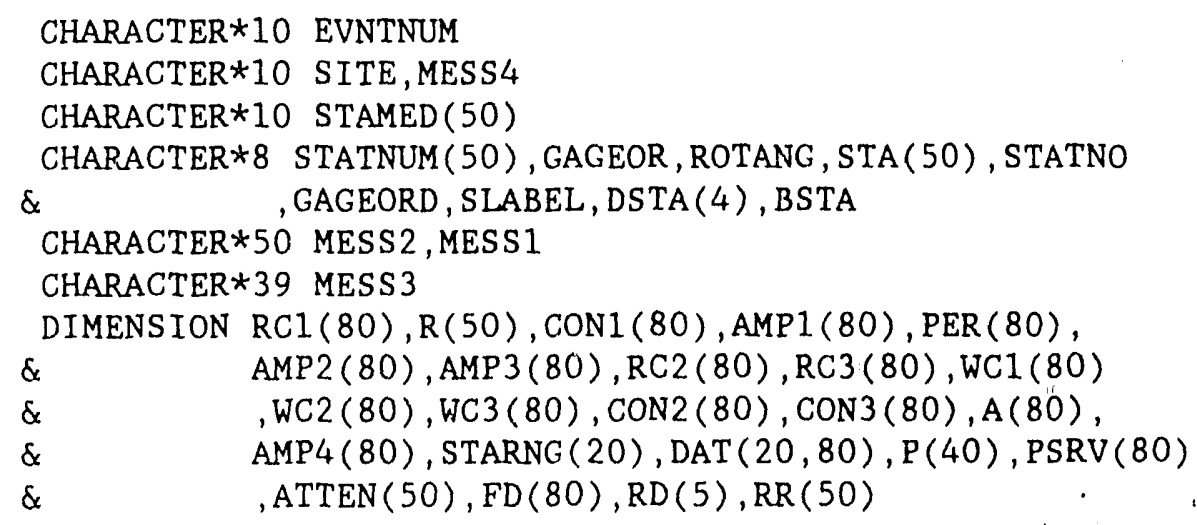

READ IN PREDICTION COEFFICIENTS

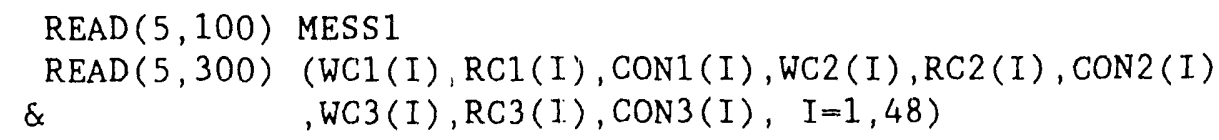

PRINT*, 'IS THERE A DATA FILE TO COMPARE WITH? (YES=1)' 
READ*, K

IF (K .NE , 1) THEN

PRINT*, 'ENTER EVENT - 10 CHAR'

READ*, MESS4

PRINT*, 'SECOND PLOT LABEL - 8 CHAR'

READ*, SLABEL

PRINT*, 'DO YOU WANT TO PREDICT DOWNHOLE PSRVS? (YES=1)'

READ*, LJ

IF (LJ .EQ . 1) THEN

PRINT*, 'HOW MANY'? (4 MAX)'

READ*, NLJ

PRINT*, 'WHICH STATION(S)? (W25 BOT,W28 BOT,W29 BOT,W30 BOT)'

$\operatorname{READ*},(\mathrm{DSTA}(\mathrm{I}), \mathrm{I}=1, \mathrm{NLJ})$

$\mathrm{IR}=1$

DO $3 I=1, N L J$

$\operatorname{STA}(I R)=\operatorname{DSTA}(\mathrm{I})$

$\operatorname{IF}(\mathrm{DSTA}(\mathrm{I}) . \mathrm{EQ}$. 'W25 BOT') STA(IR+1) $=$ 'W25 TOP'

$\mathrm{IF}(\mathrm{DSTA}(\mathrm{I})$. EQ. 'W28 BO'T') $\mathrm{STA}(\mathrm{IR}+1)=$ 'W28 TOP'

$\operatorname{IF}(\mathrm{DSTA}(\mathrm{I})$.EQ. 'W29 BOT') STA $(\mathrm{IR}+1)=$ 'W29 TOP'

$\operatorname{IF}(\mathrm{DSTA}(\mathrm{I})$.EQ. 'W30 BOT') STA(IR+1) = 'W30 'TOP'

CONTINUE

PRINT*, 'ENTER RANGES FOR DOWNHOLE STATIONS - $\mathrm{km}$ '

READ* , (RD ( I ) , I =1, NLJ)

ENDIF

PRINT*, 'DO YOU WANT TO COMPARE THIS PREDICTION WITH

\& THE ERC PREDICTION (YES $=1$ )'

READ*, MM

GO TO 1234

ENDIF

PRINT*, 'ENTER DATA TITLE FOR PLOT - 10 CHAR MAX'

READ*, MESS4.

PRINT*, 'DO YOU WANT TO COMPARE DOWNHOLE PSRVS? (YES=1)'

PRINT*, 'IF THIS IS A DOWNHOLE RUN ALL S'IATIONS IN THE

$\&$ DATA FILE WILL BE COMPARED'

READ*, LJ

C

$\mathrm{C}$

READ IN DATA

$I=1$

OPEN (UNIT $=7$, FILE $=$ ' DATAFILE', STATUS $=$ ' OLD' $\left.^{\prime}\right)$

$20 \operatorname{READ}(7,400, \operatorname{END}=10) \operatorname{STATNUM}(\mathrm{I})$, GAGEORD , ROTANG , MESS 3

$\operatorname{READ}(7,500)$ STAMED $(I)$

$\operatorname{READ}(7,600)$ EVNTNUM ; STARNG (I)

$\operatorname{READ}(7,700)(\operatorname{DAT}(I, J), J=1,73)$

$\mathrm{I}=\mathrm{I}+1$

GO TO 20

10

$\mathrm{NN}=\mathrm{I}-1$ 
C SORT THROUGH DATA TO FIND THE MATCHES ON MEDIUM (ROCK OR ALLU)

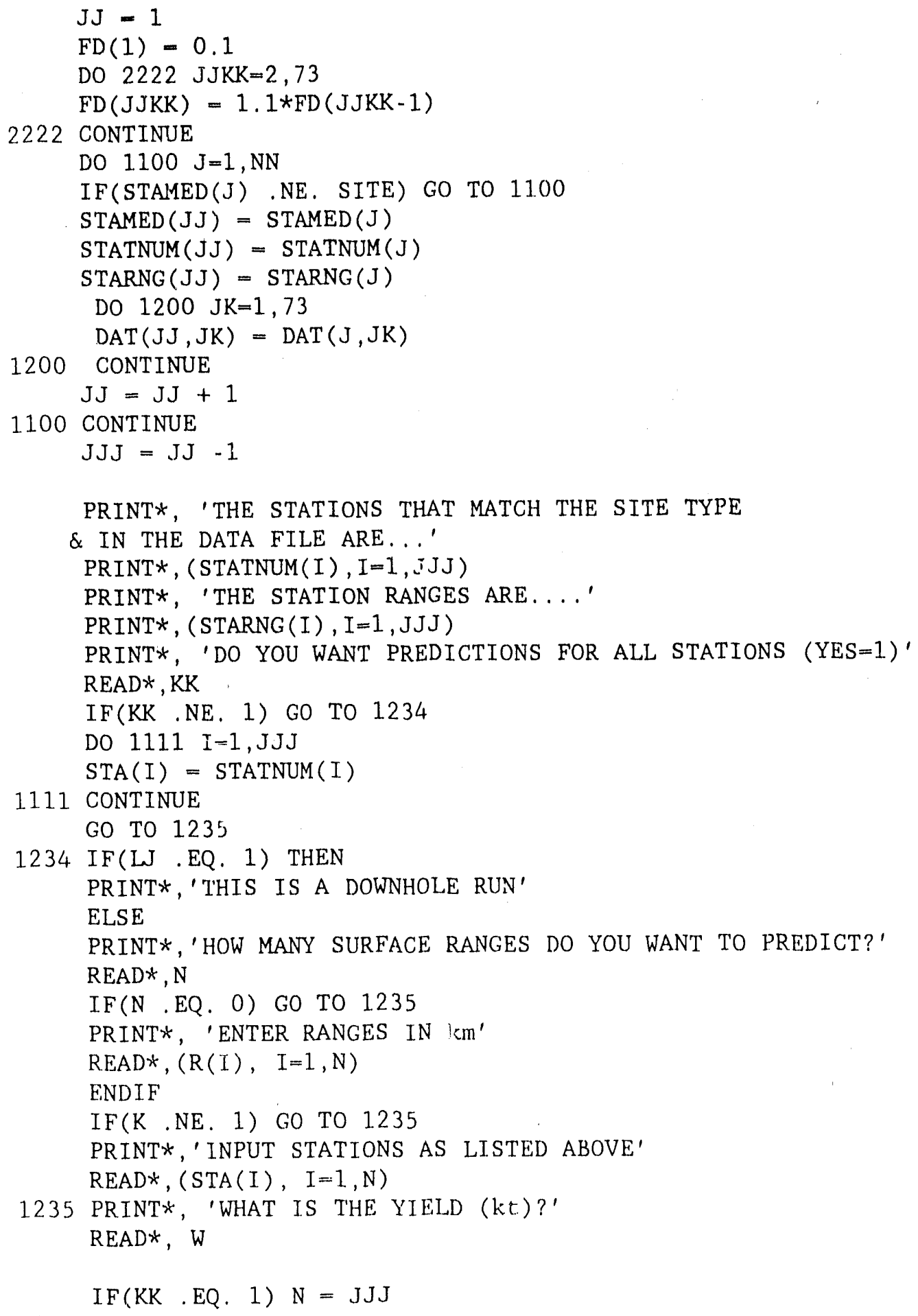


IF(L .EQ. 1 .AND, KK . NE . 1) THEN

$\mathrm{N}=\mathrm{NLJ} * 2$

$\mathrm{LT}=1$

DO 1 IT $=1$, NLW

$R(I T)=R D(L T)$

$R(I T+1)=R D(L T)$

$\mathrm{LT}=\mathrm{LT}+1$

1 CONTINUE

PRINT*, 'DOWNHOLE STATIONS ARE CALCULATED FIRST'

PRINT*, $\quad ' N=1, N$

PRINT*, $(R(I), I=1, N)$

PRINT*, ( $(\mathrm{T}$ TA (I) $, I=1, N$ )

ENDIF

DO $1000 \mathrm{~J}=1, \mathrm{~N}$

$\mathrm{F}=0.31384$

DO $2000 \quad I=1,48$

$\operatorname{IF}(K K . E Q .1) R(J)=\operatorname{STARNG}(J)$

$\operatorname{PER}(I)=1 . / F$

$\operatorname{AMP} 1(I)=(\operatorname{CON1}(I) *(W * * \operatorname{WCl}(I)) *(R(J) * * R C 1(I)))$

$\operatorname{AMP} 2(I)=(\operatorname{CON} 2(I) *(W * * W C 2(I)) *(R(J) * * R C 2(I)))$

$\operatorname{AMP} 3(I)=(\operatorname{CON} 3(I) *(W * * \operatorname{WC} 3(I)) *(R(J) * * R C 3(I)))$

$\operatorname{AMP} 4(I)=0.0$

$F=F * 1.1$

2000 CONTINUE

IF(LJ .EQ, 1 .AND. STA(J) .EQ. 'W25 BOT' .OR.

$\&$ LJ .EQ. 1 .AND. $\mathrm{STA}(\mathrm{J}), \mathrm{EQ}$. 'W28 BOT' .OR.

\& L .EQ. 1 .AND. $S T A(J) . E Q$. 'W29 BOT' .OR.

\& L .EQ. 1 .AND. $S T A(J)$.EQ. 'W30 BOT' .OR.

\& LJ .EQ, 1 ,AND. $\operatorname{STA}(\mathrm{J}), \mathrm{EQ}$. 'W12 BOT') THEN

$B S T A=\operatorname{STA}(\mathrm{J})$

CALL DWNHOLE (BSTA, ATTEN, GAGEOR)

PRINT*, (ATTEN (I) $, I=1,48)$

DO 2001 II $=1,48$

$\operatorname{AMP1}(I I)=\operatorname{AMP1}(I I) * \operatorname{ATTEN}(I I)$

$\operatorname{AMP} 2(I I)=\operatorname{AMP} 2(I I) * \operatorname{ATTEN}(I I)$

$\operatorname{AMP} 3(I I)=\operatorname{AMP} 3(I I) * \operatorname{ATTEN}(I I)$

2001 CONTINUE

ENDIF

IF (K .NE. 1) GO TO 1236

DO $3000 \mathrm{JJ}=1, \mathrm{JJJ}$

IF(STATNUM(JJ) .NE. STA(J)) GO TO 3000

$\mathrm{IJKL}=1$

DO $4000 \mathrm{~L}=1,73$

IF (FD (L) .LT, $0.3 .0 R, F D(L) . G T, 30$.$) GO TO 4000$

$\operatorname{AMP} 4(\mathrm{IJKL})=\operatorname{DAT}(\mathrm{JJ}, \mathrm{L})$ 


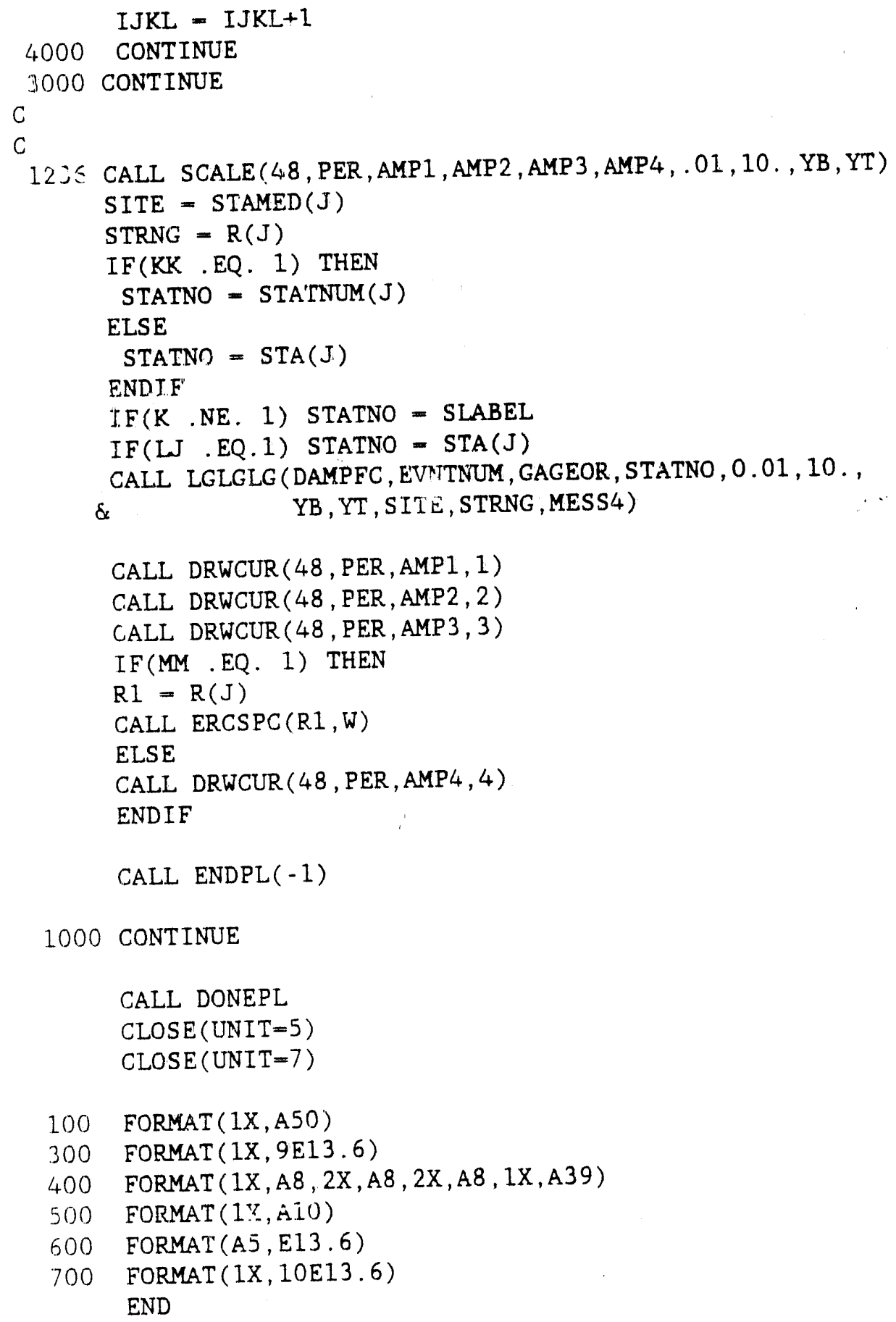


SUBROUTINE SCALE (INDXPER, PERIOD, PSRVAL1, PSRVAL2

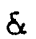

, PSRVAL3, PSRVAL4, XL, XR, YB , YT)

$* * x$ SCALE - SCALE Y AXIS FOR PLOT.

$-\dot{x}$

D. L. DOWNS. $08 / 08 / 83$.

南必不

$+$

$-\frac{1}{x}$

$\ddot{*}$

$\dot{*}$

$x+x \cdot x+x$

\section{$* \quad$ FIND MAXIMUM PERIOD}

$* * x * * x$

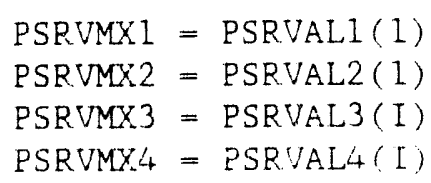




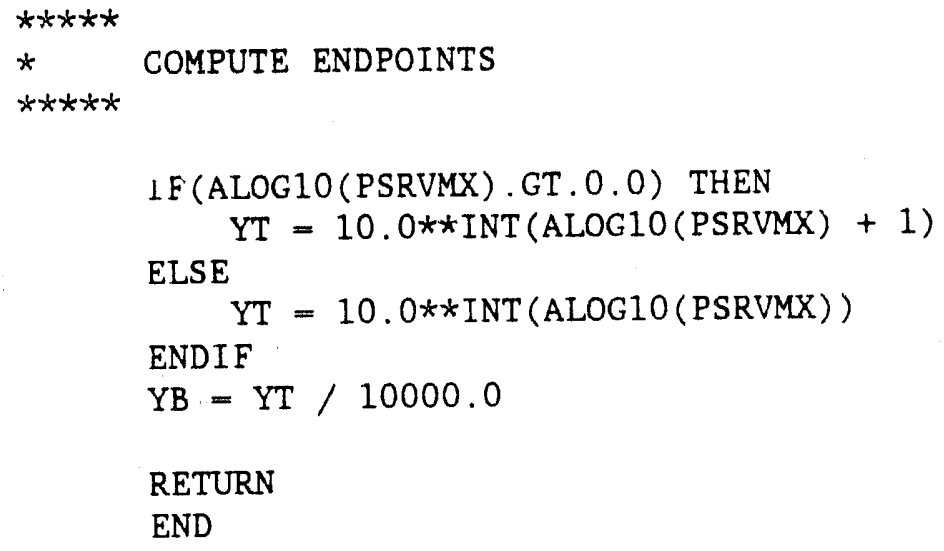


SUBROUTINE DRWCUR(INDXPER, PERIOD, PSRVAL, II)

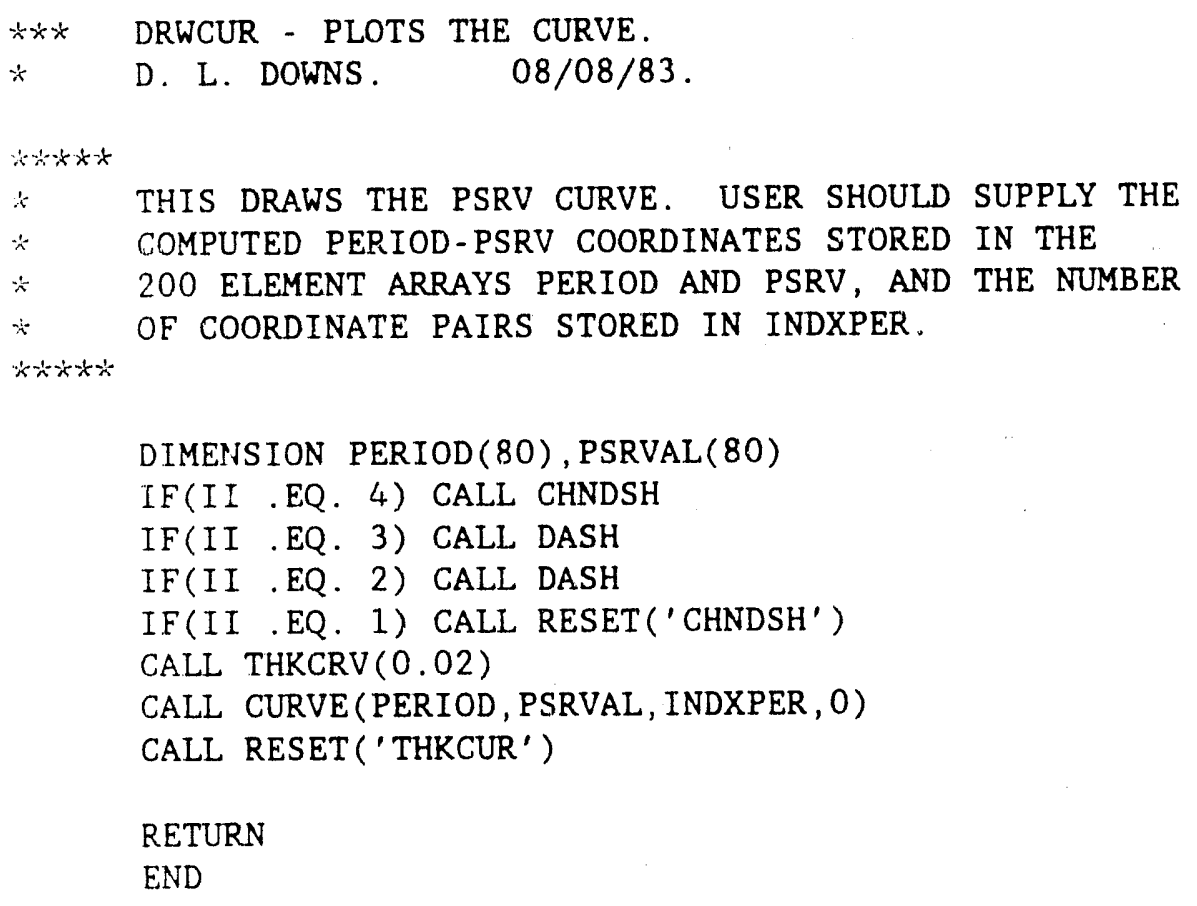


SUBROUTINE LGLGLG (DAMPFC, EVNTNAM,

GAUGEOR, STATNO,

XL, XR, YB , YT , SITE , STRNG , MESS4)

LGLGLG - CONSTRUCTS A GRID.

D. L. DOWNS . 08/08/83.

M. L. SANDERS. 09/22/86. NOS/VE VERSION.

REPLACE 'DATE(DAY)' WITH 'DATE()'.

THIS ROUTINE CONSTRUCTS A LOG-LOG-LOG GRID. THE USER SHOULD SUPPLY THE FOLLOWING ARGUMENTS

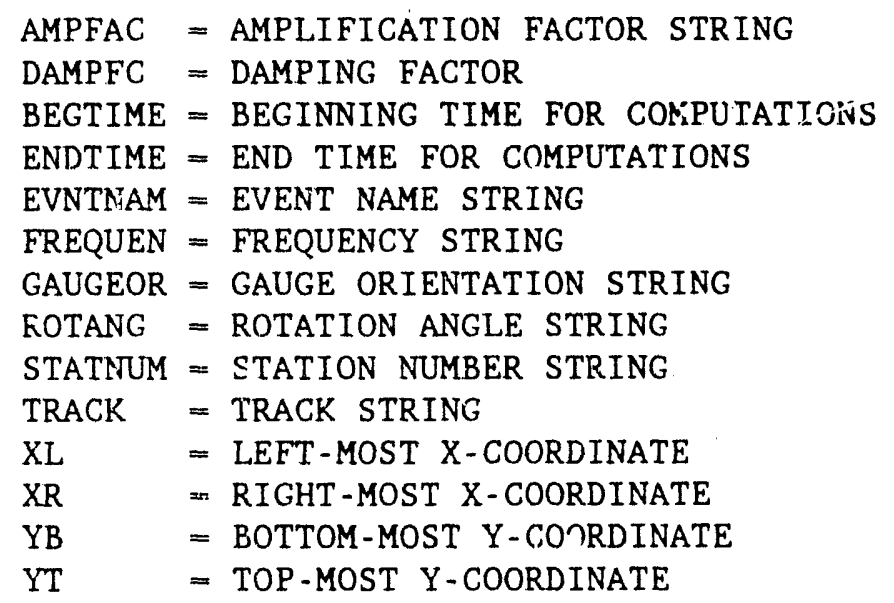


DATA LXNAME/'PERIOD - SEC'/,IXNAME/12/,IYNAME/42/

DATA LYNAME/'PSEUDO RELATIVE RESPONSE VELOCITY - CM/SEC'/

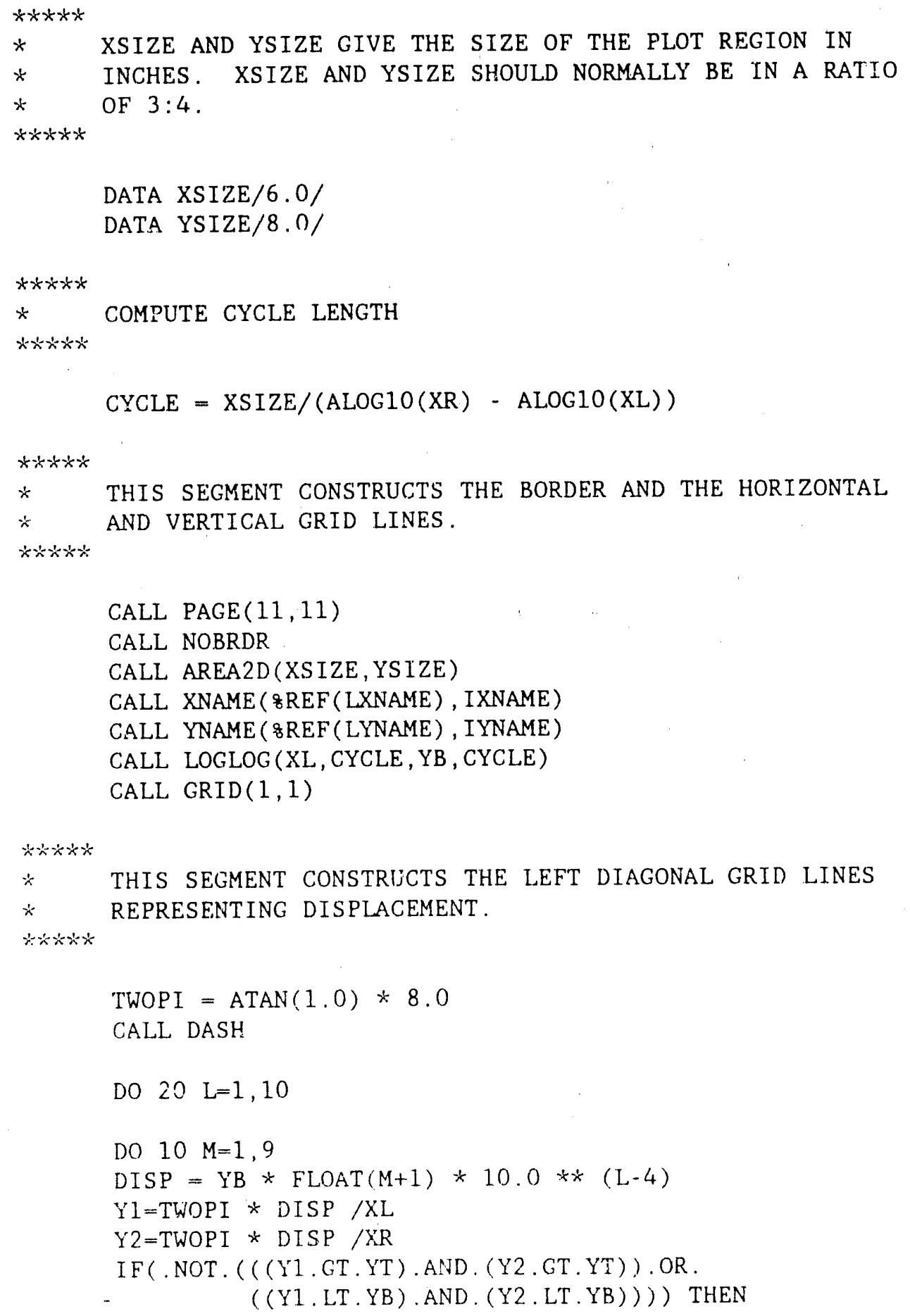


$\mathrm{SLOPE}=(\operatorname{ALOG} 10(\mathrm{Y} 2)-\operatorname{ALOG} 10(\mathrm{Y} 1)) /\left(\operatorname{ALOG} 10(\mathrm{XR})-\operatorname{ALOG10}\left(\mathrm{XL}_{1}\right)\right)$

YINT $=$ ALOG10 $(Y 1)-S L O P E * A L O G 10(X L)$

CALL ENDPTS(SLOPE, YINT, ALOG10(XL), ALOG10(XR),

ALOG10(YB) , ALOG10 (YT) , XX1, YY1, XX2, YY2)

$\mathrm{XX1}=10.0 * * \mathrm{XX1}$

$X X 2=10.0 * * X X 2$

$\mathrm{YY} 1=10.0 * * Y Y 1$

$Y Y 2=10.0 * * Y Y 2$

ENDIF

CALL RLVEC (XX1, YY1, XX2, YY2,0000)

10

CONTINUE

$* * * * * x$

PRINT DISPLACEMENT LABELS

$* * * * * *$

INDXDIS $=\operatorname{INT}($ ALOG10(YB) $)+\mathrm{L}+2$

IF ( (INDXDIS.GE. 1) . AND. (INDXDIS . LE . 8) . AND .

(Y2.GT.YB) . AND. (Y2.LT . YT)) THEN

CALL ANGLE (315)

CALL HEIGHT (0.1)

CALL RLMESS ( 8 REF (DUNITS (INDXDIS) ) $, 8,1.2 * X X 2$, YY2)

CALL RESET('ANGLE')

ENDIF

CALL RESET ('HEIGHT')

20 CONTINUE

CALL RESET('DASH')

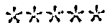

* THIS SEGMEN'T CONSTRUCTS THE RIGHT DIAGONAL GRID LINES

$*$ REPRESENTING ACCELERATION.

$x+x+x$

CALL DOT

DO $40 \mathrm{~L}=1,10$

D) $30 M=1,9$

$A C C E L=Y B * \operatorname{FLOAT}(M+1) * 980.2368 * 10.0 * *(\mathrm{~L}-5)$

$Y 1=A C C E L * X L / T W O P I$

$\mathrm{Y} 2=\mathrm{ACCEL} * \mathrm{XR} / \mathrm{TWOPI}$

IF ( . NOT . ( ( (Y1 , GT , YT ) . AND . (Y2,GT , YT $))$. OR .

((Y1.LT.YB) AAND. (Y2.LT.YB)))) THEN

SLOPE $=\left(\operatorname{ALOG} 10(Y 2)-\operatorname{ALOG10}\left(Y^{\prime} 1\right)\right) /(\operatorname{ALOG} 10(\mathrm{XR})-\operatorname{ALOG} 10(\mathrm{XL}))$

YINT=ALOG10 (Y1) -SLOPE $* A L O G 10(X L)$

CALL ENDPTS(SLOPE, YINT, ALOG10(XL), ALOG10(XR), ALOG 10(YB), ALOG10(YT) XX1, YY1 XX2, YY2) 


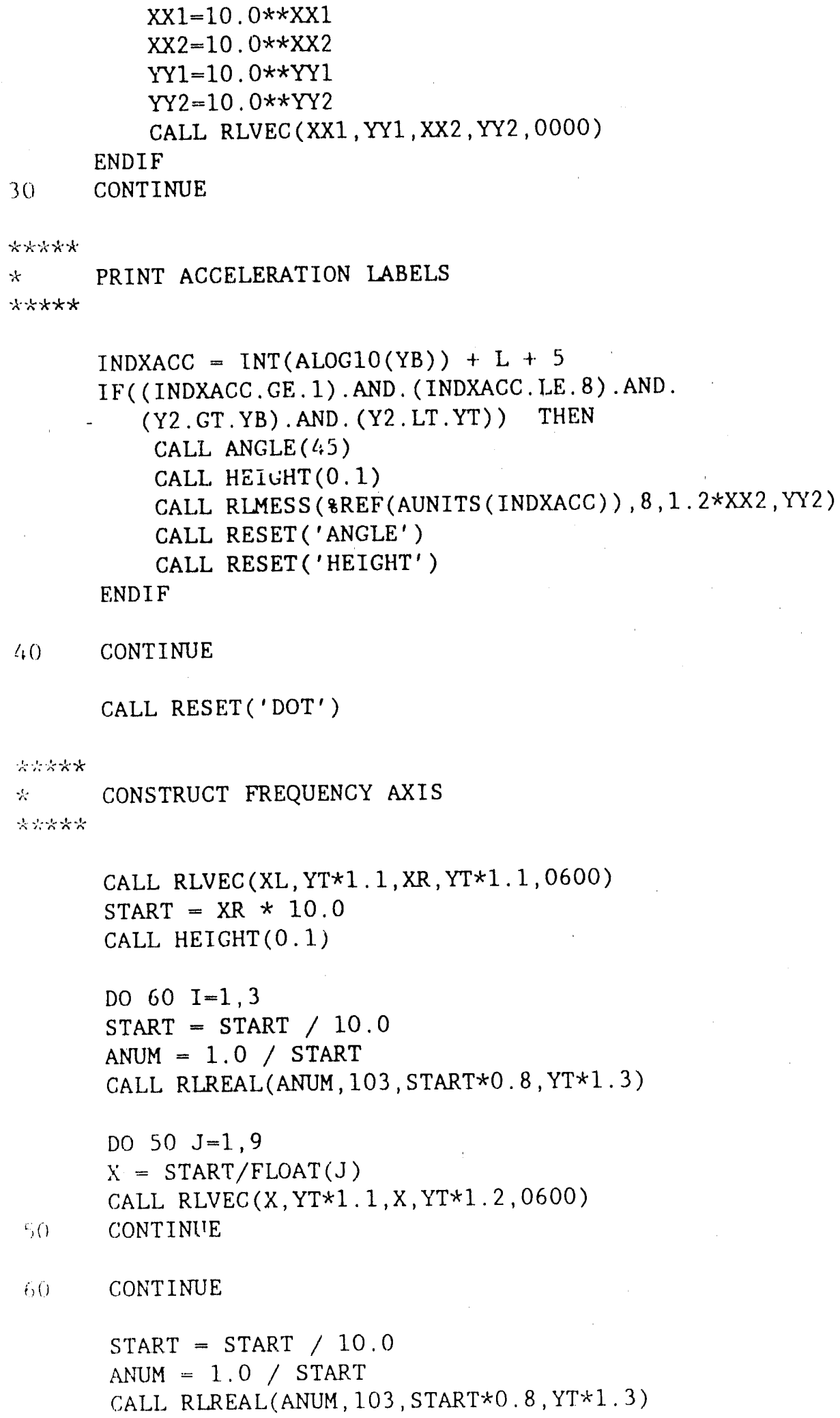


CALL RLVEC (START, YT*1.1, START, YT* $1.2,0600)$

CALL RESE'' ('HEIGHT')

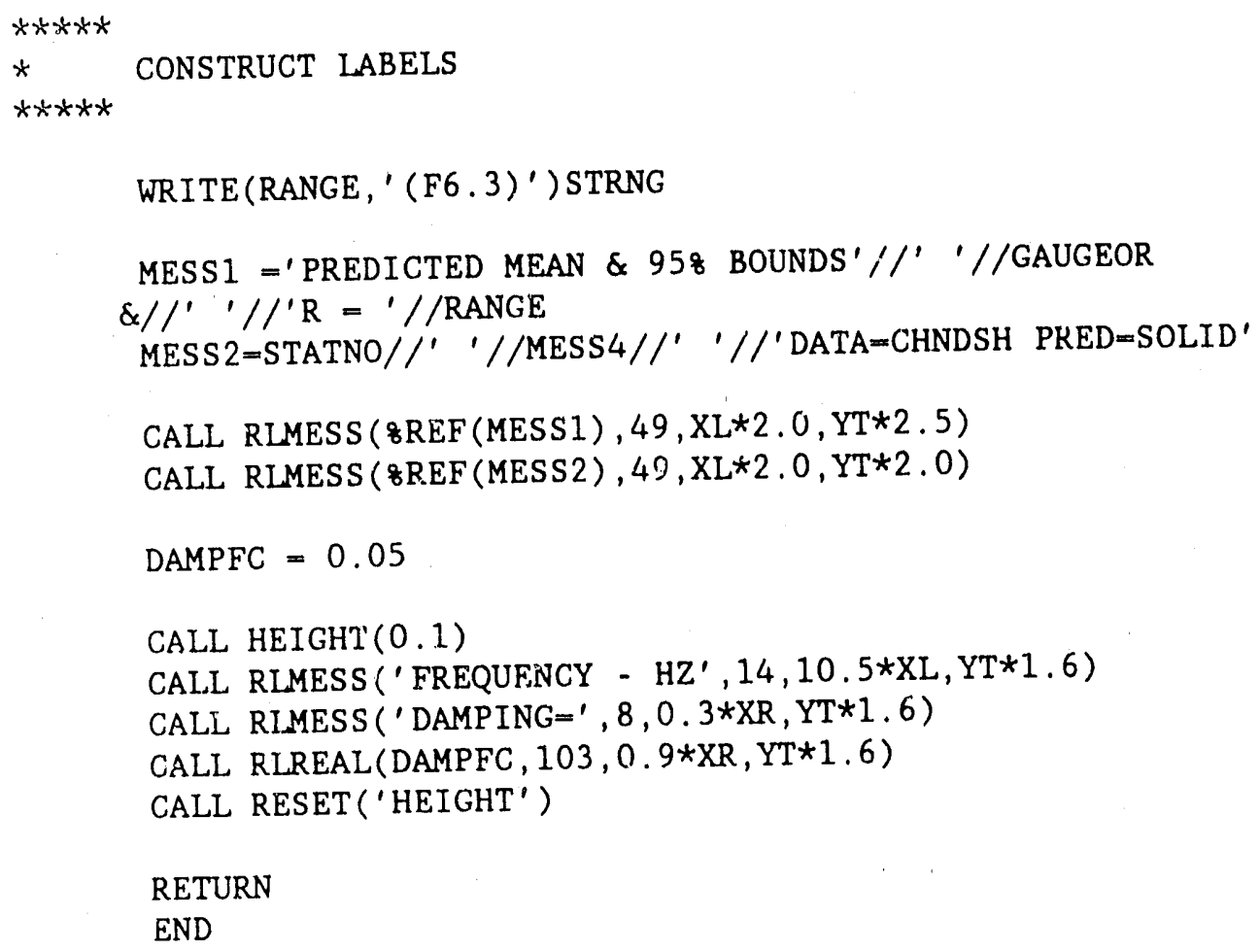


SUBROUTINE ENDPTS (SLOPE, YINT, XLEFT, XRIGHT, YBOT, YTOP,

- $\quad \mathrm{XX1}, \mathrm{YY} 1, \mathrm{XX} 2, \mathrm{YY} 2)$

ENDPTS - DETERMINE ENDPOINTS FOR THE AXIES.

D. L. DOWNS . $08 / 08 / 83$.

M. L. SANDERS . 09/22/86. NOS/VE VERSION .

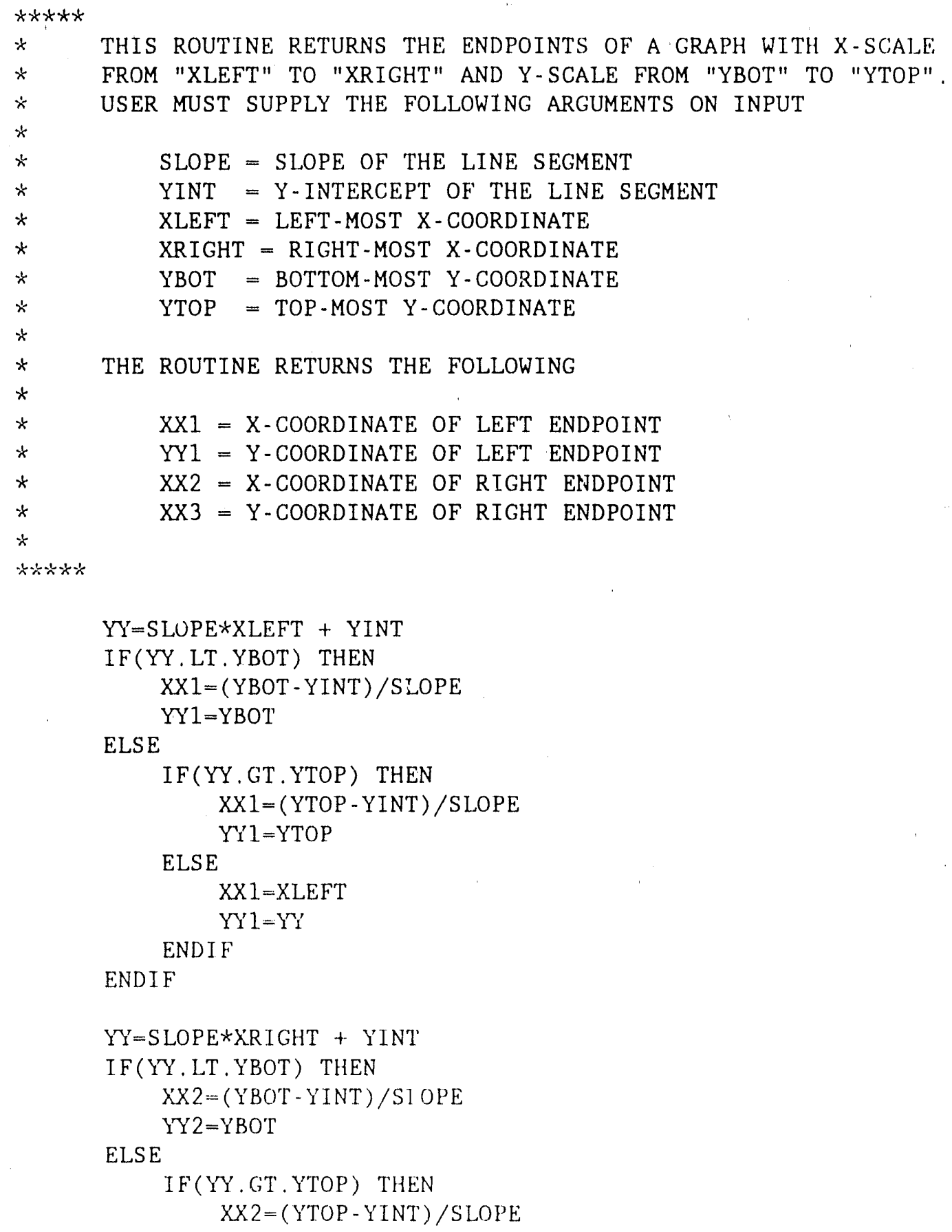

THE ROUTINE RETURNS THE FOLLOWING

$\mathrm{XX} 1=\mathrm{X}$-COORDINATE OF LEFT ENDPOINT

$Y Y 1=Y$-COORDINATE OF LEFT ENDPOINT

$X X 2=X$-COORDINATE OF RIGHT ENDPOINT

$\mathrm{XX} 3=\mathrm{Y}$-COORDINATE OF RIGHT ENDPOINT 
PROGRAM PREDICT

\author{
$Y Y 2=Y T O P$ \\ ELSE \\ $\mathrm{XX} 2=\mathrm{XR}$ I.GHT \\ $Y Y 2=Y Y$ \\ ENDIF \\ ENDIF \\ RETURN \\ END
}


SUBROUTINE ERCSPC(R,W)

DIMENSION PSRV (40), F(40), A(40), B1(40), B2 (40), PSRV2 (40)

$\&$, PS1(40), PS2 (40), P (40)

DATA $(P(I), I=1,40) / 2.469,2.234,2.022,1.829,1.655,1.478,1.355$,

$\& \quad 1.226,1.110,1.004, .908, .822, .744, .673, .609$,

$\& \quad .551, .499, .451, .408, .369, .334, .302, .274, .248$,

$\& \quad .224, .203, .183, .166, .150, .136, .123, .111, .101$,

$\&$ $.091, .082, .075, .067, .061, .055, .05 /$

$\operatorname{DATA}(\mathrm{A}(\mathrm{I}), \mathrm{I}=1,40) / 2.4,2.37,2.35,1.96,1.59,1.61,1.66,1.56,1.83$, $\& \quad 2.08,1.72,1.59,2.02,2.76,2.93,2.96,3.63,6.4$,

$\& \quad 7.15,6.82,8.65,11.3,11.0,12.1,12.1,16.7,20.1$,

$\& \quad 20.6,24.8,21.8,18.9,15.3,12.9,11.8,10.8,8.87$,

$\&$

DATA (B1(I), I $=1,40)$

$/ .699, .701, .719, .732, .749, .753, .775, .771, .748$

\& $\quad .732, .713, .698, .665, .645, .636, .632$,

$\& \quad .601, .583, .572, .555, .528, .508, .504, .509, .498$,

$\& \quad .480, .479, .478, .466, .468, .480, .480, .475, .468$,

$\& \quad .457, .463, .474, .483, .479, .491 /$

DATA (B2(I), I=1,40) /1.137,1.165,1.181,1.168,1.143,1.145,1.160,

\& $\quad 1.129,1.128,1.133,1.083,1.06,1.085,1.121$,

$\& \quad 1.134,1.134,1.15,1.255,1.276,1.263,1.303$,

$\& \quad 1.342,1.354,1.395,1.399,1.469,1.533,1.555$,

\& $\quad 1.597,1.591,1.6,1.582,1.558,1.546,1.533,1.515$,

$\& \quad 1.486,1.447,1.395,1.340 /$

C

DO $2000 I=1,40$

$\operatorname{PSRV}(I)=A(I) *(\mathrm{~W} * * B 1(I)) /(\mathrm{R} * * \mathrm{~B} \hat{L}(I))$

2000 CONCINUE

CALL DRWCUR ( 40, P, PSRV , 4)

RETURN

END 
SUBROUTINE DWNHOLE(BSTA, ATTEN, GAGEOR)

CHARACTER *7 BSTA

CHARACTER $* 8$ GAGEOR

DIMENSION ATTEN(50), W25AV(50), W25AR(50), W25AT(50),

$\& \operatorname{W} 28 \operatorname{AV}(50), W 28 A R(50), W 28 A T(50), W 29 A V(50), W 29 \operatorname{AR}(50)$,

\& W29AT (50),W30AV (50),W30AR (50),W30AT(50)

IF(BSTA .EQ. 'W12 BOT') BSTA = 'W30 BOT'

DATA(W25AV (I) , $I=1,48$ )/ $0.970567 \mathrm{E}+00,0.960824 \mathrm{E}+00,0.945569 \mathrm{E}+00,0.945425 \mathrm{E}+00$, $0.944986 \mathrm{E}+00,0.903739 \mathrm{E}+00,0.887707 \mathrm{E}+00,0.874417 \mathrm{E}+00$, $0.857737 \mathrm{E}+00,0.837766 \mathrm{E}+00,0.710168 \mathrm{E}+00,0.634193 \mathrm{E}+00$, $0.625966 \mathrm{E}+00,0.600751 \mathrm{E}+00,0.545759 \mathrm{E}+00,0.525724 \mathrm{E}+00$, $0.470580 \mathrm{E}+00,0.384996 \mathrm{E}+00,0.349719 \mathrm{E}+00,0.264270 \mathrm{E}+00$, $0.258319 \mathrm{E}+00,0.242990 \mathrm{E}+00,0.318943 \mathrm{E}+00,0.379295 \mathrm{E}+00$ $0.297380 \mathrm{E}+00,0.274413 \mathrm{E}+00,0.252245 \mathrm{E}+00,0.230439 \mathrm{E}+00$, $0.227730 \mathrm{E}+00,0.253176 \mathrm{E}+00,0.265805 \mathrm{E}+00,0.269940 \mathrm{E}+00$, $0.262102 \mathrm{E}+00,0.212969 \mathrm{E}+00,0.239881 \mathrm{E}+00,0.207327 \mathrm{E}+00$, $0.171684 \mathrm{E}+00,0.191047 \mathrm{E}+00,0.197395 \mathrm{E}+00,0.196530 \mathrm{E}+00$, $0.219242 \mathrm{E}+00,0.256933 \mathrm{E}+00,0.260930 \mathrm{E}+00,0.245302 \mathrm{E}+00$, $0.243563 \mathrm{E}+00,0.262231 \mathrm{E}+00,0.264770 \mathrm{E}+00,0.253581 \mathrm{E}+00 /$

$\operatorname{DATA}(\operatorname{W2} 2 \operatorname{AR}(\mathrm{I}), I=1,48) /$

$\&$

$0.578958 \mathrm{E}+00,0.552678 \mathrm{E}+00,0.532745 \mathrm{E}+00,0.501293 \mathrm{E}+00$, $0.523746 \mathrm{E}+00,0.488556 \mathrm{E}+00,0.480587 \mathrm{E}+00,0.443011 \mathrm{E}+0 \mathrm{C}$, $0.484371 \mathrm{E}+00,0.465867 \mathrm{E}+00,0.447501 \mathrm{E}+00,0.433176 \mathrm{E}+00$,
$0.416712 \mathrm{E}+00,0.405892 \mathrm{E}+00,0.377199 \mathrm{E}+00,0.327074 \mathrm{E}+00$, $0.349744 \mathrm{E}+00,0.365981 \mathrm{E}+00,0.365435 \mathrm{E}+00,0.408336 \mathrm{E}+00$, $0.339859 \mathrm{E}+00,0.237408 \mathrm{E}+00,0.205437 \mathrm{E}+00,0.238376 \mathrm{E}+00$, $0.183174 \mathrm{E}+00,0.190448 \mathrm{E}+00,0.271784 \mathrm{E}+00,0.337991 \mathrm{E}+0 \mathrm{U}$, $0.344358 \mathrm{E}+00,0.274489 \mathrm{E}+00,0.224670 \mathrm{E}+00,0.238821 \mathrm{E}+00$, $0.233388 \mathrm{E}+00,0.258609 \mathrm{E}+00,0.237790 \mathrm{E}+00,0.254756 \mathrm{E}+00$, $0.246286 \mathrm{E}+00,0.225383 \mathrm{E}+00,0.202474 \mathrm{E}+00,0.199485 \mathrm{E}+00$, $0.223920 \mathrm{E}+00,0.266708 \mathrm{E}+00 ; 0.277060 \mathrm{E}+00,0.295165 \mathrm{E}+00$

C

DATA (W25AT (I) , I=1, 48)/ $0.841200 \mathrm{E}+00,0.797211 \mathrm{E}+00,0.709862 \mathrm{E}+00,0.682900 \mathrm{E}+00$, $0.682307 \mathrm{E}+00,0.640752 \mathrm{E}+00,0.617915 \mathrm{E}+00,0.609621 \mathrm{E}+00$, $0.572745 \mathrm{E}+00,0.552284 \mathrm{E}+00,0.461146 \mathrm{E}+00,0.463189 \mathrm{E}+00$, $0.453180 \mathrm{E}+00,0.445168 \mathrm{E}+00,0.366134 \mathrm{E}+00,0.346819 \mathrm{E}+00$, $0.336124 \mathrm{E}+00,0.267981 \mathrm{E}+00,0.234584 \mathrm{E}+00,0.187535 \mathrm{E}+00$, $0.189875 \mathrm{E}+00,0.201060 \mathrm{E}+00,0.207088 \mathrm{E}+00,0.151977 \mathrm{E}+00$, $0.117969 \mathrm{E}+00,0.145182 \mathrm{E}+00,0.149868 \mathrm{E}+00,0.155480 \mathrm{E}+00$, $0.147538 \mathrm{E}+00,0.117723 \mathrm{E}+00,0.141921 \mathrm{E}+00,0.154823 \mathrm{E}+00$, $0.139773 \mathrm{E}+00,0.142506 \mathrm{E}+00,0.129043 \mathrm{E}+00,0.140466 \mathrm{E}+00$, $0.144874 \mathrm{E}+00,0.126004 \mathrm{E}+00,0.133236 \mathrm{E}+00,0.127862 \mathrm{E}+00$, $0.137864 \mathrm{E}+00,0.154282 \mathrm{E}+00,0.144010 \mathrm{E}+00,0.140415 \mathrm{E}+00$, $0.136960 \mathrm{E}+00,0.135715 \mathrm{E}+00,0.147196 \mathrm{E}+00,0.144700 \mathrm{E}+00 /$ 
$\operatorname{DATA}(\mathrm{W} 28 \mathrm{AV}(\mathrm{I}), \mathrm{I}=1,48) /$

$\& \quad 0.953635 \mathrm{E}+00,0.979526 \mathrm{E}+00,0.983161 \mathrm{E}+00,0.974596 \mathrm{E}+00$,

$\& \quad 0.956554 \mathrm{E}+00,0.929370 \mathrm{E}+00,0.926742 \mathrm{E}+00,0.907257 \mathrm{E}+00$,

\& $\quad 0.861580 \mathrm{E}+00,0.836409 \mathrm{E}+00,0.677089 \mathrm{E}+00,0.524683 \mathrm{E}+00$;

$\& \quad 0.449306 \mathrm{E}+00,0.408921 \mathrm{E}+00,0.357179 \mathrm{E}+00,0.338688 \mathrm{E}+00$,

$\& \quad 0.318453 \mathrm{E}+00,0.330129 \mathrm{E}+00,0.225081 \mathrm{E}+00,0.226781 \mathrm{E}+00$,

$\& \quad 0.299166 \mathrm{E}+00,0.367627 \mathrm{E}+00,0.435495 \mathrm{E}+00,0.513578 \mathrm{E}+00$,

$\& \quad 0.611466 \mathrm{E}+00,0.526239 \mathrm{E}+00,0.402578 \mathrm{E}+00,0.360592 \mathrm{E}+00$,

$\& \quad 0.354383 \mathrm{E}+00,0.403484 \mathrm{E}+00,0.436239 \mathrm{E}+00,0.451416 \mathrm{E}+00$,

$\& \quad 0.459308 \mathrm{E}+00,0.485772 \mathrm{E}+00,0.464921 \mathrm{E}+00,0.398975 \mathrm{E}+00$,

$\& \quad 0.441412 \mathrm{E}+00,0.473047 \mathrm{E}+00,0.542267 \mathrm{E}+00,0.482713 \mathrm{E}+00$,

$\& \quad 0.4542 .60 \mathrm{E}+00,0.397177 \mathrm{E}+00,0.427011 \mathrm{E}+00,0.532096 \mathrm{E}+00$,

$\& \quad 0.565205 \mathrm{E}+00,0.573599 \mathrm{E}+00,0.541258 \mathrm{E}+00,0.504431 \mathrm{E}+00 /$

C

$\operatorname{DATA}($ W28AR (I) $, I=1,48) /$

\& $\quad 0.520294 \mathrm{E}+00,0.493108 \mathrm{E}+00,0.493753 \mathrm{E}+00,0.464274 \mathrm{E}+00$,

\& $\quad 0.413465 \mathrm{E}+00,0.389040 \mathrm{E}+00,0.375082 \mathrm{E}+00,0.347076 \mathrm{E}+00$,

\& $\quad 0.371629 \mathrm{E}+00,0.341044 \mathrm{E}+00,0.341463 \mathrm{E}+00,0.300372 \mathrm{E}+00$,

\& $\quad 0.259999 \mathrm{E}+00,0.224639 \mathrm{E}+00,0.212005 \mathrm{E}+00,0.250512 \mathrm{E}+00$,

$\& \quad 0.213939 \mathrm{E}+00,0.196787 \mathrm{E}+00,0.205634 \mathrm{E}+00,0.311474 \mathrm{E}+00$,

\& $\quad 0.344947 \mathrm{E}+00,0.370879 \mathrm{E}+00,0.380389 \mathrm{E}+00,0.383036 \mathrm{E}+00$,

$\& \quad 0.367204 \mathrm{E}+00,0.440095 \mathrm{E}+00,0.515028 \mathrm{E}+00,0.478338 \mathrm{E}+00$,

\& $\quad 0.469065 \mathrm{E}+00,0.550498 \mathrm{E}+00,0.642565 \mathrm{E}+00,0.694572 \mathrm{E}+00$,

$\& \quad 0.793217 \mathrm{E}+00,0.840552 \mathrm{E}+00,0.855157 \mathrm{E}+00,0.929928 \mathrm{E}+00$,

$\& \quad 0.118723 \mathrm{E}+01,0.119309 \mathrm{E}+01,0.926757 \mathrm{E}+00,0.100847 \mathrm{E}+01$,

$\& \quad 0.964298 \mathrm{E}+00,0.117589 \mathrm{E}+01,0.129047 \mathrm{E}+01,0.144589 \mathrm{E}+01$,

\& $\quad 0.154224 \mathrm{E}+01,0.142847 \mathrm{E}+01,0.132334 \mathrm{E}+01,0.118989 \mathrm{E}+01 /$

C

$\operatorname{DATA}($ W2 $8 A T(I), I=1,48) /$

\& $\quad 0.711397 \mathrm{E}+00,0.705380 \mathrm{E}+00,0.641150 \mathrm{E}+\mathrm{C0}, 0.633919 \mathrm{E}+00$,

$\& \quad 0.612209 \mathrm{E}+00,0.561351 \mathrm{E}+00,0.490153 \mathrm{E}+00,0.442463 \mathrm{E}+00$,

$\& \quad 0.396635 \mathrm{E}+00,0.386022 \mathrm{E}+00,0.277439 \mathrm{E}+00,0.281024 \mathrm{E}+00$,

$\& \quad 0.319224 \mathrm{E}+00,0.230946 \mathrm{E}+00,0.232735 \mathrm{E}+00,0.35922 .7 \mathrm{E}+00$,

\& $\quad 0.327523 \mathrm{E}+00,0.313307 \mathrm{E}+00,0.367728 \mathrm{E}+00,0.403873 \mathrm{E}+00$,

$\& \quad 0.473644 \mathrm{E}+00,0.461 .424 \mathrm{E}+00,0.372308 \mathrm{E}+00,0.471 .681 \mathrm{E}+00$,

$\& \quad 0.436874 \mathrm{E}+00,0.422887 \mathrm{E}+00,0.393318 \mathrm{E}+00,0.408078 \mathrm{E}+00$,

$\& \quad 0.417166 \mathrm{E}+00,0.553674 \mathrm{E}+00,0.702274 \mathrm{E}+00,0.670986 \mathrm{E}+00$,

$\& \quad 0.703024 \mathrm{E}+00,0.733563 \mathrm{E}+00,0.109615 \mathrm{E}+01,0.152374 \mathrm{E}+01$,

$\& \quad 0.175071 \mathrm{E}+01,0.188512 \mathrm{E}+01,0.21 .5224 \mathrm{E}+01,0.192024 \mathrm{E}+01$,

$\& \quad 0.191774 \mathrm{E}+01,0.159596 \mathrm{E}+01,0.156515 \mathrm{E}+01,0.137213 \mathrm{E}+01$,

$\& \quad 0.128711 E+01,0.127989 E+01,0.118481 E+01,0.121 .962 E+01 /$

C

$\operatorname{DATA}(\mathrm{W} 29 \operatorname{AV}(\mathrm{I}), \mathrm{I}=1,48) /$

$\begin{array}{ll}\& & 0.975708 \mathrm{E}+00,0.975713 \mathrm{E}+00,0.977065 \mathrm{E}+00,0.976542 \mathrm{E}+00 \\ \& & 0.973667 \mathrm{E}+00,0.972819 \mathrm{E}+00,0.971512 \mathrm{E}+00,0.971852 \mathrm{E}+00, \\ \& & 0.964950 \mathrm{E}+00,0.950302 \mathrm{E}+00,0.916410 \mathrm{E}+00,0.901446 \mathrm{E}+00 \\ \& & 0.889094 \mathrm{E}+00,0.891489 \mathrm{E}+00,0.862972 \mathrm{E}+00,0.864119 \mathrm{E}+00 \\ \& & 0.853554 \mathrm{E}+00,0.847847 \mathrm{E}+00,0.807703 \mathrm{E}+00,0.743013 \mathrm{E}+00\end{array}$ 
?.722925E+00, $0.695989 \mathrm{E}+00,0.645274 \mathrm{E}+00,0.618070 \mathrm{E}+00$, $0.565571 \mathrm{E}+00,0.497885 \mathrm{E}+00,0.449492 \mathrm{E}+00,0.447024 \mathrm{E}+00$, $0.438475 \mathrm{E}+00,0.580582 \mathrm{E}+100,0.594544 \mathrm{E}+00,0.570746 \mathrm{E}+00$, $0.596985 \mathrm{E}+00,0.693954 \mathrm{E}+00,0.671136 \mathrm{E}+00,0.614244 \mathrm{E}+00$, $0.515101 \mathrm{E}+00,0.429068 \mathrm{E}+00,0.496387 \mathrm{E}+00,0.512047 \mathrm{E}+00$, $0.526410 \mathrm{E}+00,0.538661 \mathrm{E}+00,0.584358 \mathrm{E}+00,0.576124 \mathrm{E}+00$, $0.539566 \mathrm{E} \div 00,0.520360 \mathrm{E}+00,0.536965 \mathrm{E}+00,0.508113 \mathrm{E}+00 /$

DA_A (W29AR(I) , I=1,48) !

\& $\quad 0.569109 \mathrm{E}+00,0.622223 \mathrm{E}+00,0.688831 \mathrm{E}+00,0.787537 \mathrm{E}+00$, $\& \quad 0.831283 \mathrm{E}+00,0.791687 \mathrm{E}+00,0.748767 \mathrm{E}+00,0.772632 \mathrm{E}+00$, $\& \quad 0.786767 \mathrm{E}+00,0.697187 \mathrm{E}+00,0.673883 \mathrm{E}+00,0.698627 \mathrm{E}+00$, $\& \quad 0.719188 \mathrm{E}+00,0.745758 \mathrm{E}+00,0.737806 \mathrm{E}+00,0.717541 \mathrm{E}+00$, $\& \quad 0.683800 \mathrm{E}+00,0.620734 \mathrm{E}+00,0.585671 \mathrm{E}+00,0.623933 \mathrm{E}+00$, \& $\quad 0.521103 \mathrm{E}+00,0.495367 \mathrm{E}+00,0.444456 \mathrm{E}+00,0.377600 \mathrm{E}+00$, $\& \quad 0.381005 E+00,0.347815 E+00,0.408729 E+00,0.462994 E+00$, $\& \quad 0.4101 .96 \mathrm{E}+00,0.538749 \mathrm{E}+00,0.550721 \mathrm{E}+00,0.537081 \mathrm{E}+00$, $\& \quad 0.592866 \mathrm{E}+00,0.558007 \mathrm{E}+00,0.516183 \mathrm{E}+00,0.489872 \mathrm{E}+00$, $\& \quad 0.489926 \mathrm{E}+00,0.475001 \mathrm{E}+00,0.519812 \mathrm{E}+00,0.445382 \mathrm{E}+00$, $\& \quad 0.450921 \mathrm{E}+00,0.468590 \mathrm{E}+00,0.491383 \mathrm{E}+00,0.529355 \mathrm{E}+00$, $\& \quad 0.583605 \mathrm{E}+00,0.563129 \mathrm{E}+00,0.530960 \mathrm{E}+00,0.520530 \mathrm{E}+00 /$

DATA (W29AR (I), I=1,48)/

\& $\quad 0.569109 \mathrm{E}+00,0.622223 \mathrm{E}+00,0.688831 \mathrm{E}+00,0.787537 \mathrm{E}+00$, $\& \quad 0.831283 \mathrm{E}+00,0.7916 .87 \mathrm{E}+00,0.748767 \mathrm{E}+00,0.772632 \mathrm{E}+00$, $\& \quad 0.786767 \mathrm{E}+00,0.697187 \mathrm{E}+00,0.673883 \mathrm{E}+00,0.698627 \mathrm{E}+00$, $\& \quad 0.719188 \mathrm{E}+00,0.745758 \mathrm{E}+00,0.737806 \mathrm{E}+00,0.717541 \mathrm{E}+00$, \& $\quad 0.683800 \mathrm{E}+00,0.620734 \mathrm{E}+00,0.585671 \mathrm{E}+00,0.623933 \mathrm{E}+00$, \& $\quad 0.521103 \mathrm{E}+00,0.495367 \mathrm{E}+00,0.444456 \mathrm{E}+00,0.377600 \mathrm{E}+00$, $\& \quad 0.381005 E+00,0.347815 E+00,0.408729 E+00,0.462994 E+00$, \& $\quad 0.410196 \mathrm{E}+00,0.538749 \mathrm{E}+00,0.550721 \mathrm{E}+00,0.537081 \mathrm{E}+00$, $\& \quad 0.592866 \mathrm{E}+00,0.558007 \mathrm{E}+00,0.516183 \mathrm{E}+00,0.489872 \mathrm{E}+00$, \& $\quad 0.489926 \mathrm{E}+00,0.475001 \mathrm{E}+00,0.519812 \mathrm{E}+00,0.445382 \mathrm{E}+00$, $\& \quad 0.450921 \mathrm{E}+00,0.468590 \mathrm{E}+00,0.491383 \mathrm{E}+00,0.529355 \mathrm{E}+00$, $\& \quad 0.583605 \mathrm{E}+00,0.563129 \mathrm{E}+00,0.530960 \mathrm{E}+00,0.520530 \mathrm{E}+00 /$

DATA(W29AT (I), I=1,48)/

$\& \quad 0.965070 E+00,0.965703 E+00,0.958076 E+00,0.944985 E+00$, \& $\quad 0.941726 \mathrm{E}+00,0.943760 \mathrm{E}+00,0.934476 \mathrm{E}+00,0.929495 \mathrm{E}+00$, $\varepsilon \quad 0.915973 E+00,0.886283 E+00,0.879470 E+00,0.874137 E+00$, \& $\quad 0.839855 \mathrm{E}+00,0.814395 \mathrm{E}+00,0.813425 \mathrm{E}+00,0.798142 \mathrm{E}+00$, $\& \quad 0.726507 \mathrm{E}+00,0.652593 \mathrm{E}+00,0.670539 \mathrm{E}+00,0.723898 \mathrm{E}+00$, $\& \quad 0.628902 \mathrm{E}+00,0.586439 \mathrm{E}+00,0.538510 \mathrm{E}+00,0.491392 \mathrm{E}+00$, \& $\quad 0.507712 E+00,0.505412 E+00,0.549321 E+00,0.7152 E+00$, $\& \quad 0.653865 E+00,0.739065 E+00,0.743435 E+00,0.734909 E+00$, $\& \quad 0.701942 E+00,0.679371 E+100,0.596963 E+00,0.597095 E+00$, \& $\quad 0.627306 \mathrm{E}+00,0.659317 \mathrm{E}+00,0.715405 \mathrm{E}+00,0.659263 \mathrm{E}+00$, $\& \quad 0.705437 \mathrm{E}+00,0.676360 \mathrm{E}+00,0.650235 \mathrm{E}+00,0.629048 \mathrm{E}+00$, $\& \quad 0.566178 E+00,0.641429 E+00,0.641908 E+00,0.645184 E+00 /$ 
C DATA(W30AV(I) , I=1;48)/
$\&$

$\&$

$\&$

$\&$

$\&$

$\varepsilon$

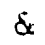

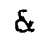

$\varepsilon$

$\varepsilon$

$\dot{\alpha}$

$\varepsilon$ $0.111762 \mathrm{E}+01,0.112638 \mathrm{E}+01,0.113207 \mathrm{E}+01,0.112807 \mathrm{E}+01$, $0.113047 \mathrm{E}+01,0.112498 \mathrm{E}+01,0.112260 \mathrm{E}+01,0.109491 \mathrm{E}+01$, $0.107558 \mathrm{E}+01,0.993633 \mathrm{E}+00,0.844433 \mathrm{E}+00,0.805705 \mathrm{E}+00$, $0.777126 \mathrm{E}+00,0.746498 \mathrm{E}+00,0.716564 \mathrm{E}+00,0.691687 \mathrm{E}+00$, $0.629604 \mathrm{E}+00,0.485322 \mathrm{E}+00,0.463809 \mathrm{E}+00,0.414819 \mathrm{E}+00$, $0.438953 E+00,0.545194 E+00,0.530773 E+00,0.601272 E+00$, $0.645164 \mathrm{E}+00,0.740238 \mathrm{E}+00,0.902831 \mathrm{E}+00,0.769824 \mathrm{E}+00$, $0.752549 \mathrm{E}+00,0.763636 \mathrm{E}+00,0.663689 \mathrm{E}+00,0.766461 \mathrm{E}+00$, $0.918749 \mathrm{E}+00,0.981195 \mathrm{E}+00,0.878173 \mathrm{E}+00,0.705556 \mathrm{E}+00$, C. $628545 \mathrm{E}+00,0.575170 \mathrm{E}+00,0.542869 \mathrm{E}+00,0.601239 \mathrm{E}+00$, $0.594752 \mathrm{E}+00,0.553771 \mathrm{E}+00,0.582443 \mathrm{E}+00,0.598299 \mathrm{E}+00$, C DATA (W30AR (I), I=1,48)/

$\& \quad 0.653456 \mathrm{E}+00,0.658319 \mathrm{E}+00,0.678996 \mathrm{E}+00,0.714990 \mathrm{E}+00$, $\& \quad 0.709428 \mathrm{E}+00,0.643330 \mathrm{E}+00,0.621079 \mathrm{E}+00,0.697935 \mathrm{E}+00$, $\& \quad 0.760587 E+00,0.696880 E+00,0.645436 E+00,0.642477 E+00$, \& $\quad 0.668535 \mathrm{E}+00,0.724780 \mathrm{E}+00,0.702498 \mathrm{E}+00,0.500357 \mathrm{E}+00$, $\& \quad 0.420956 \mathrm{E} ; 00,0.453428 \mathrm{E}+00,0.554914 \mathrm{E}+00,0.645625 \mathrm{E}+00$, $\& \quad 0.605105 \mathrm{E}+00,0.747893 \mathrm{E}+00,0.754851 \mathrm{E}+00,0.704110 \mathrm{E}+00$, $\& \quad 0.845318 \mathrm{E}+00,0.769991 \mathrm{E}+00,0.650387 \mathrm{E}+00,0.740006 \mathrm{E}+00$, $\& \quad 0.737550 \mathrm{E}+00,0.915945 \mathrm{E}+00,0.964491 \mathrm{E}+00,0.872913 \mathrm{E}+00$, \& $\quad 0.769843 E+00,0.708719 E+00,0.659835 E+00,0.613909 E+00$, $\& \quad 0.561479 \mathrm{E}+00,0.548805 \mathrm{E}+00,0.561646 \mathrm{E}+00,0.596715 \mathrm{E}+00$, $\& \quad 0.584552 \mathrm{E}+00,0.600693 \mathrm{E}+00,0.637062 \mathrm{E}+00,0.611373 \mathrm{E}+00$, \& $\quad 0.690017 E+00,0.719500 E+00,0.721972 E+00,0.743177 E+00 /$

\& $\quad 0.840569 \mathrm{E}+00,0.796278 \mathrm{E}+01), 0.765898 \mathrm{E}+00,0.699166 \mathrm{E}+00$, $\& \quad 0.683645 \mathrm{E}+00,0.740705 \mathrm{E}+00,0.786191 \mathrm{E}+00,0.824036 \mathrm{E}+00$,

$\& \quad 0.724340 \mathrm{E}+00,0.626184 \mathrm{E}+00,0.593016 \mathrm{E}+00,0.527160 \mathrm{E}+00$, $\& \quad 0.451668 \mathrm{E}+00,0.439757 \mathrm{E}+00,0.478294 \mathrm{E}+00,0.418859 \mathrm{E}+00$, $\& \quad 0.392596 \mathrm{E}+00,0.395434 \mathrm{E}+00,0 \quad 472265 \mathrm{E}+00,0.480250 \mathrm{E}+00$, \& $\quad 0.487892 \mathrm{E}+00,0.489437 \mathrm{E}+00,0.425324 \mathrm{E}+00,0.391090 \mathrm{E}+00$, $\& \quad 0.441167 \mathrm{E}+00,0.480444 \mathrm{E}+00,0.491186 \mathrm{E}+00,0.582275 \mathrm{E}+00$, \&. $\quad 0.693687 \mathrm{E}+00,0.644441 \mathrm{E}+00,0.568182 \mathrm{E}+00,0.511520 \mathrm{E}+00$, \& $\quad 0.445785 \mathrm{E}+00,0.373984 \mathrm{E}+00,0.342569 \mathrm{E}+00,0.385479 \mathrm{E}+00$, $E_{x} \quad 0.412092 \mathrm{E}+00,0.388736 \mathrm{E}+00,0.460750 \mathrm{E}+00,0.471392 \mathrm{E}+00$, $\& \quad 0.479464 \mathrm{E}+00,0.445374 \mathrm{E}+00,0.389539 \mathrm{E}+00,0.425402 \mathrm{E}+00$, \& $\quad 0.441209 \mathrm{E}+00,0.435538 \mathrm{E}+00,0.453044 \mathrm{E}+00,0.464795 \mathrm{E}+00 /$

IF(BSTA .EQ. 'W25 BOT' , AND. GAGEOR .EQ. 'VERT') THEN D) $2001 \mathrm{~J}=1,48$ $\operatorname{ATEN}(\mathrm{J})=\mathrm{W} 25 \mathrm{AV}(\mathrm{J})$

OUL CONTINUE ENDIF 


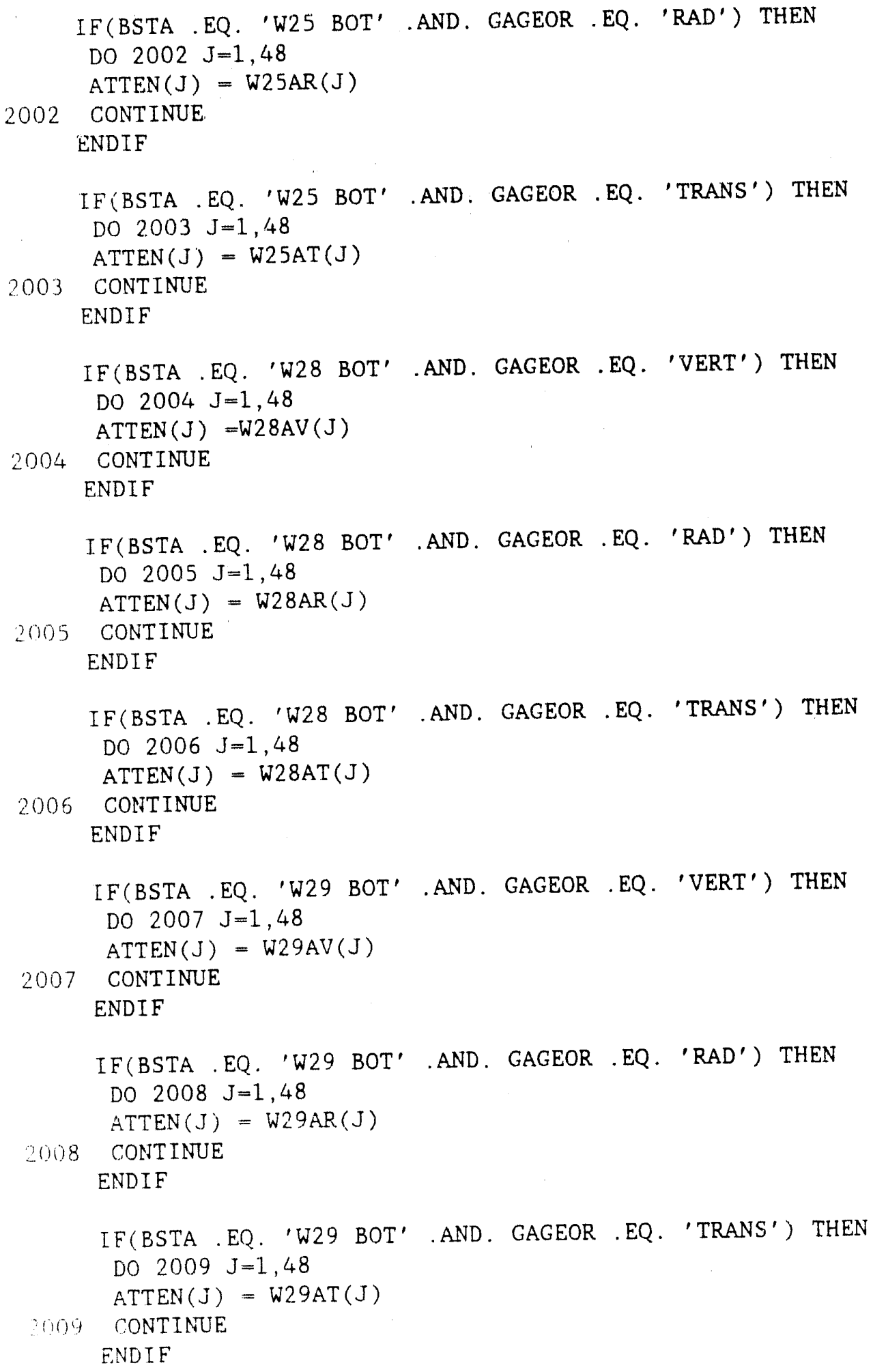




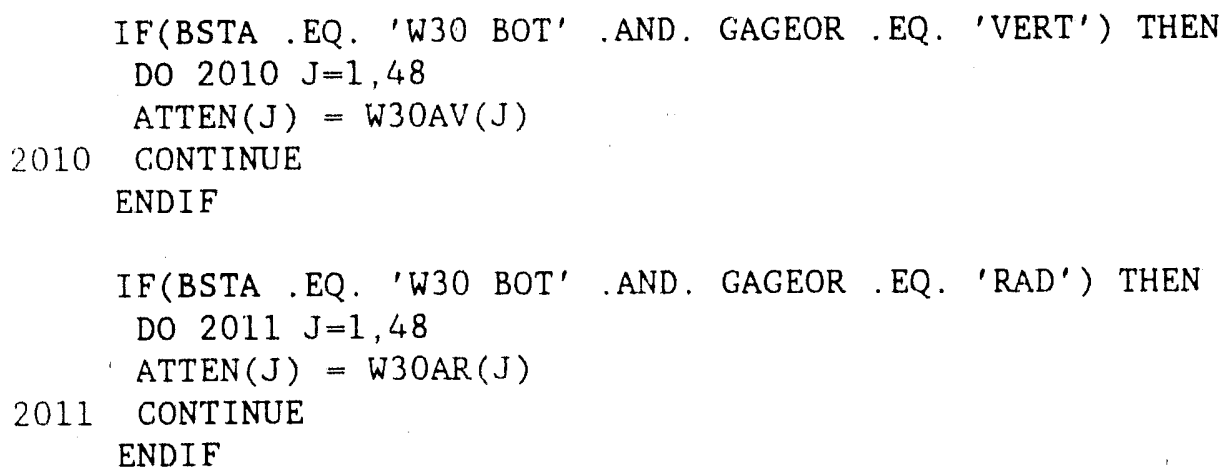


REFERENCES FOR APPENDIX B:

CA-DISSPLA User's Manual, Release 11.0, 1989, Computer Associates International, Inc., Garden City, NY (NNA.901128.0164)

Environmental Research Corporatinn, 1984, Prediction of Ground Motion Characteristics of Underground Nuclear Detonations, NVO-1163-239 (NNA.870406.0100)

Lynch, R. D., 1969, "Response Spectra for Pahute Mesa Events," Bulletin of the Seismological Society of America, Vol. 59 (NNA.890714.0073) 


\section{APPENDIX C: SEPDB AND RIB INFORMATIOND}

\section{Information from the Reference Information Base Used in this Report}

This report contains no information from the Reference Information Base.

\section{Candidate Information for the Reference Information Base}

This report contains no candidate information for the Reference Information Base.

\section{Candidate Information for the Site Engineering Properties Data Base}

This report contains no candidate information for the Site and Engineering Properties Data Base. 
1 J. W. Bartlett, Director (RW-1) Office of Civilian Radioactive Waste Management

U.S. Department ố Enrrgy

1000 Independence Arenue, S.W. Washington, D.C. 20585

1 F. G. Peters, Deputy Director (RW-2) office of Civilian Radioactive Waste Management

U.S. Department of Energy

1000 Independence Avenue, S.W.

Washington, D.C. 20585

1 T. H. Isaacs $(\mathrm{RW}-4)$

Office of Strategic Planning and International Programs

Oftice of Civilian Radioactive Waste Management

U.S. Department of Energy

1000 Independence Avenue, S.W.

Washington, D.C. 20585

1. J, D. Saltzman (RW-5)

Office of External Relations

office rf Civilian Radioactive Waste Management

U.S. Department of Energy

1000 Independence Avenue, S.W.

Washington, D.C. 20585

1 Samuel Rousso (RW-10)

office of Program and Resources Management

Office of Civilian Radioactive Waste Management

U.S. Department of Energy

1000 Independence Avenue, S.W.

Washington, D.C. 20585

$1 \mathrm{~J}, \mathrm{C}$. Bresee $(\mathrm{RW}-10)$

Office of Civilian Radioactive Waste Management

U.S. Department of Energy

1000 Independence Avenue, S.W.

Washington, D.C. 20585

1 C. P. Gertz (RW-20)

Office of Geologic Disposal

Office of Civilian Radioactive Waste Management

U.S. Department of Energy

1000 Independence Avenue, S.W.

Washington, D.C. 20585
1 S. J. Brocoum (RW-22)

Analysis and Verification Division Office of Civilian Radioactive

Waste Management

U.S. Department of Energy

1000 Independence Avenue, S.W.

Washington, D.C. 20585

1 D. D. Shelor (RW-30)

Office of Systems and Compliance

office of Civilian Radioactive

Waste Management

U.S. Department of Energy

1000 Independence Avenue, S.W.

Washington, D.C. 20585

$1 \mathrm{~J}$. Roberts (RW-33)

office of Civilian Radioactive Waste Management

U.S. Department of Energy

1000 Independence Avenue, S.W.

Washington, D.C. 20585

1 G. J. Parker (RW-332)

Office of Civilian Radioactive Waste Management

U.S. Department of Energy

1000 Independence Avenue, S.W.

Washington, D.C. 20585

1 Associate Director (RW-40)

Office of Storage and Transportation

Office of Civilian Radioactive

Waste Management

U.S. Department of Energy

1000 Independence Avenue, S.W.

Washington, D.C. 20585

1 Associate Director (RW-50)

Office of Contract Business Management

Office of Civilian Radioactive Waste Management

U.S. Department of Energy

1000 Independence Avenue, S.W.

Washington, D.C. 20585

1 C. G. Russomanno (RW-52)

office of Civilian Radioactive Waste Management

U.S. Department of Energy

1000 Independence Avenue, S.W.

Washington, D.C. 20585 
1 D. U. Deere, Chairman

Nuclear Waste Technical

Review Board

1100 Wilson Blvd. \#910

Arlington, VA 22209-2297

1 Dr. John E. Cantion

Nuclear Waste Technical Review Board 1795 Bramble Dr.

East Lansing, MI 48823

1 Dr. Melvin W. Carter

Nuclear Waste Technical Review Board 4621 El1isbury Dr., N.E.

Atlanta, GA 30332

1 Dr. Donald Langmuir

Nuclear Waste Technical Review Board 109 So. Lookout Mountain $\mathrm{Cr}$.

Golden, CO 80401

1 Dr. D. Warner North

Nuclear Waste Technical Review Board Decision Focus, Inc. 4984 E1 Camino Real Los Altos, CA 94062

1 Dr. Dennis L. Price Nuclear Wast Technical Review Board 1011 Evergreen Way Blacksburg, VA 24060

1 Dr. E1lis D. Verink Nuclear Waste Technical Review Board 4401 N.W. i b th Place Gainesville, FL 32605

5 C. P. Gertz, Project Manager Yucca Mountain Project Office U.S. Department of Energy P.O. Box 98608 - MS 523 las Vegas, NV $89193-8608$

1 C. L. West, Director Office of External Affairs DOE Field office, Nevada U.S. Department of Energy P.O. Box 98518

Las Vegas, NV 89193-85180

12 Technical Information officer DOE Field office, Nevada U.S. Department of Energy P.O. Box 98518

Las Vegas, NV 89193-8518
I P. K. Fitzsimmons, Director Health Physics \& Environmental

Division

DOE Field Office, Nevada

U.S. Department of Energy

P.O. Box 98518

Las Vegas, NV 89193-8518

1 D. R. E1le, Director

Environmental Protection Division

DOE Field office, Nevada

U.S. Department of Energy

P.O. Box 98518

Las Vegas, NV 89193-8518

1 Repository Licensing \& Quality Assurance Project Directorate Division of Waste Management

U.S. Nuclear Regulatory Commission Washington, D.C. 20555

1 Senior Project Manager for Yucca Mountain Repository Project Branch Division of Waste Management U.S. Nuclear Regulatory Commission Washington, D.C. 20555

1 NRC Document Control Desk Division of Waste Management U.S. Nuclear Regulatory Commission Washington, D.C. 20555

1 P. T. Prestholt NRC Site Representative 301 E. Stewart Ave. Las Vegas, NV 89101

1 E. P. Binna11

Field Systems Group Leader Building 50B/4235 Lawrence Berkeley Laboratory Berkeley, CA 94720

1 Center for Nuclear Waste Regulatory Analyses 6220 Culebra Road Drawer 28510

San Antonio, TX 78284

3 L. J. Jardine Technical Project officer for inp Mail Stop L-204 Lawrence Livernore National Laboratory

P.o. Bo: 808

Livernore, CA 94550 
4 R. J. Herbst

Technical Project officer for IMP

N-5, Mal1 Stop J 521

Los Alamos National Laboratory

P.O. Box 1663

Los Alamos, NM 87545

1 H. N. Kalia

Exploratory Shaft Test Manager:

Los Alamos National Laboratory

Mail Stop 527

101 Convention, Center Dr.

Suite 820

Las Vegas, NV 89109

1 J. F. Divine

Assistant Director for

Engineering Geology

U.S. Geological Survey

106 National Center

12201 Sunrise Valley Dr.

Reston, VA 22092

6 L. R. Hayes

Technical project officer

Yucca Mountain Project Branch--MS 425

U.S. Geological Survey

P.O. Box 25046

Denver, CO 80225

1 V. R. Schneider

Asst. Chief Hydrologist-MS 414

of ice of Program Coordination

\& Technical Support

U.S. Cieological Survey

12201 Sumise Valley Drive

Reston, VA 220992

1 R. B. Raup, Jr.

Geological Division Coordinator its 913

Iucca Mountain Project

U.S. Geological Survey

P. (). Box 25046

Denver, Co 80225

1). H. Appe1, Chief

Hedrologic Investigations Program $45 \quad 421$

U.S. Ceological Survey

P.O. Box 25046

Denver, cos 80225
1. E. J. Helley

Branch of Western Regional Geology

MS 427

U.S. Geological Survey

345 Middlefield Road

Menlo Park, CA 94025

1. Chief

Nevada Operations Office

U.S. Geological Survey

101 Convention Center Drive

Suite 860 , MS 509

Las Vegas, NV 89109

1 D. Zesiger

U.S. Geological Survey

101 Convention Center Dr.

Suite 860 - MS509

Las Vegas, NV 89109

1 R. V. Watkins, Chief

Project Planning and Management

U.S. Geological Survey

P.O. Box 25046

421 Federal Center

Denver, CO 80225

1 A. L. Flint

U.S. Geological Survey

MS 721

P.O. Box 327

Mercury, NV 89023

1 D. A. Beck

U.S. Geological Survey

1500 E. Tropicana, Suite 201

Las Vegas, NV 89119

1. P. A. Glancy

U.S. Ceological Survey

Federal Building, Room 22.4

Carson City, NV 89701

1 Sherman S. C. Wu

Branch of Astrogeology

U.S. Geological Survey

2255 N. Gemini Dr.

Flagstaff, AZ 86001

1.J.H. Sass

Branch of Tectonophysics

U.S. Geological Survey

$2255 \mathrm{~N}$. Geinini Dr.

Flagstaff, AZ 86001 
1 DeWayne A. Campbel1

Technical Project officer for YMP Bureau of Reclamation

Code D-3790

P.O. Box 25007

Denver, CO 80225

1 S. M. Dash

Science Applications International Corp.

14062 Denver West Parkway, Suice 255

Golden, CO 80401

1 K. W. Causseaux

NHP Reports Chief.

U.S. Geological Survey

421 Federal Center

P.O. Box 25046

Denver, CO 80225

1 V. M. Glanzman

U.S. Geological Survey

913 Federal Center

P.O. Box 25046

Denver, CO 80225

1. J. H. Nelson

Technical Project officer for YMP

Science Applications International Corp.

101 Convention Center Dr.

Suite 407

Las Vegas, NV 89109

2 SAIC-T\&MSS Library

Science Applications International Corp.

101 Convention Center Dr.

Suite 407

Las Vegas, NV 89109

1 Elaine Ezra

YMP GIS Project Manager

EG\&G Energy Measurements, Inc.

Mail Stop D-12

P.0. Box 1912

Las Vegas, NV 89125

1 R. E. Jackson, Program Manager

Roy F. Weston, Inc.

955 L'Enfant Plaza, Southwest

Washington, D.C. 20024
1 Technical Informat ion Centel.

Roy F. Weston, Inc.

955 L'Enfant Plaza, Southwost

Washington, D.C. 20024

1 D. Hedges, Vice President, Quality Assurance

Roy F. Weston, Inc.

4425 Spring Mountain Road, Suite 300

Las Vegas, Nevada 89102

1 D. L. Fraser, General Manager Reynolds Electrical \& Engineering Co Ma11 Stop 555

P.O. Box 98521

Las Vegas, NV $89193.85 \% 1$

1 R. F. Pritchett

Technical Project officer for MPl

Reynolds Electrical \& Engineering co. MS 408

P.O. Box 98521

Las Vegas, NV 89193-8521

1 B. W. Colston

General Manager \& President

Las Vegas Branch

Raytheon Services Nevada

Mail Stop 416

P.O. Box 95487

Las Vegas, NV 89193-5487

1 R. L. Bullock

Technical Project officer for YMP

Raytheon Services Nevada

Suite P250, MS 403

101 Convention Center Dr.

Las Vegas, NV 89109

1 R, E. Lowder

Technical Project officer for YMP

MAC Technical Services

101 Convention Center Drive

Suite 1100

Las Vegas, NV 89109

1 C. K. Hastings, Manager

PASS Prograin

Pacific Northwest Laboratories

P.O. Box 999

Richland, WA 99352 
1 A. T. Tamura

Science and Technology Division office of Scientific and Technical Information

U.S. Department of Energy

P.O. Box 62

Oak Ridge, TN 37831

1 Carlos G. Bell, Jr.

Professor of Civil Engineering

Civil and Mechanical Engineering Departinent

University of Nevada, Las Vegas

4505 South Maryland Parkway

Las Vegas, NV 89154

1 C. F. Costa, Director

Nuclear Radiation Assessment Division

U.S. Environmental Protection Agency

Environmental Monitoring Systems Laboratory

P.O. Box 93478

Las Vegas, NV 89193-3478

1 ONWI Library

Battelle Columbus Laboratory office of Nuclear Waste Isolation $505 \mathrm{King}$ Avenue

Columbus, $\mathrm{OH} \quad 43201$

1 T. Hay, Executive Assistant

Office of the Governor

State of Nevada

Capitol Complex

Carson City, NV

89710

3 R. R. Loux, Jr.

Executive Director

Nuclear Waste Project office

State of Nevada

Evergreen Center, Suite 252

1802 North Carson Street

Carson City, NV 89710

1. C. H. Johnson

Technical Program Manager Nuclear Waste Project Office State of Nevada Evergreen Center, Suite 252

1802 North Carson Street

Carson City, NV 89710
1 John Fordham

Water Resources Center

Desert Research Institute

P.O. Box 60220

Reno, NV 89506

1 Dr. Martin Mifflin

Water Rescurces Center

Desert Research Institute

2505 Chandler Avenue

Suite 1

Las Vegas, NV 89120

1 Eric Anderson

Mountain West Research-Southwest Inc.

2901 N. Central Ave. \#1000

Phoenix, AZ 85012-2730

1 Department of Comprehensive Planning, Clark County

2.25 Bridger Avenue, 7 th Floor

Las Vegas, NV 89155

1 Planning Department

Nye County

P.0. Box 153

Tonopah, NV 89049

1 Lincoln County Commission

Lincoln County

P.O. Box 90

Pioche, NV 89043

5 Judy Foremaster

City of Caliente

P.O. Box 158

Caliente, NV 89008

1 Economic Development Department City of Las Vegas

400 East Stewart Avenue

Las Vegas, NV 89101

1 Community Planning \& Development City of North Las Vegas

P.0. Box 4086

North Las Vegas, NV 89030

1 Director of Community Planning

City of Boulder City

P.O. Box 367

Boulder City, NV 89005 
1 Commission of the European

Communities

200 Rue de la Loi

B-1049 Brussels

BELCIUN

2. M. J. Dorsey, Librarian

YMP Research and Study cienter

Reynolds Electrical \& Engineering

Co. . Inc.

MS 407

P.O. Box 98521

Las Vegas, NV 89193-8521

1. Ainy Anderson

Argonne National Laboratory

Building 362

9700 So. Cass Ave.

Argonne, I.L 60439

$\begin{array}{lll}1.6300 & \text { T. O. Hunter } \\ 1 & 6310 & \text { T. E. Blejwas, Actg. } \\ 1 & 631.0 A & \text { L. E. Shephard } \\ 1 & 6312 & \text { F. W. Bingham } \\ 1 & 6313 & \text { L. S. Costin } \\ 1 & 6315 & \text { F. B. Nimick, Actg. } \\ 1 & 6316 & \text { R. P. Sandoval } \\ 2 & 6318 & \text { R. J. Macer for } \\ & & \text { 100/1232833/SAND88-3032/QA } \\ 2 & 6318 & \text { L. J. Erickson for DRMS } \\ & & \text { files 55/F08-06/30/66, } \\ & & \text { 55/F08-04/07/87, } \\ 1 & 6319 & \text { R. R. R08-04/08/88 } \\ & & \text { S. A. Landenberger } \\ 5 & 3141 & \text { Document Processing } \\ 8 & 3145 & \text { for DoE/OSTI } \\ 3 & 3151 & \text { G. C. Claycomb } \\ 20 & 6341 & \text { WMT Library } \\ 1 & 6410 & \text { D. J. McCloskey, Actg. } \\ 1 & 8523-2 & \text { Cental Technical Files } \\ 1 & 9300 & \text { J. E. Powe11 } \\ 1 & 9310 & \text { J. D. Plimpton } \\ 1 & 9311 & \text { A. J. Chabai } \\ 3 & 9514 & \text { J. S. Philips }\end{array}$




\section{SAND88-3032}

The number in the lower right-hand corner is an accession number used for Office of Civilian Radioactive Waste Management purposes only. It should not be used when ordering this publication.

NNA.911210.0121 
